\title{
A COMPARATIVE ANALYSIS OF TOURISM DESTINATION IMAGE AND PRODUCT-COUNTRY IMAGE/
}

\author{
STATIA ELLIOT, B.Comm., M.A.
}

A thesis submitted to the Faculty of Graduate Studies and Research in partial fulfillment of the requirements for the degree of

Doctor of Philosophy in Management

Sprott School of Business

Carleton University

Ottawa Ontario

Copyright $\odot$ Statia Elliot, 2007 


$\begin{array}{ll}\begin{array}{l}\text { Library and } \\ \text { Archives Canada }\end{array} & \begin{array}{l}\text { Bibliothèque et } \\ \text { Archives Canada }\end{array} \\ \begin{array}{l}\text { Published Heritage } \\ \text { Branch }\end{array} & \begin{array}{l}\text { Direction du } \\ \text { Patrimoine de l'édition }\end{array} \\ \begin{array}{l}\text { 395 Wellington Street } \\ \text { Ottawa ON K1A 0N4 }\end{array} & \begin{array}{l}\text { 395, rue Wellington } \\ \text { Ottawa ON K1A ON4 }\end{array} \\ \text { Canada } & \begin{array}{l}\text { Canada } \\ \end{array}\end{array}$

Yourfile Votre référence ISBN: 978-0-494-36782-7 Our file Notre référence ISBN: 978-0-494-36782-7

NOTICE:

The author has granted a nonexclusive license allowing Library and Archives Canada to reproduce, publish, archive, preserve, conserve, communicate to the public by telecommunication or on the Internet, loan, distribute and sell theses worldwide, for commercial or noncommercial purposes, in microform, paper, electronic and/or any other formats.

The author retains copyright ownership and moral rights in this thesis. Neither the thesis nor substantial extracts from it may be printed or otherwise reproduced without the author's permission.
AVIS:

L'auteur a accordé une licence non exclusive permettant à la Bibliothèque et Archives Canada de reproduire, publier, archiver, sauvegarder, conserver, transmettre au public par télécommunication ou par l'Internet, prêter, distribuer et vendre des thèses partout dans le monde, à des fins commerciales ou autres, sur support microforme, papier, électronique et/ou autres formats.

L'auteur conserve la propriété du droit d'auteur et des droits moraux qui protège cette thèse. $\mathrm{Ni}$ la thèse ni des extraits substantiels de celle-ci ne doivent être imprimés ou autrement reproduits sans son autorisation.
In compliance with the Canadian

Privacy Act some supporting forms may have been removed from this thesis.

While these forms may be included in the document page count, their removal does not represent any loss of content from the thesis.
Conformément à la loi canadienne sur la protection de la vie privée, quelques formulaires secondaires ont été enlevés de cette thèse.

Bien que ces formulaires aient inclus dans la pagination, il n'y aura aucun contenu manquant.

\section{Canadä}




\begin{abstract}
This study advances place image theory through research that combines knowledge from the two fields of marketing that have dealt most extensively with place image: Tourism Destination Image (TDI) - the effects of beliefs, ideas, and impressions that a person has of a destination; and, Product-Country Image (PCI) - the effects of "place" image on buyer attitudes toward products from various origins. Although the focus of both fields is place image, each has developed independently of the other, and notwithstanding their common object of interest, there has been no systematic research that fully combines the two perspectives. Therefore, this comparative analysis of TDI and PCI represents the first ever in-depth cross-fertilization of ideas between these two significant fields of research.
\end{abstract}

To explore the potential relationships between cognitive and affective dimensions of place, and tourism and product beliefs and behaviours, a theoretical model is developed by merging research and knowledge from both fields. The resulting Integrated Model of Place Image (IMPI) incorporates a mix of TDI and PCI image measures, comprising eight constructs and 26 variables, that establish a framework for the analysis of any place of interest.

The Integrated Model is tested using consumer survey data from South Korea ( $n=349$ ) and Canada ( $n=307$ ), to compare image measures of these two countries, the U.S., Australia and Japan, in a $2 \times 4$ analysis using Structural Equation Modeling. The results reveal that cognitive country image has greater influence on product factors, affective country image has greater influence on destination factors, and familiarity only influences product beliefs and behaviours. Additionally, consumer beliefs exhibit a 
strong cross-over effect, particularly in the direction from product beliefs to destination receptivity. The influence of destination beliefs on receptivity to that country's products, though weaker, is also evident.

The results contribute to both the theoretical foundations, and practical analysis of place image. For researchers, the results shed much light on the theories postulated in the conceptual model. The relationships between the core constructs of image, beliefs and behaviours are identified, as are new relationships between product and tourism constructs, along with their relative strengths. For practitioners, the model dynamics raise important issues. The IMPI identifies which image-related variables are important, and which are not, and how consumers evaluate products and destinations. Supported by empirical results, the IMPI is presented for the future study of TDI and PCI. 


\section{Acknowledgements}

It is with great appreciation that I wish to recognize the support of my supervisor, Dr. Nicolas Papadopoulos, for guiding me through not only this thesis, but the beginning of a new career path, and stage of my life. Nicolas, you have been my mentor, my friend, my guiding light, setting standards of quality and morality in all that you do, that I both aspire to and admire. Thank you.

To Dr. Roland Thomas, I extend my gratitude for your patience in teaching. Of all my courses, yours were the most valuable to me, and the additional time that you gave in support of my thesis was instrumental, and greatly appreciated.

To Dr. George Haines, I extend my gratitude for your wisdom and graciousness. We have never had a conversation that I did not learn from, and I value the notes you gave me upon my first teaching position at Carleton.

To my thesis committee members, Professors Smith and Johansen, I am extremely honoured to have had your contributions to my work. Thank you sincerely.

I am indebted to colleagues in South Korea, whose assistance was instrumental to overcoming the challenges of collecting data in a foreign country. In particular, I wish to thank Dr. Samuel Seongseop Kim of Sejong University, David Seung Hyun Yoon, Team Leader of the COEX World Trade Centre, and Major Jinu Lee, a student at the Korean Military Staff College.

I also thank my Bridge-mates, fellow students and colleagues who shared their time and experiences with me, and without whom my Ph.D. journey would have been quite lonely. Finally, I thank the Sprott School of Business, faculty and staff. I am proud to call Sprott my Alma Mater. 


\section{Dedication}

I dedicate this work to my sister, Sandra, whose passing changed my life path, to my husband, who is my rock, my children, who are my light, and my parents, who are my roots. I have taken this journey surrounded by your love and support. Thank you.

\section{Journey}

We cannot really walk in another's shoes,

But we can stroll their streets,

Enter their shops and cafes,

See their monuments and places of worship,

Hear their music and language,

Feel their climate,

And experience their world.

As we journey, we find something of ourselves.

And the further we travel from home,

The longer we explore,

The deeper we look,

The greater the self-discovery.

Statia Elliot, Hill’s View Villa, Seoul, 2004 


\section{Table of Contents}

Abstract - -

Acknowledgements -

Dedication - -

Table of Contents - vi

List of Tables -

List of Figures - --

List of Appendices -

Chapter 1 Introduction -

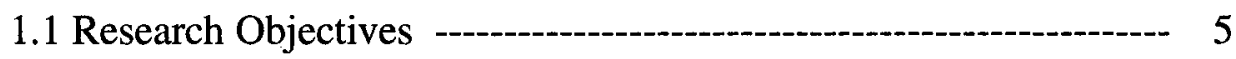

1.2 Role of Image in Marketing - -

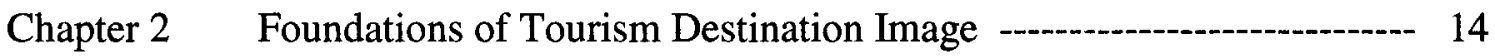

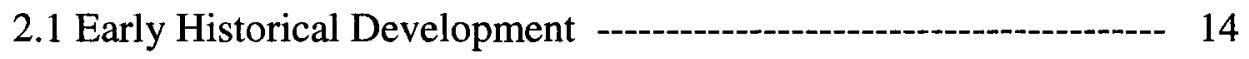

2.2 Formation and Influences -

2.2.1 Information Sources --_- 19

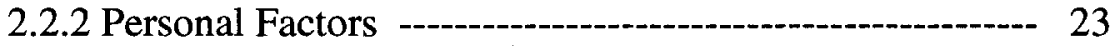

2.3 TDI Conceptualization -.-- 28

2.4 Relationship to Behaviour--- 39

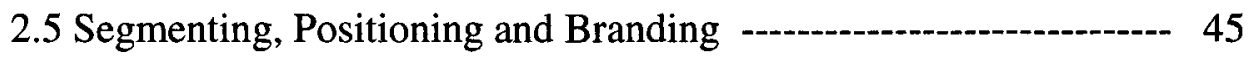

2.6 Methods of Analysis - - 53

2.7 Conclusions - 61

Chapter 3 Foundations of Product Country Image -

3.1 Historical Development - 
3.2 Cognitive, Affective and Conative Dimensions -a-n 70

3.3 Halo, Summary Construct and Flexible Models --a-a-a-o- 76

3.4 Country and Product Image Disentanglement --------------------- 79

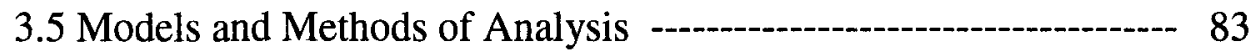

3.6 Conclusions -

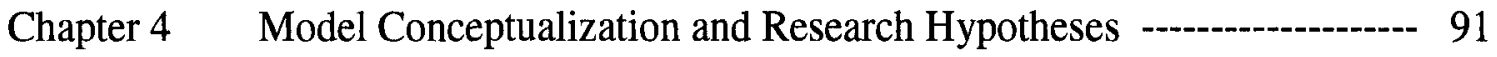

4.1 Model Conceptualization ---o--- 91

4.2 Research Hypotheses - --_- 95

Chapter 5 Research Design and Methodology -

5.1 Construct Measurement -.-106

5.2 Study Design -

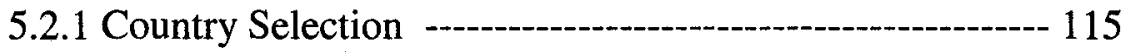

5.2.2 Method of Measurement ---o--- 122

5.2.3 Sampling and Fieldwork ---a-----o------ 127

5.3 Data Analysis Methodology - 132

Chapter 6 Data Analyses and Results - 137

6.1 Data Preparation - - 137

6.2 Descriptive Analysis - 139

6.3 Analysis of Open Ended Data Results --a- 142

6.3.1 The United State's Image - 148

6.3.2 Japan's Image -

6.3.3 Australia's Image -

6.3.4 Canada's Image - 


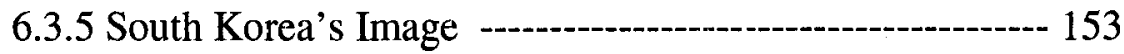

6.4 Across Country Comparison of Means -

6.5 Analysis by Dimension - 156

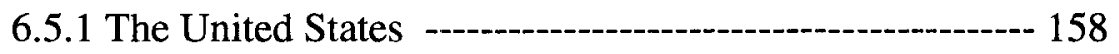

6.5.2 Japan - - 159

6.5.3 Australia -.- 160

6.5.4 Canada - 161

6.5.5 South Korea -...- 163

6.6 Exploratory Factor Analyses -

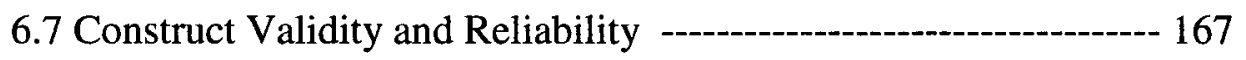

6.7.1 Convergent Validity -a-o- 168

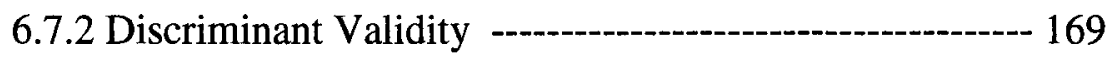

6.8 Confirmatory Factor Analyses - -.-- 173

Chapter 7 Structural Equation Modeling Analyses and Results ------------------ 177

7.1 Path Structure -

7.1.1 U.S. Model - South Korea Sample -------a--a-------- 179

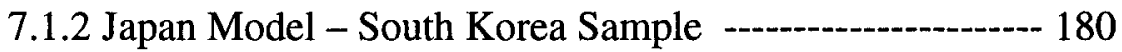

7.1.3 Australia Model - South Korea Sample ----------------- 181

7.1.4 Canada Model - South Korea Sample --------o------ 182

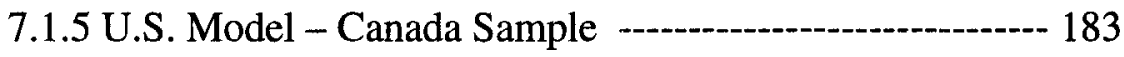

7.1.6 Japan Model - Canada Sample - -

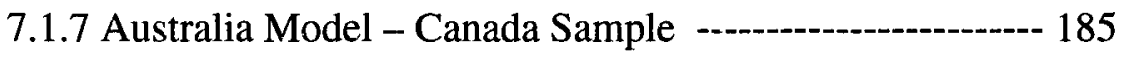

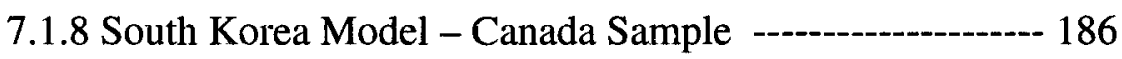


7.2 Measurement Structure

7.3 Hypotheses Testing -

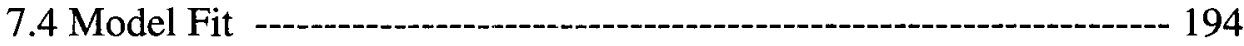

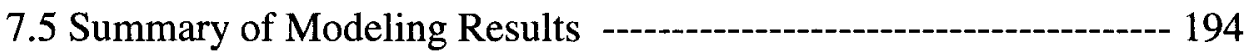

7.6 Explanatory Power of the Model --a- 198

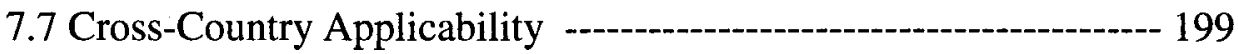

Chapter 8 Discussion and Implications

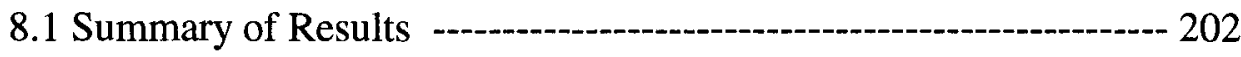

8.2 Study Limitations -

8.3 Implications and Benefits -

8.3.1 For Academic Researchers -

8.3.2 For Practitioners - -

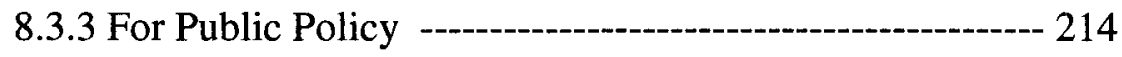

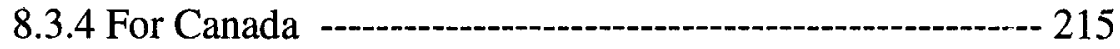

8.3.5 For Future Research

8.4 Conclusions - - 222

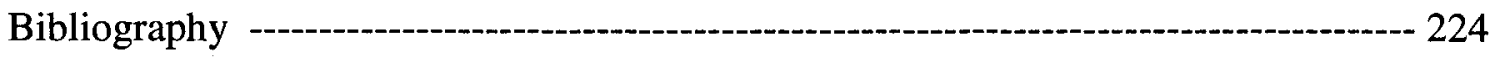




\section{List of Tables}

1. Dimensions/Attributes of the Perceived TDI

2. Cognitive, Affective and Normative Mechanisms for COO Effects

3. Tourism and Product Country Image Hypothesized Relationships

4. Dimensions of TDI

5. Examples of TDI Familiarity Measures

6. Integrated Tourism and Product Country Image Model Variables

7. Sociodemographic and Economic Characteristics of Study Countries

8. Variable Measurement Scales

9. Comparison of Means, Pre and Post Replacement of Missing Values 138

10. South Korean and Canadian Sample Characteristics

11. Comparison of Completion Rates for Open-Ended Quesitons 143

12. "What images come to mind when you think of these countries?"

13. "What products come to mind when you think of these countries?"

14. "What tourism characteristics come to mind?"

15. U.S. Image Responses

16. "What images come to mind when you think of Canada?" 152

17. Mean Scores for all Variables by Study Sample and Dimension

18. Country Rankings based on Mean Scores by Dimension 165

19. Sampling Adequacy and Test of Sphericity 166

20. Summary of Reliability Tests by Construct 168

21. Correlation Matrix of Independent Variables 170

a. U.S. Correlation Matrix - South Korean Sample 170 
b. Japan Evaluation Correlation Matrix - South Korean Sample ------ 170

c. Australia Evaluation Correlation Matrix - South Korean Sample -- 170

d. Canada Evaluation Correlation Matrix - South Korean Sample ---- 171

e. U.S. Evaluation Correlation Matrix - Canadian Sample --------- 171

f. Japan Evaluation Correlation Matrix - Canadian Sample ---------- 171

g. Australia Evaluation Correlation Matrix - Canadian Sample ------ 172

h. South Korea Evaluation Correlation Matrix - Canadian Sample -- 172

22. Comparison of Product, Tourism and Full Model Fit Statistics -ב-ב-a- 174

23. Confirmatory Factor Analysis Factor Loadings by Construct -a-a-a-a 175

24. Structural Equation Modeling Variable Loadings by Construct --..----- 188

25. Path Coefficients for all Hypothesized Relationships by Model ------------ 190

26. Summary of Hypotheses support - 193

27. Comparison of Final Model Fit Statistics --- 194

28. Reduced Form Equations $\mathrm{R}^{2}$ for Endogenous Model Constructs ----------- 198

29. Cross-Country Hypotheses Testing of Model Invariance - - 200

30. Summary of Main Findings for CI, PCI and TDI -....... 203

a. The U.S. -

b. Japan - 204

c. Australia -

d. Canada and South Korea - 206 


\section{List of Figures}

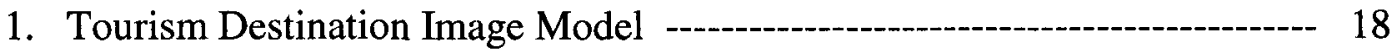

2. Continuum of Image Formation Agents ---o-n 21

3. The Components of TDI -..- 29

4. A General Framework of TDI Formation - 31

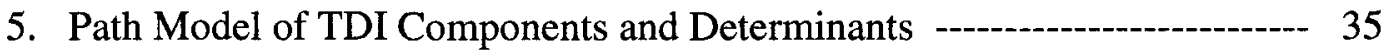

6. General Model of Traveller Leisure Destination Awareness and Choice --- 41

7. Two Paralleled Typologies of Image -

8. Empirical Model of Receptivity To Products from Various Origins ------- 75

9. Halo Model -

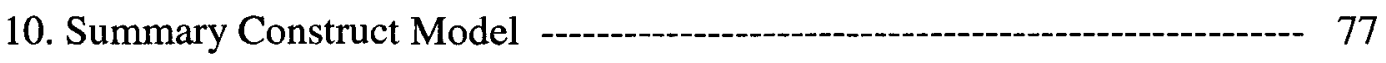

11. Single Flexible Model

12. Early Model of Nation-Product Image Interactions -

13. Model of Relative Product Images -

14. Comprehensive Product-Country Image Model - ---_- 85

15. Integrated Model of Place Image --

16. Integrated Model of Place Image with Hypothesized Relationships ------- 104

17. Structural Integrated Model of Place Image -

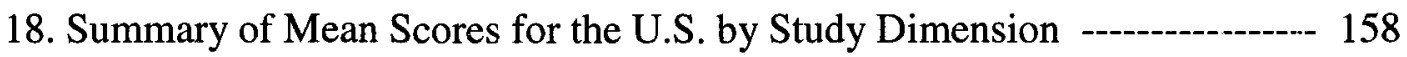

19. Summary of Mean Scores for Japan by Study Dimension -

20. Summary of Mean Scores for Australia by Study Dimension -.-_-_- 161

21. Summary of Mean Scores, All Countries, South Korean Sample ---------- 162

22. Summary of Mean Scores, All Countries, Canadian Sample -.-.-_- 164 
23. Structural Equation Models

a. U.S. Model - South Korean Sample --_-- 179

b. Japan Model - South Korean Sample -a- 180

c. Australia Model - South Korean Sample --_- 181

d. Canada Model - South Korean Sample --_- 182

e. U.S. Model - Canadian Sample -

f. Japan Model - Canadian Sample - - 184

g. Australia Model - Canadian Sample - 185

h. South Korea Model - Canadian Sample -

24. Final Integrated Model of Place Image -

25. Integrated Model of Place Image with Relationships and Measures ------- 211 


\section{List of Appendices}

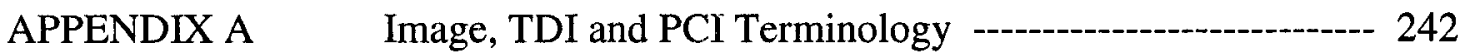

APPENDIX B Product Country Image Dimensions -...-- 254

APPENDIX C A Comparison of TDI and PCI Research Streams ------.--- 257

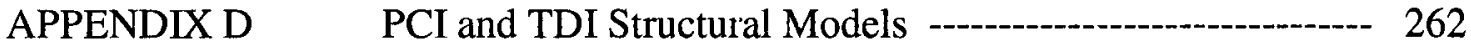

APPENDIX E Variable Descriptive Statistics - -

E-1: Korean Sample - - 266

E-2: Canadian Sample -

APPENDIX F Test of Mean Difference Significance - -

APPENDIX G Exploratory Factor Analysis Initial Pattern Matrices ------- 277

G-1: U.S. EFA - South Korean Sample ---ב---- 277

G-2: Japan EFA - South Korean Sample ------------------- 278

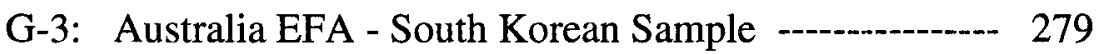

G-4: Canada EFA - South Korean Sample -------------- 280

G-5: U.S. EFA - Canadian Sample …- 281

G-6: Japan EFA - Canadian Sample ---_---- 282

G-7: Australia EFA - Canadian Sample ------------_----- 283

G-8: South Korea EFA - Canadian Sample --------------- 284

APPENDIX H $\quad$ Confirmatory Factor Analysis LISREL Models

H-1: U.S. Product Model - South Korean Sample --------- 285

H-2: U.S. Tourism Model - South Korean Sample ------- 285

H-3: Japan Product Model - South Korean Sample -----.- 286

H-4: Japan Tourism Model - South Korean Sample ------ 286 
H-5: Australia Product Model - South Korean Sample -.--- 287

H-6: Australia Tourism Model - South Korean Sample ---- 287

H-7: Canada Product Model - South Korean Sample ------ 288

H-8: Canada Tourism Model - South Korean Sample ----- 288

H-9: U.S. Product Model - Canadian Sample -_-a--a- 289

H-10: U.S. Tourism Model - Canadian Sample -ב-_-_---- 289

H-11: Japan Product Model - Canadian Sample ----------- 290

H-12: Japan Tourism Model - Canadian Sample ---------- 290

H-13: Australia Product Model - Canadian Sample ------- 291

H-14: Australia Tourism Model - Canadian Sample ------- 291

H-15: South Korea Product Model - Canadian Sample ----- 292

H-16: South Korea Tourism Model - Canadian Sample ---- 292

APPENDIX I Hypothesis Testing for all Models

APPENDIX J Model Invariance Test

J-1: U.S. Model Null Hypothesis Test of Equality for South Korean and Canadian Samples -----o-------- 294

J-2: U.S. Model Alternative Hypothesis Test of Inequality for South Korean and Canadian Samples ---.--.- 295

APPENDIX K Questionnaire on International Products and Tourism ---.-- 296 


\section{Chapter 1 Introduction}

This study aims to advance place image theory through research that combines elements from the two areas that have dealt with the role of place images in marketing more than any others: Product-Country Image (PCI) and Tourism Destination Image (TDI). PCI represents the effects of "place" image on buyer attitudes toward products from various origins. TDI represents the effects of beliefs, ideas, and impressions that a person has of a destination. Although the focus of both fields is place image, each has developed independently of the other. Given their common object of interest, the potential of their relationship has been mentioned by a few authors [Melissen, 2004; Kotler, 1993], and the subject of some empirical work [Anholt, 2007b; Heslop et al, 2005]. Yet, there has been no systematic research that fully combines the two perspectives. Therefore, this comparative analysis of PCI and TDI represents the first ever in-depth cross-fertilization of ideas between these two significant fields of marketing research.

Numerous studies show that whether developed deliberately or by default, the image of a country is a powerful stereotype that influences the behaviour of consumers, industrial buyers, tourists and foreign investors [Papadopoulos and Heslop, 2002]. In today's global economy, more and more private firms and public sector authorities seek to develop place marketing strategies as a means of gaining competitive advantage internationally. The application of marketing and branding techniques in the country context can be a powerful force for global wealth distribution and cultural as well as economic development [Anholt, 2002]. Interest in the marketing of countries, and other geographically defined places, has grown substantially in the past five years among 
academic researchers, public policy makers, and business practitioners internationally. The field of study is best known as country image in PCI, as destination image in TDI, with common references to place image within both streams. The terms are used interchangeably in this paper unless the context requires a specific term.

One aspect of place marketing that has found particular favour in both practitioner and academic circles is place branding, defined as the selection of a consistent element mix to identify and distinguish 'place' through positive image building [Cai, 2002]. While the value of place image is well recognized, theory development in the area is lacking and a much deeper understanding of its specifics is required to enable places to build on the positive elements of their image, and to address the negative.

A review of the literature reveals that tourism is an image-driven industry, and that TDI has been a significant focus of research for more than 30 years. In the 1970s, a number of key articles established the importance of image as an influencer of travel behaviour. Credited as the first to do so, Hunt $[1975$, p.1] went so far as to state that "it seems likely that images, as perceived by individuals in the travel market, may have as much to do with an area's tourism development success as the more tangible recreation and tourist resources". In the decades to follow, many notable studies considered the influence of image on traveler choice [Pearce, 1982; Woodside and Lysonski, 1989], the measurement of image [Echtner and Ritchie, 1993; Phelps, 1986], and its formation [Baloglu and McCleary, 1999a; Gartner, 1993]. However, much of the existing research is descriptive, and specific to the measurement of one destination's image. Even with the publication of over 200 articles in the tourism literature, the study of TDI still lacks an accepted theory-based framework or solid conceptualization [Beerli and Martin, 2004a]. 
The study of a product's "country of origin", or PCI research, is even more extensive, consisting of over 1,000 major publications produced since the 1960s [Papadopoulos, 2004]. Here, too, are studies that consider the influence of image on consumer behaviour, measure image, and assess its formation [Papadopoulos and Heslop, 1993]. Yet, this body of research has been largely ignored by the tourism literature, just as the findings from TDI research have not been incorporated in studies of PCI.

Several PCI and TDI models exist that reflect numerous and varied conceptions of place image. Empirical studies have assessed a wide range of image components, typically through the application of Likert or bipolar adjective scales to measure specific place attributes. For example, key constructs of PCI include beliefs about a nation's level of advancement, affect for its people, and product assessments [Papadopoulos and Heslop, 2002]. Key constructs of TDI include natural resources, tourism infrastructure, and atmospherics [Beerli and Martin, 2004a].

Given the substantial bodies of work within PCI and TDI, the increased interest in the emerging field of place branding, and the call by many authors to "look over the disciplinary fences" [Melissen, 2004, p. 26] and to "encourage more cross-fertilization between the component fields of place branding" [Anholt, 2004, p. 11], a systematic comparative analysis of place-image related theory is both important and timely. This study conceptualizes the relationships among key PCI and TDI constructs, develops an integrated model of place image, and empirically measures their relationships.

The theoretical benefits begin with an extensive and thorough literature review of TDI and PCI, conducted in a systematic way to lead to an in-depth comparison of relevant theories from each field. Within TDI, a wide range of academic journals was 
reviewed, including the Journal of Travel Research, Annals of Tourism Research and International Journal of Tourism Research, supplemented with government publications [e.g. Canadian Tourism Commission], and related books by the most respected authors of the field, including Gunn [1972], Kotler [2002, 2003], Morgan and Pritchard [1998, 2002, 2003], Goeldner and Ritchie [2003], and Anholt [2007a].

In PCI, a similar search covered leading academic journals such as the Journal of International Business Studies, Journal of Marketing Research, European Advances in Consumer Research, Journal of International Consumer Marketing and Management International Review, supported by electronic databases, government resources [e.g. Canadian Trade Commission and Department of Foreign Affairs] and books by leaders in the field, including Papadopoulos and Heslop [1993], Jaffe and Nebenzahl [2006], and Kotler et al. [1993, 1997].

This dual search of the TDI and PCI literatures reveals a richness of place image concepts, measurements and theories, and contributes both to each field individually and, more importantly, to the first fully integrated examination of place image perspectives as part of the same study. Where there are weaknesses in one field, strengths from the other can be found. Where there is a knowledge gap in one field, potential solutions can be found in the other. Through the cross-fertilization of ideas, the overarching theory of place image is enhanced.

This contribution to place image theory facilitates the simultaneous assessment of TDI and PCI related concepts. It contributes to our understanding of relationships between country image, product and tourism beliefs, and product and tourism receptivity. 
Because of the dual interests of the study, it has great potential for replication and future development within each of the two streams.

The practical benefits of this study are realized through the application of the model in a multi-country analysis. First, producers will find the results of interest when preparing market entry and positioning strategies. The results can help exporters to determine whether a global or local strategy would be most effective, and guide decisions related to brand naming, packaging, advertising and distribution. Both tourism and product marketers can strengthen image-based branding strategies based on the identification of image strengths and weaknesses by market.

The dissertation is divided into eight chapters. Following from the above brief outline of the theoretical and applied contributions, the present first chapter sets out the research goal and objectives, and includes an overview of the role of image in marketing as an introduction to the theme that underlies the entire study. Chapter 2 presents an extensive review of the TDI literature. A review of the PCI literature is presented in Chapter 3. Chapter 4 presents the conceptual model reflecting the integration of TDI and PCI theory. The study design and empirical application comprises Chapter 5. Chapter 6 and 7 present the research findings. Chapter 8 concludes with a discussion of study implications, benefits and limitations.

\subsection{Research Objectives}

The focus of this study is the comparative analysis of two vast streams of research, namely TDI and PCI. The overall research goal is to contribute to marketing theory an effective approach to examining and identifying place image that encompasses both 
products associated with the place and the tourism image of the place itself. A theoretical model is proposed to simultaneously measure product and tourism related image dimensions in order to better understand their relationships. Through this process, the image dimensions of a country can be examined and tentified, as well as more specific images for products and tourism. This is analogous to the identification of a corporate brand identity, with individual sub-brands. Here, the corporate brand is a country, and the sub-brands are industry sectors.

In light of the above overall goal, the study has four main specific objectives:

1) To conceptualize a structural model of country image effects that encompasses elements from both the PCI and TDI research streams, based on a detailed review of the literature.

2) To examine whether, and if so how, the images of a country's products and of the country as a tourism destination affect each other and are affected by the overall country image, through an empirical application of the model.

3) To test the model cross-nationally and for the images of multiple countries, in order to assess its cross-country validity and applicability. And,

4) To examine the findings with a view to identifying policy and strategy implications arising from the relationships between the PCI and TDI image dimensions.

Additionally, Canada is identified as a primary country of investigation not only because of the author's origin and interest, but because it is a country that relies on exports (over $40 \%$ of GDP), and benefits from significant tourism revenues (2\% of GDP). And while many Canadians and those foreign to Canada might well view its image 
positively, why or how is unclear. By applying the findings in the Canada case, the applicability of the study approach will be directly tested.

To effectively link (a) the above objectives with the empirical work, in order to operationalize the model, and (b) the theoretical work with the policy interest of the study in Canada's image from both the PCI and TDI perspectives, the following key questions have been specified:

1) How does a consumer evaluate products and travel destinations?

2) Does a country's image influence foreign consumers' perceptions of that country's products, and if so, how?

3) Does a country's image influence foreign consumers' perceptions of that country as a travel destination, and if so, how?

4) If there is a country image effect, does it influence product beliefs and destination beliefs similarly or differently?

5) What, if any, is the relationship between consumer beliefs and their willingness to buy foreign products and/or travel to foreign destinations?

6) Does foreign travel experience affect consumers' perceptions of a country's products, and if so, how?

7) Does consumption of foreign products affect consumers' perceptions of a country as a travel destination, and if so, how?

8) Can a country have a corporate brand, with tourism and product sector sub-brands? If so, what are the common dimensions of the country's corporate image?

9) What is the image of Canada, of Canada as a travel destination, and of Canadian products? 
10) How, if at all, are these images interrelated? What are the implications for Canadian policy and strategy in the respective sectors?

In summary, the major contributions of the study are fourfold: (i) each stream of research benefits from advances found in the other, through analysis of the similarities and differences in conceptualization, measurement and hypothesized relationships of key image constructs; (ii) ways in which products and tourism affect each other are assessed by measuring these two key aspects of country image within the same study; (iii) the theoretical model's practical applicability is tested through a multi-nation evaluation of country image; and (iv) implications for policies and strategies for country-image based marketing and branding are based on the identification of overarching image dimensions of PCI and TDI.

Before looking at the relationship of image to place, the next section provides an overview of the role of image more generally in marketing [Elliot, 2004].

\subsection{Role of Image in Marketing}

Early concepts of image evolved from the field of social psychology, for it was here that image was first presented as an organizational resource of value [Boulding, 1956], and its influence on behaviour initiated. Image is an all important element of being that psychologists define as a memory code or representation in the mind, used to summarize complex information that the human imagination might otherwise find intolerable [Boulding, 1956]. Poisez [1989] identified the functions of image as: (i) reducing the complexity of information processing; (ii) acting as a gatekeeper to more 
extensive elaboration; and, (iii) serving as a simplifying heuristic when a peripheral route to attitude change is followed. In summary, the psychologists' perspective is that image and behaviour are "intertwined like the strands of a rope" [Grunig, 1993, p.123], with much of our understanding still to be untangled.

In the field of marketing, image permeates much of what is known and practised. However, image remains an elusive concept, challenging academics and practitioners to define it, understand it, and manage it. Originating from the Latin word imitari, or imitation, a current definition from Webster's Dictionary is that image is an optically formed representation of form or feature, of someone or something. In short, it is a mental picture. In practise, the concept has germinated a range of definitions. It can be defined narrowly as a visual cue, or broadly as the total impression an entity makes on the minds of people [Dichter, 1985]. The entity that is the object can also range from a single product or store, brand or company, person or place. Some of the most common definitions from the literature are listed in Appendix A. A gestalt of the conceptualizations produces a meta-definition of image as the summation of all impressions, perceptions, beliefs, attitudes, ideas, experiences, knowledge, feelings and emotions an individual holds toward an object.

It is hard to say when the concept of image was first applied to branding. Certainly, the modern history of brands can be traced back some 130 years with the introduction of such strong product images as Pear's soap and Pinkham's vegetable compound [Twitchell, 2000]. However, it was not until the 1950s that the role of image in marketing would be more fully explored. Through that decade and into the next, a number of academics searching for a deeper understanding of consumer behaviour began 
to study image [Tyler, 1957; Martineau, 1958; Spector, 1961]. The belief took hold that if one can influence image, one can influence behaviour [Nelson, 1962], and the importance of image to marketing was set.

Fifty years later, its importance continues to be measured in various ways including, for example, through manipulations of product associations in order to assess the resulting influence on product equity [Faircloth et al., 2001]. Through the years, terminology has changed, but the view that image plays a key role in marketing has held. It is a concept that crosses functions, audiences, and media. It has been studied in a holistic way, in relation to specific components of marketing, in isolation, and in relation to other concepts such as identity and culture [Hatch and Schultz, 1997].

Theories of image at the corporate level have evolved from early concepts, such as Kennedy's [1977] model of how company image is formed and influenced by policy and personnel. Later models, such as Dowling's [1986], add communication elements to illustrate the transmission of internal image to external image. Then, models by Abratt [1989] and Stuart [1999] added elements of strategic management to the development of a corporate identity, and corporate image became the external view held by an organization's publics. Other authors focus on related concepts such as corporate branding [Balmer, 1998], corporate reputation [Fombrun and Shanley, 1990], corporate culture [Hatch and Schultz, 2003] and corporate associations [Brown, 1998]. A current proposition in the literature is that the concepts of corporate identity, image, reputation and branding be woven together to form a new branch of corporate level marketing [Balmer and Gray, 2003]. 
Advertising and a company's visual communication are often considered the principal components of image creation [Meenaghan, 1995]. Two streams of models that explain how advertising affects consumers are cognitive and behavioural. The cognitive approach presents consumer decision making as a linear, sequential process. Key models include the cognitive-response model, the resource-matching theory, the dual-process model of persuasion, and the experiential bases of persuasion theory [Meyers-Levy and Malaviya, 1999]. All follow rational steps in an analytical manner, and are most often associated with consumers who are highly involved in the decision process. Alternatively, the behavioural approach considers the consumer decision process to be more influenced by symbolism and emotion. In reality, most consumers fall between these extremes, using both rational and emotional choice factors in their decision process.

Another theory of how advertising is processed is the theory of visual rhetoric, which recognizes the sender's intention to influence the consumer through the use of visual imagery [Scott, 1994]. Imagery is a cognitive process, elicited by a picture, words or instructions to imagine in which perceptual information is represented in working memory [Miller et al., 2000]. The communication of meaning through advertising imagery is believed to have a greater affect on consumer attitudes and intentions than discursive stimuli [Burns et al., 1993]. Empirical tests support the picture superiority effect, whereby pictures influence attitudes more than verbal information [Babin and Burns, 1997].

Also relevant to image in marketing is the image congruence theory, whereby consumers favour products perceived to be congruent with their self-image [Graeff, 1996]. Studies of symbolic purchasing behaviour have found the communication of favourable and congruent symbolic images to be effective [Leigh and Gabel, 1992]. 
Place, the marketing mix element comprising retail, service and distribution considerations, has been studied from an image perspective since the 1950s [Martineau, 1958]. There is now a sizable body of research on store image, much of which can be categorized under three topics: (i) the influence and benefits of store image; (ii) the customer's emotive response to store image; and, (iii) the measurement of store image attributes. Findings support the notion that a positive store image is a competitive advantage, contributing to store patronage, loyalty, revenues and customer attraction [Steenkamp and Wedel, 1991].

In the services marketing literature, the study of image first appeared in the mideighties. Gronroos [1984] developed a service quality model with image as the central filter, influencing the perceptions and expectations of the consumer. Later tests of the influence of image on service found it to be the primary path to customer loyalty, and the strongest driver of repurchase intentions [Andreassen and Lindestad, 1998]. Other studies have examined the influence of specific attributes, such as contact personnel and physical environment, concluding that there are multi-faceted cues with the potential to affect both attitudes and behaviours toward the service provider [Nguyen and LeBlanc, 2002]. Studies that consider the role of image in distribution find that factors such as personal selling and contact are key to image, and even subtle differences can translate into substantial sales gains or losses [Panitz, 1988].

Observations of consumer behaviour suggest that pricing, too, acts as a cue to image formation, and much research has been conducted to understand its influence. Empirical tests confirm that price is capable of communicating image information. For example, consumers can be influenced by the reference price they hold from past 
experience in relation to the product, the range of prices within a product-line [Petroshius and Monroe, 1987], and even by the right digits of a price, such as 98 or 99 endings, which give the impression of relatively low price [Schindler and Kibarian, 2001]. Other studies have explored atinterplay of brand, store and price cues, and found that a negative perception of value invoked by a relatively high price, is reduced when a favourable brand or store name is introduced [Dodds et al., 1991]. Lastly, when positive perspectives for brand, store and price combine, buying intentions are positively affected [Dodds et al., 1991].

With the apparent shift in marketing emphasis to more corporate-level communications, an effective corporate image requires functional integration to achieve consistent internal and external communication. Corporate image theories hold some relevance for place image, in that the identification of a corporate brand identity with individual sub-brands is somewhat analogous to a country brand with individual sector brands.

To conclude, image theory in marketing provides some insight to the psychological mechanisms that link image to behaviour, the factors that moderate this link, the potential for positive and negative influences, and the complexities of image management beyond the first impression. Above all, the importance of image across fields of marketing is manifest, supporting the exploration of image as it relates to geographic place. The next chapter speaks specifically to the foundations of place image in a tourism context. 


\section{Chapter 2 Foundations of Tourism Destination Image}

It seems likely that images, as perceived by individuals in the travel market, may have as much to do with an area's tourism development success as the more tangible recreation and tourist resources [Hunt, 1975].

John Hunt [1975], often credited with being the first to establish the importance of image as an influencer of travel behaviour, described the beginnings of destination image research in the 1970s as being analogous to three peasants breaking in a new field, in reference to his own work and that of Edward Mayo and Clare Gunn [Pike, 2002]. Three decades and hundreds of studies later, concepts rooted in the work of these early pioneers are still present today.

\subsection{Early Historical Development}

In his early examination of the phenomenon of image in relation to tourism, Hunt [1975] defined image in vague terms such as "impressions", or "the perceptions held by potential visitors about an area". His large-scale study of the U.S. Rocky Mountain States measured respondents' perceptions of state attributes and resident characteristics, through a random mail survey of some 3,000 households in five major U.S. cities. Based on a comparison of mean scores from semantic differential scaled questions, he concluded that states do in fact have images, and that place of residence is a significant factor in determining people's perceived image of a destination.

Early studies of TDI focused on the measurement of tangible attributes to determine their relative importance. For example, in a study of regional images in the U.S., Mayo [1973] found scenery, lack of congestion, and climate to be most significant. Using the same methodological approach, Anderssen and Colberg [1973] found cost, 
climate, and scenery to be the most significant attributes of destination image. This type of attribute-based research became the modus operandi of TDI, and persists today.

By the end of the 1970s, while the measurement approach remained largely unchanged, the conceptualization of destination image had broadened. Crompton [1979, p.18], who is still commonly referenced, expanded the definition of image as "the sum of beliefs, ideas, and impressions that a person has of a destination". The author surveyed 617 students from 12 U.S. universities to assess Mexico's TDI in terms of two dimensions: a descriptive dimension and an importance dimension. Like Hunt [1975], he used semantic differential scales to measure a list of attributes. Analysis of variance indicated significant differences between the two dimensions. The most significant descriptive attributes were cost and climate. However, the attributes rated as being most important were sanitation and safety. This type of performance/importance approach to TDI study has also persisted over time [Oppermann, 1996; Joppe et al., 2001; Pike et al., 2004].

Crompton [1979] concluded that the obvious strategy was to focus on image dimensions with strength in terms of both the importance and the descriptive dimensions, which in the case of Mexico was "friendly people". However, he also suggested a strategy of identifying groups of respondents who scored more highly on descriptive dimensions as a potential target market, perhaps spurring later studies that use image as a strategic approach to market segmentation [Haahti, 1986; Ahmed, 1991; Leisen, 2001].

Also noteworthy of Crompton's [1979] work is his methodology. He used semantic differential scales to measure individual attributes, and factor analysis to identify the most salient attribute groupings. This approach to image measurement has 
continued over three decades of TDI research. Another common feature of his work still evident today is the presence of dual study objectives. Crompton's [1979] first objective was to examine the relationship between descriptive and importance attributes. His second objective was to identify the image attributes that should be emphasized to most effectively market Mexico as a vacation destination. Throughout TDI's development, study after study has empirically tested one or more theoretical aspects of the image concept, but very typically with the measurement of a particular destination image as a lead objective.

Another valuable first in TDI is Gunn's [1972] stage theory of image development. In the first stage, the mental construct of a place is defined as "organic", derived unintentionally through life's contacts with education, media and people. The next stage, defined as "induced", represents an image modified by promotional travel information. The last stage, defined as "modified-induced" represents an image changed by actual travel and personal experience. From this point, visitor experience was recognized as a key influencer [Pearce 1982; Phelps 1986; Chon 1990; Baloglu, 2001], and Gunn's theory of image development has endured.

To summarize, the contributions of the early pioneers of TDI research include the attribute-based model with measurement by scales [Mayo, 1973; Hunt, 1975; Crompton, 1979], the conceptualization of image as "the sum of beliefs, ideas, and impressions that a person has of a destination" [Crompton, 1979, p.18], the stage theory of an image evolving from "organic" to "modified-induced" [Gunn, 1972], the identification of key influencers such as experience, the presence of dual study objectives, and the consideration of image as a segmentation variable [Crompton, 1979]. 
Despite its promising beginnings in the 1970s, relatively little research was published on TDI in the 1980s [Ritchie, 1996]. However, it is worth noting that several models were developed in this decade, in attempts to understand destination choice. These models typically borrowed from general theories of the product consumption process of narrowing alternatives from an initial opportunity set of all possible choices, to a realizable set of what is known and feasible, to a post-evaluative choice set, and finally, to a decision set. When this selection process is applied to vacation consumption, destination images become critical to the process, acting as "pull" factors toward the final selection. For example, Van Raaij and Francken [1984] developed a vacation sequence model with five stages: (i) generic decision; (ii) information acquisition; (iii) joint decision making; (iv) vacation activities; and, (v) satisfaction and complaints. In the information acquisition stage, destinations that consumers are aware of are evaluated, positively or negatively, to come up with an "evoked" set of destinations. In Woodside and Lysonski's [1989] model of traveler destination awareness and choice, travelers construct destination preferences based on awareness and affective associations. While these early models did not explicitly include "image" as a model variable, several stages involved attitudes and intentions and concepts closely related to image. Haahti's model [1986] returns to a cognitive structure, with an Image Comparability component, as the key to identifying "primary competitors". A later model of travel destination choice considered not only the influence of attributes, but also the influence of inhibitors [Um and Crompton, 1992]. The authors found attributes to be most influential in the early evoked stage of the destination decision process. By contrast, in later stages it was the inhibitors that significantly influenced decisions. 
At this stage of TDI development, the importance of image may well have been recognized, but the understanding of image formation, conceptualization and influence was still evolving.

\subsection{Formation and Influences}

It was during the decade of the nineties that TDI research really took off, and continues without signs of slowing. To capture and attempt to make sense of the development of TDI, the multitude of studies is divided into three sections that correspond to the TDI framework in Figure 1. Adapted from Beerli and Martin [2004a], the framework is presented here to guide the pursuant discussion of TDI literature, beginning with Formation and Influences.

\section{Figure 1: Tourism Destination Image Model [adapted from Beerli and Martin,} 2004a]
I. Formation and Influences
II. Conceptualization
III. Behaviour

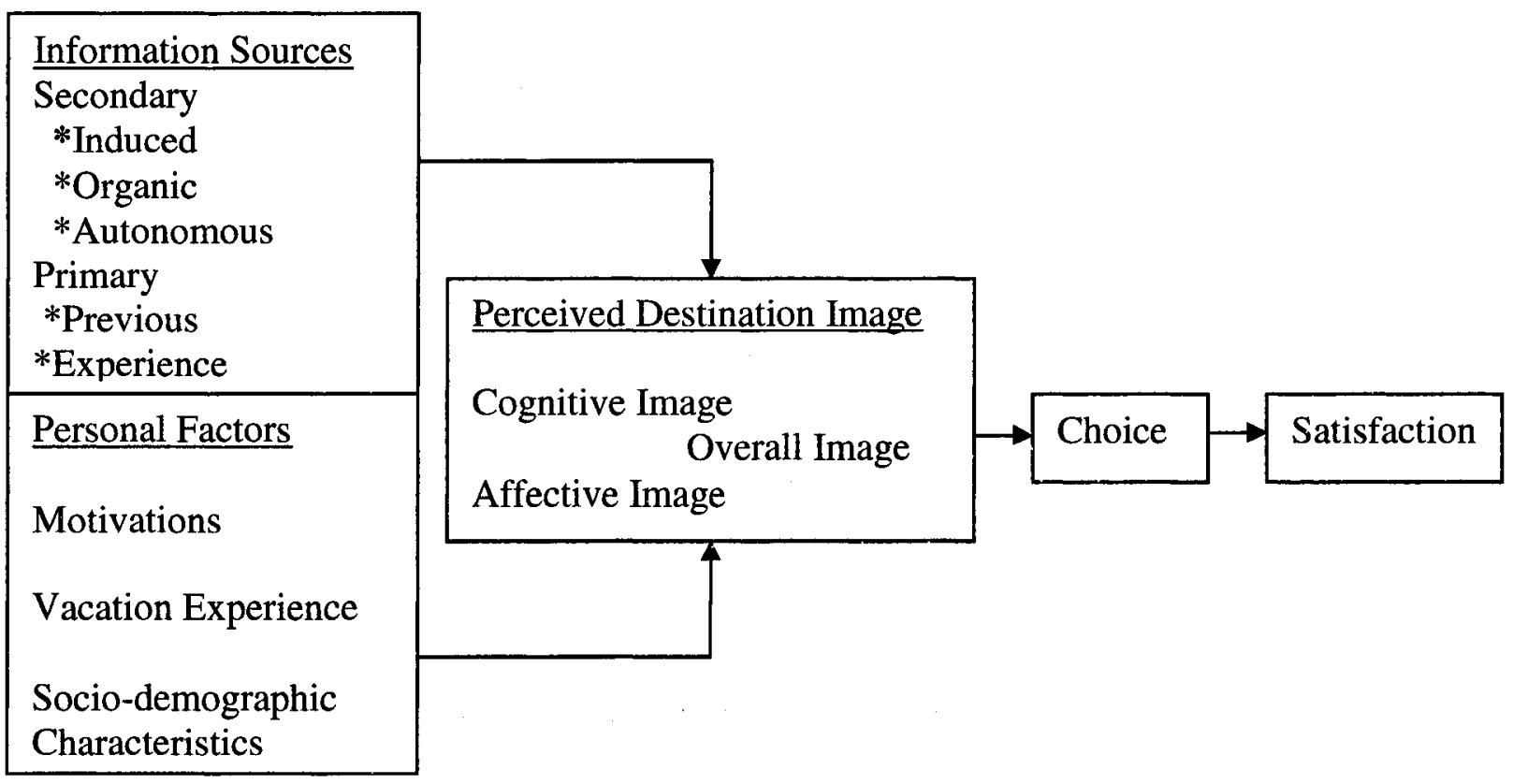




\subsubsection{Information Sources}

More than a decade after Gunn's [1972] stage theory of image formation, Phelps [1986] suggested a simplified, two-stage process. The author combined Gunn's [1972] organic and induced image stages to form a "secondary image", based on all formal sources of information, such as brochures and guide books, as well as all informal sources, such as information from friends. The author distinguished a "primary image" as the image held by visitors familiar with the destination, similar to Gunn's [1972] modified-induced image. Phelps [1986] assessed the influence of secondary images by comparing the destination image of first-time visitors $(n=48)$ to primary images held by repeat visitors $(\mathrm{n}=49)$ to Menorca, Spain. A comparison of secondary and primary images revealed differences, but with a degree of overlap. Interestingly, she also found that the main factor in destination choice was not so much the destination itself, but trip package elements such as accommodation type and flight availability. However, this result may have been influenced by her convenience sampling of charter flight passengers. Also, findings are based on a very small sample. For example, the author's claim that unexpected deviations between pre-trip images and actual trip experience had little effect on holiday enjoyment is based on just 23 post-trip surveys.

Fakeye and Crompton's [1991] study returned to a Gunn-type [1972] model, conceptualizing image formation as a three-step process: organic, induced and complex. The organic image is formed as a result of non-tourism information, and exists prior to exposure to tourism destination promotion. The induced image is a result of tourismspecific promotional messages, formed when a consumer actively searches for information. The complex image is a result of experiences at the destination. The 
authors studied the Lower Rio Grande Valley, Texas, using a three-category sample of prospective visitors $(n=131)$, first-timers $(n=188)$ and repeat visitors $(n=235)$. As expected, statistically significant differences in mean scores were found between the visitor and non-visitor sub-samples. Perhaps more interesting is the authors' attempt to link the three phases of image formation to three types of promotional activity: informative, persuasive and reminding. They suggest that informative promotion is most effective at the organic image stage, to provide tourists with knowledge of a destination and build awareness. Persuasive promotion is most effective at the induced image stage, to persuade potential tourists to make an actual purchase commitment. Finally, remindertype promotion is most appropriate at the complex image stage, to encourage repeat visitation.

Gartner [1993] viewed the process of image formation as a continuum of separate "agents", defined as "forces producing a specific result", that act independently or in combination to form a destination image unique to an individual. A summary of his continuum is shown as Figure 2. It is similar to Gunn's [1972] stage theory of TDI, but with additional detail in terms of the source and type of agent.

Gartner [1993] considered the detailed breakdown of agents important because, as in general consumer behaviour theory [Howard and Sheth, 1969], he viewed destination selection as a process of narrowing alternatives from an initial opportunity set of all possible destinations, to an evoked set of approximately three destinations. Destination images are critical to this process, acting as "pull" factors toward the final selection. Gartner's [1993] work is also well noted for his conceptualization of destination image as comprising three hierarchically interrelated components: cognitive, affective and 
conative. This typology is borrowed from general theories of image [Boulding, 1956]. The cognitive component is based on the evaluation of the "facts" held by a consumer, and is most typically measured through an assessment of a destination's attributes. The affective component is based on the consumer's feelings about the destination and its attributes. Lastly, the conative component requires measures of consumer intended actions to assess.

Figure 2: Continuum of Image Formation Agents [Gartner, 1993]

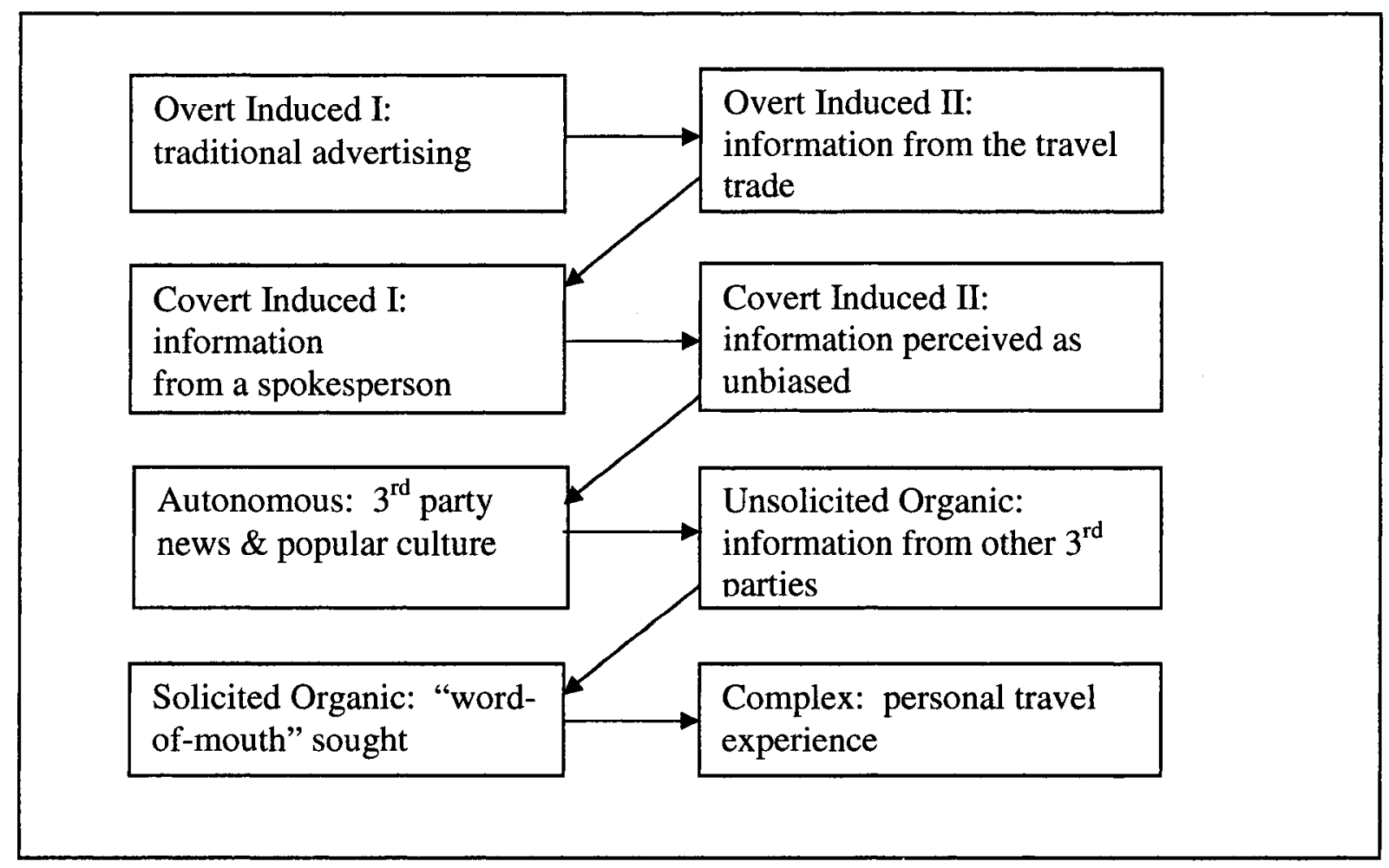

Another notable contribution of Gartner's [1993] theoretical work is his summation of the preceding two decades of TDI research. He described four key characteristics of destination image: 
1) The larger the entity, the more slowly images change. This statement is particularly relevant for tourism, where marketing is often managed at the macro level of country.

2) Induced image formation attempts must be focused and long term. This statement follows from the first, in that image change can be slow, thus requiring time to effect.

3) The smaller the entity in relation to the whole, the less of a chance for the smaller entity to develop an independent image. This statement has relevance for lower level destinations (e.g. towns, within regions, within states, within countries), that must be aware of any existing images of larger destinations in which they are situated.

4) Effective image change depends on an assessment of presently held tourism images. This last statement sums Gartner's [1993] espousal of research to collect baseline data prior to any efforts to change a currently held image.

The influence of advertising on image and traveller attitude was assessed by Bojanic [1991]. In a random survey of 2,000 U.S. metropolitan households, analysis of variance indicated that the greater the exposure to tourism destination advertising, (i) the more favourable the attitude toward the destination, and (ii) the greater the likelihood of visitation to the destination within the next three years. Recent studies of the influence of imagery on TDI have shown that even motion pictures - an element of popular culture as identified by Gartner [1993] - alter destination image and influence the interest in visiting featured locations [Kim and Richardson, 2003]. Jenkins [2003] found evidence 
of a "hermeneutic circle", whereby tourists (here, backpackers to Australia) reproduce iconic images from promotional material in their own trip photos, thus perpetuating certain imagery.

A unique study of secondary source influence on image formation was undertaken by MacKay and Fesenmaier [1997]. The authors used pictorial elements from promotional material to measure respondents' image interpretation. While this might seem an obvious method given the visual nature of tourism marketing, to date TDI measurement has relied almost universally on words and/or simply destination name to evoke TDI. Here, a total of 10 graduate students from the U.S. and Taiwan were presented with visual images of the study location, Riding Mountain National Park in Manitoba, Canada, and asked to rate the images in terms of three dimensions: attractiveness, uniqueness and texture. Three types of images were presented: landscapes, images of people involved in activities, and images of manmade structures. Though tested on a small scale, results suggest a strong link between visual elements and image formation, with landscape images having a particularly strong effect. Demographics (e.g. respondent age, marital status) were less significant. This leads to the next area of investigation: the influence of personal factors on image formation.

\subsubsection{Personal Factors}

Socio-demographics, as in most marketing research, are believed to play a role in image formation. One element that has received little attention is that of culture. Richardson and Crompton [1988] analyzed a subset of 624 surveys collected in a national survey of 3,873 Canadians, and used log linear modelling to assess the relative influence 
of culture. They found that French and English Canadians held different perceptions of 10 vacation attributes. In a small but methodologically interesting study, MacKay and Fesenmaier [2000] found that American and Taiwanese students $(n=10)$ interpreted tourism destination imagery differently. Therkelsen [2003] argued that destinations are culture-bound products, whose meanings are influenced by the cultural background of the tourist. The author suggested that some TDI elements may be recognized globally, while others may be market specific, presenting a challenge to place marketers to distinguish between the two. The influence of culture on image formation, however, remains largely unknown. Even the influence of such a basic demographic characteristic as age is inconclusive. Smith and MacKay [2001], in a study of memories of tourism destination pictures, found no significant age-related differences between 90 older and 90 younger adult subjects, based on an analysis of covariance (ANCOVA). Thus, while many variables that form TDI have been identified, much work remains to establish their importance.

Several TDI studies have considered travel experience, or the level of familiarity with a destination, when sampling respondents. In the studies reviewed in the preceding section on information sources, experience was seen as a means of control to isolate the effects of primary and secondary information, building on the staged approach to image formation initiated by Gunn [1972]. Later studies picked up on the significance of experience in image formation and focused specifically on assessing its influence. The experience variable is typically measured in one of two ways: either a comparison of respondents' destination images pre and post trip; or, a comparison of the destination image of visitors to that of non-visitors. 
As an example, Pearce [1982] studied the influence of travel experience by comparing the pre and post travel images of visitors to Greece $(n=31)$, Morocco $(n=41)$ and a control group of non-travelers $(n=25)$. He found that experience had a positive influence on image, in that visitors' post-travel image of the destination had improved. Interestingly, he also found that visitors' image of their own country-of-origin (in this case, Britain), as well as their image of countries similar to the country visited (e.g., Tunisia) also changed post-travel. Experience was found to change attitudes to holiday environments in general, supporting the adage that "travel broadens the mind". Pearce's [1982] study, though limited in size, is noteworthy for his application of a repertory grid methodology, rather than analysis of variance which was at that time, and is now, the more common approach to TDI analysis. Also worth noting here is the emergence of certain common attributes in TDI measurement such as shopping, people, culture, scenery, and beaches, where applicable.

To account for traveller experience, Chon [1991] compared the destination image of first time visitors $(n=240)$, to that of travellers en-route to South Korea $(n=204)$. Following a common approach to TDI research, the author used convenience sampling at a tourist location (Los Angeles and Seoul airports), administered a scale-based survey, and analyzed the variance of mean scores. Like Pearce [1982], he found a positive change based on the measurement of attributes such as shopping, people, culture and beauty, among others. The author concluded with marketing strategy recommendations, suggesting that the attributes rated most favourably be the focus of promotions, and those attributes rated most unfavourably be the focus of product upgrades. 
This link from TDI to tourism product has been explored by using visitor experience to assess strengths and weaknesses of a destination's products and services. For example, Chaudhary [2000] compared the pre and post images of India by 152 visitors from three countries as a gap analysis between expectations and satisfaction levels. Analysis of variance indicated most of the 20 measured attributes fell short of expectations, leading the author to recommend efforts to improve key product dimensions. The gap is in contrast to most studies of the image differences between prospective and actual tourists, which more typically find a positive relationship between image and experience [Awaritefe, 2004]. Also, the author then compared the images held by visitors across their three countries of origin, and found no cross-cultural differences. However, this may have been due to limited sample size when the 152 respondents were segmented by origin.

By the current decade, sufficient work had been undertaken to confirm that both travel experience and exposure to information sources are significant determinants of TDI. Baloglu [2001] created a composite measure of experience and information sources, which he termed a "familiarity index". The author tested his index by measuring the image of Turkey held by U.S. travellers $(n=448)$ through a mail survey to a list maintained by the Turkish National Tourism Office (NTO) in New York, most likely producing higher than average levels of familiarity with Turkey. The author's statistical analysis expanded from the methods commonly found in TDI research to date. Baloglu [2001] used both Principal Components Analysis (PCA) to identify the most significant image dimensions, and Multiple Analysis of Variance (MANOVA) to compare groups of respondents differentiated by level of destination familiarity on several variables 
simultaneously. He found that the higher the familiarity with the destination, the more positive the image. The author recommended that marketing efforts employ a mix of advertising, public relations and sales promotion to have the greatest effect on "familiarity", given its multi-dimensional nature. Another variable considered to influence image formation is the visitor's country of origin, or geographic location. However, assessments of its influence on image are inconclusive. Baloglu [2001] contends that it is experience and knowledge of a destination that determines image, not geography.

Crompton's [1979] study, also noted earlier, assessed the image of Mexico and found that the further away the respondent was from Mexico, the more favourable their image of the destination. The author concluded that as destination familiarity increased, the destination image became more complex, and less reliant on stereotyping. And, the relationship of image to geographical location may be positive or negative, depending on whether the "familiarity", in Baloglu's [2001] terminology meaning travel and information, is positive or negative. In the case of Mexico, the proximity to border towns that were often portrayed negatively was believed to have negatively influenced the image of the whole country.

Another expansion to the experience variable is the consideration of the length-ofstay at a particular destination during travel. Vogt and Andereck [2003] measured the pre and post travel image of 748 visitors to Arizona, through the collection of trip diaries distributed at a state-run welcome centre. They found that both experience and length-ofstay resulted in an increase of knowledge about the destination. However, destination desirability changed only slightly. They concluded that desirability may be hard to affect 
during travel, particularly if tourists are already satisfied. Thus, the influence of lengthof-stay on TDI is still a matter of debate.

The passage of time, even without travel experience, is also thought to influence image formation. Yet, longitudinal studies of TDI are extremely rare, in part due to the methodological challenges of capturing comparable data over protracted periods of time. One such effort, by Gartner and Hunt [1987], measured the change in image of the State of Utah from 1971 to 1983. A random survey of 1,917 households across the U.S. in 1983 was compared to similar data collected in 1971. Based on analysis of variance between the two time points, a positive change in state image was found, attributed to the influence of advertising and other information sources, described as organic and induced agents. Thus, the real cause of the change may have been secondary information, rather than the passage of time itself. The authors also found that geographically closer respondents were more favourably influenced, again supporting the contention that familiarity - either positive or negative - is a strong determinant of image [Balogiu, 2001].

\subsection{TDI Conceptualization}

After two decades of studies measuring various components of TDI, almost all using structured lists of attributes to do so [Hunt, 1975; Goodrich, 1977; Crompton, 1979; Pearce, 1982; Haahti and Yavas, 1983; Phelps, 1986; Gartner, 1989], a new model was introduced by Echtner and Ritchie [1991]. The authors not only built upon past studies of TDI, but considered studies of brand, store and corporate image, as well as theories from social psychology. Their resulting conceptualization of TDI is three-dimensional, as shown in Figure 3. 
Figure 3: The Components of TDI [Echtner and Ritchie, 1991]

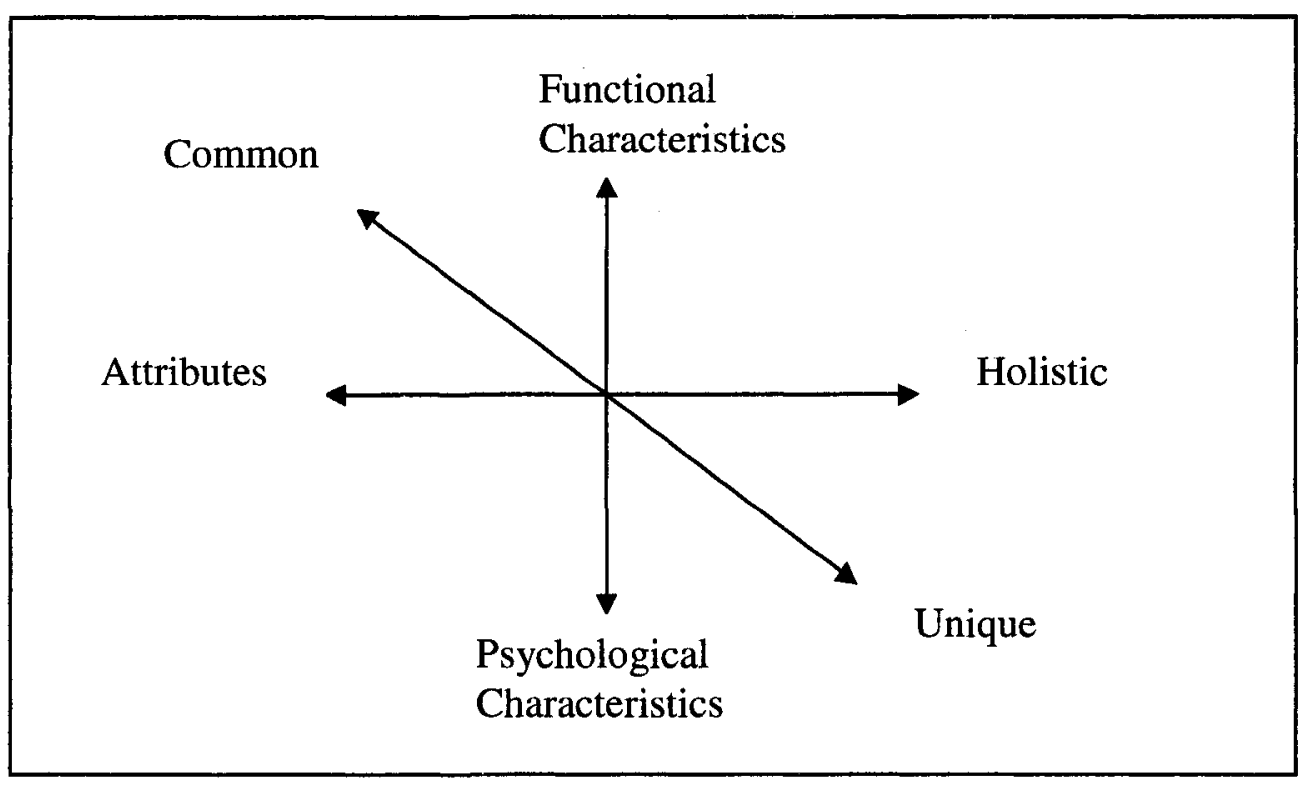

In one dimension (holistic-attributes), their model introduces a holistic component to represent the interpretation of image as a total impression, or "gestalt" [Dichter, 1985], in addition to the traditional attribute-based component of TDI. A second dimension (functional-psychological) reflects destination characteristics that range from the directly observable or measurable attributes (e.g. scenery, attractions, accommodations, price), to the more abstract, intangible attributes (e.g. friendliness, safety, atmosphere). Lastly, a third dimension (common-unique) represents a concept largely overlooked to this point, the continuum from common attributes to unique attributes. The authors argue that a TDI can be composed of the impressions of a core group of traits by which all destinations can be compared (e.g. price, climate, friendliness), as well as by those truly unique features so frequently associated with a particular destination (e.g. Taj Mahal in India, Carnival in Rio). While Figure 3 conceptually divides TDI into distinct components, the authors note that overlap exists between dimensions, in that holistic impression can be based on 
combinations and interactions of attributes, and likewise, attributes can be influenced by overall impression. Additionally, the distinction between functional and psychological attributes is frequently unclear (e.g. cleanliness). The delineation of dimensions, nevertheless, allows for measurement. And as in any applied methodology, the subsequent interpretation is critical.

The authors contend that because TDI is multi-dimensional, the common approach of rating structured lists of attributes is an incomplete measurement. This was a bold statement for its day, given that the vast majority of TDI studies to that time had used structured methods to measure primarily tangible attributes. Pike [2002] found that only six of 142 TDI studies he reviewed explicitly showed an interest in affective images. Echtner and Ritchie [1991] recommended a combination of structured methods to capture the common, attribute-based components, and unstructured methods to capture the more holistic and unique components to effectively measure TDI. Attributes should also be expanded to reflect a fuller range of functional and psychological characteristics. The authors' summary of attributes used by researchers to measure TDI clearly shows a favouring of functional measures (e.g. scenery, price, climate) over psychological measures (e.g. atmosphere, accessibility), with the exception of "friendliness". The Echtner and Ritchie [1991] model, much-referenced and much-used in subsequent studies, greatly influenced the evolution of TDI research.

Echtner and Ritchie [1991, 1993] were not the only authors to conceptualize TDI in a fundamentally new way that changed the direction of research. Another concept which stands out in terms of its pervasiveness, is the approach of disaggregating TDI into cognitive and affective components. In response to the critique that most TDI studies 
focus on cognitive image components, Baloglu and Brinberg [1997] introduced a theoretical model of response to place that focused solely on affective image components. In their multi-dimensional scaling (MDS) analysis of the affective images of 11 Mediterranean destinations, they found variance across destinations in terms of both positive (arousing, exciting, pleasant, and relaxing) and negative dimensions (sleepy, gloomy, unpleasant, and distressing). They concluded that studying the affective image of destinations would well support positioning strategies.

It was not until the end of the decade that Baloglu and McCleary [1999a] attempted to bring together a range of known determinants into one general framework of TDI formation, shown as Figure 4. Here, TDI is formed by both stimulus factors comprised of information sources and experience; and by personal factors - comprised of social and psychological variables. The authors tested their framework using path analysis in a study of the image held by potential visitors of four Mediterranean countries.

Figure 4: A General Framework of TDI Formation [Baloglu and McCleary, 1999a]

\begin{tabular}{|l|l|l|l|}
\hline $\begin{array}{l}\text { Personal Factors } \\
\text { Psychological } \\
\text { Values } \\
\text { Motivations } \\
\text { Personality } \\
\text { Social } \\
\text { Age } \\
\text { Education } \\
\text { Marital Status } \\
\text { Others }\end{array}$ & $\begin{array}{lll}\text { Destination Image } \\
\text { Perceptual/Cognitive }\end{array}$ & $\begin{array}{l}\text { Stimulus Factors } \\
\text { Information Sources } \\
\text { Amount } \\
\text { Type }\end{array}$ \\
Affective & Previous Experience \\
& Gistribution \\
& \\
\hline
\end{tabular}

Their exploratory research design was hypotheses-based, with a relatively complex set of multi-item constructs. For example, travel motivation was measured 
using five factors: relaxation/escape, excitement/adventure, knowledge, social, and prestige. Other personal factors measured include age and education. A range of attributes representing cognitive elements of destination image were also factor analyzed to produce three dimensions: quality of experience, attractions, and value/environment. The affective elements of destination image were measured using four bipolar scales: arousing/sleepy, pleasant/unpleasant, exciting/gloomy, relaxing/distressing to derive a composite score. In terms of stimulus factors, found on the right-hand side of the model, respondents' use of nine information sources was measured, as well as their rating of the importance of four categories of information sources on a 4-point Likert scale. Lastly, global image was measured as a single item, on a 7-point Likert scale.

Using 448 surveys received in response to a mailing list maintained by the Turkish NTO [see also Baloglu, 2001], the authors' findings shed some light on the complexities of TDI, particularly in terms of the relationships between the cognitive, affective and global components of image. They found that information sources, age and education influence cognitive evaluations, which in turn combine with motivations to influence affect. Of note, they conclude that the influence of cognitive evaluations on affect was greater than the influence of motivations. Finally, the global image was more influenced by affect than by cognitive evaluations. The authors interpret affect as an intervening variable between cognitive evaluations and giobal image. Their study is significant in terms of its presentation and measurement of TDI as multi-dimensional, complex and dynamic.

In a companion study, Baloglu and McCleary [1999b] once again compared the TDI of four Mediterranean countries (Turkey, Greece, Italy and Egypt), conceptualizing 
the image construct as having three components: cognitive, affective, and overall image. To summarize, they measured four affective components using bipolar scales (e.g. gloomy-exciting), 14 cognitive components using a Likert scale (e.g. Turkey offers little offers much "natural attractions"), and one overall image using a Likert scale (very negative-very positive). In the first Baloglu and McCleary [1999a] study, the interest was TDI formation. Path analysis was used to assess the influence of formative variables such as information source. In Baloglu and McCleary [1999b], the study objective was to compare the TDI of four destinations. Rather than path analysis, MANOVA is employed. Their approach produced significantly differentiated results by country for all components, with the cognitive component producing the most differentiating elements. TDI of visitors and non-visitors also differed significantly. The authors concluded by noting that the highest rated attributes, in this case "history and culture", may not be the most influential if undifferentiated from competition. Alternatively, they recommended seeking the main distinguishing attributes for effective destination positioning.

The conclusion perhaps led to another methodological expansion by Baloglu and Mangaloglu [2001]. In this later study, the authors apply the same measures of cognitive and affective image components, but add an open-ended question in an attempt to more fully capture the complexities of TDI. In an assessment of the image of the same four countries (Turkey, Greece, Italy and Egypt), but from the perspective of 46 tour operators and travel agents rather than travellers, respondents were asked to write the first three adjectives or nouns that came to mind for each destination. The study results led the authors to conclude that TDI be measured by both scale items and unstructured techniques to identify "true" images. 
Yet another conceptualization of TDI was formulated by Tapachai and Waryszak [2000]. They, too, were stimulated by their perceived limitations of the common approach to TDI of measuring primarily functional, or cognitive, attributes in a structured format. Instead, the authors used a "beneficial image framework" for TDI analysigs; conceptualizing image under five value dimensions: (i) functional (e.g. cheap shopping); (ii) social (e.g. suitable for all people); (iii) emotional (e.g. calm); (iv) epistemic (e.g. cultural experience); and, (v) conditional (e.g. accessibility). In a study of the image of Thailand and the U.S., 247 Australian university students listed their perceived benefits of each country, in an open format. Through content analysis of the responses, statements were formed to represent the five value dimensions. Respondents were then asked to freely express their agreement or disagreement with the statements. Responses were coded based on degree of agreement, and the value dimensions were subsequently ranked. Functional values were most highly rated -- perhaps some measure of vindication for the popular attribute-based model -- followed by epistemic values for both destinations. The authors were satisfied that their methodology was effective in TDI assessment.

As another step toward a conceptual framework, Gallarza et al. [2002] undertook an extensive review of 65 TDI studies, published between 1971 and 1999. Based on their findings, the authors conceptualized image as (i) complex (e.g. it has cognitive, affective and conative elements); (ii) multiple (e.g. it is a multi-item construct); (iii) relativistic (e.g. it varies across people); and, (iv) dynamic (e.g. it is affected by time and distance). While they did not provide an operational model of TDI, they did provide a valuable taxonomy of methodology and statistical procedures used for measurement. Their 
taxonomy reveals such commonalities as the use of Likert scales for data collection, as well as the complexities of research, and the frequent combination of analytical methods. To capture the structure of TDI, multivariate techniques predominate, particularly information reduction techniques such as factor analysis. The authors also categorized the volume of past literature in terms of object of study, finding "country" to be most common, and in terms of subject of study, finding "tourists" to be most common. As a literature review, this study contributes to the understanding of TDI.

Another worthy contribution to the understanding of TDI formation by Beerli and Martin [2004a], as shown in Figure 5, goes one step further than the Baloglu and McCleary framework [1999a] by incorporating actual vacation experience, and testing their model post-travel.

Figure 5: Path Model of TDI Components and Determinants [Beerli and Martin, 2004a]

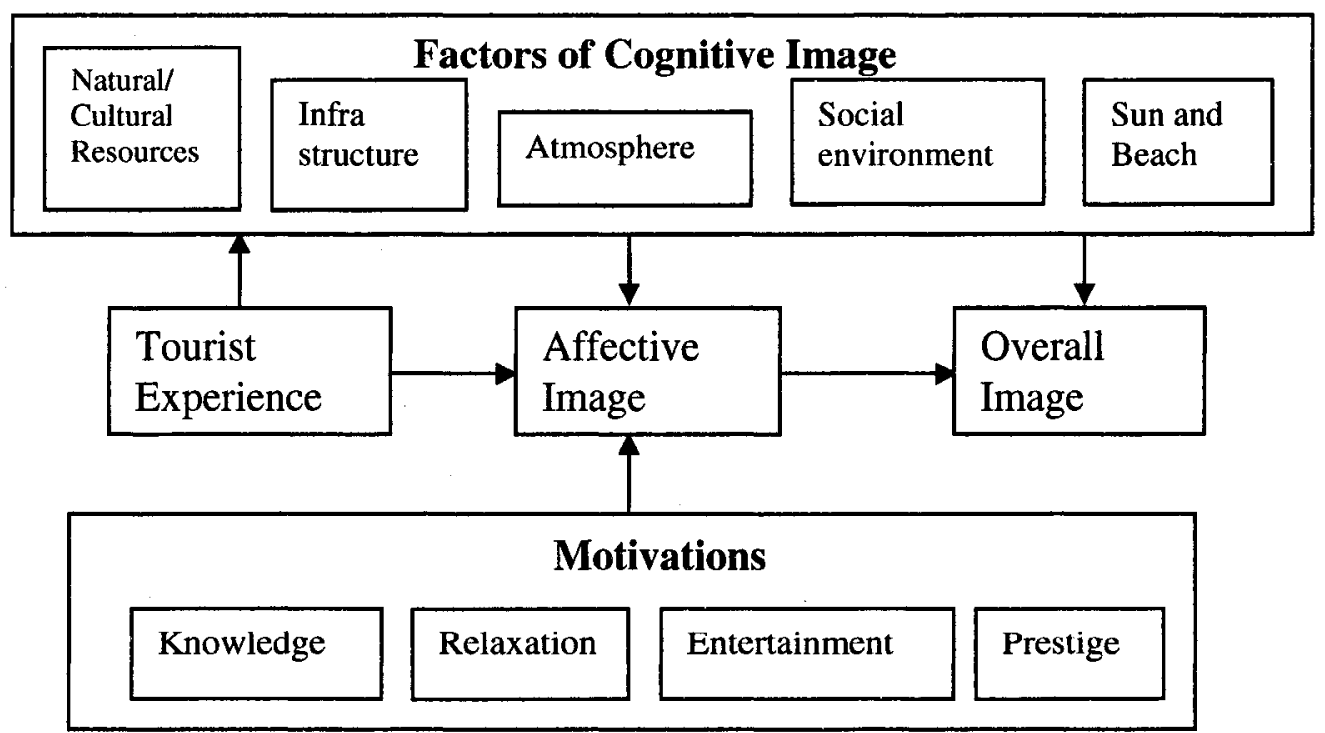

In a study of the image held by 616 visitors to the Island of Lanzarote, Spain, upon their departure, the authors confirmed the directional findings of Baloglu and 
McCleary [1999a], and also found that travel experience had an effect on TDI. Again, this was a hypotheses-based explanatory study with complex constructs, similar to those used by Baloglu and McCleary [1999a]. Both motivation, comprised of 19 variables, and cognitive image, comprised of 24 variables, were factor analyzed to reduce the dimensions included in the path analysis. Affective image was comprised of two variables (pleasant/unpleasant and exciting/boring), and overall image was measured as a single item, on a 7-point Likert-type scale.

Information sources, considered to be significant influences on image formation, were captured in terms of both variety and importance. Respondents were asked to identify which of nine sources of information they used: travel agents, brochures/travel guides, friends/family members, airlines, tour operator/company, advertisements, books/movies, articles/news, and direct mail from the destination. Variety of information was then captured as the sum of the number of information sources used, ranging from 0 to 9. Additionally, four information source categories were rated in terms of their importance to respondents' impression of each destination: professional advice, word-ofmouth, advertisements, and books/movies/news. The authors found both variety of information used and importance of type of information significantly influenced the cognitive evaluation of destination. Also of note is their assessment of the influence of socio-demographic variables, which indicated that country-of-origin had the greatest influence on both cognitive and affective image components.

This study goes a long way in addressing two key issues that have persisted throughout the research of TDI. First, image lacks an accepted conceptualization. Studies frequently omit a definition of the term, or simply define image as "perceptions" 
[Hunt, 1975; Richardson and Crompton, 1988] or "impressions" [Gartner and Hunt, 1987], adding little to the understanding of the concept. Second, despite the common method of scales to measure image, the attributes used vary from study to study, with little homogeneity. Beerli and Martin [2004a] provide a useful table that summarizes attributes found throughout the literature, reproduced as Table 1.

Table 1: Dimensions/Attributes of the Perceived TDI [Beerli and Martin, 2004a]

\begin{tabular}{|l|l|l|}
\hline Natural Resources & General Infrastructure & Tourist Infrastructure \\
Weather & Development/quality of & Hotel/ self-catering \\
Temperature & roads, airports, ports & Accommodation \\
Rainfall & Private/public transport & Number of beds \\
Humidity & facilities & Categories \\
Hours of sunshine & Development of health & Quality \\
Beaches & services & Restaurants \\
Quality of seawater & Development of & Number \\
Sandy or rocky beaches & telecommunications & Categories \\
Length of beaches & Development of & Quality \\
Overcrowding of beaches & commercial infrastructure & Bars, discos, clubs \\
Wealth of countryside & Extent of building & Ease of access to destination \\
Protected nature reserves & development & Excursions at the destination \\
Lake, mountain, desert, etc. & & Tourist centres \\
Variety and unique flora,fauna & & Network of tourist info \\
\hline Leisure and Recreation & Culture, History and Art & Political and Economic \\
Theme parks & Museums, historical & Factors \\
Entertainment/ sports & buildings, monuments, etc. & Political stability \\
Golf, fish, hunt, ski, scuba & Festival, concerts, etc. & Political tendencies \\
Water parks, Zoos & Handicraft & Economic development \\
Trekking & Gastronomy & Safety \\
Adventure activities & Folklore & Crime rate \\
Casinos, Night life & Religion & Terrorist attacks \\
Shopping & Customs and ways of life & Prices \\
\hline Natural Environment & Social Environment & Atmosphere of the Place \\
Beauty of the scenery & Hospitality and & Luxurious \\
Attractiveness of cities, towns & friendliness of local & Fashionable \\
Cleanliness & residents & Place with good reputation \\
Overcrowding & Underprivileged and & Family-oriented \\
Air and noise pollution & poverty & Exotic, Mystic \\
Traffic congestion & Quality of life & Relaxing \\
& Language barriers & Stressful \\
& & Fun, enjoyable, Pleasant \\
& & Boring \\
& & Attractive or interesting \\
\hline
\end{tabular}


There are likely more attributes than can be feasibly measured in one study. However, the range provides a menu from which individual researchers can choose, and possibly, a categorization that might encourage some standardization in future.

A companion study by Beerli and Martin [2004b] again combines measurement of the cognitive, affective and overall image components, as well as determinants of its formation such as motivations, previous vacation travel, and socio-demographics (respondent age, gender, education level, social class and country of residence). The authors once again use TDI data from 616 visitors to Lanzarote, primarily employing Likert-type scales to capture cognitive image ( 24 items), affective image ( 2 attributes), overall image (1 item), motivations (19 items), and experience $(1$ item). In the first Beerli and Martin [2004a] study, the interest was TDI formation. Path analysis was used to assess the influence of formative variables such as information source. In Beerli and Martin [2004b], information sources are not assessed, and more focus is given to the conceptualization of cognitive, affective, and overall image dimensions.

The authors' findings suggest that tourists' motivations, defined as the advantages sought on the vacation, influence the affective component of TDI. Thus, if tourists' motivations and perceived nature of the destination are congruent, the affective image is positively influenced. Experience was also found to have a positive relationship with image, but with first time visitors the cognitive component was most influenced, while with repeat visitors, the affective component was most influenced. The authors suggested that perhaps experienced travellers are more tolerant in their assessments, but advised further study of this variable. Their path model was presented earlier as Figure 5. 
A recent conceptualization of destination image is modeled by Tasci and Gartner (2007). They have developed a complex framework that includes static inputs (e.g. history), supply-side inputs (e.g. destination marketing), demand-side inputs (e.g. perceiver sociodemographics), and independent inputs (e.g. news), to form a destination image comprised of attributes and holistic components, which then influences consumer behaviour pre, post and during travel. The authors conclude that there are still many facets of TDI yet to be investigated empirically.

Now that the formation and conceptualization of TDI have been explored, the relationship of TDI to behaviour is considered.

\subsection{Relationship to Behaviour}

There is broad agreement amongst tourism researchers and practitioners alike that TDI influences travel behaviour [Bigne et al., 2001], and a number of notable studies established this relationship in the early stages of TDI research [Goodrich, 1978; Woodside and Lysonski, 1989]. However, in comparison to the volume of TDI studies that focus on formation and conceptualization, the number of studies related to behaviour is surprisingly low, and perhaps in inverse proportion to its importance. While behaviour, which can encompass destination preference, intention to visit, actual choice, satisfaction, and repeat visitation, is typically seen as the desired end result of a positive TDI, the existing body of literature focuses more on the image concept itself, and less so on its behavioural effect. This may reflect the pervasive assumption that the relationship is positive, thus questions have been limited. It is also common for travel behaviour studies to be undertaken under the auspices of terms other than image, such as perceptions and 
satisfaction. Additionally, the measurement of the link from TDI to behaviour presents the greatest methodological challenges. Nonetheless, there have been important contributions to the understanding of TDI's influence on behaviour.

Goodrich [1978] was among the first to empirically establish the relationship between vacation destination preference, perception, and choice. While the author used the term "perception" rather than "image", he defined the concept as the familiarity with and knowledge about a destination, which can also be taken to mean "image" in a broad sense. To ascertain the relationship between perception and destination preference, he uses a Fishbein-type [1967] choice model. Though popular in studies determining preferences for or choice of products, ranging from groceries to automobiles, this was the first formal application of the model to travel research. Basically, the model holds that an individual's attitude toward an object is a function of the amount of valued attributes the individual perceives the object to have, and of the importance of those attributes to the individual. Goodrich [1978] applied the model to a survey of 230 American Express card holders' preferences for nine sun destinations. As theorized, he found that the more favourable a destination's image, the greater the likelihood of that destination being chosen.

Woodside and Lysonski [1989] developed their own destination choice model, once again adapting general theories of consumer behaviour research to a travel behaviour context. Like Goodrich [1978], they did not use the term "image", but describe "the mental category a traveller assigns to a destination", which influences "the linking of positive or negative associations with that destination", and "indicates how the destination is positioned in the consumer's mind" [Woodside and Lysonski, 1989, p.8]. 
The authors' model of destination awareness and choice, shown as Figure 6, posits that travellers form destination preferences from awareness and affective associations. The affective associations construct here is comparable to the affective image component of other models [Baloglu and Brinberg, 1997]. The awareness construct is categorized into four sets of destinations: the consideration, the inert, the inept and the unavailable set.

Figure 6: General Model of Traveller Leisure Destination Awareness and Choice [Woodside and Lysonski, 1989]

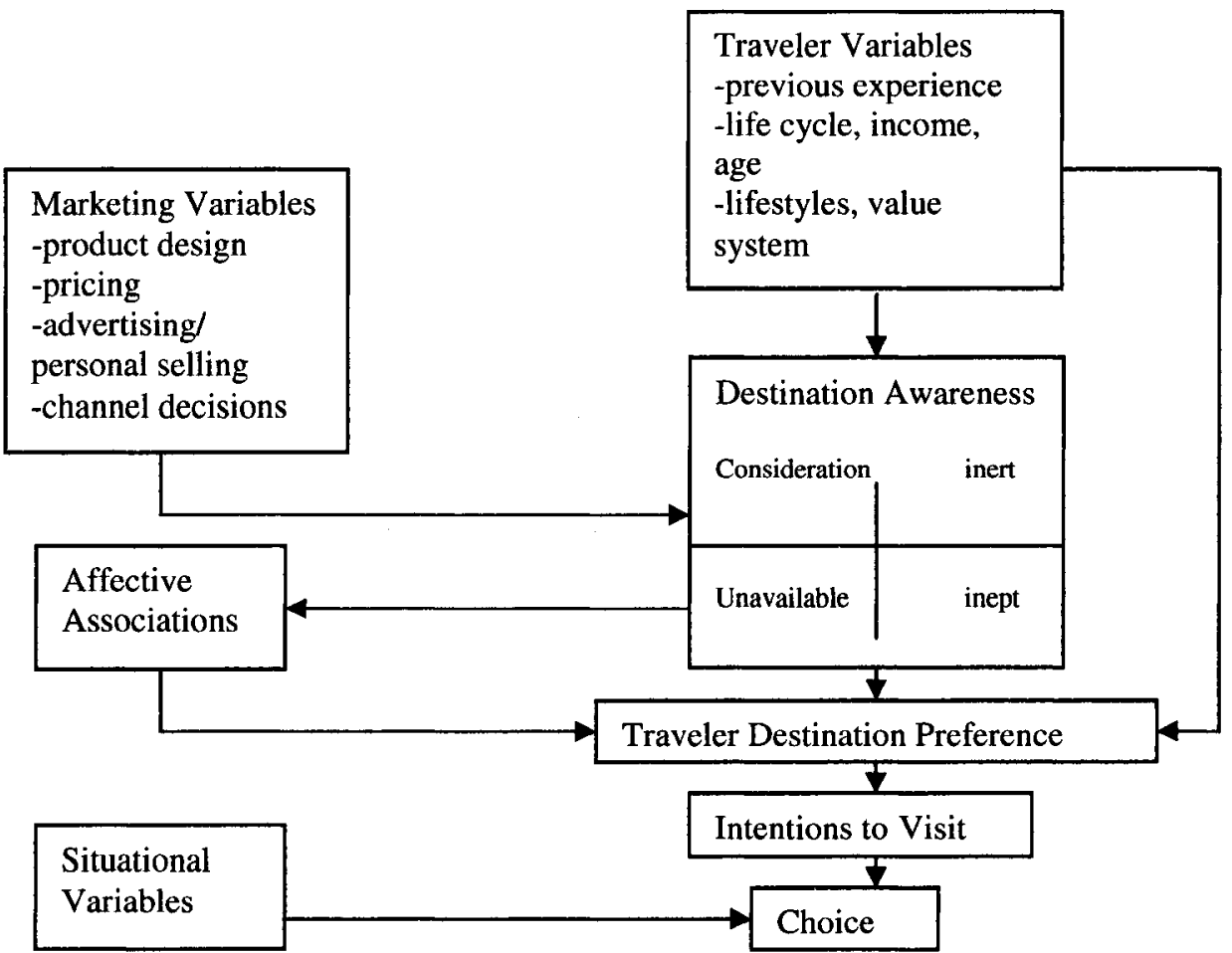

This approach to categorization has its origins in consumer behaviour theory [Howard and Sheth, 1969]. Brands are categorized into subsets that the consumer is aware of, is considering buying, is not considering buying, and lastly, a set the consumer is unaware of. The influence of affective associations was not tested by the authors, who focused instead on the influence of awareness on destination preference and intention to 
visit. In their study of 92 New Zealand university students' destination awareness and choice, they found the size of the consideration set to be quite small, averaging 4.2 countries, and from this set, a destination is most likely to be chosen.

Chon [1990, p.5] reviewed 23 TDI studies as the basis for his model of destination image and traveller buying behaviour. He specifically considers image, stating that "it is the central postulate of the proposed model that an individual traveller's travel behaviour can be explained through a framework of imagery change throughout his [sic] entire travel experience". Once again, the author borrows from general theories of buyer behaviour, describing the decision process as multi-staged, linked to buyer motivations, and with the objective being the satisfaction of needs. His model begins with buyer needs, or "push" factors, and destination cues, or "pull" factors, as the antecedents to travel motivation. At this stage, a primary image of the destination is constructed and a decision to travel is made. The primary TDI is subsequently modified through information search, resulting in a decision to travel based on performance expectancy. While untested, Chon [1990] hypothesized that satisfaction would be dependant upon "evaluative congruity" between perceived TDI and perceived reality. The highest satisfaction would be realized when the perceived TDI and the perceived reality of the destination travelled to are both positive. The lowest satisfaction would be realized when the perceived TDI is positive, yet the perceived reality of the destination is negative.

Sirgy and Su [2000] developed a model of travel behaviour with underpinnings of consumer psychology, considering the degrees of self-congruity and functional congruity as significant predictors of travel behaviour. They defined self-congruity as the match 
between the destination visitor image and tourists' self-concept, and functional congruity as the match between the utilitarian attributes of the destination and the tourist's ideal expectations related to those attributes. The authors proposed that the formation of a destination visitor image is influenced by a multitude of destination environmental "cues", such as atmospheric, service, price, location and promotion cues. The greater the match between the destination visitor image and the tourist's self-concept, the more likely it is that the tourist will visit the destination. The relationship, however, is moderated by such factors as knowledge, involvement and prior experience. For example, the effect of self-congruity on behaviour is greater for tourists with less knowledge than for tourists with more knowledge. Lastly, the authors proposed that self-congruity biases functional congruity. That is, where congruence is high, tourists will process the utilitarian attributes of a destination in a more favourable light. While these propositions seem reasonable based on findings in other fields of consumer behaviour, they were not tested by Sirgy and $\mathrm{Su}$ [2000], and they have yet to be supported in the travel research context.

Bigne et al. [2001] explored the relationship between TDI, travel behaviour, and post-travel evaluations. The authors introduced the concept of quality, and adopted the sequence: image $\rightarrow$ quality $\rightarrow$ satisfaction $\rightarrow$ post-purchase behaviour. In a study of 514 tourists to two towns in Spain, they used structural equation modeling (SEM) to empirically show that tourism image is a direct antecedent of perceived quality, satisfaction, intention to return, and willingness to recommend a destination. The model, however, is a simple structure comprised of all single variable measures. This said, the authors found that quality and satisfaction influenced some aspects of behaviour, and concluded that destination image plays an essential role. 
An interesting attempt at using TDI to predict choice was undertaken by Sirakaya et al. [2001] in a survey of 326 students' choice of destination. Using a probabilistic model, the authors identified three of eight image factors as potential predictors of choosing Turkey as the next vacation destination. The three factors were "cognitive evaluation of attractiveness", "tourist services and attractions", and "comforting/relaxing", which scored above the other factors (e.g. cultural similarity, safe/calming, cost). The authors also found that familiarity had a moderating effect on image formation, confirming earlier TDI studies. However, the results cannot be generalized, limited by the sample focus on one destination, Turkey, with which only $7 \%$ of respondents were familiar. The identification of particular images is, of course, of interest to tourism marketers. A study with practical application by Day et al. [2002] surveyed the U.S. market to identify images of Queensland, Australia most likely to stimulate travel to the destination. The authors claimed a stronger image in the market-place, and greater influence on stakeholders, as successes of their research process.

Murphy et al. [2000], in a Canadian study of visitors' perceptions, focused on two primary constructs of the destination product: overall environment (e.g. climate, scenery, cleanliness, heritage, friendliness) and constructed infrastructure (e.g. food, attractions, hotels). A data set of 610 visitors was taken from a larger exit survey in order to test a conceptual model using PLS path analysis. The authors found that visitors' perceptions of the quality and value of the environment and infrastructure were positively related to their intention to return. Because the composition of environment and infrastructure mirrors components of image, a parallel conclusion is that, once again, TDI affects travel behaviour. 
A recent model of TDI by Heslop et al. [2005], partly inspired by the early phases of development of the present thesis, is one that makes reference to PCI literature, directly borrowing some concepts from the PCI field and incorporating them in a tourism context. In a one-country survey of visitors to Nepal, the researchers found that people and country-level constructs commonly used in PCI research are significantly related to evaluations of the destination, and indirectly to behaviour. Though product-level measures are not included in their study, the authors conclude that theoretical convergence of the PCI and TDI fields can be accommodated, with attitude theory as a common thread, and they recommend that TDI research incorporate country image constructs.

In summary, whether image is considered directly, or components of image such as perceptions, affective associations, and positive and negative attributes are the focus, there is some positive relationship to traveller behaviour.

\subsection{Segmenting, Positioning and Branding}

The current phase of TDI study has turned its attention to destination branding, and the practical implications for TDI in marketing strategy. Perhaps with this current phase the study of TDI has simply come full circle. One of the first researchers to identify image as a factor in tourism's development, Hunt [1975] was stimulated to consider the influence of image on travelers based on early marketing and consumer research of the influence of brands. [Spector, 1961]. He reasoned that if consumers were buying brands not only for what the product did for them, but for what the product meant to them, then perhaps it was a destination's image that differentiated it from other places, 
and not simply the functional resources, which can be quite equal. Thus began the research focus on TDI, which has lasted for four decades. While the link to branding has occasionally surfaced, it remained for the most part unstated until the late 1990s. In 1997, the American Marketing Science conference included a special track on "Branding Tourism Destinations". The track organizer, Gnoth [1998, p.759], observed that "although branding has been with marketers for quite some time and, since the late 80s, experienced a renewed interest in academe and the market place, branding tourism destinations is a relatively new development".

This said, the study of TDI has continually shown its links to marketing strategy, with much of the research exhibiting practical applications. Here lies a strength of TDI research. It is most typically applied to real places, with data collected in most studies from real tourists, resulting in very real managerial considerations. Here too, however, lies a weakness of TDI research. From an academic perspective, much of the research is ungeneralizable, lacking standardization, and thus limiting in its advancement of TDI theory.

One link from TDI research to marketing practice commonly found in the literature is segmenting. A vast stream of segmentation research exists in the tourism literature that has established the effectiveness of segmentation strategies [Ritchie, 1996]. While the most traditional approach has been to segment the travel market by sociodemographic variables such as age and income, other popular criteria include activity and lifestyle [Gonzalez and Bello, 2002]. Within the scope of this paper, however, the focus is on studies that use TDI as a means of market segmentation. For example, Haahti [1986] considered the relative position of Finland in a twelve-country study in which he 
identified the strengths and weaknesses of each country in the tourist's minds in order to develop perceptual segments of traveler types (e.g. scenery seekers, economy travelers, culture tourists). Based on his findings of each country's unique advantages, he suggested positioning strategies. While TDI studies have frequently considered a country's image in isolation, positioning studies require an expansion of the frame of reference to include more than one destination [Pike and Ryan, 2004].

Ahmed [1991] concluded that an overall image assessment is inadequate to develop tourism positioning strategies, because different segments perceive components of TDI differently. He identified image strengths in relation to competition, to segment the U.S. market both regionally, and in terms of touring experience in Utah, the destination state. Based on a large-scale survey of 1,782 households across the U.S., the author concluded that an organic image exists post-travel that is distinct from the induced image of non-visitors. Finally, he recommended that image strengths identified regionally and in terms of experience be the basis of an effective campaign to position the destination. Ahmed's [1991] work, and that of his supervisor, Gartner [1986, 1989], make Utah arguably the most studied state in the U.S. in terms of TDI research. Whether this has helped Utah to market itself more effectively is unknown.

More recently, Leisen [2001] surveyed 903 households across the U.S. to segment the market of potential visitors to New Mexico based on images held, or perceptions of attributes, finding four distinct segments: socio-cultural, natural, recreational and climate. The segment expressing the most favourable image also stated the highest intent to visit. Conversely, the segment expressing the least favourable image stated the lowest intent to visit. Thus, the author recommended allocation of promotional resources to target these 
segments accordingly -- a strategy recommended in early research by Crompton [1979]. So from segmenting, TDI studies moved toward positioning, defined as "the act of establishing a specific image of services offered and rendered in the minds of consumers in a target market" [Crompton et al., 1992].

While the evolution from image to brand may seem natural, it has been slowed by the unique challenges that destination branding presents. These challenges are frequently documented. Morgan and Pritchard [1998] identified three unique challenges of destination branding: i) a lack of control over the total marketing mix; ii) relatively limited budgets; and, iii) political considerations. Henderson [2000] discussed the difficulties of commodification of a place that is in reality a multifaceted entity, serving a variety of users, constantly evolving, and with a history comprised of layers of meaning. Laws et al. [2002] raised issues related to the very nature of the tourism industry, such as seasonality, the resulting short-term planning cycle, and the divergence of aims between public and private sector stakeholders. The basic principles of branding call for cohesive management of all product and service elements, and coordination of the complete marketing mix. In tourism, however, a destination marketing organization most often controls only one of the traditional four "P"s of the mix, that being "promotion", with limited direct control of "price", "place", or even "product". Thus, attempts to apply branding techniques to destinations tend to focus on the selection of key attributes to promote, and branding is at the symbolic level, rather than the functional or experiential level. Gnoth [1998] believes that the more symbolic experiences are for tourists, the more successful the brand is in the long term. However, the more symbolic the brand attributes, the more difficult they are to communicate as unique, and the more easily they 
can be copied by competitors in any number of ways [Gnoth, 1998]. The challenge of destination branding can be daunting. But it has its advantages. Destination branding can enhance a nation's or other place's economy, national self-image and identity [Morgan al., 2002]. Laws et al. [2002] view the essential advantage of destination branding as the creation of a favourable position for the destination that distinguishes it from competitors. Using product branding terminology, he calls this the destination brand personality, defined as the emotional link between consumer and product.

Interestingly, the practice of place branding by destination marketers has outpaced the extent to which it has been studied academically. In a collection of destination branding case studies, Morgan et al., [2002] present a balance between academics who argue its complexities, and practitioners who espouse its virtues. Regardless, the bulk of the destination branding literature has only emerged this century, and central to its inquiry is image.

Based on the limited and emerging literature on destination branding, Cai [2002] attempts to distinguish between formation of a destination image and the branding of it. He defines destination image as "perceptions about a place as reflected by the associations held in tourist memory", and destination branding as "selecting a consistent element mix to identify and distinguish it through positive image building" [Cai, 2002, pp.722-723]. Simply, "image" is a mental construct, and "branding" is a strategy or process. Image is therefore not synonymous with brand, but rather a source of its equity. The process of destination branding has been compared to the process of destination image management [Laws et al., 2002]. 
The relationship between image and brand is presented by Cai [2002] as a comparison of three distinctly different but hierarchically interrelated components of image: cognitive, affective and conative [based on Gartner, 1993], to three classifications of brand associations: attributes, benefits and attitudes [based on Keller, 1998]. His typologies are presented as Figure 7.

Figure 7: Two Paralleled Typologies of Image [Cai, 2002]

\begin{tabular}{|l|l|}
\hline $\begin{array}{l}\text { Gartner's Image } \\
\text { Components: }\end{array}$ & $\begin{array}{l}\text { Keller's Types of } \\
\text { Association: }\end{array}$ \\
\begin{tabular}{|l|l|}
\hline $\begin{array}{l}\text { Cognitive: internally } \\
\text { accepted picture of } \\
\text { destination attributes }\end{array}$ & $\begin{array}{l}\text { Attributes: } \\
\text { descriptive features } \\
\text { characterizing a } \\
\text { product or service }\end{array}$ \\
\hline $\begin{array}{l}\text { Affective: motives - } \\
\text { what to be obtained } \\
\text { from the destination }\end{array}$ & $\begin{array}{l}\text { Benefits: Personal } \\
\text { value and meaning } \\
\text { attached to the } \\
\text { attributes }\end{array}$ \\
\hline $\begin{array}{l}\text { Conative: actions and } \\
\text { behaviour after } \\
\text { cognitive and } \\
\text { affective evaluations }\end{array}$ \\
\hline
\end{tabular} \\
\hline
\end{tabular}

Basic consumer behaviour theory suggests that consumers make product choices based on brand images [MacInnis and Price, 1987]. The parallel theory in tourism is that travelers make destination choices based on TDI. Cai [2002] believes that the link required to move destination image studies to the level of branding is the brand identity, defined as "a set of brand associations that the brand strategist aspires to create or maintain" [Aaker and Joachimsthaler, 2000, p.40]. He recommends a process of 
destination branding that begins with the selection of brand elements in order to form strong associations that are reflective of the attributes, affective and attitude components of the destination image in a complex recursive model. He then presents the results of a destination branding case study of Old West Country, a marketing consortium in New Mexico, and concludes that cooperative branding across multiple communities builds a stronger destination identity than branding of an individual community.

Cooperative marketing is also the focus of a case study by Laws et al. [2002] that explores the destination image of five tourist regions in Queensland, Australia. The authors identify unique brand personalities, such as "relaxed fresh outdoors" for Brisbane, and "exciting, fast paced" for the Gold Coast. To address the complexity of TDI, they view the destination product not as the totality of all possible destination elements, but rather as a packaged selection of elements. The study captured the perceptions of regional visitors, as well as visitors to accommodation properties within the regions. Findings support a cooperative marketing approach, based on respondents' needs for a mix of regional information and accommodation-specific information.

The experience of New Zealand's 100\% Pure brand, launched in 1999, is presented by Morgan et al. [2003]. Here, the authors focus on the management context, and expand the traditional marketing mix to include two additional "Ps"; "politics" and "paucity". Recognizing that branding a country is a politicized activity, they advocate the involvement and cooperation of public and private stakeholders as vital to the creation of a durable destination brand. The authors detail a branding process as follows. The brand is New Zealand; the brand essence is landscape; the brand position is New Pacific Freedom; the brand values are contemporary, spirited, free, sophisticated and 
innovative. Key to the process was the input of multiple stakeholders, credited for the resulting and now recognizable tagline, "100\% Pure New Zealand", though its effectiveness has been questioned [Jaffe and Nebenzahl, 2006]. Multiple brands within a destination may also exist. National brands may need to encompass several regional subbrands, and supra-brands may require coordination across regions, or countries [Morgan et al., 2002]. Clearly, much more study is required to fully understand the application of branding to destinations.

Pike and Ryan [2004] analyzed the market positions held by a competitive set of destinations through a comprehensive comparison of cognitive, affective, and conative perceptions. The authors suggest this method as a means to identify the key feature(s) of a multi-attributed destination to differentiate it from its competition in a way meaningful to consumers. They tested their theory by surveying 763 households across New Zealand and assessing the relative Importance-Performance of five domestic destinations. The cognitive image component was measured by factor analysis of attribute importance items, ranging from infrastructure to weather. Conation was measured by stated intention to visit. Lastly, the affective component of image was measured with an Affective Response Grid consisting of four semantic differential scales: pleasant/unpleasant, relaxing/distressing, arousing/sleepy, and exciting/gloomy. Baloglu has also applied this grid to perceptions of destinations [Baloglu and Brinberg, 1997; Baloglu and McCleary, 1999a, b; and, Baloglu and Mangaloglu, 2001]. Based on results, the authors recommended strategies for positioning domestic short break destinations in New Zealand. With this study, measuring image is seen as a necessary step to destination branding. 


\subsection{Methods of Analysis}

Image measurement has been, and continues to be, the most popular type of TDI study undertaken. Most typically, one destination is the focus of the study, and its image is measured in comparison to that of other destinations, or more commonly, in isolation. Studies of TDI measurement tend to be empirical, some with theoretical propositions, many without a theoretical frame, but nonetheless with some method of statistical measurement, and TDI-related findings of interest. There are also a few notable papers that have conceptualized image from a theoretical perspective, without empirical testing. From the earliest TDI works by Hunt [1975], Goodrich [1978] and Crompton [1979], the approach to image measurement seems to have been set. A structured list of tourist product and service-related attributes is ranked by scale to identify relative strengths and weaknesses of a destination as perceived by the consumer.

Another common feature of the early TDI works is their American origin. While many destinations have been studied, including the U.S. [Hunt, 1975], Mexico [Crompton, 1979], the Caribbean and other "sun" destinations [Goodrich, 1978], all of the aforementioned research was undertaken by American-based authors. Almost all of their works appeared in tourism academic journals published in the U.S., most typically, the Journal of Travel Research and the Annals of Tourism Research. A case in point is Baloglu [1999, 2001], who has cultural ties to Turkey, a country which he frequently includes in his TDI studies, yet he is U.S. based and publishes in U.S. journals. In the 1980s, a few authors based outside of the U.S, such as Haahti and Yavas [1983], began to publish in such journals as the European Journal of Marketing, providing a new perspective to the study of TDI. 
Interestingly, Haahti and Yavas [1983] build their work from a foundation of tourism segmentation studies undertaken by other European scholars. Their study measures tourist perceptions of 12 European countries to determine the relative position of Finland in comparison to competing destinations in terms of salient destination choice criteria. The authors identified 10 destination choice attributes, ranging from product related features such as "camping" and "entertainment", to non-tangible features such as "friendly" and "change from the usual". Attributes were ranked by 9-point Likert scales to identify the relative strengths and weaknesses of each destination as perceived by travellers. The authors found that different countries do indeed have unique advantages and disadvantages in the mind of the tourist, based on a ranking of country attributes by mean scores. They concluded by going so far as to suggest a positioning statement: “Another trip to Spain? Why not visit Finland this year?" Rather than commenting on the quality of this particular line, it is worth noting the direct connection to marketing strategy, commonly found at the conclusion of TDI studies.

Similar research was undertaken by Gartner [1989] in his study of the image of four States, based once again on an extensive survey $(n=1,917)$ in 1983 by the Institute of Outdoor Recreation and Tourism, Utah State University [see also Gartner and Hunt, 1987]. While the author cautioned that attribute models may not measure the most important attributes in the consumer decision process, he too used a structured set of 15 attributes to assess the relative positions of the States. All but one attribute "receptiveness" - were descriptive of tangible activities and settings (e.g. skiing, camping, parks). The author suggested that his use of MDS methodology to analyze the data can uncover underlying product attributes. . He concluded with an interpretation of State 
positions based on comparable advantages, such as skiing for Colorado, and parks for Wyoming, which he recommended be "exploited" in future marketing campaigns.

In 30 years of TDI research the array of studies have utilized a range of measurement techniques. Although a standardized methodology has not emerged, there are some commonalities to be found. In one of the first reviews of the TDI literature, Echtner and Ritchie [1991] assessed 15 previous studies and found that all but one had used a structured scale approach. To more effectively measure TDI, they proposed a combination of structured and unstructured approaches, as reviewed earlier.

Jenkins [1999], in her assessment of the different techniques used to measure TDI, critiqued past studies that rely solely on structured methods, and advocated for a combination of quantitative and qualitative methods, with direct reference to Echtner and Ritchie [1991]. From this point in the TDI literature to the present, study after study adopted the Echtner and Ritchie [1991] model, or adapted it in part, to assess a range of destinations around the globe. Choi et al. [1999] borrowed the three-continuum framework to assess Hong Kong's TDI. Murphy [1999] applied the model to determine the image held by 383 backpackers visiting Australia, using MDS. Chen and Hsu [2000] mirrored the attributes used by Echtner and Ritchie [1993] to measure the attractiveness of overseas destinations to 265 Korean tourists, using ANOVA. Rezende-Parker et al. [2003] utilized a combination of structured and unstructured methodologies, to determine the TDI of Brazil as perceived by 246 Americans who responded to an on-line survey. Hui and Wan [2003] used the popular framework to examine the TDI of Singapore held by 131 tourists. O'Leary and Deegan [2003] built their methodology around the Echtner 
and Ritchie model [1993] to assess the TDI of Ireland in terms of common attributebased components and holistic aspects $(n=281)$.

Hsu et al. [2004] also used the now recognizable combination of structured and unstructured methodologies to assess the TDI of the State of Kansas, through a telephone survey of 417 households across 12 states. In this study, it is worth noting how the findings supported the combination of methodologies. When asked in unaided format, respondents' top three image descriptors of Kansas were: "agriculture related", "flat land", and "Wizard of Oz". In the structured format, none of these three images were included in the 19 attributes used. The author's found the overall image of Kansas to be neutral and somewhat vague, or as they termed it, "fuzzy", likely from a lack of awareness, presenting state marketers with an especially challenging task if the image of Kansas is to change.

Despite the many praises of combining structured and unstructured techniques, not all TDI studies use this methodology. Suh and Gartner [2004] used only the intangible (psychological) / tangible (functional) continuum of Echtner and Ritchie's model [1991, 1993], applying a structured list of 16 attributes to measure visitor perceptions of Seoul, South Korea $(n=420)$. Other researchers use their own mix of structured and unstructured techniques without reference to Echtner and Ritchie [1991]. For example, Andersen et al. [1997] considered the imagery of Denmark held by 780 visitors to fine arts exhibitions in Scotland by soliciting visitors' images of famous Danish buildings, famous Danish people, and free associations with Denmark, as well as visitors' perceptions based on a structured list of 11 image dimensions. The authors found that widely held, stereotypical images of Denmark as a destination for bicycle and 
farmhouse holidays persisted. Even amongst a group of art-minded consumers, the image of Denmark as a destination for museum and gallery visitation was weak, challenging the destination's task of diversification.

Selby and Morgan [1996] also used a mix of structured and unstructured methods to evaluate the image of Barry Island in South Wales. Typical of many TDI studies, the authors focused very much on the practical marketing implications of their findings, stressing the value of place image in market research to assist in the formulation of tourism policy, with specific recommendation for the Wales Tourist Board, one of the sponsoring partners of the research. Hankinson [2004b] used the repertory grid technique to assess image attributes associated with 25 U.K. destinations. Interestingly, his purpose was to measure the relative saliency specifically of history, heritage and culture in shaping the perceptions of TDI, which he suggested were attributes more closely aligned with a destination's organic image, formed largely outside the influence of marketing. Based on a limited survey of 25 tourism marketers, he found "history, heritage and culture" attributes to be the second most salient category, after "activities and facilities". Although these categories were somewhat broad to be meaningful, the author's work demonstrates one of the many applications of TDI measurement.

Certainly there continue to be TDI studies that apply the more traditional method of structured attribute lists, but for an interesting variety of reasons. Oppermann [1996] used 15 attributes to rank and rate the image of 30 North American convention destinations. Rather than the most common consumer-based study, he surveyed 123 "trade experts" and used importance-performance analysis to interpret results. Schneider and Sonmez [1999] used a structured list of attributes to explore visitors' image of Jordan 
( $\mathrm{n}=65)$, a region rarely studied from a tourism perspective. Joppe et al. [2001] used 15 attributes to compare the importance and satisfaction ratings of 359 visitors to Toronto who responded to a questionnaire inserted in the tourism magazine, Where Toronto.

Echtner and Ritchie [1993] undertook an empirical test of their conceptual framework, and as a result, produced a "standard" questionnaire designed for future TDI research, consisting of three open-ended image questions and 34 scale items. The authors undertook a thorough process to develop the scales. First, their literature review produced a master list of TDI attributes, expanded through focus group input to 360 image statements, refined by a panel of judges to 35 attributes, then measured by two scale items each in a pre-test. Finally, they surveyed 600 students to determine their perceived image of four countries: Japan, Jamaica, Kenya and Switzerland. Diverse countries were selected in order to produce a set of standardized scales, to be effective across destination types. Factor analysis produced a final 34 items, and eight factors:

- Comfort/security

- Interest/adventure

- Natural state

- Tourist facilitation

- Resort atmosphere/climate

- Cultural distance

- Inexpensiveness

- Lack of language barrier

The three open-ended questions that were found to be effective in measuring holistic and unique components of image were:

1) What images or characteristics come to mind when you think of $X$ as a vacation destination? (functional holistic component) 
2) How would you describe the atmosphere or mood that you would expect to experience while visiting $X$ ? (psychological holistic component)

3) Please list any distinctive or unique tourist attractions that you can think of in $X$. (unique component)

Because of the clear impact that this framework has had on subsequent TDI research, the conclusions of Echtner and Ritchie's study [1993] are reiterated here:

- Destination image should be envisioned as having two main components: those that are attribute-based and those that are holistic;

- Each of these components contains functional (or more tangible) and psychological (or more abstract) characteristics; and,

- Images of destinations can also range from those based on "common" functional and psychological traits to those based on more distinctive or even unique features, events, feelings or auras.

In a review of TDI literature, Pike [2002] examined 142 papers published from 1973 to 2000 . Though the statistical manipulation of data has been approached in a variety of ways, the most common method of data collection continues to be the multiattribute model, whereby a predetermined list of attributes describing common destination features is used. Survey respondents then rate the attributes, most typically using Likert-type scales for cognitive elements, and/or adjective-based semantic differential scales for affective elements. The majority of papers that Pike [2002] reviewed -- 114 out of 142 -- used structured techniques to operationalize the TDI 
construct. He also found that the most popular type of destination of interest is countries (56 papers), the most popular regions for study are North America (58) and UK/Europe (45), and over half study one destination only (75). A major shortcoming identified through this review is that relatively few papers measured TDI within a specific travel context (only 23). A strength is that the vast majority of study respondents were actual visitors or potential visitors, with only a few studies using student samples (15 papers). The most common statistical technique is factor analysis (41 papers), followed by t-tests (21), perceptual mapping (21), analysis of means (20), and a range of less common methods including importance-performance analysis, repertory grid, mapping and conjoint analysis. A comparable breakdown of study methods was found by Gallarza $e t$ al. [2002]. Strikingly, almost all papers rely upon word-based approaches to elicit consumer perceptions of TDI.

A unique study in terms of its methodology, by MacKay and Couldwell [2004], utilized visitor-employed photography (VEP). The technique was applied by distributing cameras to respondents and asking them to photograph scenes that contributed most to their image of the destination, and to record in a diary the main subject of the photographs, the main reason they took it, and whether the image was positive or negative. The resulting visitor-generated images (a total of 1,642 photographs taken by 129 study participants) were categorized into three subject themes (infrastructure, animation and personalization), and two motivations (aesthetics and nostalgia). While VEP appears to be an effective method to capture TDI's multi-dimensions, it is rarely utilized, likely due to logistical challenges. 
There are also a few studies that explicitly show how the methodology selected to measure TDI can influence results. One example is a study comparing respondents' image attribute ratings during and after an event, to the same respondents' direct report of image change, and finding contrasting information in terms of the event's influence on image [Li, 2004]. The more subjective measure, the respondent's own report of image change, indicated a greater, and more positive change than the more objective measure of pre and post attribute ratings. The findings are indicative of the difficulties inherent in measurement of a mental construct such as image. The format of survey questions has also been found to impact results. Driscoll et al. [1994] applied semantic differential scales in two different formats: scaled response format, whereby respondents rated each destination separately using a list of attributes; and grid response format, whereby respondents rated each attribute across destinations in a more direct comparison. The two formats produced dissimilar results, confirming the findings of an earlier study by Jaffe and Nebenzahl [1984], which also suggested that different formats evoke different information processing tasks. Thus, results are not always comparable across studies if data collection formats have differed.

\subsection{Conclusions}

From early social psychologists' view of image as a powerful and positive phenomenon, acting as a type of information gatekeeper, or simplifying heuristic, to marketing research, where image manipulations have provoked change in consumer behaviour, image has been regarded as a kind of mystical prodigy, with great ability to 
influence attitudes. In tourism, very much an image-driven industry, it seems only fitting that the relationship between TDI and traveler behaviour would be of great interest.

However, this literature review reveals that TDI research is still very much evolving, and that few theoretical foundations exist. The early pioneers of TDI research helped conceptualize TDI, and introduced the attribute-based model as an effective means to study the TDI phenomenon [Hunt, 1975; Crompton, 1979]. Perhaps they did so with such effect that change has been seen as unnecessary. Image measurement has been slow to evolve, with some shift from the lone, structured attribute model to a combination of structured and unstructured techniques [Echtner and Ritchie, 1991]. Four decades of research have explained the significance of some factors that influence image formation, particularly information sources [Phelps, 1986; Fakeye and Crompton, 1991; Gartner, 1993], travel experience and familiarity [Pearce, 1982, Chon, 1991, Baloglu, 2001], but have not explained the influence of many other factors, including culture [Richardson and Crompton, 1988] and even basic demographics [Smith and MacKay, 2001]. Still other important research that would contribute to our understanding of TDI, such as longitudinal study, is almost nonexistent [Gartner and Hunt, 1987].

Models of TDI formation have provided some understanding of the relationship between cognitive and affective components of image [Baloglu and McCleary, 1999], and of the relative importance of a range of destination attributes [Beerli and Martin, 2004], yet an accepted framework is missing. Studies of image and behaviour support the general belief that a positive TDI is more likely to result in destination choice [Goodrich, 1978], and traveler satisfaction [Bigne et al., 2001], but why or how remains unclear. Most recently, destination branding studies highlight the importance of image to 
successfully position a place [Morgan et al., 2002; Laws et al., 2002; Cai, 2002]. Despite the many challenges of branding something as complex as a destination, practitioners are doing it, and academic research needs to catch up. Additionally limiting is the frequent use of small samples, making the generalizability of many TDI study findings doubtful.

While a significant body of empirical work exists, with threads of theory throughout, a clearer conceptualization of TDI, a comprehensive framework, greater homogeneity of measures, and more sophisticated measurement techniques would solidify the theoretical foundations of this important field of study. Next, Chapter 3 reviews the related measures and methodologies used in the TDI counterpart research stream on the product-side: Product Country Image (PCI). The findings from the examination of TDI and PCI are brought together in Chapters 4 and 5, to develop and test the first ever Integrated Model of Place Image that is the object of this thesis. 


\section{Chapter 3 Foundations of Product Country Image}

The "Made In" label... a "tremendous influence" [Dichter, 1962] or a "little understood panacea" [Papadopoulos and Heslop, 2002]?

The study of country image from the perspective of international product and service buying behaviour is even more extensive than from the perspective of TDI. In this context, country image can be defined as the "overall perception consumers form of products from a particular country, based on their prior perceptions of the country's production and marketing strengths and weaknesses" [Roth and Romeo, 1992, p.480]. More specifically, product country image (PCI) defines the effect of country image, or "place" image, on buyer attitudes toward products from various origins [Papadopoulos, 1993]. Other terms that commonly refer to this phenomenon are "country of origin", and the "Made in" concept, in reference to the communication of place as typically found on a product label. $\mathrm{PCI}$ is the term used in this study, to simplify, and to most accurately define the current interest, which is the effect of country image on products.

\subsection{Historical Development}

The recognition of the significance of PCI dates back to the 1960s, when Dichter [1962], in an article that urged marketing managers to prepare for a new "world customer", stated that 'the little phrase 'Made in X' can have a tremendous influence on the acceptance and success of products over and above the specific advertising techniques used by themselves" [p.116]. He proposed six world market groups of customers based largely on social status, and used the automobile as a symbol of global class development. "It is the automobile which represents achievement and personal freedom for the middle 
class" [Dichter, 1962, p.118]. It might be said that today, given that the automobile is becoming almost as common a commodity as food and shelter, travel may be evolving to become one of the principal new symbols of social status, adding to the relevance of the current study to investigate potential relationships between country image, product and tourism evaluations, and behaviour.

While Dichter's 1962 paper is worthy of mention as a first, it is a non-empirical dialogue that only mentions the "Made in" concept in passing. Schooler [1965] is credited as the first author to empirically test the "Made in" concept. In a study of product bias in Central America, sparked by the signing of The General Treaty on Central American Economic Integration in 1960, he examined what he called "invisible barriers... of product bias and predilection on the basis of national origin" [Schooler, 1965, p.394]. The author presented 200 university students in Guatemala City with two products, where only the label of origin was changed to reflect one of four test countries (Guatemala, El Salvador, Costa Rica and Mexico). Interestingly, he included travel experience as a variable that might influence country image. His results showed that attitude toward a country and preconceptions regarding the products of that country were related. However, no significant difference was attributable to travel. Though this seems counterintuitive, perhaps this is why travel so rarely appears as a consideration in subsequent studies of PCI.

One study did in fact find travel to be a correlate of product and country images, in a comparison of Canadians who had traveled to a country with those who had not [Papadopoulos and Heslop, 1986]. Travel to a country was found to influence consumer evaluations of that country's products, by reducing the gap between the prevailing image, 
and the actual capabilities of a country's products. However, this link between travel and product images has been extensively ignored in the subsequent research. Conversely, Schooler's [1965] research instrument - the semantic differential scale - has endured as the method of analysis to measure components of PCI.

Fast forward forty years and the "Made in" concept has "moved to a new level, well beyond its required use on product labels" [Papadopoulos and Heslop, 2000, p.2]. Place associations connote far more than place of manufacture. They are used by marketers in an attempt to conjure images beyond the functional product attributes, and studied by academics in an attempt to understand their power. In an extensive survey of the PCI literature, Papadopoulos and Heslop [2003] catalogued 766 works, supporting an earlier claim that PCI is the most researched issue in international buyer behaviour [Tan and Farley, 1987]. From this mass, the authors identified nine key conclusions, as follows:

1) National and other place images are powerful stereotypes that influence behaviour in all types of target markets;

2) The effects of national images vary depending on the situation;

3) Origin images affect price expectations;

4) PCIs appear to consist of seven key constructs (level of advancement, feelings about its people, links with country, price, market presence, satisfaction and product assessment);

5) In the case of hybrid products, buyers may distinguish between a product's country of design, manufacture, assembly and/or the producer's home country;

6) PCIs of specific product classes are related to a country's global product image; 
7) Buyers distinguish between national and product images, and between major, niche and less developed countries as producers;

8) PCIs may shift slowly over time or quickly as a result of intervening events; and,

9) The effectiveness of 'buy domestic' campaigns is unclear.

While these conclusions suggest great progress in the study of PCI, others view the findings of the field as only somewhat generalizable, based on a construct that is relatively ambiguous, and thereby refuting common beliefs regarding the impact of PCI [Peterson and Jolibert, 1995]. In an attempt to sort out what is and is not known about PCI, one of the first consolidations of PCI research, conducted by Bilkey and Nes [1982] is considered here. The authors reviewed 25 major research papers that all provide empirical evidence of PCI effects on product evaluations. This evidence was found across studies of products in general (e.g. foreign products), classes of products (e.g. food), specific types of products (e.g. desk pen, dress shirt), and specific brands (e.g. Gillette). The authors also found a hierarchy of country biases, based on a positive relationship between product evaluations and degree of economic development. The greater a country's economic development, the higher the evaluation of its products.

Alongside the evidence supporting PCI, the authors also identified a number of methodological limitations. First, most of the studies they reviewed involved only the single cue of country of origin, perhaps yielding a more significant cue effect than if multiple cues were involved. Second, most of the studies employed verbal product references, leaving respondents to evaluate products in the absence of seeing something tangible. Third, the use of different semantic scales raised questions of validity and 
reliability. The Bilkey and Nes study [1982] greatly influenced the PCI work that followed. It is said to be referenced in nine out of ten PCI studies since its publication [Peterson and Jolibert, 1995].

A decade later, Roth and Romeo [1992] published an empirical study that included a review of eight assessments of country image. Their objective was to operationalize the country image construct, and to develop a framework to match country image dimensions with product category dimensions. To this point in the PCI research, most studies did not link image dimensions to product categories. One exception was a study by Han and Terpstra [1988], which examined product-country relationships, a topic that will be addressed later in Section 3.4.

The eight studies reviewed by Roth and Romeo [1992] assessed country image constructs that had been developed either by scaled items grouped according to mean scores, or by factor analysis. Based on their review of these country image constructs, the authors identified four dimensions that were consistent across the studies, and applicable to product image:

1) Innovativeness: use of new technology and engineering advances;

2) Design: appearance, style, colors, variety;

3) Prestige: exclusivity, status, brand name reputation; and,

4) Workmanship: reliability, durability, craftsmanship, manufacturing quality.

A summary of the country and product image dimensions reported by these authors, and expanded to include more recent work, is included as Appendix B. 
Another significant meta-analysis of PCI research was undertaken by Liefeld [1993]. His review of 22 experimental studies of country-of-origin found much evidence of effects across consumer and industrial products. Verlegh and Steenkamp [1999] also synthesized country image findings to establish the foundations for future research in the field. The authors employed the Pearson's product moment correlation coefficient to measure effect size from the empirical results reported in 41 studies. They found the average effect size to be 0.39 , considered to be a medium to large effect.

An earlier meta-analysis based on the empirical findings from 52 PCI studies reported a comparable average of 0.30 for the effect size of country image on product quality, but a much lower average of 0.19 for the effect size of country image on purchase intentions [Peterson and Jolibert, 1995]. Verlegh and Steenkamp [1999] also found the country effect on product quality to be greater than the effect on purchase intentions. Both meta-analyses also considered the influence of a number of methodological aspects typical of PCI research. For example, both found effect sizes to be smaller for multi-cue studies than for single-cue studies. Yet in their comparisons of between-subject and within-subject study designs, Verlegh and Steenkamp [1999] found effect sizes to be smaller for between-subject designs, while Peterson and Jolibert [1995] found no such influence. The 1999 analysis went further to reveal a similar effect size for student and consumer samples, and a greater effect size for comparisons of products across more developed and less developed countries, than effect sizes for comparisons of products within either of the two. 


\subsection{Cognitive, Affective and Conative Dimensions}

Building from the Heslop and Papadopoulos [1993] review of PCI research, Verlegh and Steenkamp [1999] distinguished in some detail between the cognitive, affective, and normative aspects of country image. While much of the PCI research to this point had focused on the cognitive components of country image, such as quality attributes, Verlegh and Steenkamp [1999] discussed the symbolic and emotional connotations that country image may well evoke. To structure their review, they made reference to a framework developed by Obermiller and Spangenberg [1989], reproduced here as Table 2.

Table 2: Examples of Cognitive, Affective and Normative Mechanisms for Countryof-Origin Effects [Obermiller and Spangenberg, 1989]

\begin{tabular}{|l|l|l|}
\hline Mechanism & Description & Major Findings \\
\hline Cognitive & $\begin{array}{l}\text { Country of origin is a cue for } \\
\text { product quality }\end{array}$ & $\begin{array}{l}\text { Country of origin is used as a 'signal' } \\
\text { for overall product quality and quality } \\
\text { attributes, such as reliability and } \\
\text { durability [Li and Wyer, 1994] }\end{array}$ \\
\hline Affective & $\begin{array}{l}\text { Country of origin has } \\
\text { symbolic and emotional } \\
\text { value to consumers } \\
\text { attribute that links the product to } \\
\text { symbolic and emotional benefits, } \\
\text { including social status and national } \\
\text { pride [Askegaard and Ger, 1998] }\end{array}$ \\
\hline Normative & $\begin{array}{l}\text { Consumers hold social and } \\
\text { personal norms related to } \\
\text { country of origin }\end{array}$ & $\begin{array}{l}\text { Purchasing domestic products may be } \\
\text { regarded as a 'right way of conduct', } \\
\text { because it supports the domestic } \\
\text { economy [Shimp and Sharma, 1987]. } \\
\text { By the same token, consumers may } \\
\text { refrain from buying goods from } \\
\text { countries with objectionable activities } \\
\text { or regimes. }\end{array}$ \\
\hline
\end{tabular}

Verlegh and Steenkamp [1999, p.539] conclude with a strong recommendation for future research: 
"It seems important to recognize the fact that country of origin is not "just another' quality cue, but that its effects on consumer behaviour are based on a wider range of connotations, including affective and normative dimensions. In this light, it may be valuable to design studies in which the cognitive, affective and normative influences of country of origin are explicitly modeled and their (possibly contradictory) influences are disentangled. It is likely that such research cannot suffice with the methods that have been typically applied in past research on country-of-origin effects."

This is one point where the models and research approaches developed in the field of TDI provide some useful insights that will be adapted in order to more comprehensively assess not only the cognitive and conative components of country image, but the affective dimension as well. A broad conceptualization of place image will be further explored in Chapter 4.

PCI studies have typically focused on product attribute ratings. For example, one of the first to study PCI was Nagashimsa [1970], by assessing U.S. and Japanese business peoples' perceptions of price and value, service and engineering, advertising and reputation, and design and style. During the next decade, Cattin et al. [1982] continued this focus, measuring PCI in terms of price, reliability, workmanship, technicality, and performance. Even into the 1990s, PCI continued to be assessed through a reliance on product-related measures. Nebenzahl and Jaffe [1996] employed an expanded list of variables, but still featuring the traditional measures of price, reliability, quality, innovativeness, technology, service and performance.

By contrast, Papadopoulos and Heslop [1989], in a multi-country study of Canada's country and product image, introduced country dimensions that were more personality-oriented. They found Canada's product image to be relatively low in terms of market awareness, and Canada's country image to be relatively high in terms of attributes such as likeability and trustworthiness. Thus, the authors suggested that exporters 
advertise claims of producer reliability, and that domestic producers strengthen areas of engineering, reliability and market presence. While this process of identifying the specific attributes or dimensions can form the basis of the "FAB approach" to communicating features, advantages and benefits, it can more easily become an ineffective "laundry list" of wordy advantages that rarely influence buyers, and "when used alone, they are unable to portray the overarching and distinct 'umbrella' concept that a successful brand image is all about" [Papadopoulos and Heslop, 2002, p.312]. A more explicit inclusion of the affective components of PCI would support the identification of the symbolic and emotional aspects of country image, thereby capturing a deeper essence of place that would resonate more effectively with world consumers. A country must find its own unique je ne sais quoi -- whatever it takes to symbolize and make its image globally competitive.

Askegaard and Ger [1998], in a conceptual application of stereotype and semiotic theory to PCI theory, also concluded with a call for more attention to affective dimensions in the construction of the image phenomenon, recommending "the direction of inscribing imagery related to products and their places or origin in communication theory" [Askegaard and Ger, 1998, p.58]. While early researchers may have noted the link between the affective process and a stereotype effect in PCI studies [Obermiller and Spangenberg, 1989], it has been largely ignored empirically. Country stereotypes can be considered as cognitive shortcuts to memory biases held by individuals, as a way of categorizing and simplifying information. A cue, such as country, can evoke information retrieval involving both cognitive and affective processes, thus influencing perceptions and evaluations. This processing is thought to be context-specific, another issue not 
explicitly addressed in the PCI research. Askegaard and Ger [1998] proposed a conceptual model of contextualized product-place images comprised of four dimensions: place, product (or phenomenon), market context and usage context. While conceptually

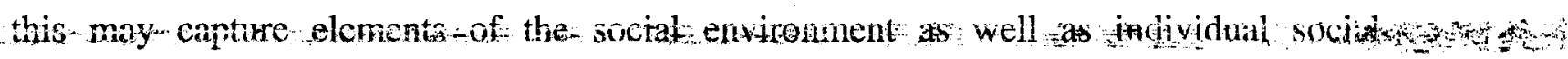
psychology, such a model has not been operationalized.

Much remains unknown in terms of how consumers process country image cues in evaluations of foreign products to explain why people are affected differently by PCI. Zhang [1997] considered individual differences in a consumers' need for cognition (NFC) to explain the influence of PCI. In a survey of 192 university students in the northeastern U.S. using repeated-measure MANOVA, he administered an abbreviated NFC scale to measure the degree to which respondents enjoyed "effortful thinking". A comparison of the scores to country image effect sizes indicated that NFC influences the extent to which individuals utilize PCI cues. In summary, the lower the NFC, the more influential PCI was in that consumer's product evaluation, while consumers with a relatively higher NFC were more prone to evaluate product attribute information. Thus, NFC was found to be a moderator of PCI effect. While this finding may help explain individual differences in PCI effect, its practical application may be limited by the difficulties and subjectivity in assessing consumer NFC.

There is an exploration of the influence of affective aspects of PCI in a study by Papadopoulos et al. [1993]. The primary purpose of that study was to introduce independent measures for the image of product and the image of country, and to examine the relationship between them. The survey of 305 Ottawa respondents, assessing six countries and their products, used MANOVA analysis to confirm the distinction of the 
two measures. To this point in PCI research, country image had rarely been measured as a distinct entity, the majority of studies using only product-related measures to model PCI effects. In distinguishing between country and product image, Papadopoulos et al. [1993] revaled some interesting effectson the affective, cognitive and conative-dimensions of $-1.2=$ image. The authors noted that cognitive and affective variables related to a country's economy, politics and culture had greater influence than conative variables. Also, country dimensions that tapped affective and conative aspects correlated strongly with product dimensions. Most notable, affective aspects were more closely related to willingness to buy than to product evaluation, giving rise to the recent focus on affective aspects of PCI.

When affective components of PCI image are measured separately, they are found to have "a significant and direct influence on willingness to buy" [Orbaiz and Papadopoulos, 2003, p.101]. This contribution to PCI theory represents one of the first attempts to independently measure affective country dimensions within a PCI model. The authors simultaneously tested the relationship between cognitive product evaluations (product beliefs), cognitive country-origin evaluations (country image), knowledge of a country's products (familiarity), affective feelings toward country (country affect), ethnocentrism [Shimp and Sharma, 1987], and receptivity (Buy). The model is shown as Figure 8.

The authors surveyed 198 consumers in Pamplona, Spain about their place and product attitudes with respect to three countries (Spain, France and Argentina) and one region (Basque Country, Spain). The six constructs in Figure 8 (names capitalized for ease of recognition), comprising 31 variables in total, were measured using 7-point 
bipolar adjective scales. Structural Equation Modeling with Latent Variables was used to test the model (using EQS). The relationships that were found to be statistically significant are indicated by solid lines in Figure 8, and those found to be insignificant are indicated by dashed lines. The model supports the traditional PCI relationships, confirming Country Image to Product Beliefs, Product Beliefs to Buy, and Familiarity to Product Beliefs, and rejecting Country Image to Buy, and Familiarity to Buy.

Figure 8: Empirical Model of Receptivity to Products from Various Origins [Orbaiz and Papadopoulos, 2003]

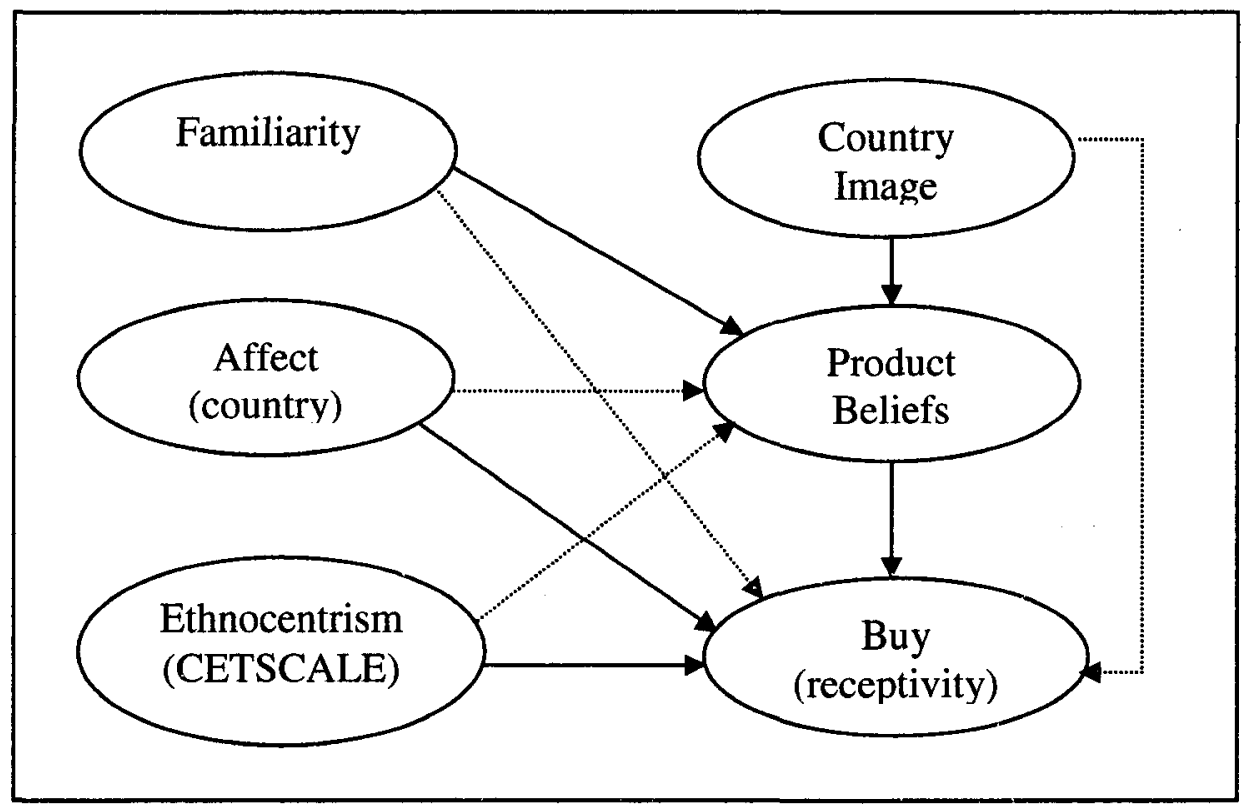

In addition, the model identifies some interesting relationships between the new constructs, supporting Ethnocentrism to Buy, and Country Affect to Buy, but rejecting Ethnocentrism to Product Beliefs, and Country Affect to Product Beliefs. In terms of the Country Affect construct (of most interest here), these findings support the notion that affective aspects of PCI may directly impact purchase behaviour, regardless of one's product beliefs. In other words, an individual's cognitive evaluation of a product can be 
over-ruled by opposing emotive feelings when it comes to the decision to buy. A strong Affect can even influence Beliefs, as was the case for France. The authors suggest that this is a result of antipathy that the Spanish consumers felt toward France. In summary, this study contributed to the theories of PCI by simultaneously testing a new set of constructs. The authors suggest future research to retest the influence of affect on product evaluations, as is tested here.

\subsection{Halo, Summary Construct, and Flexible Models}

From the 1960s to the end of the 1980s, most PCI studies either implicitly or explicitly viewed the role of country image as a "halo", influencing consumers" perceptions of foreign products. While other researchers had explored the halo effect of country image [Erickson et al., 1984], the modeling approach by Han $[1989,1990]$ is most strongly linked to this concept. Basically, Han [1989] viewed the Halo effect as applicable when consumers were unfamiliar with foreign products, thereby using country image to infer product quality. The structural relationship is thus: country image $\rightarrow$ product beliefs $\rightarrow$ brand attitude, as illustrated by the Halo Model in Figure 9 .

Figure 9: Halo Model based on Han [1989]

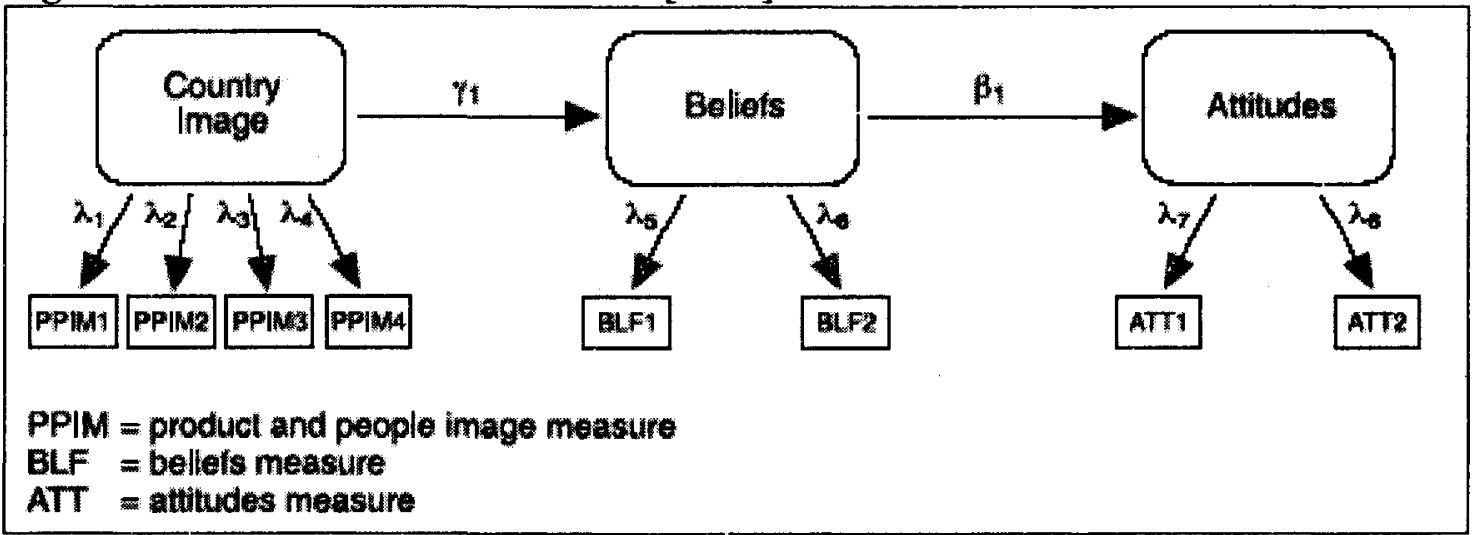


Han [1989] further postulated that when consumers are familiar with foreign products, they make abstractions of their product beliefs onto country image, which in turn directly affects their brand attitude. The structural relationship of this Summary Construct theory is: product beliefs $\rightarrow$ country image $\rightarrow$ brand attitude, as illustrated in Figure 10.

Figure 10: Summary Construct Model based on Han [1989]

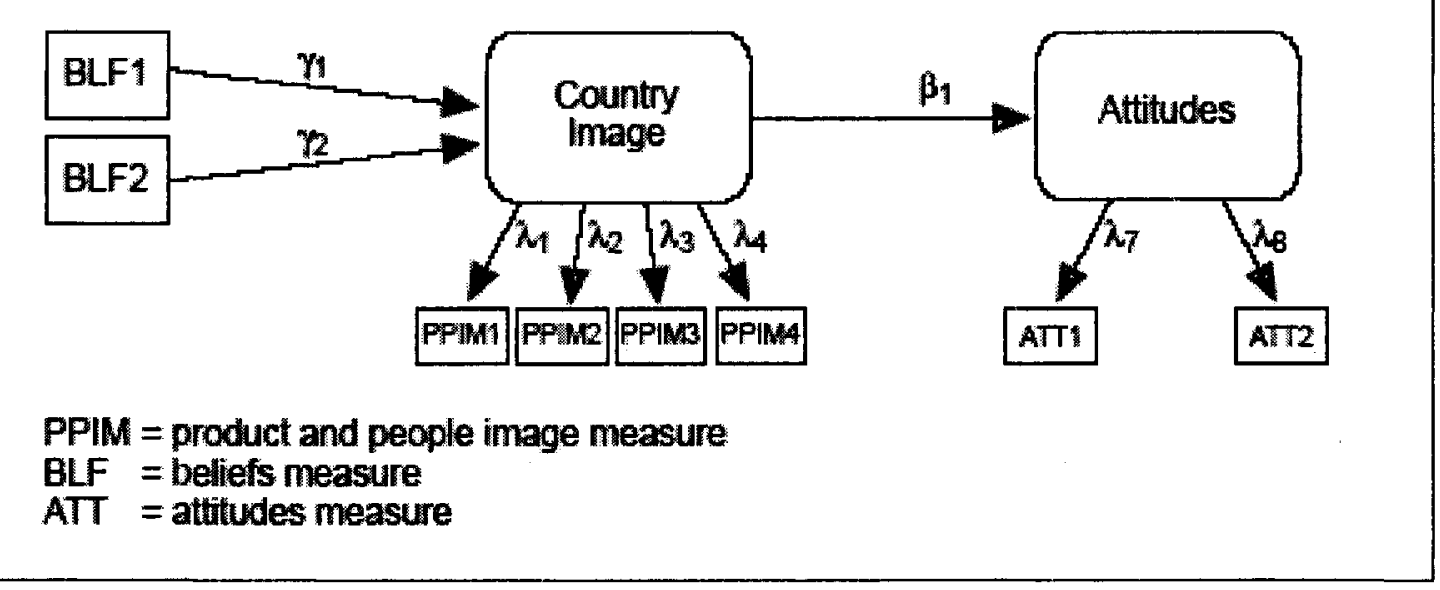

Han [1989] tested his models in a limited survey of 116 respondents in a Midwestern U.S. city, assessing their perceptions of two products (TVs and cars) from three countries (U.S., Japan and Korea). While the results support the author's hypotheses that country image serves as a halo when consumers are unfamiliar with a product, and as a summary construct when consumers are familiar with a product, his simplistic modeling has been subsequently refuted.

Knight and Calantone [2000] took a more in-depth look at basic cognitive processing theory to conclude that, quite logically, it is probable that consumers use both country origin (when known) and product beliefs simultaneously to derive attitudes, 
regardless of knowledge level. The authors improved upon the Han model [1989] by developing the Single Flexible Model, illustrated in Figure 11. Their model allows for the simultaneous processing of country image and product belief information, with the relative importance of each moderated by factors such as consumer knowledge and involvement. The authors used structural equation modeling to test all three models (Halo, Summary Construct and Single Flexible) for both a high and a low knowledge state, across three respondent groups, and found the flexible model to be superior. Results showed Country Image to be a significant antecedent of attitudes and beliefs, and beliefs to be a significant antecedent of attitudes, regardless of knowledge level.

Further issues raised by these authors in relation to consumer characteristics are of relevance here. First, consumers are often unable to detect the true quality of a foreign product, and this uncertainty increases the reliance on extrinsic cues such as image. If this claim holds for tangible products that the consumer at least sees before purchasing, what is the influence of extrinsic cues for an unseen product such as travel, often to a distant place?

Figure 11: Single Flexible Model [Knight and Calantone, 2000]

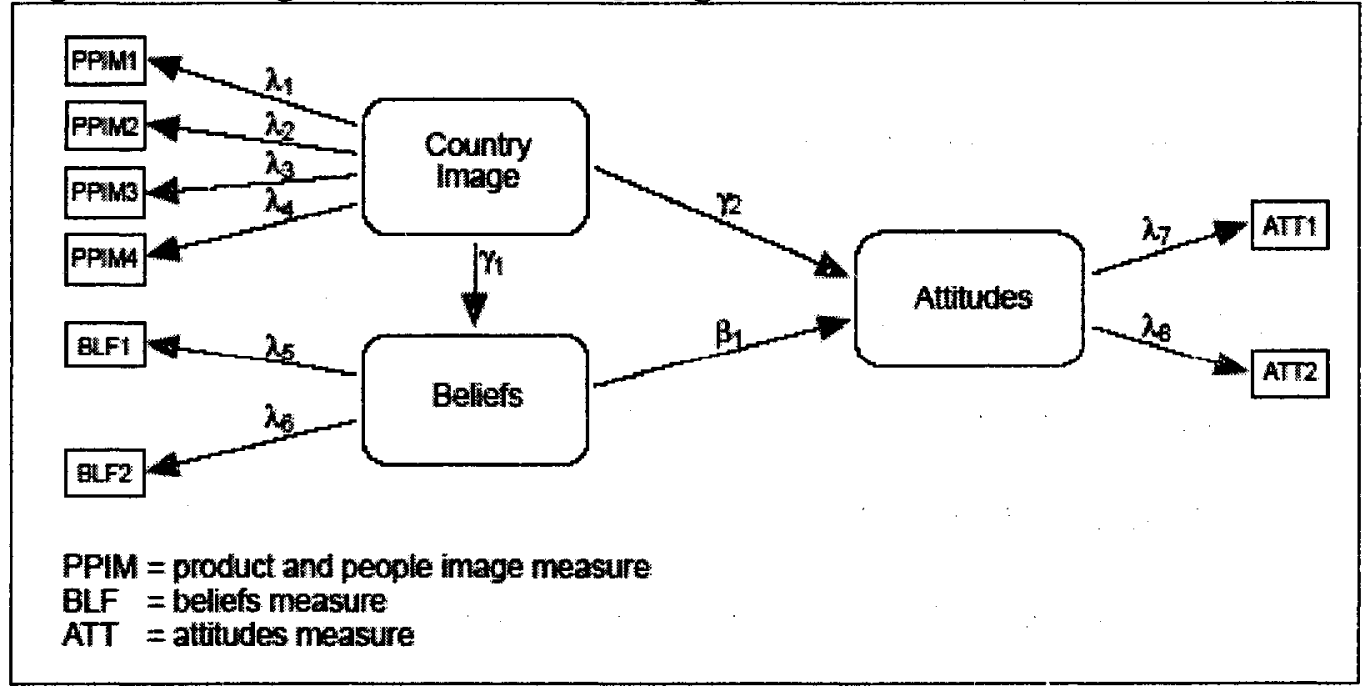


Second, Knight and Calantone [2000] discuss a number of cultural differences that implicate consumer behaviour. While some consumer motivations may be relevant in North America, such as prestige and display, others may be more particular to Asian consumers, such as repayment, social obligations, investment in future favours, intense desire to maintain societal harmony, and collectivism. Potential implications of these consumer characteristics are considered in the interpretation of the South Korean and Canadian data.

\subsection{Country and Product Image Disentanglement}

After two decades of PCI studies that for the most part measured image of a country's product, not image of a country, Papadopoulos et al. [1988] and others began to separate country image as a dimension. This distinction opened the exploration of the relationships between country image, product beliefs and product evaluations [Heslop et al., 1993]. Later studies have separated the constructs further to explore the relationship between country image and brand [Nebenzahl and Jaffe, 1996; Kim and Chung, 1997] and product associations that are no longer single country phenomena. Research of the growing phenomenon of bi-national, or hybrid products calls for a further partitioning of country effects to account for cases of a different country of assembly (COA) and/or country of design (COD) for one product [Chao, 1993].

In the earliest stages of this research stream, Papadopoulos et al. [1988] developed a model based on theories of cognitive learning that explain the mental mapping which occurs between stereotypes held, beliefs and attitudes. The authors developed scales after reviewing literature ranging from political science to sociology that provided an understanding of the potential dimensions of country image. Then, they 
surveyed 2,200 consumers from eight countries, to test their theories. Their early model is depicted as Figure 12. As can be seen, the traditional and tested PCI variables of reliability, workmanship, technicality and quality now comprise a Product Quality Beliefs construct, and a new construct representing Beliefs about Country and People is introduced.

The empirical test of the model supported all eight structural paths, with moderate overall fit of the model itself. Beliefs about a country and its people, or simply country image, were found to be predictive of beliefs about that country's product quality, or simply, product image.

Figure 12: Early Model of Nation-Product Image Interactions [Papadopoulos et al., 1988]

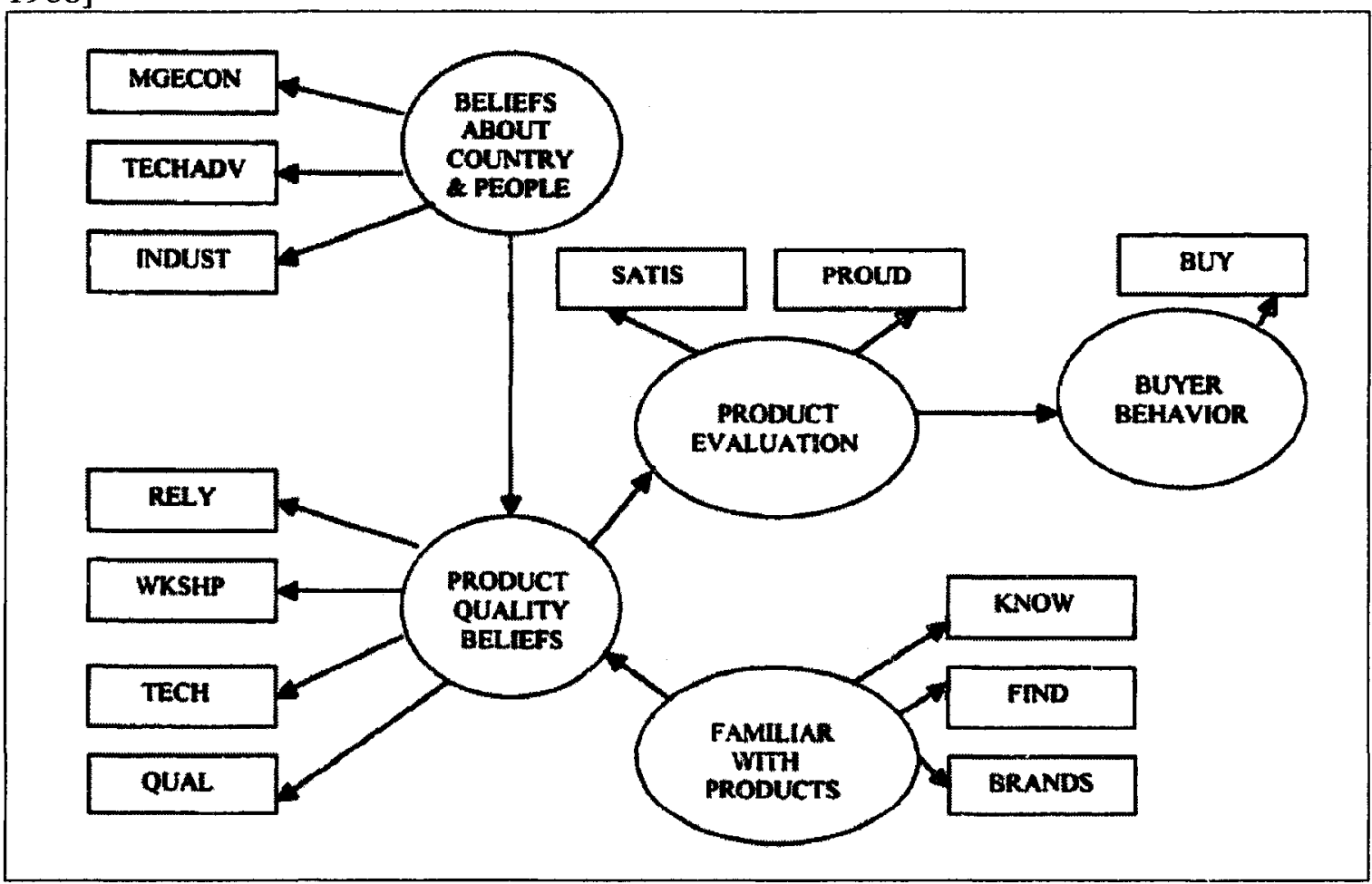

Han and Terpstra [1988] also attempted to disentangle country and product image for the purpose of comparing the influence of source country-of-origin and product brand 
on 150 U.S. consumer evaluations of uni-national and bi-national products. The authors considered foreign brands that are foreign made and U.S. made, and U.S brands that are foreign made and U.S. made, hypothesizing that not all consumers perceive all products from one country as the same. For comparison, they selected two products, cars and TVs, and four countries, the U.S., Japan, Germany and Korea, and measured five image dimensions: technical advancement, prestige, service, workmanship and economy. The authors found that country rankings were not consistent across product dimensions (e.g. Germany high on prestige, low on economy), yet rankings of particular dimensions did travel across products (e.g. prestige high for German cars and TVs), suggesting that distinctive country image dimensions do exist. In fact, the authors found the influence of source country to be greater than that of brand name.

Roth and Romeo [1992] examined the relationship between country and product by means of a survey of 368 graduate students from three countries (Ireland, Mexico and the U.S.). Respondents evaluated six product categories from ten countries, on four image dimensions (innovativeness, design, prestige, and workmanship) for product and for country. The resulting degrees of product-country match were compared to respondents' willingness to purchase the products from each of the ten countries evaluated. Results suggested that a strong product-country match can act as predictor of willingness to buy foreign products. In other words, if a country has a positive image that is important to a product, consumers are more willing to buy that product from the country, which seems logical. However, contrary to past research, the authors also found the country image construct to be one dimensional, quite likely due to the seemingly 
obvious overlap of their dimensions (e.g. innovativeness could be reflected in design, and high craftsmanship could lead to prestige).

Chao [1993] evaluated the product and country images of 120 U.S. consumers, considering not just country-of-origin, but country-of-design (COD) and country-ofassembly (COA). The author compared three COAs and three CODs, illustrative of the increasing complexity of research design, and reflective of the reality of today's global product mix. He found that consumer evaluations of design and product quality were influenced by COD and COA, as well as price, and that price-quality relationships were country specific, again suggestive of unique country image dimensions.

Nebenzahl and Jaffe [1996] surveyed 305 U.S. university students to compare perceptions of two global brands (Sony and GE) from five countries (Japan, the U.S., Russia, Hungary and Poland). They found the perceived value of products to be a weighted average of perceived brand and perceived made-in country values. Similarly, Kim and Chung [1997] found that both country image and brand popularity influenced market share. The authors' results suggest that brands originating from a particular country share intangible assets that are unique to brands from that country (e.g. buyers of Japanese brands consider price and reliability, whereas buyers of U.S. brands consider size). The product evaluated in this study was the automobile, worth noting because of the frequency in which it is selected, primarily because of the recognizable brands found within this product category [Han and Terpstra, 1988; Haubl, 1996; Pappu et al., 2007].

Another study that considered the relative influence of country-of-origin and brand [d'Astous and Ahmed, 1999] surveyed 194 salesmen of electronic equipment. Interestingly, the salesmen perceived country-of-origin to be much less important than 
brand reputation for shoppers of VCRs. However, in a comparison survey of 190 consumers, country-of-origin had a greater influence than other attributes. The authors suggested that this result reflects a "nesting" of country perceptions within brand evaluations. Evidently, PCI is more important than salespeople - and perhaps their managers - may think!

\subsection{Models and Methods of Analysis}

Of the hundreds of studies that have explored the effects of PCI from various consumer and product perspectives, the most common approach is a descriptive examination of the image of a particular country, or countries, from the perspective of respondents in another country, or countries [Papadopoulos and Heslop, 2002]. Fewer studies have tried to understand the relationships between the main PCI-related constructs of image, beliefs and behaviour. To do so requires a theory-based model. There are approximately $25 \mathrm{PCI}$ models, reflecting numerous and varied constructs of place image [Papadopoulos and Butt, 2005]. Some have already been presented in this paper, such as the popular Halo and Summary Construct models [Han, 1989], which have been subsequently criticized as questionable, and oversimplified [Nebenzahl et al., 1997; Knight and Calantone, 2000]. Knight and Calantone [2000] improved upon the Han model [1989] by developing the Single Flexible Model, illustrated earlier as Figure 11. Their model allows for the simultaneous processing of country image and product belief information, with the relative importance of each moderated by factors such as consumer knowledge and involvement. Nebenzahl et al. [1997] conceptualized an integrated model 
of PCI in an attempt to account for a taxonomy of country-related images, shown as Figure 13.

While their model illustrates the complexity of $\mathrm{PCI}$, it has not been operationalized. Other models have tested PCI within a broader context of consumer choice [Liefeld et al., 1996], and within a narrower context such as the influence of a product's region of origin [Van Ittersum et al., 2003], or the influence of social tendencies (e.g. patriotism, ethnocentrism) on purchase-related behaviour [Granzin and Olsen, 1998].

Figure 13: Model of Relative Product Images [Nebenzahl et al., 1997]

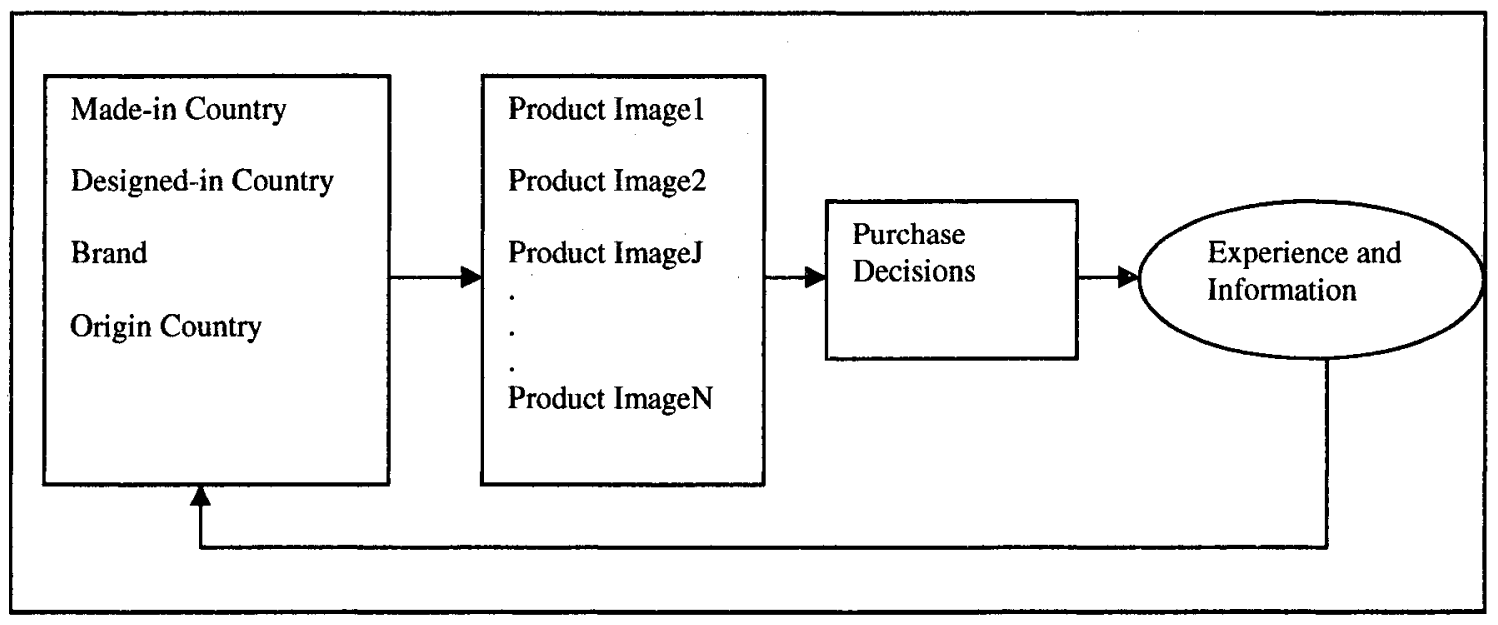

The model found to most comprehensively consider the relationships of interest here, namely country and product image, beliefs and behaviour, is that presented by Heslop et al. [2004], shown in Figure 14. The first version of this model [Papadopoulos et al., 1988] focused on the basic relationships from Country Beliefs to Product Beliefs, Product Beliefs to Product Evaluation, and Product Evaluation to Buyer Behaviour. The effect of Familiarity on Product Beliefs was also considered. Comparing the first (Figure 12) and most recent (Figure 14) versions highlights the refined separation of the country 
image construct into Country and People Description, and Country and People Competence, to more fully represent PCI effects. Also, structural paths from the Familiarity construct to Product Evaluation and Willing to Buy have been added. Variables include affective (e.g. trustworthy, friendly) workmanship) and conative (investment, ties, purchase) dimensions of PCI. This model is considered to be the most comprehensive to date. Empirically tested and refined over the years, the basic foundations of the model hold: Country Image $\rightarrow$ Product Beliefs $\rightarrow$ Behaviour.

Figure 14: Comprehensive Product Country Image Model [Heslop et al., 2004]

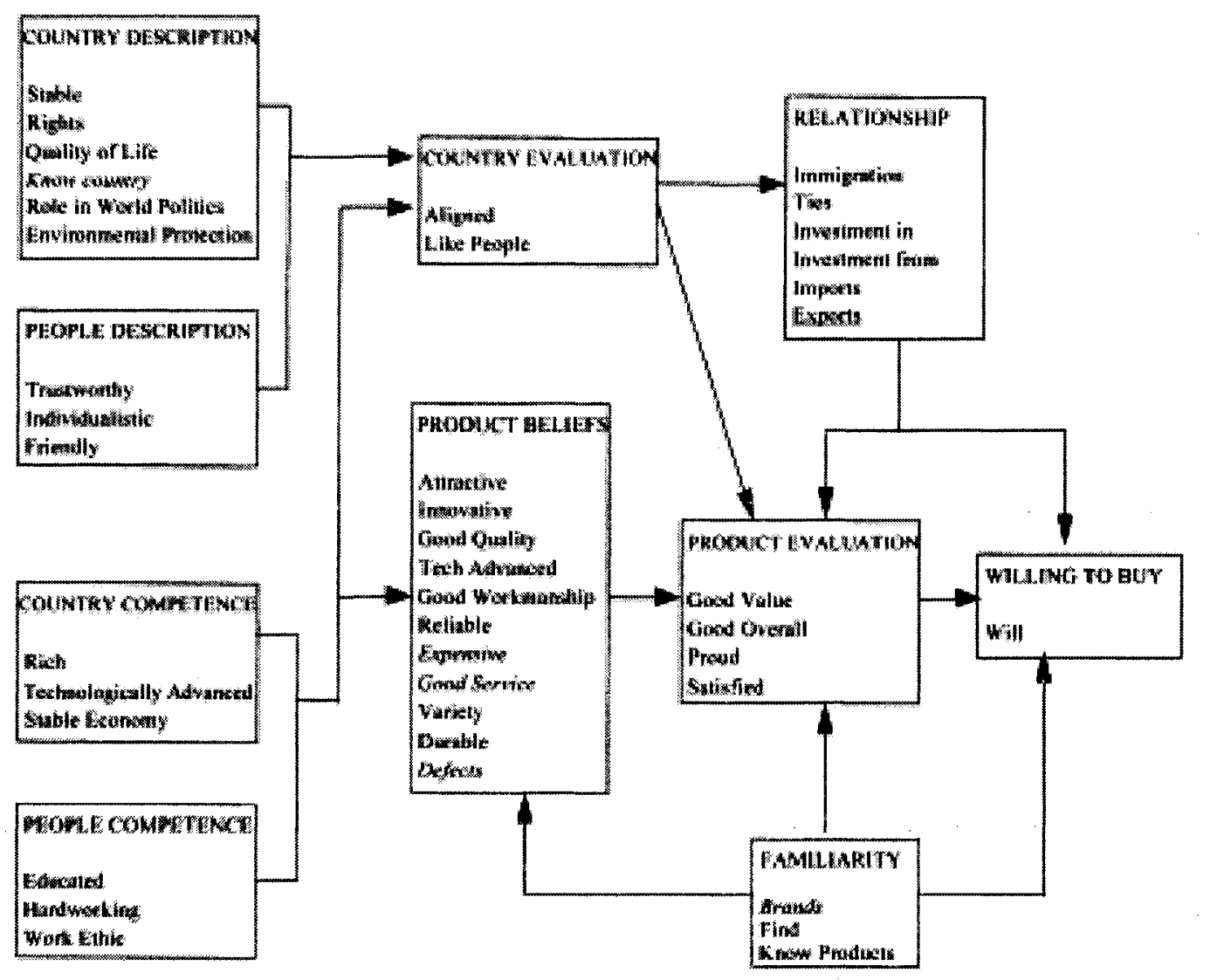


Methods of PCI analysis have also evolved. While the semantic differential scale has been employed for decades [Schooler, 1965], multivariate analysis is more recent. Now, there are sophisticated statistical procedures to analyze modeled relationships such as those proposed in Figure 14. The authors used structural equation modeling (PLS program) to simultaneously estimate measurement and structure [Heslop et al., 2004]. More will be said about SEM in Chapter 5, and its current popularity in PCI modeling [Haubl, 1996; Van Ittersum et al., 2003; Essoussi and Merunka, 2007].

Of relevance and interest, too, is the model developed by Orbaiz and Papadopoulos [2003]. As described earlier, the authors simultaneously tested the relationship between product beliefs, country image, familiarity, country affect, ethnocentrism, and receptivity. The model (see Figure 8), tested using Structural Equation Modeling (EQS program), supports the traditional PCI relationships, confirming once again Country Image to Product Beliefs, Product Beliefs to Buy, and Familiarity to Product Beliefs. Findings also supported the notion that affective aspects of PCI may directly impact purchase behaviour, regardless of one's product beliefs.

An evaluation of structural modeling in PCI [Papadopoulos and Butt, 2005] highlights several points relevant to this study. First, modeling was surprisingly rare in PCI research until recent years. With the number of PCI studies estimated to be more than 1000 , the authors found only 21 structural models published between 1987 and 2004, three of which were from a single study [Han, 1989, 1990]. Second, there is little consistency in the model conceptualizations, as evidenced by the authors' tabulation of 76 model constructs, comprised of 438 measures. Third, the authors' evaluation of the models suggest wide variability in research quality, as assessed by a range of indicators 
of the specification of key constructs, methodological rigor of input data, robustness of model testing, and generalizeability of findings. In summary, the analysis led the authors [Papadopoulos and Butt, 2005, p.9] to call for improvements in:

- Conceptualization, sampling, and the cross-national testing and validation of proposed models, to improve their generalizeability; and,

- Use of past research as a building block for new studies, to improve model consistency.

Since 2004, the growth in modeling has been considerable, such that it has almost become de rigueur as a methodology in current PCI analysis. A new journal dedicated to the study of Place Branding was launched in 2004 to promote the benefits to be derived from a cross-disciplinary interchange of theory [Papadopoulos, 2004]. Place image received an additional boost in popularity when the popular nation brander, Simon Anholt [2007b], released a Nation Brand Index as a "unique barometer of global opinions". The index is based on perceptions of a worldwide panel of 28,500 people in 35 countries, and is published quarterly. The index measures six areas of national competence: tourism, exports, people, governance, investments, and culture and heritage. While broad in scope, the depth is limited by inclusion of a limited number of questions for each area of competence. Nonetheless, it is noteworthy that Canada fares well, typically placing in the top five nation brands.

\subsection{Conclusions}

Forty years and some 1,000 articles after the first published empirical evidence of product bias based on national origin [Schooler, 1965], PCI is recognized as a powerful 
stereotype that can affect consumer evaluations of products, classes of products, specific products and product brands [Bilkey and Ness, 1982]. In fact, the rise of "nation (or place) branding" over the recent past, as noted in the introduction, serves to illustrate the importance being ascribed to place images, and to the products and other characteristics associated with them, by countries and places around the world. As well, governmentdriven place marketing efforts may help to further raise the importance of PCI for businesses and subnational places as they try to adjust their strategies to match and capitalize upon government "blanket" campaigns.

As evidence of the vastness of PCI research, which was brought about by academic interest and fuelled by the growing interest in PCI on the part of practitioners, several consolidations and meta-analyses have been undertaken in attempts to make sense of the plethora of work. The effect size of country image on product quality has been averaged across studies, ranging from 0.30 [Peterson and Jolibert, 1995] to 0.39 [Verlegh and Steenkamp, 1999]. Methodological approach has been found to influence effect size (e.g. multi-cue, between-subject design studies may produce smaller effects than singlecue, within-subject design studies) however, the significance of this influence is a matter of debate [Liefeld, 1993; Peterson and Jolibert, 1995].

Similar to the beginnings of TDI, much of the early PCI work focused on productrelated measures until the introduction of personality-oriented dimensions, such as "friendliness" and "trustworthiness", and conative dimensions, such as "desire for closer ties" and "more investment" [Papadopoulos et al., 1988]. Affective components of PCI image have been found to significantly influence consumer behaviour [Orbaiz and Papadopoulos, 2003] and several authors have called for more explicit modeling of 
cognitive and affective influences of PCI [Aakegaard and Ger, 1998; Verlegh and Steenkamp, 1999]. A comparison of the TDI and PCI research streams is presented in Appendix C.

Another similarity to TDI is the focus of many PCI studies on descriptive measurements of one country's image from the perspective of respondents in another country. The earliest models began to explore rather simplistic structural relationships between key concepts, such as: country image $\rightarrow$ product beliefs $\rightarrow$ brand attitude [Han, 1989]. Other authors considered the probability of simultaneous influences of country origin, beliefs and product knowledge on the formation of consumer attitudes [Knight and Calantone, 2000] and models have been developed to consider more complex relationships between the concepts of country image, product beliefs, product evaluations, familiarity and behaviour [Papadopoulos et al., 1988].

A significant development in the modeling of PCI relationships has been the disentanglement of country and product image dimensions, with distinct constructs to represent country image and product or brand image [Han and Terpstra, 1988; Roth and Romeo, 1992; Nebenzahl and Jaffe, 1996]. As PCI models have grown in complexity, so too have their statistical analysis. A review of 21 structural models found significant improvements in the development and refinement of PCI constructs [Papadopoulos and Butt, 2005]. The use of Structural Equations Modeling (SEM), supported by advanced statistical tools such as LISREL, have enhanced the sophistication of PCI analysis, and deepened the understanding of causal relationships [Heslop et al., 2005].

Based on this review of two vast, yet distinct streams of place image theory, past and present models, and emerging thought, Chapter 4 now presents a new concept that 
integrates constructs, and proposes new relationships, in an attempt to improve overall conceptualization of place image. 


\section{Chapter 4 Model Conceptualization and Research Hypothesis}

From the early work of Boulding [1956], image has been considered a significant predictor of human behaviour, influencing thoughts, feelings, and actions. Theorists have explored the role of image throughout marketing. A long history of market research confirms its strong influence on consumer behaviour in a number of contexts, notably that of store image [Martineau, 1958; Thang and Tan, 2003], brand image [Balmer, 1998; Aaker and Joachimsthaler, 2000], and corporate image [Kennedy, 1977; Dowling, 1986; Stuart, 1999]. The effect of place image has been extensively studied within the subfields of PCI and TDI. Place image is acknowledged as a significant factor in tourism destination selection [Beerli and Martin, 2004], and foreign product evaluation [Papadopoulos and Heslop, 2002].

Though an early PCI study [Papadopoulos and Heslop, 1986] found a correlation between travel and product evaluations, the relationship has been largely ignored by both the TDI and PCI streams, with only a few exceptions. Mossberg and Kleppe [2005] identify substantial overlap between the concepts of country image and destination image, and conceptualize an integrated model, but without empirical test. Heslop et al. [2005] incorporate country-level constructs from PCI within a TDI model, but do not include product measures. The knowledge that has developed within each field has never been fully compared, nor combined, considered, and empirically tested, in a systematic way.

\subsection{Model Conceptualization}

In order to explore how consumer perceptions of place might influence attitudes, country image, product and destination beliefs, familiarity and behaviour are modeled 
simultaneously. From the extensive literature review of TDI and PCI, models most relevant to this objective have been examined in order to support the development of a joint model of analysis. Building from a review of PCI structural models by Papadopoulos and Butt [2005], a selection of top models, assessed as most relevant and of highest quality, is included in Appendix D. Quality is based on the quantitative ratings given to each model by the authors, and relevance is based on a match of model constructs to those of interest here (e.g. country and product image, cognitive and affective components, and familiarity).

The review of the TDI literature revealed very few studies that have modeled the relationship of the constructs of interest here. Appendix D includes a summary of key characteristics of only six TDI models: three that treat image as a dependent variable, and model its formation [Baloglu and McCleary, 1999; Beerli and Martin, 2004a, b]; and, three that treat image as an independent variable, and model its influence on behaviour [Murphy et al., 2000; Bigne et al., 2001; Heslop et al., 2005]. The fact that image is treated as often as a dependent variable in TDI is distinctly different from its treatment in PCI. All 21 models reviewed by Papadopoulos and Butt [2005] treat image as an independent construct, predictive of behaviour at either the intermediate point in the purchase decision-making hierarchy (e.g. "preferences") or the end point (e.g. "intent to buy"). To match the objective of this study, image is treated as a predictor construct.

A similarity of PCI and TDI research is the consideration in both fields of cognitive and affective components of place image. Separate constructs have been modeled in TDI to reflect and measure Cognitive place evaluations, Affective place evaluations, and a holistic measure termed Overall Image by Baloglu and McCleary 
[1999a, b] and Beerli and Martin [2004a, b]. In PCI, authors have also developed distinct constructs to reflect affective place image components [Haubl, 1996; Orbaiz and Papadopoulos, 2003]. Thus, a distinction is made in this study between cognitive and affective country image.

Another similarity of PCI and TDI research, to varying degrees, is the consideration of experience, or familiarity, with either product or destination. From the early study of TDI, the level of familiarity with a destination has been considered [Gunn, 1972; Pearce, 1982; Chon, 1991]. More recently, Baloglu [2001] developed a "familiarity index", and both the Baloglu and McCleary [1999a] and Beerli and Martin [2004a,b] models include measures of familiarity. Surprisingly, familiarity is less common in PCI studies, despite its proven influence [Papadopoulos et al., 1988; Heslop et al., 2001 and 2004; Orbaiz and Papadopoulos, 2003]. Relevant to both PCI and TDI, familiarity is included as a model construct of the current study.

A significant difference found in the PCI and TDI literature is the level of analysis, or application of models. While PCI studies have moved to quite complex subdivisions of image at levels of multi-product categories, brands and hybrid mixes of origins (e.g. country of assembly, country of design), TDI studies continue to regard image at a very general level. The result is that most measures of TDI encompass a range of cognitive/affective, tangible/intangible, and country/product variables. Thus, to differentiate between country and product-related variables in this model, PCI theories are referenced [Papadopoulos et al., 1988; Haubl, 1996; Knight and Calantone, 2000; Heslop et al., 2001, 2004; Orbaiz and Papadopoulos, 2003]. 
Lastly, the outcome of interest in this study is consumer behaviour as a dependent measure. Again, PCI research has incorporated and measured behaviour more extensively than has TDI research. Also, the variables differ, in that TDI tends to measure "intention to return" to a destination, and/or "likelihood of recommending" a destination [Bigne et al., 2001], whereas the most frequent behavioural measure in PCI appears to be "willingness, or intent, to buy" [Haubl, 1996; Heslop et al., 2001, 2004; Orbaiz and Papadopoulos, 2003]. Measures are included to reflect both tourism and product related consumption behaviour patterns.

In summary, the constructs included in the integrated model, measured indirectly through multiple indicators, are grouped into four categories:

1) Country Image;

2) Beliefs;

3) Familiarity; and

4) Receptivity.

The basic conceptualization of an Integrated Model of Place Image (IMPI) is presented as Figure 15. This figure illustrates the basic structural relationships that link the newly combined TDI and PCI constructs.

Figure 15: Integrated Model of Place Image

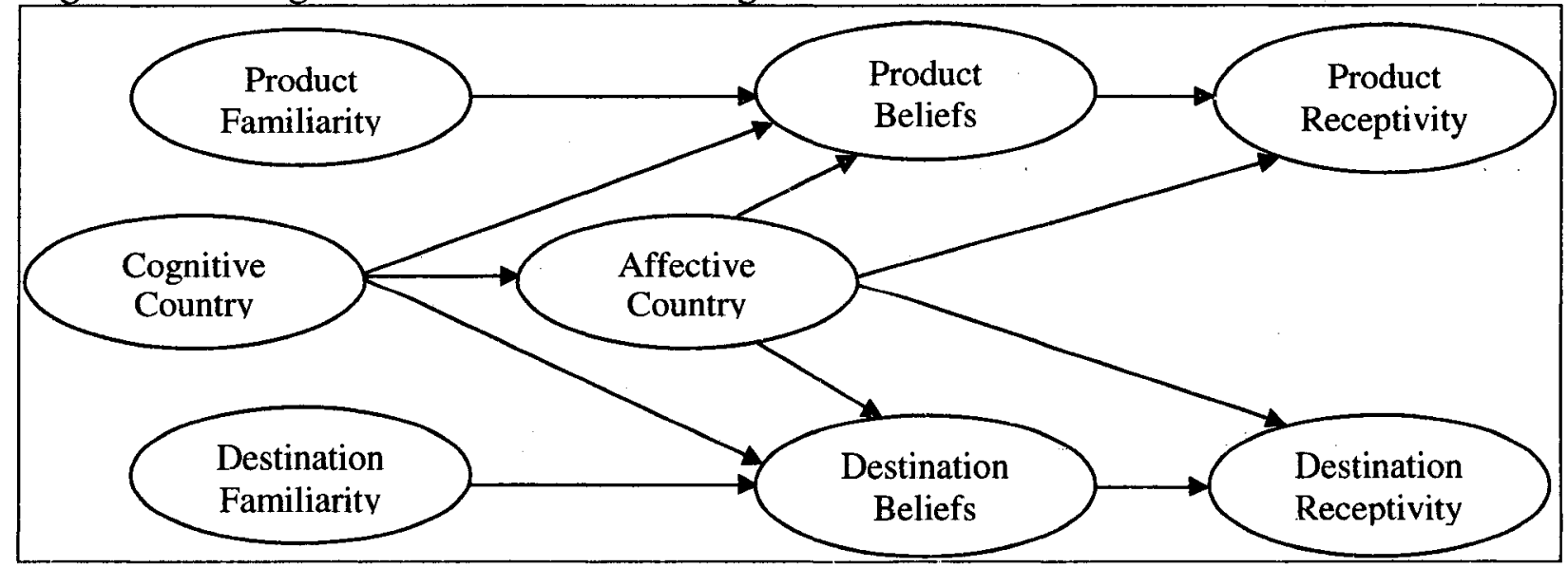


Section 4.3 that follows defines each construct, along with their hypothesized relationships. At the end of this section Figure 16 presents a full conceptualization of the IMPI with all hypothesized paths.

\subsection{Research Hypotheses}

Now that key TDI and PCI constructs have been identified, and an integrated model conceptualized, the relationships between country-related images, beliefs and behaviour are hypothesized. To begin, the theoretical base for each construct is discussed.

\section{Cognitive Country Image ( $\operatorname{Cog} \mathrm{CI})$}

Since the late 1980 s, the separation of country image from a country's product image has been researched in the context of PCI [Papadopoulos et al., 1988; Han, 1989, 1990; Heslop and Papadopoulos, 1993]. In terms of known relationships, the review of PCI literature confirmed the direct effect of Country Image on product beliefs, and indirect effect on product receptivity. By contrast, in over 30 years of TDI research, the concepts of country image and tourism product image have only been measured separately once [Heslop et al., 2005]. The simultaneous influence of a separate country image construct on travel destination beliefs and product beliefs has never been tested.

More commonly, TDI models have distinguished between cognitive and affective components, indicating a hierarchical effect of image, whereby a cognitive image influences an affective image, which in turn influences a conative image [Gartner, 1993]. Empirically tested by Baloglu and McCleary [1999a], the authors found that cognitive evaluations influenced affective image. While some evidence suggests a bi-directional 
relationship between cognitive and affective image, to maintain one exogenous country image construct, the cognitive-affective relationship is considered uni-directional in the model. To simultaneously examine the influence of country image on product and travel beliefs, the following three hypotheses are tested:

HI: A country's cognitive image is positively related to that country's affective image.

H2: A country's cognitive image is positively related to beliefs about that country's products.

H3: A country's cognitive image is positively related to beliefs about that country as a travel destination.

\section{Affective Country Image (AffCI)}

As stated earlier in section 3.2 on Cognitive, Affective and Conative Dimensions, much of PCI research has historically focused on the cognitive components of country image, such as quality attributes, overlooking the symbolic and emotional connotations that country image may well evoke [Verlegh and Steenkamp, 1999]. Yet, when affective components of PCI image are measured separately, they are found to have "a significant and direct influence on willingness to buy" [Orbaiz and Papadopoulos, 2003, p.101].

Until recently, TDI research has also focused on the cognitive, or tangible, components of image. Pike [2002] found that only six of 142 TDI studies he reviewed explicitly showed an interest in affective images. In another TDI literature review, Etchner and Ritchie [1991] found a favouring of functional measures (e.g. scenery, price, climate) over psychological measures (e.g. atmosphere, accessibility), with the exception of "friendliness". In fact, one of the earliest studies of TDI, Crompton [1979] identified "friendly people" as a key image dimension. 
Examples of the separation of cognitive and affective image components are more common in recent TDI literature. Of note is the work of Baloglu [Baloglu and Brinberg, 1997; Baloglu and McCleary, 1999b; Baloglu and Mangaloglu, 2001], who uses four bipolar scales to measure Affective Image: Arousing-Sleepy, Pleasant-Unpleasant, Exciting-Gloomy, and Relaxing-Distressing. Several other studies expressly consider tangible and intangible image components [Choi et al., 1999; Murphy, 1999; Chen and Hsu, 2000; Hui and Wan, 2003; O’Leary and Deegan, 2003; Suh and Gartner, 2004].

In terms of the influence of an affective country image construct, findings support the notion that affective aspects of PCI may directly impact purchase behaviour, regardless of one's product beliefs, and that a strong affect can even influence product beliefs [Orbaiz and Papadopoulos, 2003]. Thus, both direct and indirect influences of Affect on receptivity are tested. The following four relationships are hypothesized:

H4: A country's affective image is positively related to beliefs about that country's products.

H5: A country's affective image is positively related to beliefs about that country as a travel destination.

H6: A country's affective image is positively related to receptivity toward that country's products.

H7: A country's affective image is positively related to receptivity toward that country as a travel destination.

\section{Product Beliefs (ProdBel)}

Since the work of Papadopoulos et al. [1988] and Knight and Calantone [2000] to distinguish between country image and product image, others have considered this separation, and a range of distinct constructs representing the product level has emerged. 
Though PCI studies, for the most part, model a common path from Country Image to Product Evaluation to Behaviour, the intermediate product construct varies in composition. Some model Product Image and Product Beliefs as distinct constructs [Knight and Calantone, 2000]. Some distinguish Product Beliefs and Product Evaluation [Heslop et al., 2001 and 2004]. Others make a distinction between Product Sector Beliefs and Product Specific Beliefs [Haubl, 1996] or between General and Specific Product Attributes [Parameswaran and Pisharodi, 2002]. Here, Product Beliefs represents the product-level construct that is both influenced by image, and predictive of behaviour.

In terms of relationships, the traditional link from product beliefs to product buying behaviour is tested. Additionally, the model tests whether consumer beliefs about products have any relation to their travel behaviour. This path represents a new relationship, untested in past research because of the lack of cross over between PCI and TDI streams. The IMPI enables the following hypotheses to be measured:

H8: Beliefs about a country's products are positively related to receptivity toward that country's products.

H9: Beliefs about a country's products are positively related to receptivity toward that country as a travel destination.

\section{Destination Beliefs (DestBel)}

Destination Beliefs represents a new construct. In the TDI context, as discussed earlier, a multitude of country and product type variabies have most typically been combined together in "one big" TDI construct. Attempts at segregation have been made, but not on the basis of country/product. The most common separation of variables is 
tangible/intangible [Choi et al., 1999; Murphy, 1999; Chen and Hsu, 2000; Hui and Wan, 2003; O'Leary and Deegan, 2003; Suh and Gartner, 2004]. Also emerging in the literature is a separation of image components by affective/cognitive [Baloglu and Brinberg, 1997; Baloglu and McCleary, 1999b; Baloglu and Mangaloglu, 2001; Beerli and Martin, 2004b]. Echtner and Ritchie [1991] introduced a framework that consists of three continuums: (i) attribute-holistic; (ii) functional-psychological; and (iii) commonunique, as reviewed in Chapter 2. The authors' functional-psychological continuum is comparable to the cognitive-affective division, while their attribute-holistic continuum is perhaps the closest to the concept of a product-country division. They describe this continuum as comprising both perceptions of individual attributes (e.g. climate, accommodation facilities, friendliness) as well as more holistic impressions of place (e.g. mental pictures or imagery).

While the link from product beliefs to behaviour is well established in PCI research, it has been less studied in TDI. Tourism researchers agree, however, that TDI influences travel behaviour [Bigne et al., 2001], with behaviour ranging from destination preference and intention to visit, to actual choice, satisfaction, and repeat visitation. Goodrich [1978] was among the first to empirically establish the relationship between vacation destination preference, perception, and choice. More recently, Bigne et al. [2001] empirically shows the link from destination quality, to satisfaction, intention to return, and willingness to recommend a destination. This positive relationship between destination beliefs and travel receptivity is tested, as well as a newly proposed relationship between destination beliefs and product receptivity. Again, this is an untested path, hypothesized within the IMPI as follows: 
H10: Beliefs about a country as a travel destination are positively related to receptivity toward that country's products.

H11: Beliefs about a country as a travel destination are positively related to receptivity toward that country as a travel destination.

\section{Product Familiarity (ProdFam)}

The very nature of the study of PCI - that country image influences consumers' perceptions of foreign products - implies that product familiarity plays a significant role. The "Halo" effect holds that when consumers are unfamiliar with a foreign product, they use country image to infer product quality, whereas the "Summary Construct" theory holds that when consumers are familiar with a foreign product, they make abstractions of their product beliefs onto country image [Han, 1989]. Alternatively, the Single Flexible Model holds that country image and beliefs simultaneously influence attitudes, with the relative weighting influenced by product knowledge level [Knight and Calantone, 2000]. Questions continue regarding the extent to which consumers rely on country image as an extrinsic cue when evaluating product quality. Thus, Product Familiarity is included in the IMPI.

The view that familiarity affects behaviour indirectly through beliefs is tested by examining the relationship between familiarity and product beliefs. The view that familiarity affects behaviour directly is tesied by examining the relationship between familiarity and product receptivity. In the absence of previous empirical testing, it is assumed here that travel is a special product case. As such, the patterns hypothesized between product familiarity, product beliefs, and product receptivity are assumed to replicate, perhaps to a lesser degree, between product familiarity, destination beliefs, and 
travel receptivity. In other words, familiarity with a country's products is positively related to product and travel beliefs and behaviour. Hypotheses are as follows:

H12: Consumer's familiarity with a country's products is positively related to their beliefs about that country's products.

H13: Consumer's familiarity with a country's products is positively related to their beliefs about that country as a travel destination.

H14: Consumer's familiarity with a country's products is positively related to receptivity toward that country's products.

H15: Consumer's familiarity with a country's products is positively related to receptivity toward that country as a travel destination.

H16: Consumer's familiarity with a country's products is positively related to their affective image of that country.

\section{Destination Familiarity (DestFam)}

Throughout the TDI literature, the consumer's knowledge of a place has been recognized as a significant variable in the formation of image. One of the earliest conceptualizations of TDI is the Stage Theory of Image Development [Gunn, 1972], whereby image is defined as a mental construct. The image begins "organically", derived unintentionally through education, media, and people. The influence of promotional-type material produces an "induced" image. Finally, actual travel experience produces a "modified-induced" image. Later, Phelps [1986] collapsed the Stage Theory into two knowledge-influenced types of image: a "secondary" image derived from all formal communication, such as travel guides, and informal communications, such as word-ofmouth; and, a "primary" image derived from actual travel. Other notable studies have considered the relationship of travel knowledge and/or actual experience to TDI [Pearce, 1982; Chon, 1990, 1991; Ahmed, 1991; Fakeye and Crompton, 1991; Baloglu, 2001], 
often with a specific focus on promotional material. For example, Gartner [1993] considered the influence of "information formation agents" ranging from tourism advertising to information from the travel trade.

The focus on marketing in TDI research is reflective of the strong marketingoriented culture within the tourism industry [Ritchie, 1996]. Destination marketers who spend considerable amounts of money to develop promotional material are eager to understand its effectiveness. Baloglu [2001] reflected the importance of both information sources (informational familiarity) and actual travel experience (experiential familiarity) in the development of a composite measure he termed the "familiarity index". He found that the index was positively correlated to TDI, thus recommending that destinations increase promotional efforts in order to increase destination familiarity. Other researchers have simplified the measurement of travel familiarity to a single measure, using scale ranges such as "great experience" to "no experience" [Beerli and Martin, 2004], and "not at all familiar" to "extremely familiar" [MacKay and Fesenmaier, 1997].

In terms of relationships, the TDI literature shows much evidence of a direct link from travel knowledge to perceptions of destination image [Baloglu, 2001]. Upon closer examination of the composition of TDI, it seems that the link is to dimensions of the Destination Product (e.g. quality of experience, attractions) and to affective dimensions (e.g. relaxing, exciting). The IMPI introduced here hypothesizes that Destination Familiarity is positively correlated with the affective and product levels. Additionally, a positive relationship between Destination Familiarity and Product Beliefs and behaviour is proposed. In other words, knowledge of a country positively influences not only travel 
beliefs and behaviour toward that country, but product beliefs and behaviour as well. The Destination Familiarity relationships are hypothesized as follows:

H17: Consumer's familiarity of a country as a travel destination is positively related to their beliefs about that country's products.

H18: Consumer's familiarity of a country as a travel destination is positively related to their beliefs about that country as a travel destination.

H19: Consumer's familiarity of a country as a travel destination is positively related to receptivity toward that country's products.

H20: Consumer's familiarity of a country as a travel destination is positively related to receptivity toward that country as a travel destination.

H21: Consumer's familiarity of a country as a travel destination is positively related to their affective image of that country.

\section{Product and Destination Receptivity (ProdRec/DetRec)}

As the review of TDI and PCI literature revealed, whether image is considered directly, or components of image such as perceptions, affective associations, and positive and negative attributes are the focus, there is clearly a positive relationship to behaviour. The focus of this study is the inter-relationships among image-related variables, and not an in-depth analysis of each construct. Therefore, consumer behaviour is measured by using receptivity as the dependant variable of interest.

\section{Summary of Hypotheses}

In total, 21 relationships between the eight model constructs are hypothesized. The full conceptualization of the IMPI is presented as Figure 16, and the 21 hypotheses are summarized in Table 3. 
Figure 16: IMPI with Hypothesized Relationships

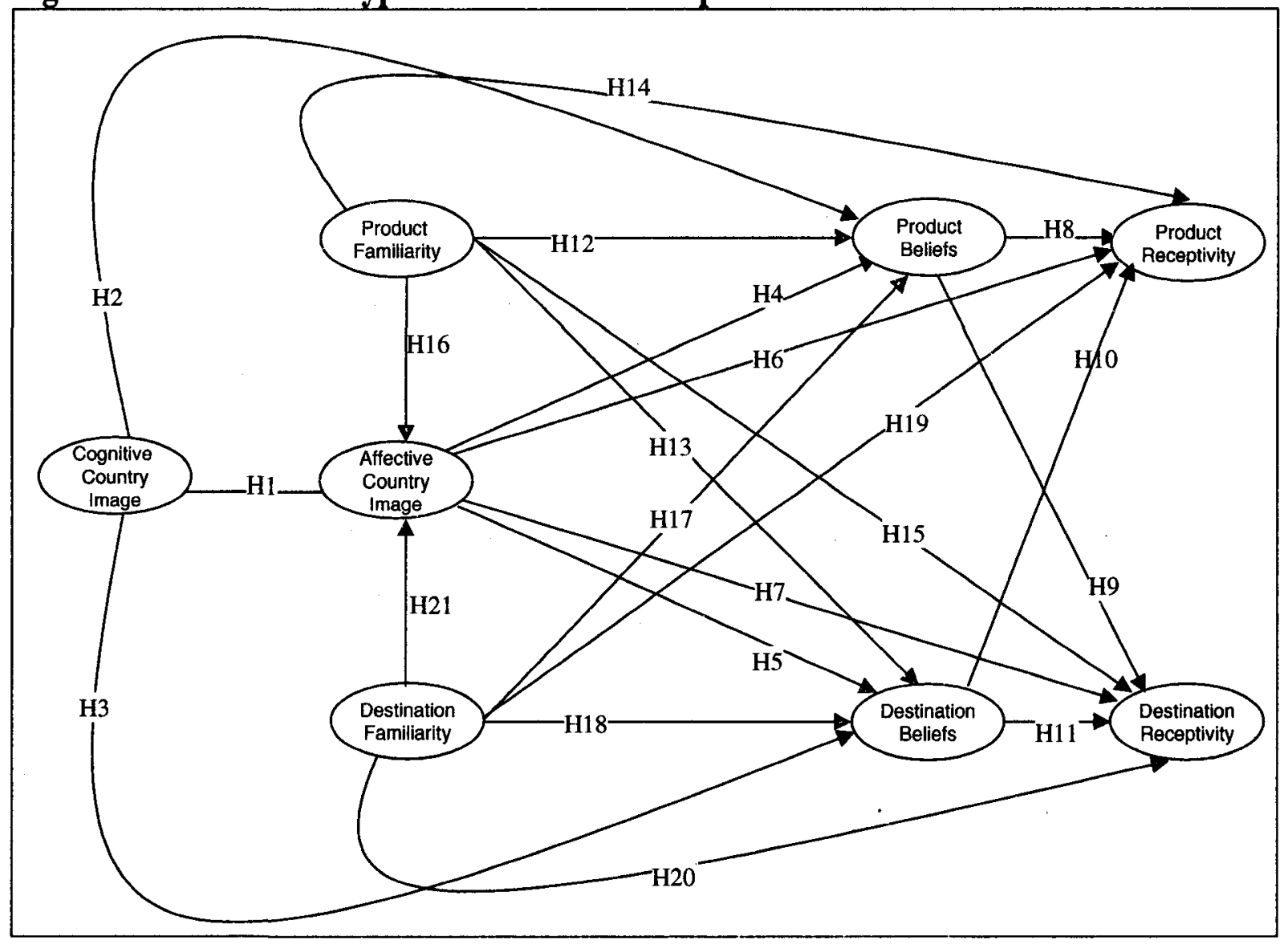

Table 3: Tourism and Product Country Image Hypothesized Relationships

\begin{tabular}{|l|l|}
\hline H1 & A country's cognitive image is positively related to that country's affective image. \\
\hline H2 & $\begin{array}{l}\text { A country's cognitive image is positively related to beliefs about that country's } \\
\text { products. }\end{array}$ \\
\hline H3 & $\begin{array}{l}\text { A country's cognitive image is positively related to beliefs about that country as a } \\
\text { travel destination. }\end{array}$ \\
\hline H4 & $\begin{array}{l}\text { A country's affective image is positively related to beliefs about that country's } \\
\text { products. }\end{array}$ \\
\hline H5 & $\begin{array}{l}\text { A country's affective image is positively related to beliefs about that country as a } \\
\text { travel destination. }\end{array}$ \\
\hline H6 & $\begin{array}{l}\text { A country's affective image is positively related to receptivity toward that } \\
\text { country's products. }\end{array}$ \\
\hline H7 & $\begin{array}{l}\text { A country's affective image is positively related to receptivity toward that country } \\
\text { as a travel destination. }\end{array}$ \\
\hline H8 & $\begin{array}{l}\text { Beliefs about a country's products are positively related to receptivity toward that } \\
\text { country's products. }\end{array}$ \\
\hline H9 & $\begin{array}{l}\text { Beliefs about a country's products are positively related to receptivity toward that } \\
\text { country as a travel destination. }\end{array}$ \\
\hline
\end{tabular}




\begin{tabular}{|l|l|}
\hline H10 & $\begin{array}{l}\text { Beliefs about a country as a travel destination are positively related to receptivity } \\
\text { toward that country's products. }\end{array}$ \\
\hline H11 & $\begin{array}{l}\text { Beliefs about a country as a travel destination are positively related to receptivity } \\
\text { toward that country as a travel destination. }\end{array}$ \\
\hline H12 & $\begin{array}{l}\text { Consumer's familiarity with a country's products is positively related to their } \\
\text { beliefs about that country's products. }\end{array}$ \\
\hline H13 & $\begin{array}{l}\text { Consumer's familiarity with a country's products is positively related to their } \\
\text { beliefs about that country as a travel destination. }\end{array}$ \\
\hline H14 & $\begin{array}{l}\text { Consumer's familiarity with a country's products is positively related to } \\
\text { receptivity toward that country's products. }\end{array}$ \\
\hline H15 & $\begin{array}{l}\text { Consumer's familiarity with a country's products is positively related to } \\
\text { receptivity toward that country as a travel destination. }\end{array}$ \\
\hline H16 & $\begin{array}{l}\text { Consumer's familiarity with a country's products is positively related to their } \\
\text { affective image of that country. }\end{array}$ \\
\hline H17 & $\begin{array}{l}\text { Consumer's familiarity of a country as a travel destination is positively related to } \\
\text { their beliefs about that country's products. }\end{array}$ \\
\hline H18 & $\begin{array}{l}\text { Consumer's familiarity of a country as a travel destination is positively related to } \\
\text { their beliefs about that country as a travel destination. }\end{array}$ \\
\hline H19 & $\begin{array}{l}\text { Consumer's familiarity of a country as a travel destination is positively related to } \\
\text { receptivity toward that country's products. }\end{array}$ \\
\hline H20 & $\begin{array}{l}\text { Consumer's familiarity of a country as a travel destination is positively related to } \\
\text { receptivity toward that country as a travel destination. }\end{array}$ \\
\hline H21 & $\begin{array}{l}\text { Consumer's familiarity of a country as a travel destination is positively related to } \\
\text { their affective image of that country. }\end{array}$ \\
\hline
\end{tabular}

Now that an Integrated Model of Place Image has been conceptualized, and relationships hypothesized, Chapter 5 will describe the research design, measurements and study implementation. 


\section{Chapter 5 Research Design and Methodology}

The main focus of the study is the comparative analysis of TDI and PCI, with the development of an integrated theoretical model as the goal. By integrating tourism and product constructs within the same model, the relationships between country image, product and tourism beliefs, and product and travel receptivity is empirically assessed for the first time. The contribution to theory of this new model is the principal goal. Therefore, of prime importance to the design of the empirical test of the model is the reliability and validity of the measurements. Additionally, for the model to have theoretical value, it must also have relevance in terms of its practical application. As such, the empirical test must have a high degree of "mundane realism" [Liefeld, 1993]. While the empirical test of the model strives for the highest degree of reliability and realism, the limits of market research (e.g. time, budget, respondent accessibility) dictate the need for some concessions.

Keeping in mind the main objectives of the study, elements of design are now reviewed. The first element considered is construct measurement, as this was directly determined by the study objective. Next, country selection is discussed, as this element supports the model's generalizability. The data collection method is reviewed, and lastly, statistical methods of analysis are presented.

\subsection{Construct Measurement}

Construct indicators were selected based upon a thorough review of both the TDI and PCI literature. The principal focus of the model is the simultaneous testing of product and tourism related constructs in order to determine their relationships. Existing 
constructs proven in past research were selected wherever possible and appropriate. The cornerstone relationships of the model are also well proven, and are three-fold: (i) country image affects beliefs; (ii) familiarity affects beliefs; and (iii) beliefs affect behaviour, or receptivity, the term used here to mean the consumers' willingness to buy or travel. While several other construct relationships are known within the fields of TDI and PCI, again, to maintain the focus here on the influence of country image on products and tourism, only those measures that reflect interests common to both fields are included. For example, while TDI models often include formation constructs, or influencers, such as motivations [Baloglu and McCleary, 1999a], and PCI models often include attitude or evaluations as an intervening variable between beliefs and receptivity [Heslop et al., 2004], these are not included here for reasons of parsimony. Also, the decision was made to exclude variables related to cost and/or expense to avoid introduction of an influence that is outside the current scope of study. It is important to note that, where necessary, specific indicators for each construct were adjusted during on-going refinements to the model and in the questionnaire development phase in an attempt to derive the best possible model.

\section{Cognitive Country Image (CogCI)}

TDI has most typically been measured as a multi-item construct that comprises an undifferentiated mix of country items (e.g. security, general infrastructure, politics, economics, language, natural and social environment) and country-product items (e.g. tourist facilities, resort atmosphere, cultural attractions, adventure and nature). Therefore, the TDI literature is not particularly helpful in deriving tested measures for this construct. 
Instead, measures for the country image construct for this IMPI were selected from the PCI field. Country image as a separate construct has been researched most frequently by Papadopoulos and Heslop [as author(s) or co-author(s) in, for example, 1988, 1989, 1993, 1994, 1998, 2000, 2002, 2003, 2004], including the largest PCI study ever, surveying 6,094 consumers across 15 countries [Papadopoulos and Heslop, 2000]. While the authors have used country image constructs comprising as many as 20 variables [Papadopoulos et al., 1993], a recent country image construct comprising five variables is preferable [Orbaiz and Papadopoulos, 2003] for two reasons. First, this country image construct comprises purely cognitive items: standard of living, wealth, technology level, education, and stability. Second, this construct comprises a manageable number of variables - within an eight-construct model - that have been extensively tested in past research [Papadopoulos et al., 1988 and 1993; Haubl, 1996; Heslop et al., 2001]. Their common use can also be seen in the table of Product Country Image Dimensions, Appendix B. Thus, Cognitive Country Image is a multi-item, exogenous construct, comprised of four of these variables:

Cognitive Country Image

1. Quality of life

2. Wealth

3. Technology level

4. Education

\section{Affective Country Image (AffCI)}

The purpose of the Affective Country Image construct is to capture the feelings and emotions of place image, versus the more factual components found in Cognitive Country Image. In TDI, Beerli and Martin [2004a, b] have narrowed this measure to two emotional attributes that they assess as adequate to represent the affective space of 
destination image: pleasant/unpleasant, and exciting/boring. Because "friendliness" is a frequent and significant affective variable in TDI, it is also included in the IMPI. Two studies have compiled lists of attributes in an attempt to consolidate and perhaps even standardize TDI measurements. The image dimensions identified by Echtner and Ritchie [1993], and Beerli and Martin [2004a] are listed in Table 4.

\section{Table 4: Dimensions of TDI}

\begin{tabular}{|l|l|}
\hline Echtner and Ritchie [1993] & Beerli and Martin [2004a] \\
\hline Comfort/Security & Natural Resources \\
\hline Interest/Adventure & Tourist Leisure and Recreation \\
\hline Natural State & General Infrastructure \\
\hline Tourist Facilitation & Tourist Infrastructure \\
\hline Resort Atmosphere/Climate & Culture, History and Art \\
\hline Cultural Distance & Political and Economic Factors \\
\hline Inexpensiveness & Natural Environment \\
\hline Lack of Language Barrier & Atmosphere of Place \\
\hline & Social Environment \\
\hline
\end{tabular}

While the majority of common TDI variables are cognitive in nature, an affective dimension seen throughout the literature in some form is: "comfort/security" [Echtner and Ritchie, 1993], which is also be included in the IMPI. Other affective-type dimensions, seen above in Table 4, relate to the interest in, or atmosphere of a place, or feelings about its social environment. These broad concepts are reflected here by using the term "ideal".

Three of the variables selected from TDI have also been used as affective measures in PCI, namely, pleasant and peaceful [Haubl, 1996], friendly [Orbaiz and Papadopoulos, 2003], and some form of comfort/security/stability [Heslop et al., 2004]. Another affective variable tested in PCI research is trustworthiness of the origin's people 
[Heslop and Papadopoulos, 1993]. Thus, Affect is a multi-item, endogenous construct, comprised of six variables:

\section{Affective Country Image}
5. Pleasant
6. Exciting
7. Friendly
8. Safety
9. Trustworthy
10. Ideal

\section{Product Beliefs (ProdBel)}

The selection of indicators for Product Beliefs relies again on the work of Orbaiz and Papadopoulos [2003], as it is felt to represent the culmination of much work in defining a separate construct that is both proven and parsimonious. In addition to their four measures of quality, reliability, workmanship and good overall products, innovativeness and value are added because of their frequent and significant role in PCI research (see Appendix B). Product Beliefs is a multi-item, endogenous construct, comprised of six variables:

Product Beliefs

11. Quality

12. Reliability

13. Workmanship

14. Innovativeness

15. Value for money

16. Good Overall Products

Destination Beliefs (DestBel)

The work of Echtner and Ritchie [1991, 1993], and Beerli and Martin [2004a] generated the list of common TDI dimensions in Table 4. To support the development of a new Destination Beliefs construct, five common and representative product elements 
are selected here, along with a sixth element to capture a more holistic impression, analogous to the last variable in the Product Beliefs construct. These measures are generic interpretations of popular attributes, applicable to a range of destinations. For example, beaches, and natural resources are commonly used TDI attributes for sun destinations, but would not be applicable to assess an urban destination's image. Here, "appealing scenery" is used as a more generic interpretation of the destination atmosphere. Likewise, "suitable" is the descriptor for accommodation, to provide the flexibility for a destination that features ferry boats and beach huts, to one featuring highspeed trains and five-star hotels. "Quality attractions" and "lots to see and do" also allow for flexibility in interpretation to reflect the context of a variety of destinations. The purpose of the variables is to measure the respondent's beliefs about any destination on a positive to negative scale. As such, Destination Beliefs is a multi-item, endogenous construct, comprised of six variables:

Destination Beliefs

17. Appealing Scenery

18. Suitable Accommodation

19. Quality Attractions

20. Lots to see and do

21. Value for money

22. Good Overall Destination

\section{Product Familiarity (PF) and Destination Familiarity (DF)}

The level of familiarity with a country has been found to significantly influence both product evaluations [Orbaiz and Papadopoulos, 2003] and destination image [Baloglu, 2001]. In PCI studies, familiarity is often approached in the abstract (e.g., "how familiar are you with the products of X"), regardless of actual product experience. 
At the other extreme, some PCI studies present a tangible product for respondents to assess [Schooler, 1965]. Thus, familiarity can be considered at many levels.

In TDI, familiarity has been defined and measured at three distinct levels [Fakeye and Crompton, 1991]. As discussed earlier, the first level, referred to as "organic", defines a state of knowledge about a country that is based upon unsought secondary information, including anything from a geography lesson in school to a media report in a newspaper. The next level, referred to as "induced", defines a state of knowledge that has been influenced by promotional-type information received about a country. Lastly, a "complex" level of familiarity defines a state of knowledge that is based upon actual experience, meaning visitation in the TDI context. Operationally, TDI studies typically measure the familiarity concept as either country experience or simply country knowledge (see Table 5), depending on study objectives.

Table 5: Examples of TDI Familiarity Measures

\begin{tabular}{|c|c|c|}
\hline Variable & Reference & Method \\
\hline $\begin{array}{l}\text { Experience } \\
\text { Pre/Post Visitation } \\
\text { Visitor/Nonvisitor }\end{array}$ & $\begin{array}{l}\text { Pearce [1982] } \\
\text { Phelps [1986] } \\
\text { Chon [1991] } \\
\text { Ahmed [1991] }\end{array}$ & $\begin{array}{l}\text { Tour company clients } \\
\text { Airport departure survey } \\
\text { Airport departure survey } \\
\text { Random mail survey }\end{array}$ \\
\hline $\begin{array}{l}\text { Knowledge } \\
\text { Information }\end{array}$ & $\begin{array}{l}\text { Baloglu [2001] } \\
\text { Crompton [1979] } \\
\text { Fakeye and Crompton } \\
{[1991]}\end{array}$ & $\begin{array}{l}\text { NTO mailing list } \\
\text { University student sampling } \\
\text { Chamber of Commerce list } \\
\text { of visitors (and roll-out to } \\
\text { non-visitor friends and } \\
\text { relatives) }\end{array}$ \\
\hline
\end{tabular}

Here, the interest is in the influence of familiarity (experience or knowledge based). The representative sample of potential consumers (addressed later in Section 
5.2.3) should exhibit a sufficient degree of variance in familiarity to enable meaningful interpretation. As a comprehensive approach, Product and Destination Familiarity are multi-item, exogenous constructs, comprised of the following variables:

Product Familiarity

23. Product Knowledge

24. Brand recognition

25. Use

26. Ease to find

27. Satisfaction
Destination Familiarity

28. Country Knowledge

29. Trips to country $X$

30. Knowledge from media, from school, from family roots

The model constructs Product Familiarity and Destination Familiarity are measured using scales, as listed in Table 7, as well as by using non-scale questions, provided later in Section 5.2.2, on Method of Measurement.

\section{Product and Destination Receptivity (ProdRec/DestRec)}

Product and Destination Receptivity are both multi-item, endogenous constructs, measured by "willing to buy/travel" as well as by other scales that have been tested in the context of both PCI [Orbaiz and Papadopoulos, 2003], and TDI [Bigne et al, 2001].

\section{Product Receptivity}

31. Ownership pride

32. Open to imports

33. Willingness to buy products from $X$
Destination Receptivity

34. Closer country ties

35. Willingness to travel to $X$

To summarize, the proposed model contains eight hypothetical constructs, representing latent variables, to be measured indirectly by the 35 indicators listed in Table 6. The number of indicators ranges from two to six per construct, considered manageable, and reasonable, given the eight constructs of interest, and statistical program 
capabilities. While the inclusion of this number of variables was intended to avoid the use of single-item constructs, following factor analysis one single-item construct emerged (see Chapter 6).

Table 6: Integrated Tourism and Product Country Image Model Variables

\begin{tabular}{|c|c|c|}
\hline Construct & \begin{tabular}{|l|} 
Variables \\
\end{tabular} & Adapted from: \\
\hline $\begin{array}{l}\text { Country Image } \\
\text { (Cognitive) }\end{array}$ & $\begin{array}{l}\text { 1. Quality of life } \\
\text { 2. Wealth } \\
\text { 3. Technology level } \\
\text { 4. Education } \\
\end{array}$ & $\begin{array}{l}\text { Orbaiz and Papadopoulos } \\
\text { [2003] }\end{array}$ \\
\hline Country Image (Affective) & $\begin{array}{ll}\text { 5. } & \text { Pleasant } \\
\text { 6. } & \text { Exciting } \\
\text { 7. } & \text { Friendly } \\
\text { 8. } & \text { Safety } \\
\text { 9. } & \text { Trustworthy } \\
\text { 10. } & \text { Ideal country } \\
\end{array}$ & $\begin{array}{l}\text { Beerli and Martin [2004]; } \\
\text { Echtner and Ritchie } \\
\text { [1991]; Haubl [1996]; } \\
\text { Orbaiz and } \\
\text { Papadopoulos [2003] }\end{array}$ \\
\hline Product Beliefs & $\begin{array}{l}\text { 11. Quality } \\
\text { 12. Reliability } \\
\text { 13. Workmanship } \\
\text { 14. Innovativeness } \\
\text { 15. Value for money } \\
\text { 16. Good overall products }\end{array}$ & $\begin{array}{l}\text { Orbaiz and Papadopoulos } \\
\text { [2003] }\end{array}$ \\
\hline Destination Beliefs & $\begin{array}{l}\text { 17. Appealing scenery } \\
\text { 18. Suitable accommodation } \\
\text { 19. Quality attractions } \\
\text { 20. Range of activities } \\
\text { 21. Value for money } \\
\text { 22. Good tourism destination }\end{array}$ & $\begin{array}{l}\text { Echtner and Ritchie } \\
\text { [1993]; Beerli and Martin } \\
\text { [2004] }\end{array}$ \\
\hline Product Familiarity & $\begin{array}{l}\text { 23. Product Knowledge } \\
\text { 24. Brand recognition } \\
\text { 25. Use } \\
\text { 26. Ease to find } \\
\text { 27. Satisfaction }\end{array}$ & $\begin{array}{l}\text { Fakeye and Crompton } \\
\text { [1991]; Orbaiz and } \\
\text { Papadopoulos [2003] }\end{array}$ \\
\hline Destination Familiarity & $\begin{array}{l}\text { 28. Country knowledge } \\
\text { 29. Trips to country } \\
\text { 30. Info from media, school, } \\
\text { family roots }\end{array}$ & $\begin{array}{l}\text { Fakeye and Crompton } \\
\text { [1991]; Baloglu and } \\
\text { McCleary [1999a]; } \\
\text { MacKay and Fesenmaier } \\
\text { [1997] }\end{array}$ \\
\hline Product Receptivity & $\begin{array}{l}\text { 31. Ownership pride } \\
\text { 32. Open to imports } \\
\text { 33. Willingness to buy }\end{array}$ & $\begin{array}{l}\text { Orbaiz and Papadopoulos } \\
\text { [2003] }\end{array}$ \\
\hline Destination Receptivity & $\begin{array}{l}\text { 34. Closer ties } \\
\text { 35. Willingness to travel }\end{array}$ & Bigne et al. [2001] \\
\hline
\end{tabular}




\subsection{Study Design}

To test the model and capture and assess consumer perspectives of these indicators, the following empirical study was implemented.

\subsubsection{Country Selection}

As noted in the introduction and other parts of this report, the overall goal of the study is to develop and test the integrated TDI/PCI theoretical model. At the same time, the country of primary interest from an applied policy perspective is Canada. To effectively satisfy both the theoretical objective and policy interest, the study was conceptualized so as to involve empirical testing in two countries, South Korea and Canada, with regards to the images of four countries, including Canada and three comparators. This section outlines the rationale and further specifics of these decisions.

\section{Main Country of Interest: Canada}

Research shows that Canada is little understood abroad, often stereotyped as inhospitable due to its cold climate and vast wilderness, and even "boring" from a tourism perspective [Canadian Tourism Commission, 2003]. Despite Canada's reliance on exports (over $40 \%$ of GDP), and over $\$ 26$ billion generated by tourism ( $2 \%$ of GDP), its products are rated significantly lower than those of many competitors [Papadopoulos and Heslop, 2000], and, compared to other major global tourism destinations, it attracts a significantly smaller portion of visitors from beyond the U.S. The fact that Canada is a sizable exporter, yet perhaps under-rated because of lack of awareness or negative image associations, makes its image an interesting and appropriate object for testing given the purposes of this study. 


\section{Data Collection: South Korea and Canada}

To evaluate Canada from a foreign perspective, the research was implemented in South Korea, selected for reasons that satisfy both the methodological and policy perspectives of the research. First, the author has had the personal experience of living in South Korea. First-hand experience not only supports the logistics of undertaking primary market research, but greatly assists the interpretation of findings. The knowledge gained through living in a country, experiencing day-to-day life, learning about people and place, provides an unequalled understanding of that market and is often cited as a key criterion for determining appropriate data collection sites [Malhotra et al., 1996]. Second, South Korea is one of the Asian "tiger" markets opening rapidly to global trade and travel, and as such, represents a common site for marketing research as well as a potential growth market for Canada.

Third, capturing South Korean perspectives on Canada is particularly timely given that, in January 2005, the two countries initiated negotiations for a bilateral free trade agreement. Canada and South Korea have had forty years of formal diplomatic relations, during which time the two countries have forged both economic and social ties. Each year between 7,000 and 8,000 South Koreans immigrate to Canada, bringing the population of Canadians of Korean descent to over 200,000. Additionally, some 50,000 Korean students at various levels are currently studying in Canada. Economically, Canadian foreign direct investment in Korea reached $\$ 609$ million in 2003 , including ties between major corporations such as Korea's SK Telecom and Canada's industry leader, Telus, and within major sectors such as aerospace, with Bombardier helping to build 
Light Rail Systems in Korea. In total, bilateral trade between the two countries surpassed $\$ 7$ billion in 2003, making Korea Canada's $8^{\text {th }}$ largest trading partner.

In terms of tourism, it is important to note a little-known fact - that South Koreans were not able to travel outside their country, except for business, until 1989 [Canadian 'Tourism Commission, 2007a]. Since the borders have opened, South Korean outbound travel has grown by as much as $12.7 \%$ a year. Some 173,000 South Koreans visited Canada in 2005, up $20.6 \%$ from 2002, a growth trend interrupted in 2003 due to SARS, but expected to continue well into the future [Canadian Tourism Commission, 2007b]. The Canadian Tourism Commission increased its 2007 marketing investment in South Korea, identifying the country as one of four high-yielding Asia-Pacific markets (along with Japan, China and Australia). South Korea has proven to be a source of highspending tourists for Canada. South Korean tourists spend approximately $\$ 218$ million a year in Canada. Amongst Asia-Pacific tourists to Canada, this is second only to Japanese tourist spending of $\$ 402$ million, and ahead of revenues of $\$ 210$ million from Australian tourists and $\$ 154$ million from Chinese tourists [Canadian Tourism Commission, 2007b].

South Korea positions itself as an economic hub of Northeast Asia, a region expected to be a key leader of the global economy in the $21^{\text {st }}$ century, with a regional population of 1.5 billion. South Korea's population of 48.8 million represents a sizable market for goods. 2005 imports were worth $\$ 343.0$ billion U.S., and consumer appetite is growing. Free trade zones and bilateral trade agreements are available for those companies, and countries, willing to invest. Strategy will be key, with image playing a central role. 
Given the above, South Korea was seiected as the foreign market for data collection, and Canada, which was already selected as the country whose image is the principal study interest, as a second country in which the field study was implemented. The use of two country samples enabled comparative analyses of the findings across the countries whose images were tested.

Table 7: Sociodemographic and Economic Characteristics of Study Countries ${ }^{1}$

\begin{tabular}{|c|c|c|}
\hline Characteristic & South Korea & Canada \\
\hline Population (2006) & $48.8 \mathrm{~m}$ & $31.6 \mathrm{~m}$ \\
\hline \multicolumn{3}{|l|}{ Population: } \\
\hline$<15$ years & $20.9 \%$ & $19.0 \%$ \\
\hline$>60$ years & $11.0 \%$ & $16.7 \%$ \\
\hline Population annual growth rate & $0.42 \%$ & $1.1 \%$ \\
\hline Urban pop. & $82.5 \%$ & $78.9 \%$ \\
\hline$\overline{\text { GDP (billions Cdn) }}$ & $\$ 1,007.38$ & $\$ 1,439.27$ \\
\hline GDP per capita & $\$ 20,858$ & $\$ 44,175$ \\
\hline GDP growth rate & $5 \%$ & $2.7 \%$ \\
\hline Unemployed & $3.7 \%$ & $6.3 \%$ \\
\hline \multicolumn{3}{|l|}{ Structure of Employment } \\
\hline Agriculture & $6 \%$ & $2 \%$ \\
\hline Industry & $26 \%$ & $23 \%$ \\
\hline Services & $67 \%$ & $75 \%$ \\
\hline Exports (billions US) & $\begin{array}{c}\$ 360.0 \\
\text { electronic products } \\
\text { automobiles } \\
\text { machinery \& equip } \\
\text { steel, ships } \\
\text { petrochemicals }\end{array}$ & \begin{tabular}{|c}
$\$ 360.0$ \\
crude petroleum \& \\
products \\
natural gas \\
motor vehicles \& parts \\
lumber, wood pulp, \\
newsprint \\
crude \& fabricated metals \\
wheat
\end{tabular} \\
\hline Major markets & $\begin{array}{c}21.8 \% \text { China } \\
\text { 14.6\% U.S. } \\
\text { 8.5\% Japan } \\
\text { 5.5\% Hong Kong }\end{array}$ & $84 \%$ U.S. \\
\hline Imports (billions US) & $\begin{array}{c}\$ 343.0 \\
\text { crude oil } \\
\text { food } \\
\text { machinery \& equip } \\
\text { chemicals } \\
\text { base metals }\end{array}$ & $\begin{array}{c}\$ 314.3 \\
\text { motor vehicles \& parts } \\
\text { industrial machinery } \\
\text { crude petroleum } \\
\text { chemicals } \\
\text { agricultural machinery }\end{array}$ \\
\hline
\end{tabular}




\begin{tabular}{|c|c|c|}
\hline Major suppliers & $\begin{array}{c}\text { 18.5\% Japan } \\
\text { 14.8\% China } \\
\text { 11.8\% U.S. } \\
\text { 6.2\% Saudi Arabia }\end{array}$ & $57 \%$ U.S. \\
\hline Adult literacy & $98 \%$ & $99 \%$ \\
\hline $\begin{array}{l}\text { Hofstede cultural dimension } \\
\text { scores }^{2} \\
\text { Power distance } \\
\text { Individualism } \\
\text { Masculinity } \\
\text { Uncertainty avoidance } \\
\text { Long term orientation }\end{array}$ & $\begin{array}{l}60 \\
18 \\
39 \\
85 \\
75\end{array}$ & $\begin{array}{l}39 \\
80 \\
52 \\
48 \\
23\end{array}$ \\
\hline Ethnic groups & $\begin{array}{c}\text { Korean } 99.9 \% \\
\text { Chinese } .0004 \%\end{array}$ & $\begin{array}{c}\text { British/Irish 28\% } \\
\text { French 23\% } \\
\text { Other Europe 15\% } \\
\text { Asian/Arab/African 6\% } \\
\text { Indigenous Amerindian } \\
2 \% \\
\text { Mixed background 26\% }\end{array}$ \\
\hline $\begin{array}{l}\text { Surveyed City, Population } \\
\text { (metro) }\end{array}$ & $\begin{array}{c}\text { Seoul } \\
10,300,000\end{array}$ & $\begin{array}{c}\text { Toronto } \\
5,072,075 \\
\end{array}$ \\
\hline Currency Unit & Korean Won & Canadian Dollar \\
\hline
\end{tabular}

Table 7 compares South Korea and Canada on a number of sociodemographic and economic characteristics. Notably, South Korea has a larger, much more condensed population, unilingually and ethnically homogenous in comparison to Canada's population. Economically, Canada is wealthier, with a GDP per capita more than double that of Korea. However, South Korea's high growth rate is narrowing the gap each year. Interestingly, the value of exports and imports are similar for both countries, yet exports are significantly dissimilar in terms of trading patterns. Canada's trade is heavily dependant on the U.S. market, whereas Korea's is more diversified, though, logically, concentrated in Asian markets (e. China, Japan, Hong Kong). 
Perhaps the most significant difference between the two countries is in terms of culture, where they diverge on every dimension of the Hofstede scores [Hofstede, 2001]. South Koreans accept a large power distance between societal levels, whereas Canadians favour a more equal power distribution; South Korea is highly collectivistic, whereas Canada is more individualistic; South Koreans exhibit more feminine characteristics, Canadians more masculine; lastly, South Koreans are more likely to avoid risk, and are more long-term oriented than Canadians. The influence of these cultural differences is considered in the analysis sections of Chapter Six.

\section{Cross-Country Comparison: Japan, U.S.A., Australia}

To consider Canada (or any other single country) in isolation would limit the contextual sense of the findings and constrain the potential validity and generalizability of the model [Malhotra et al., 1996]. Therefore, a multi-country comparison was undertaken to enhance the generalizability of the findings. To identify additional countries, competing destinations to Canada were considered. Country selection was based on a comparison of Canadian and South Korean outbound travel destinations, and economic and population size of country.

In terms of South Korean outbound travel, the top five destinations, listed in rank order, are: China, Japan, the U.S., Thailand and the Philippines. Canada, currently in twelve place, may not realistically hope to achieve a top five ranking, but has identified Australia (currently ranked ninth) as a main competitor [Canadian Trade Commission, 2004]. In terms of Canadian outbound travel, the vast majority head south. Of the 17.7 million Canadians who traveled outside of Canada in 2003, 12.7 million, or $71.6 \%$, 
traveled to the U.S. Of the 5 million who traveled overseas, almost half traveled to the popular European destinations of the U.K., France, Germany, Italy, the Netherlands and Spain. Another 1.3 million Canadians traveled to the popular sun destinations of Mexico, Cuba and the Dominican Republic. Approximately 1 million outbound Canadians traveled to Asia-Pacific, with China and Japan receiving the largest shares.

Countries selected for the comparative analysis are Japan, the most popular AsiaPacific destination for outbound travel; the U.S., as the prime long-haul destination for South Koreans, and short-haul destination for Canadians, as well as being a country perhaps compared to Canada as part of the same evoked set given their geographic proximity and similar tourism features; and, Australia, a competitor from both the tourism and product perspectives and a country most comparable to Canada in terms of economic and population size. Together with Canada, for South Korean respondents this provides evaluations of two Asia-Pacific and two North American countries. For the Canadian sample, the three comparator countries are retained (Japan, U.S., and Australia) and Canada, since it is the home country, is replaced by South Korea.

All the identified countries are known to respondents to varying degrees, which is desired in order to provide the insights sought. Japan, for example, is the largest economy in Asia-Pacific, and has a unique history with South Korea that provides interesting results. From Japan's 1910 to 1945 colonization of Korea, to the co-hosting of the 2002 World Cup, the two countries have deep ties that no doubt influence image, beliefs and behaviour. The U.S. is not only Canada's largest trading partner, but also has a unique relationship with South Korea, as a military ally and economic force. Additionally, there is much past research that has selected Japan and the United States for 
comparison [Knight and Calantone, 2000; Kim and Chung, 1997; Han, 1989] with notable differences in PCI. Australia, selected because of its comparable size to Canada, is not only a popular tourist destination for South Koreans, but a popular student destination for ESL education.

Inter-country comparisons are made at the general level of country and product, without identification of specific products, categories of products, seasons or brands. This decision reflects the primary objective of the study which is to assess the more macro relationships between country image, product and tourism beliefs, and behaviour. No doubt there would be interesting differences at other levels of analysis, but these are beyond the scope of the current study.

\subsubsection{Method of Measurement}

The study instrument was a structured questionnaire, comprising five sections. The first included 12 scales evaluating the four test countries and their people, randomly sequenced. The second section included 12 randomized scales evaluating products from those countries. The third section included six randomized scales evaluating tourism characteristics. The fourth section included three summary scales related to overall country, product, and tourism quality, as well as three open-ended questions to capture more holistic image-related responses. The last section comprised questions related to demographics, travel frequency, and country knowledge. The demographics section captured gender, age, education, household size and income. The travel questions captured number of trips to each of the subject countries, as well as purpose of trip: tourism, study, work, other. The last question in this section related to the role of school, 
media and family ties in shaping country views. All scale questions used a bipolar adjective scale, anchored by opposites such as "pleasant-unpleasant", and "good qualitypoor quality".

\section{$\underline{\text { Scale Variables }}$}

The bipolar adjective scale is a widely used method of attitudinal measurement. It is a closed-ended form of survey question with a limited set of response options, structured as a scale. The scale features two anchor points at either end, representing extremes in attitude using bipolar adjectives (e.g. friendly, unfriendly), with an assumed neutral midpoint (e.g. neither friendly nor unfriendly). The points of the scale are then assigned numbers, ranging, say from 1 to 5 , or 1 to 7 , that allow statistical tabulation to determine the relative significance of respondent's attitudes. An alternative method considered was the Likert scale, which is anchored numerically but was thought to be potentially less clearly defined for respondents. The common feature of the two scales is the categorization of data, whereby the measurement scale consists of a set number of categories.

The selection of an appropriate number of categories is important, with the most common approach being 5 or 7 [Aaker et al., 1995]. However, the selection of category points often seems arbitrary. In all levels of measurement and methods of scaling, the quality of the tool will determine the quality of the results. Scales, by definition, assume equal intervals between points and a symmetrical distribution. There are, however, issues in terms of the reliability and validity of this construction. Typically underlying the ordinal categorical variables are continuous variables that represent people's attitudes, as 
is the case in this study. The assumption is that the underlying continuous variables follow multivariate normal distributions with zero means and unit variances. Thus, estimates of the correlations can be obtained [Poon, 1999]. At question is the appropriateness of analyzing an unobserved multivariate normal distribution by way of observed categorical response data.

Table 8: Variable Measurement Scales

\begin{tabular}{|c|c|c|}
\hline SEM & Variable & 7-Point Bipolar Adjective Scale \\
\hline $\mathrm{X}_{1}$ & Quality of life & poor / good quality of life \\
\hline $\mathrm{X}_{2}$ & Wealth & poor / rich \\
\hline $\mathrm{X}_{3}$ & Technology level & not technologically / technologically advanced \\
\hline $\mathrm{X}_{4}$ & Education & not highly educated / highly educated people \\
\hline $\mathrm{X}_{5}$ & Product knowledge & I know little / a lot about products from X \\
\hline $\mathrm{X}_{6}$ & Brand recognition & unrecognizable / recognizable brands \\
\hline $\mathrm{X}_{7}$ & Product availability & products from $\mathrm{X}$ are hard / easy to find \\
\hline$X_{7}$ & Product use & I rarely / often use products from $X$ \\
\hline $\mathrm{X}_{9}$ & Product satisfaction & I am not satisfied / satistifed with products from $X$ \\
\hline$X_{10}$ & Country knowledge & I know very little / a lot about country $\mathrm{X}$ and its people \\
\hline $\mathrm{Y}_{1}$ & Pleasant & unpleasant / pleasant \\
\hline $\mathrm{Y}_{2}$ & Exciting & boring / exciting \\
\hline $\mathrm{Y}_{3}$ & Friendly & unfriendly / friendly people \\
\hline $\mathrm{Y}_{4}$ & Safety & dangerous / safe \\
\hline $\mathrm{Y}_{5}$ & Trustworthy & not trustworthy / trustworthy people \\
\hline $\mathrm{Y}_{6}$ & Product Quality & poor / good quality products \\
\hline $\mathrm{Y}_{7}$ & Product Reliability & unreliable / reliable products \\
\hline $\mathrm{Y}_{8}$ & Product Value & poor / good value for the money \\
\hline $\mathrm{Y}_{9}$ & Workmanship & poor / good workmanship \\
\hline $\mathrm{Y}_{10}$ & Innovativeness & imitative / innovative products \\
\hline$Y_{11}$ & Good overall products & poor / good overall products \\
\hline $\mathrm{Y}_{12}$ & Appealing scenery & unappealing / appealing scenery \\
\hline $\mathrm{Y}_{13}$ & Accommodation & unsuitable / suitable accommodation \\
\hline $\mathrm{Y}_{14}$ & Quality attractions & low / high quality attractions \\
\hline $\mathrm{Y}_{15}$ & Range of activities & little / lots to see and do \\
\hline$Y_{16}$ & Good overall destination & poor/good tourism destination overall \\
\hline $\mathrm{Y}_{17}$ & Willing to buy & I am not willing / willing to buy products from $\mathrm{X}$ \\
\hline $\mathrm{Y}_{18}$ & Proud to own & I would not be proud / proud to own products from X \\
\hline $\mathrm{Y}_{19}$ & Welcome imports & I would not welcome / welcome more imports from X \\
\hline $\mathrm{Y}_{20}$ & Willing to travel & I am not willing / willing to travel to $X$ \\
\hline $\mathrm{Y}_{21}$ & Closer ties & we should not have / have closer ties with $\mathrm{X}$ \\
\hline
\end{tabular}


On the other hand, given a large number of response categories (e.g. 7), the absence of skewness, and equal thresholds across items, reasonable results are possible. Thus, 7 or 9 points should be used to obtain more precise data. Any more categories could result in confusion on the part of the respondent [Miller, 1956]. In weighing considerations of clarity, and reliability versus brevity, a 7-point bipolar adjective scale was selected. The underlying variables were assumed to have a multivariate normal distribution, given the relatively large target sample of 300 respondents. Additionally, a 7-point scale has been proven effective in the most similar data scenario found as a comparison [Orbaiz and Papadopoulos, 2003]. To operationalize the variables for measurement, the scales implemented are presented in Table 8 .

\section{$\underline{\text { Non-Scale Variables }}$}

While the IMPI builds most directly from the theoretical foundations of PCI, a significant enhancement to the analysis from the TDI research field is the addition of open-ended questions to capture holistic impressions of place image. A question introduced by Echtner and Ritchie [1993], strong proponents of combining structured and unstructured survey methodologies, was adapted to capture country, product and tourismrelated images:

a. "What images or characteristics come to mind when you think of these countries?"

b. "What products come to mind? (band, product category, or company name)"

c. "What tourism characteristics come to mind? (attraction, location, or feature)" 
In addition to the construct measures for PF and DF, familiarity is captured more directly using non-scale questions in a separate section of the study instrument with the following questions:

a. "How many trips have you taken outside Canada/South Korea since January 2004?"

b. "Have you ever been to any of these countries? (US, Japan, Australia, Canada/South Korea)"

c. "For what purpose? (tourism, study, work, other)"

d. "Have any of the following played a role in shaping your views:

- Things I learned in school

- Things I learned from the media (TV, radio, newspapers, magazines, etc.)

- I have family roots there (immigrated from there, or have relatives who live there)."

Lastly, respondent demographics are captured, limited to variables commonly studied in PCI and TDI, namely: age, gender, education, number of persons living in the household, and household income [Baloglu and McCleary, 1999; Bilkey and Nes, 1982].

An introductory paragraph preceded the survey questions in order to communicate the purpose of the research, and to ensure confidentiality, and detailed instructions were provided including an example of scale completion. The English questionnaire is included as Appendix K.

\section{Questionnaire Translation}

The questionnaire was developed in English, then translated and back-translated for the Korean application in accordance with recognized procedures for cross-cultural market research [Brisles, 1970]. Most studies use local bilingual students or professional translators for this task, but this often results in problems because, notwithstanding their knowledge of the languages involved, such translators have little or no familiarity with 
the technical terms used in any particular study. To avoid such problems and further enhance the quality of the research, for this study the Korean translation was undertaken by Dr. Samuel Seongseop Kim, Professor in the Department of Hospitality and Tourism Management, Sejong University, Seoul. Dr. Kim is fully bilingual and very familiar with tourism image research, having completed his $\mathrm{PhD}$ at Texas $\mathrm{A} \& \mathrm{M}$ University under the supervision of Dr. John Crompton, a well-recognized pioneer of TDI research, and having himself published several articles related to the subject (Crompton and Kim, 2001; Kim, Crompton and Botha, 2000). Additionally, Dr. Kim reviewed the Korean version with a number of his graduate students to verify its appropriateness and comprehensiveness. Following the back-translatation, a few wording adjustments were required, reflecting the challenge in finding equivalent meanings between two languages that are as structurally different as English and Korean. The translation process proved to be more time consuming than was estimated, but it was considered to be a crucial step to ensure linguistic equivalence and improve the quality of the study.

\subsubsection{Sampling and Fieldwork}

Options were considered for the selection of "best" sample, and for means of distribution and collection. The selection of measures for familiarity in particular influenced data requirements. As was seen in Table 5, TDI surveys are often distributed to groups of known travelers (e.g. airport passengers, tour group clients). The exception in Table 5, a study by Ahmed [1991], undertook a random household survey. However, the author was assessing U.S. residents' image of Utah. The interest was in a short-haul, in-country destination, where a sufficient percentage of visitors and non-visitors existed 
within the general population to conduct a valid comparison. While random sampling may be best to evaluate short-haul destination images, it may not be best to evaluate longhaul destination images. In studies where the interest is in a long-haul destination, such as Americans' perceptions of the image of Korea [Chon, 1991], or Turkey [Baloglu, 2001], choice-based surveys were the method of choice. Chon [1991] surveyed consumers at the airport departure area and on selected flights between the U.S. and South Korea. Baloglu [2001] mailed a survey to a list obtained from the Turkish National Tourism Office (NTO) of people who had requested information about Turkey.

Choice-based sampling procedures are more commonly found within the TDI literature than within the PCI literature for two reasons. First, familiarity is a more common construct within TDI, thereby requiring a more specified sample by which to measure its effects. Second, a population of travelers and/or non-travelers is more easily identifiable and accessible than a population of users/non-users of a country's products. Because the interest here is in measuring both product and travel familiarity, a range of methods was considered.

\section{Consideration and Selection of Sampling Method}

Before discussing the range of methods, or the "how" of the proposed survey, the "why" of the survey must be reiterated to clarify what kind of sample population is "best". First, in the interests of theory, the model must test equally across countries. Second, in the interests of public policy, a certain level of product and destination familiarity with the main country of interest, Canada, is required to produce more meaningful results. Given that only $20.8 \%$ of South Koreans travel outside their country in a given year (10 
million travelers), of whom less than $2 \%$ travel to Canada $(173,000)$, a completely random survey was not likely to provide sufficient numbers of respondents with "complex" familiarity. Likewise, the outbound travel from South Korea and Canada to the comparator countries (Japan, U.S.A., and Australia) would also be relatively low. Therefore, the approach needed to target a population believed to be more highly disposed to travel, and by extension, foreign product consumption, than the average population. Several sampling methods were considered, and rejected because of either inaccessibility (e.g. airport intercept or in-flight survey); sub-optimal population (e.g. student survey); and/or, cost (e.g. massive household mailing).

The selected method of questionnaire distribution was an intercept of adults attending travel shows in South Korea and Canada. This method was preferred for its effectiveness and manageability, and its ability to reach a desired sample of adults likely to have a higher than average level of familiarity with the countries selected, given their assumed interest in travel. By extension, if travel is considered to be one form of foreign product, an assumption might be made that consumers attending a travel show are relatively open-minded to foreign products. Given a higher incidence of travel, respondents might also have higher familiarity with foreign products.

\section{$\underline{\text { Pilot Tests }}$}

To test the comprehensiveness and ease of use of the Korean-version questionnaire, a pilot test was implemented. Fifty questionnaires were distributed to a convenience sample of Korean students at the South Korea Military College, Daejon, in May, 2005. Forty-six questionnaires were fully completed $(n=46)$, without any 
detectable difficulties. Three questionnaires were not returned, and only one questionnaire was not sufficiently completed (excluded if greater than $10 \%$ blank). Thus, the Korean questionnaire was deemed to be satisfactory and ready for the full implementation.

To test the comprehensiveness and ease of use of the English-version questionnaire, a pilot test was implemented in-class to a convenience sample of 37 business students at Carleton University, Ottawa during the fall term, 2005. Thirty-six questionnaires were fully completed $(n=36)$, without any detectable difficulties. Only one questionnaire was not sufficiently completed (excluded if greater than $10 \%$ blank). Thus, the questionnaire was deemed to be satisfactory and ready for the full implementation. The test also provided a time estimate of 15 minutes to fully complete a questionnaire.

\section{$\underline{\text { Data Collection }}$}

The first wave of data collection in South Korea was implemented during the Korea World Travel Fair (KOTFA) in June 2005 at the COEX World Trade Center in Seoul, by permission from the COEX Center. Some 80,000 consumers attend this annual show which features travel booths from hundreds of destinations. Student volunteers from Dr. Kim's undergraduate class in tourism were recruited to collect the data. The students were presented a complete overview of the project in English, simultaneously translated into Korean by Dr. Kim. Additionally, students were given a one-page instruction sheet to follow, and all were required to complete the questionnaire to 
facilitate their understanding of the task. The author remained on site throughout the duration of the show to supervise the data collection.

Because of the eight-page length of the questionnaire, and the 15-minute estimated completion time, a location was required at the KOTFA show that would allow for uninterrupted time for respondents. Also, it would be necessary to collect the target of 300 surveys within the two-day timeframe of the show. After observing the flow of consumer traffic, a booth was set up behind the snack bar, an area where consumers taking a break from the show itself were likely to congregate. As consumers sat down in the area, they were approached and offered a small incentive to complete the questionnaire. The gift was a Canada lapel pin, 300 of which were given to the author by the Canadian Tourism Commission office in Seoul for the purposes of this study. The incentive appeared sufficient to encourage respondents to complete a questionnaire. Most were able to complete the questionnaire in 10 to 15 minutes. Students approached every person who entered the snack area, and while the exact number of refusals was difficult to track, it was estimated to be just less than half. The number of questionnaires collected was 310 , with only seven questionnaires having more than $10 \%$ unanswered questions and thus excluded.

For the Canadian data collection, a similar consumer travel show was selected in the major Toronto market. The Toronto Travel and Leisure Show, held at the International Centre in Mississauga, November, 2005, is the biggest consumer travel show in Canada, attracting some 20,000 consumers. A booth was purchased for the show, and located at the end of a row of booths in an attempt to find a relatively quiet location for respondents to sit and complete a questionnaire. Eight chairs where placed around the 
booth table so that eight respondents could sit and complete the questionnaire at the same time. While this arrangement was slightly different from the Korean data collection arrangement, it is not thought to have affected the comparability of the two data sets.

Students from a local university were recruited to collect data, and paid a per diem rate to work from 9:00 A.M. to 4:00 P.M. each of the two days, with a target set of 30 questionnaires per day, per student, to be collected. A thorough training session was provided for the students, and all were required to complete the questionnaire to facilitate their understanding of the task. Again, the author remained on site throughout the duration of the show to supervise the data collection. The Toronto consumers were also offered a small incentive to complete the questionnaire. Completion time ranged from 10 to 15 minutes, as in Seoul, with an average of 11 minutes. The non-response rate was also similar to that at the Seoul show, at just over one-half of those approached. A total of 300 surveys were collected of which 271 were usable, with 29 questionnaires found to be more than $10 \%$ blank and thus excluded.

\subsection{Data Analysis Methodology}

Structural equation modeling (SEM) is used to analyze the theoretical model. SEM has been around since the 1960s, and while common in PCI [Han, 1989; Haubl, 1996; Heslop et al., 2004], its use is extremely limited in TDI research [Bigne et al., 2001; Reisinger and Turner, 1999]. Its rarity, however, has more to do with a lack of structural investigation within the field of TDI than with methodological issues. As a method of analysis, the advantages of SEM include the ability to control for measurement error, simultaneous testing of multiple hypothesized relationships, and more powerful ways to 
assess measure reliability and validity [Mackenzie, 2001]. It is particularly suited to the analysis of latent constructs, where multiple measures are hypothetically related to a single construct, as is the case here. A graphical presentation of the SEM model is shown as Figure 17. An explanation of the model components follows, using standard mathematical notation [Stevens, 2002].

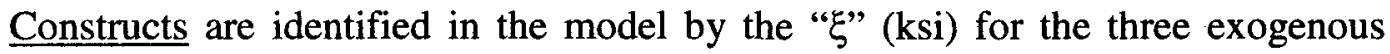
constructs: 1. Cognitive Country Image (CogCI); 2. Product Familiarity (ProdFam); 3. Destination Familiarity (DestFam); and " $\eta$ " (eta) for the five endogenous constructs: 1. Affective Country Image (AffCI); 2. Product Beliefs (ProdBel); 3. Destination Beliefs (DestBel); 4. Product Receptivity (ProdRec); and, 5. Destination Receptivity (DestRec).

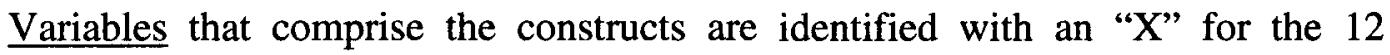
variables linked to the exogenous constructs, and by a "Y" for the 23 variables linked to the endogenous constructs. Each linkage from construct to variable is identified with a " $\lambda$ " (lambda), which represents the loading of a particular variable to its construct. Note that not all $\lambda s$ are included in Figure 17 due to space limitations and for simplicity of presentation.

Measurement error is recognized and accounted for in SEM, as represented by a " $\delta$ " (delta) for the terms associated with $X$ variables, and by " $\varepsilon$ " (epsilon) for the terms associated with $\mathrm{Y}$ variables. Conceptually, every measure has an associated error term, acknowledging that measures are imperfect and thus include some error. However, for 
constructs associated with only a single measure, the model will not be able to estimate measurement error. Thus, the amount of measurement error will be pre-specified to zero before attempting to estimate model parameters.

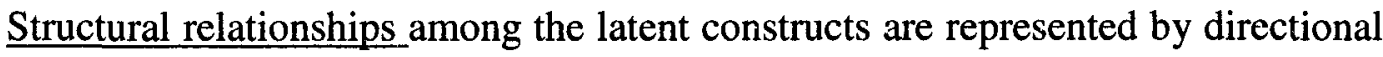
arrows in Figure 17. Parameters representing regression relations between latent constructs are identified by " $\gamma$ " (gamma) for the regression of an endogenous construct, Affective Country Image, on the exogenous construct, Cognitive Country Image. Parameters representing regression of one endogenous construct on another are identified by " $\beta$ " (beta). Note that not all regressions are included in Figure 17 to avoid clutter. To see all hypothesized relationships that will be tested refer back to Figure 16.

Structural error represents less than perfect predictability of endogenous constructs, identified by a " $\zeta$ " (zeta) in Figure 17. The exogenous constructs are allowed to co-vary freely. The covariance is identified by an " $\varphi$ " (phi) for the exogenous constructs.

\section{$\underline{\text { Structural Equation Model analysis }}$}

There are a variety of software computer packages designed for SEM, the three most popular being LISREL, EQS and Amos. Of these, LISREL, developed by Joreskog and Van Thillo in 1972, is by far the most widely used in marketing research [Reisinger and Turner, 1999]. LISREL uses maximum likelihood (ML) techniques, whereby the 
probability of the observed data given the hypothesized model is maximized. If a test model is believed to be theoretically strong, then LISREL is a good option.

\section{Figure 17: Structural Integrated Model of Place Image}

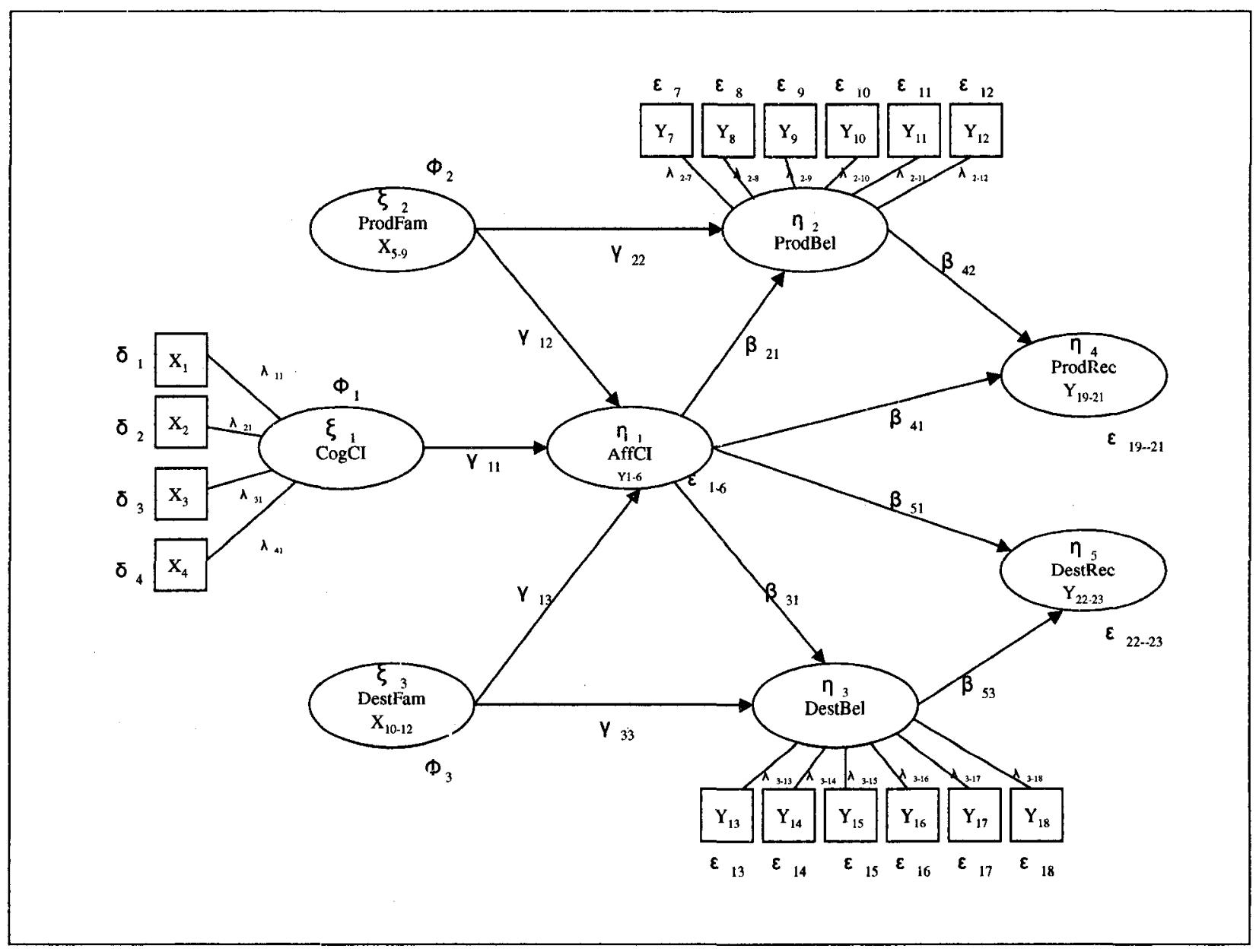

An alternative option considered was Wold's PLS method of partial least squares [Fornell and Bookstein, 1982]. However, only one example of PLS could be found in the TDI literature [Murphy et al., 2000], and only two PCI studies with comparable objectives have used PLS [Heslop et al., 2001, 2004]. As consensus suggests that LISREL is superior for SEM analysis, this method was selected. 
With the method of analysis now identified, more can be said about appropriate sample size. While a range between 100 and 200, is common, a minimum size of 300 is suggested in situations where components have only a few low loadings [Stevens, 2002, p.395], or when the data set is to be divided to test for cross-validation of a model [Reisinger and Turner, 1999]. Therefore, for flexibility in data analysis, a sample of 300 was targeted. All data collected was scrutinized for readability and completeness during the data entry phase, in addition to post-entry analysis. Surveys less than $90 \%$ complete were not included in the path analysis, to avoid data bias due to missing values. Analysis of the study results follows in Chapter Six and Chapter Seven.

The combination of test results sheds much light on the theories postulated in the conceptual model. The relationships between the core constructs of image, beliefs and behaviours are identified, as are new relationships between product and tourism constructs, along with their relative strengths. The findings suggest which image-related variables are important, and which are not; how consumers evaluate products and destinations; and finally, what the image is of Canadian products, and Canada as a travel destination. A final model, supported by the empirical results, is presented for the future study of place image. 


\section{Chapter 6 Data Analysis and Results}

All data from the completed questionnaires (included if $90 \%$ or more of questions complete) were coded and manually entered into the Statistical Package for the Social Sciences program (SPSS version 14.0) by the author: Korean pilot $(n=46)$, the Korean survey ( $n=303)$, the Canadian pilot $(n=36)$ and the Canadian survey $(n=271)$. All 132 scale variable means ( 33 variables $\times 4$ countries $=132$ variables) between the pilot samples and the main samples were compared, and were without any notable significant differences. Thus, the pilots and main surveys for each country were combined, resulting in a Canadian sample of $n=307$ and a Korean sample of $n=349$ which were used in the analysis.

\subsection{Data Preparation}

Several steps were taken to clean and prepare the data for analysis. Blanks in the data base were highlighted and checked against the original questionnaires, and complete sections in which the blank appeared were also checked. In this random way, the accuracy of the entered data was assessed. While the data entry had been extremely time intensive (over 200 hours to code and enter all 656 questionnaires) it was found to be extremely accurate.

In the questionnaire, the positive or negative ends of the 7-point scale items were randomly assigned to the left or right end of the scale to prevent response routinization (e.g., "poor" might be assigned to the right for one scale, i.e. at point "7", but to the left for another, i.e. at point " 1 "). In the SPSS database, all items were coded such that "poor" is always on the left (1) and "good" always on the right (7). 
Variables measured on a nominal scale were coded into dummy, or interval variables. The responses to the open-ended questions were entered verbatim as nominal variables.

To determine how to approach the issue of missing values (coded as 9 in the database), the number of missing values for each variable was recorded. In most cases, the percentage of missing values was low. The average number of missing values was approximately 4.3 , or $1.3 \%$ per data set of $300+$. Before replacing missing values with variable means, the impact of this process was assessed for the variables that had the highest number of missing values. The three summary variables (ideal country, good overall products, good overall destination) had the highest number of missing values at 7\%. The means were compared before and after replacing missing values with variable means, and the differences were negligible (not statistically significantly), as seen in Table 9. All missing values were replaced with variable means in order to have a more complete data set for the higher-level analysis to follow.

\section{Table 9: Comparison of means pre and post replacement of missing values}

\begin{tabular}{|l|l|l|l|l|}
\hline Variable $^{\mathrm{I}}$ & \multicolumn{3}{|l|}{ South Korea } & \multicolumn{2}{l|}{ Canada } \\
\hline & Pre & Post & Pre & Post \\
\hline Ideal country & 5.30 & 5.301 & 3.88 & 3.878 \\
\hline Good overall products & 4.79 & 4.793 & 4.18 & 4.182 \\
\hline Good overall destination & 5.74 & 5.742 & 3.93 & 3.927 \\
\hline
\end{tabular}

Australian results selected for presentation as it was the country with the most missing values

One last step undertaken to prepare the data was to delete the open-ended response columns in each data base, in order to have a more workable file for the 
quantitative analysis to follow. The open-ended results are analyzed separately, in Section 6.3.

\subsection{Descriptive Analysis}

The results of the descriptive analysis are presented in Table 10 to provide a profile of the South Korean and Canadian samples. Overall, about $48 \%$ of the South Korean respondents were male and $52 \%$ female, with a high $73 \%$ having university education. The average number of persons per household was 4 , and average annual household income, converted from Won to Canadian dollars, was approximately $\$ 34,000$. Given that the average per person income in Korea is just over $\$ 20,000$, this might represent one full-time and one part-time wage earner and two children per household, and be considered fairly representative of the population. Notwithstanding the young age of respondents, a good $39 \%$ of the sample was 30 years and older.

Just less than half (49\%) had traveled out of Korea in the last 18 months prior to the survey. The most foreign trips taken were to Japan (30.1\%), and the least to Canada (8.9\%), which is logical, considering the relative travel distances. When asked what played a role in shaping their views of Canada, most $(56.8 \%)$ identified "things learned from the media", and about one-fifth identified "things learned in school" $(24.1 \%)$ and "family roots in Canada" (18.3\%). The media also had the greatest role in shaping their views of the U.S. (68.7\%), Japan (71.9\%) and Australia (58.8\%). 
Table 10: South Korean and Canadian Sample Characteristics (valid percentages)

\begin{tabular}{|c|c|c|c|}
\hline Variable & Category & $\begin{array}{c}\text { South Korea } \\
n=349\end{array}$ & $\begin{array}{c}\text { Canada } \\
\text { n=307 }\end{array}$ \\
\hline \multirow{2}{*}{ Gender } & Male & 48.1 & 47.5 \\
\hline & Female & 51.9 & 52.5 \\
\hline \multirow[t]{6}{*}{ Age } & Less than 20 years & 22.9 & 17.1 \\
\hline & 20 to 29 years old & 38.2 & 21.4 \\
\hline & 30 to 39 years old & 27.0 & 9.9 \\
\hline & 40 to 49 years old & 6.1 & 10.2 \\
\hline & 50 to 59 years old & 3.5 & 15.5 \\
\hline & 60 years or older & 2.3 & 25.9 \\
\hline \multirow[t]{8}{*}{ Education } & No high school & 0 & 1.3 \\
\hline & Some high school & 0.3 & 11.8 \\
\hline & High school graduate & 8.4 & 13.5 \\
\hline & Some college & 0 & 11.5 \\
\hline & College graduate & 0.3 & 12.5 \\
\hline & Some university & 41.9 & 16.8 \\
\hline & University graduate & 32.3 & 30.6 \\
\hline & Other & 16.8 & 2.0 \\
\hline \multirow[t]{6}{*}{ \# of Persons in Household } & 1 & 2.4 & 7.1 \\
\hline & 2 & 5.7 & 40.6 \\
\hline & 3 & 17.0 & 21.4 \\
\hline & 4 & 53.6 & 15.0 \\
\hline & 5 & 15.8 & 9.4 \\
\hline & 6 or more & 5.5 & 6.5 \\
\hline \multirow[t]{6}{*}{ Total Household Income } & Level 1 & 7.4 & 10.6 \\
\hline & Level 2 & 28.7 & 18.7 \\
\hline & Level 3 & 35.8 & 24.2 \\
\hline & Level 4 & 7.7 & 19.0 \\
\hline & Level 5 & 9.0 & 14.7 \\
\hline & Level 6+ & 11.4 & 12.8 \\
\hline \multirow[t]{6}{*}{ \#Foreign Trips(past 18mn) } & 0 & 51.0 & 9.8 \\
\hline & 1 & 24.1 & 8.5 \\
\hline & 2 & 10.0 & 10.4 \\
\hline & 3 & 4.9 & 11.7 \\
\hline & 4 & 3.2 & 31.7 \\
\hline & 5 or more & 6.8 & 27.9 \\
\hline \multirow[t]{8}{*}{ Country Visits (ever) } & U.S. Yes & 17.2 & 85.3 \\
\hline & U.S. No & 82.8 & 14.7 \\
\hline & Japan Yes & 30.1 & 13.7 \\
\hline & Japan No & 69.9 & 86.3 \\
\hline & Australia Yes & 10.3 & 16.6 \\
\hline & Australia No & 89.7 & 83.4 \\
\hline & Canada Yes & 8.9 & $\mathrm{Na}$ \\
\hline & Canada No & 91.1 & $\mathrm{Na}$ \\
\hline
\end{tabular}




\begin{tabular}{|l|l|c|c|}
\hline & South Korea Yes & na & 8.1 \\
\hline & South Korea No & na & 91.9 \\
\hline What shaped views: School & U.S. & 50.7 & 72.4 \\
\hline & Japan & 49.6 & 56.0 \\
\hline & Australia & 24.3 & 44.4 \\
\hline & Canada & 24.1 & $\mathrm{Na}$ \\
\hline & South Korea & na & 30.7 \\
\hline What shaped views: Media & U.S. & 68.7 & 84.6 \\
\hline & Japan & 71.9 & 75.8 \\
\hline & Australia & 58.8 & 67.2 \\
\hline & Canada & 56.8 & $\mathrm{Na}$ \\
\hline & South Korea & na & 56.3 \\
\hline What shaped views: Roots & U.S. & 20.0 & 40.6 \\
\hline & Japan & 14.8 & 5.5 \\
\hline & Australia & 15.9 & 14.7 \\
\hline & Canada & 18.3 & $\mathrm{na}$ \\
\hline & South Korea & na & 2.7 \\
\hline
\end{tabular}

The Canadian sample was also better educated than the broader population, with more than $70 \%$ having some college or university education, but was otherwise quite representative. About $48 \%$ of the respondents were male and $52 \%$ female, most households comprised two or three persons, $45 \%$ of the respondents reported an annual household income over $\$ 75,000$, and the median age of respondents was just over 40 .

The Canadian sample was more likely to have travelled outside their country in the past 18 months, with $60 \%$ having taken four or more trips and only $9.8 \%$ not having travelled out-of-country at all. The sources of influence in shaping country views also differs between samples, in that Canadians identify school as having more of a role than it appears to have for South Koreans, particularly in shaping Canadians' views of the U.S. Like South Koreans, Canadians identify the media as having the greatest influence in shaping their country views, and family roots as having the least influence. Understandably, Canadians have more family ties with the U.S., whereas South Koreans have more family ties with Japan. 
Overall, these are very good samples for the purposes of this study, given that relatively higher educated and younger individuals are more likely to reflect the views of opinion leaders, and typically know more about and have a greater interest in travel and foreign products.

\subsection{Analysis of Open Ended Data Results}

To further explore the complexities of place image, responses were captured to open-ended questions regarding top-of-mind characteristics related to each country's general country image, product-country image and tourism destination image. The responses to the three questions are summarized in the tables that follow. For each question, respondents were given three blank lines to fill in for each country. Therefore, a total of 12,564 and 11,052 responses were possible from the South Korean and Canadian samples respectively ( 3 lines $\times 3$ questions $x 4$ countries x 349 South Korean and 307 Canadian respondents).

While many lines were left blank $(14,187$ lines or $60 \%), 9,429$ lines were completed, providing a rich set of responses for analysis. As seen in Table 11, the Canadian sample completion rate was higher than the Korean rate ( $46.3 \%$ versus $34.3 \%)$, and the overall completion rate was an acceptable $40 \%$. Also of note, the completion rate is highest for General Country Image (52.1\%), and the number of completions decreases significantly for the next two questions. Next, the categorized responses are summarized in Tables 12, 13 and 14, with the most common categories highlighted in each table in order to illustrate relative strengths and weaknesses. 
Table 11: Comparison of Completion Rates for the Open-ended Questions

\begin{tabular}{|l|r|r|r|r|}
\hline Question & South Korea & \multicolumn{1}{c|}{ Canada } & \multicolumn{1}{c|}{ Total } & Completion \\
\hline 1. General Country Image & 2,001 & 2,104 & 4,105 & $52.1 \%$ \\
\hline 2. Product Country Image & 995 & 1,567 & 2,562 & $32.5 \%$ \\
\hline 3. Tourism Destination Image & 1,314 & 1,448 & 2,762 & $35.1 \%$ \\
\hline Number of responses & 4,310 & 5,119 & 9,429 & $40.0 \%$ \\
\hline Total potential responses & 12,564 & 11,052 & 23,616 & \\
\hline Completion rate & $\mathbf{3 4 . 3 \%}$ & $\mathbf{4 6 . 3 \%}$ & $\mathbf{4 0 . 0 \%}$ & \\
\hline
\end{tabular}

To begin, Table 12 summarizes the responses to the question "what images or characteristics come to mind when you think of these countries?" In terms of the total responses received by country, a reflection of familiarity is that South Koreans provide the most number of responses for Japan (575) and the least number for Canada (401), whereas Canadians provide the most number of responses for the U.S. (624), and, the least number of responses for South Korea (346). Logically, the closer the country, the more familiar it is, or perhaps, the more comfortable the respondent is in responding.

Interestingly, too, it is these close neighbours that attract the most positive and negative responses. South Koreans say almost as many negative things about Japan (110) as positive (123). Likewise, Canadians say the most negative things about the U.S. (108), but also many positive things (156). In addition to general, descriptive words (e.g. clean, kind, crowded), Japan also received many responses in the Industry/Product category, particularly from Canadians (182), who strongly associated "technology" with Japan.

In all country cases, in response to General Country Image, respondents overwhelmingly provide generic mentions $(85.6 \%)$ versus specific brands, places or persons (14.4\%). Comparatively, the U.S. received the most specific mentions (23.9\%), while South Korea received the least $(6.4 \%)$. 
Table 12: "What images come to mind when you think of these countries?"1

\begin{tabular}{|l|c|c|c|c|c|c|c|c|}
\hline & South Korea & \multicolumn{2}{l|}{ Canada } \\
\hline & US & JP & AU & CA & US & JP & AU & SK \\
\hline Positive & 162 & 123 & 73 & 97 & 156 & 118 & 129 & 57 \\
Descriptor & $28.5 \%$ & $21.4 \%$ & $16.1 \%$ & $24.2 \%$ & $25.0 \%$ & $21.1 \%$ & $22.6 \%$ & $16.5 \%$ \\
\hline Negative & 84 & 110 & 6 & 11 & 108 & 85 & 10 & 85 \\
Descriptor & $14.8 \%$ & $19.1 \%$ & $1.3 \%$ & $2.7 \%$ & $17.3 \%$ & $15.2 \%$ & $1.8 \%$ & $24.6 \%$ \\
\hline Geographic & 55 & 63 & 40 & 37 & 69 & 24 & 26 & 10 \\
Places & $9.7 \%$ & $11.0 \%$ & $8.8 \%$ & $9.2 \%$ & $11.1 \%$ & $4.3 \%$ & $4.6 \%$ & $2.9 \%$ \\
\hline Natural & 26 & 89 & 261 & 150 & 66 & 102 & 302 & 61 \\
Features & $4.6 \%$ & $15.5 \%$ & $57.6 \%$ & $37.4 \%$ & $10.6 \%$ & $18.2 \%$ & $52.9 \%$ & $17.6 \%$ \\
\hline Man-made & 44 & 19 & 21 & 17 & 63 & 21 & 11 & 9 \\
Features & $7.7 \%$ & $3.3 \%$ & $4.6 \%$ & $4.2 \%$ & $10.1 \%$ & $3.8 \%$ & $1.9 \%$ & $2.6 \%$ \\
\hline Military & 63 & 28 & 0 & 0 & 24 & 5 & 0 & 21 \\
Related & $11.1 \%$ & $4.9 \%$ & & & $3.8 \%$ & $0.9 \%$ & & $6.1 \%$ \\
\hline Industry & 56 & 99 & 26 & 41 & 74 & 182 & 35 & 69 \\
Related & $9.9 \%$ & $17.2 \%$ & $5.7 \%$ & $10.2 \%$ & $11.9 \%$ & $32.5 \%$ & $6.1 \%$ & $19.9 \%$ \\
\hline Resource & 1 & 1 & 15 & 7 & 3 & 2 & 10 & 7 \\
\& Agr. & $0.2 \%$ & $0.2 \%$ & $3.3 \%$ & $1.7 \%$ & $0.5 \%$ & $0.4 \%$ & $1.8 \%$ & $2.0 \%$ \\
\hline Sport & 12 & 15 & 2 & 24 & 12 & 4 & 22 & 7 \\
Related & $2.1 \%$ & $2.6 \%$ & $0.4 \%$ & $6.0 \%$ & $1.9 \%$ & $0.7 \%$ & $3.9 \%$ & $2.0 \%$ \\
\hline Known & 39 & 9 & 2 & 4 & 23 & 0 & 7 & 0 \\
Person & $6.9 \%$ & $1.6 \%$ & $0.4 \%$ & $1.0 \%$ & $3.7 \%$ & & $1.2 \%$ & \\
\hline Other & 26 & 19 & 7 & 13 & 26 & 17 & 19 & 20 \\
& $4.6 \%$ & $3.3 \%$ & $1.5 \%$ & $3.2 \%$ & $4.2 \%$ & $3.0 \%$ & $3.3 \%$ & $5.8 \%$ \\
\hline Total & 568 & 575 & 453 & 401 & 624 & 560 & 571 & 346 \\
\hline Generic & 413 & 480 & 408 & 361 & 486 & 520 & 523 & 322 \\
& $73.0 \%$ & $83.9 \%$ & $90.1 \%$ & $90.5 \%$ & $78.6 \%$ & $93.2 \%$ & $91.6 \%$ & $93.6 \%$ \\
\hline Specific & 153 & 92 & 45 & 38 & 132 & 38 & 48 & 22 \\
& $27.0 \%$ & $16.1 \%$ & $9.9 \%$ & $9.5 \%$ & $21.4 \%$ & $6.8 \%$ & $8.4 \%$ & $6.4 \%$ \\
\hline
\end{tabular}

${ }^{\mathrm{I}}$ Frequencies and percentages based on total open-ended responses

Table 13 summarizes the responses to the question "what products come to mind when you think of these countries?" In total, across the countries, 2,562 responses were received, representing about one-third (32.5\%) of the total potential number of responses. 
Table 13: "What products come to mind when you think of these countries?" 1

\begin{tabular}{|l|c|c|c|c|c|c|c|c|}
\hline & \multicolumn{3}{|l}{ South Korea } & \multicolumn{3}{l|}{ Canada } \\
\hline & US & JP & AU & CA & US & JP & AU & SK \\
\hline Natural & 1 & 0 & 3 & 6 & 6 & 2 & 4 & 1 \\
Resources & $0.2 \%$ & & $9.1 \%$ & $15.4 \%$ & $1.1 \%$ & $0.4 \%$ & $1.4 \%$ & $0.4 \%$ \\
\hline Food \& & 35 & 3 & 2 & 4 & 52 & 28 & 69 & 13 \\
Beverage & $8.4 \%$ & $0.6 \%$ & $6.1 \%$ & $10.3 \%$ & $9.8 \%$ & $5.7 \%$ & $25.0 \%$ & $4.9 \%$ \\
\hline Clothing \& & 113 & 11 & 1 & 9 & 80 & 17 & 36 & 30 \\
Related & $27.0 \%$ & $2.2 \%$ & $3.0 \%$ & $23.1 \%$ & $15.1 \%$ & $3.4 \%$ & $13.0 \%$ & $11.2 \%$ \\
\hline Household & 37 & 27 & 1 & 1 & 27 & 4 & 21 & 1 \\
Goods & $8.9 \%$ & $5.4 \%$ & $3.0 \%$ & $2.6 \%$ & $5.1 \%$ & $0.8 \%$ & $7.6 \%$ & $0.4 \%$ \\
\hline Entertain- & 12 & 319 & 1 & 1 & 34 & 219 & 41 & 73 \\
ment & $2.9 \%$ & $63.5 \%$ & $3.0 \%$ & $2.6 \%$ & $6.4 \%$ & $44.4 \%$ & $14.9 \%$ & $27.2 \%$ \\
\hline Transporta- & 65 & 103 & 1 & 0 & 144 & 165 & 7 & 91 \\
tion & $15.6 \%$ & $20.5 \%$ & $3.0 \%$ & & $27.2 \%$ & $33.5 \%$ & $2.5 \%$ & $34.0 \%$ \\
\hline Advanced & 75 & 13 & 0 & 1 & 49 & 36 & 1 & 23 \\
Technology & $17.9 \%$ & $2.6 \%$ & & $2.6 \%$ & $9.2 \%$ & $7.3 \%$ & $0.4 \%$ & $8.6 \%$ \\
\hline Other & 0 & 8 & 0 & 0 & 16 & 3 & 2 & 5 \\
Industry & & $1.6 \%$ & & & $3.0 \%$ & $0.6 \%$ & $0.7 \%$ & $2.2 \%$ \\
\hline Services & 75 & 10 & 9 & 8 & 88 & 8 & 35 & 12 \\
$\&$ Misc. & $17.9 \%$ & $2.0 \%$ & $27.3 \%$ & $20.5 \%$ & $16.6 \%$ & $1.6 \%$ & $12.7 \%$ & $4.5 \%$ \\
\hline Agriculture & 2 & 0 & 14 & 7 & 11 & 4 & 48 & 4 \\
$\&$ Fish & $0.5 \%$ & & $42.4 \%$ & $17.9 \%$ & $2.1 \%$ & $0.8 \%$ & $17.4 \%$ & $1.5 \%$ \\
\hline Other & 3 & 8 & 1 & 2 & 23 & 7 & 12 & 14 \\
& $0.7 \%$ & $1.6 \%$ & $3.0 \%$ & $5.1 \%$ & $4.3 \%$ & $1.4 \%$ & $4.3 \%$ & $5.2 \%$ \\
\hline Total & 418 & 502 & 33 & 39 & 530 & 493 & 276 & 268 \\
\hline Generic & 32 & 49 & 25 & 27 & 300 & 306 & 233 & 178 \\
& $7.7 \%$ & $9.8 \%$ & $75.8 \%$ & $69.2 \%$ & $57.1 \%$ & $62.4 \%$ & $85.3 \%$ & $66.4 \%$ \\
\hline Specific & 386 & 452 & 8 & 12 & 225 & 184 & 40 & 90 \\
& $92.3 \%$ & $90.2 \%$ & $24.2 \%$ & $30.8 \%$ & $42.9 \%$ & $37.6 \%$ & $14.7 \%$ & $33.6 \%$ \\
\hline
\end{tabular}

${ }^{\mathrm{T}}$ Frequencies and percentages based on open-ended responses

The drop in completion rate from General Country Image to PCI is due largely to the very small number of responses given by South Koreans for both Australia (33) and Canada (39). On the contrary, both South Koreans and Canadians give many PCI responses for Japan (502 and 493 respectively). Interestingly, 90\% of South Koreans' PCI responses for Japan are specific brand mentions, possibly reflecting a relatively higher degree of product familiarity. However, this may also be explained by a greater 
likelihood for South Koreans to recall specific brands versus generic products, as they do so for the U.S. as well $(92.3 \%)$. By comparison, the number of brand mentions Canadians provide for the U.S. is $42.9 \%$. Yet, Canadians are very familiar with U.S. products. This suggests a cultural tendency toward brand versus generic product recall that will be explored further as the analysis continues.

Table 13 also highlights differences in the top categories by country. South Koreans are most likely to mention U.S. clothing and Japanese electronics (in the entertainment category), whereas Canadians are more likely to mention cars for both the U.S. and Japan, as well as electronics for Japan.

To further explore Country Image, Table 14 summarizes the responses to the question "what tourism characteristics come to mind when you think of these countries?" In total, across the countries, 2,762 responses were received, representing just over onethird of the potential number of responses (35.1\%).

Here, the number of responses goes down across all countries in comparison to the number of General Country Image responses. However, the drop is more evenly distributed then it was for PCI responses. Again, Canada and South Korea received the fewest number of responses (196 and 141 respectively) and South Korea gave the highest number of responses to Japan (443); Canadians gave the highest number of responses to the U.S. (542).

In all country cases except for Canadians' responses for Australia, the mention of a specific geographic place is the most common category, particularly for the U.S. and Japan. The U.S. also received a large number of responses in the Attractions category; while Australia's TDI strength is in the Nature category. 
Table 14: "What tourism characteristics come to mind when you think of these countries?"1

\begin{tabular}{|l|c|c|c|c|c|c|c|c|}
\hline & \multicolumn{9}{|l|}{ South Korea } & \multicolumn{1}{l|}{ Canada } \\
\hline & US & JP & AU & CA & US & JP & AU & SK \\
\hline Geographic & 277 & 288 & 144 & 148 & 203 & 104 & 100 & 33 \\
Places & $65.0 \%$ & $65.0 \%$ & $57.8 \%$ & $75.5 \%$ & $37.5 \%$ & $29.7 \%$ & $24.1 \%$ & $23.4 \%$ \\
\hline Attractions & 140 & 139 & 54 & 8 & 200 & 79 & 60 & 21 \\
& $32.9 \%$ & $31.4 \%$ & $21.7 \%$ & $4.1 \%$ & $36.9 \%$ & $22.6 \%$ & $14.5 \%$ & $14.9 \%$ \\
\hline Nature & 0 & 5 & 43 & 21 & 67 & 81 & 194 & 36 \\
Related & & $1.1 \%$ & $17.3 \%$ & $10.7 \%$ & $12.4 \%$ & $23.1 \%$ & $46.7 \%$ & $25.5 \%$ \\
\hline Activity & 0 & 0 & 0 & 0 & 14 & 13 & 18 & 7 \\
& & & & & $2.6 \%$ & $3.7 \%$ & $4.3 \%$ & $5.0 \%$ \\
\hline $\begin{array}{l}\text { Sport } \\
\text { Related }\end{array}$ & 0 & 1 & 3 & 12 & 14 & 3 & 14 & 1 \\
\hline Accommoda- & 0 & $0.2 \%$ & $1.2 \%$ & $6.1 \%$ & $2.6 \%$ & $0.9 \%$ & $3.4 \%$ & $0.7 \%$ \\
\hline tion & & 0 & 1 & 3 & 2 & 0 & 1 \\
\hline Food \& & 0 & 2 & 0 & 0 & 4 & 17 & 6 & 9 \\
Beverage & & $0.5 \%$ & & & $0.7 \%$ & $4.9 \%$ & $1.4 \%$ & $6.4 \%$ \\
\hline Other & 9 & 8 & 5 & 6 & 37 & 51 & 23 & 33 \\
& $2.1 \%$ & $1.8 \%$ & $2.0 \%$ & $3.1 \%$ & $6.8 \%$ & $14.6 \%$ & $5.5 \%$ & $23.4 \%$ \\
\hline Total & 426 & 443 & 249 & 196 & 542 & 350 & 415 & 141 \\
\hline Generic & 12 & 82 & 53 & 36 & 168 & 210 & 261 & 101 \\
& $2.8 \%$ & $18.6 \%$ & $21.5 \%$ & $18.6 \%$ & $31.1 \%$ & $60.9 \%$ & $63.2 \%$ & $72.1 \%$ \\
\hline Specific & 410 & 360 & 194 & 158 & 372 & 135 & 152 & 39 \\
& $97.2 \%$ & $81.4 \%$ & $78.5 \%$ & $81.4 \%$ & $68.9 \%$ & $39.1 \%$ & $36.8 \%$ & $27.9 \%$ \\
\hline
\end{tabular}

${ }^{\mathrm{I}}$ Frequencies and percentages based on open-ended responses

There is also a discernable difference in type of TDI response, with South Korea again providing specific place or attraction names (e.g. Mt. Fuji, Tokyo), while Canadians are more likely to provide generic features (e.g. mountains, temples).

In sum, the varying pattern of responses seems to suggest differences in both respondents' level of association (e.g. South Koreans more likely to think brand than Canadians), as well as a difference in content, or category of association (e.g. Japan received more industry responses; Australia received more tourism responses). These differences will be explored further in the following analysis of the results by country. 


\subsubsection{The U.S. Image}

South Koreans view the U.S. quite positively, with almost twice as many positive descriptors (162) than negative (84). The top responses associated with the U.S. are "strong" (31), "big" (18), "rich" (17), and "free" (16). Canadians also view the U.S. positively, and use some similar descriptors, such as "big" (15), and "rich" (12), as well as more people descriptors, such as "friendly" (18), and "fun" (13).

In terms of PCI, the category of U.S. strength differs by sample. South Koreans' top responses fall in the Clothing category, particularly the Nike brand (67), as well as several other clothing brand mentions, including, Calvin Kline, Levis, Polo and DKNY (20 in total). For Canadians, it is the American car that tops the response list, with 69 mentions for "car/auto" in general, as well as frequent brand mentions for GM (25) and Ford (21). Strikingly, South Koreans are much more likely to mention U.S. brands ( $92.3 \%$ of product mentions), compared to only $42.9 \%$ brand mentions by Canadians.

Table 15: U.S. Image Responses

\begin{tabular}{|l|r|r|}
\hline U.S. image responses: & South Korea & \multicolumn{1}{c|}{ Canada } \\
\hline 1. General Country Image & 568 & 624 \\
\hline 2. Product Country Image & 418 & 530 \\
\hline 3. Tourism Destination Image & 426 & 542 \\
\hline Number of responses & 1,412 & 1,696 \\
\hline Total potential responses & 3,147 & 2,763 \\
\hline Response rate & $\mathbf{4 5 . 0 \%}$ & $\mathbf{6 1 . 4 \%}$ \\
\hline
\end{tabular}

This tendency can also be seen in South Koreans' TDI mentions of specific place names and attractions, with "New York" (67), "Las Vegas" (63), "The Grand Canyon" (59) and "Disney" (39) topping the list. Canadians geographic responses are much the same: "New York" (52), "Las Vegas" (27), "Disney" (68) and "The Grand Canyon" (32), with "Florida" added to the list (31). Yet, while South Koreans make no mention of 
Americas' nature, activities, sports, accommodations, nor food and beverage, Canadians are more likely to mention general features, such as "beach" (19), and other attractions. Not surprisingly, Canadians are much more familiar with their southern neighbour, and the difference is greater as respondents move from General Image to PCI and TDI, shown in Table 15.

\subsubsection{Japan's Image}

Both South Koreans and Canadians provide many positive descriptors for Japan (123 and 118 respectively). South Koreans describe Japan as "clean" (25), an "economic strength/power" (14), and "rich" (12). Canadians use more personal words to describe Japan as "polite" (13) and "reserved/reliable/respectful" (8).

Both samples indicated a high number of negatives, too. Here, South Koreans are very personal, using strong insults such as "double-faced", and "mean". Canadians focus more on the impersonal, such as, "busy cities", "crowds", and "expensive". This may partially be explained by cultural differences in that, reflective of South Koreans' collectivistic nature, they are more likely to attribute positives to the group and negatives to the individual, whereas Canadians' more individualistic nature tends to the opposite: praise the individual, and criticize the group.

Another strength for Japan is the Industry/Product category, as was seen in Table 14 and 15. The strength is bolstered by responses in two categories: Entertainment (538) and Transportation (268). The Entertainment category contains the number one brand mention of the entire study, "Sony", with 224 mentions by South Koreans, and 55 by Canadians. South Koreans were also more likely to mention other brands, such as 
"Panasonic" (21), "Nikon" (16), and "Sanyo" (13). Canadians, by contrast, were more likely to identify generic product categories, such as "electronics" (50), "TVs" (22) and "cameras "(14).

Similarly in the Transportation category, Canadians' most common response is "auto/car" (78), whereas South Koreans' most common response is "Toyota" (52). While Canadians do also mention brands: "Honda" (36), "Toyota" (35); only three South Koreans mention "car"!

In TDI, Japan's strengths are also found in two categories: Geographical Place and Attractions. Tokyo is the top mentioned Geographical Place of the study, with 94 responses from South Koreans, and 69 from Canadians. South Koreans mention many other cities, such as, "Osaka" (42), "Hokaido" (25), and "Sapporo" (15), as well as specific attractions, including, "hot spas" (64), and "Mt. Fuji" (40), reflecting not only a higher familiarity than Canadians, who more commonly mention generic features, such as "mountains" (17), "scenery" (13) and "temples" (11), but perhaps a greater cultural tendency to recall more specific than generic country associations.

\subsubsection{Australia's Image}

Australia's image strength is clearly its nature. In response to the General Country Image question, Australia received the highest number of responses of any category for Natural Features (57.6\%), with 261 South Korean responses and 302 Canadian responses.

Notably, Australia received very few negative comments (16) and many more positives (202). South Koreans describe Australia as "big" (17) and "clean" (13). 
Canadians describe Australia as "friendly" (40) and "fun" (12), again responding more personally with the positives.

Clearly, Australia's top association is the kangaroo, mentioned 100 times by South Koreans and 53 times by Canadians, making it the number one natural feature of the study. The perhaps more elusive koala followed behind with 52 combined responses.

Australia's weakness is in PCI, with only 33 responses by South Koreans (and 1,014 , or $96.8 \%$ blanks). Canadians' knowledge is significantly higher, with 276 responses, the highest number of responses being in the Food and Beverage category. In line with Canadians view of "fun Aussies", top responses are for "wine" (23) and "beer/Fosters" (26), as well as "sheep/wool/lamb" (30) in the Agriculture category.

In response to TDI, Geographic Places are commonly mentioned by both South Koreans and Canadians, with "Sydney" at the top (92 and 56 responses respectively), second only to Tokyo, but first if the mentions for the "Sydney Opera House" are considered (49 and 19 responses respectively). To balance this strong, urban attraction is the Australian "outback", identified by 44 Canadians, along with "beaches" (26) and “scenery" (11).

\subsubsection{Canada's Image}

The pattern of Canada's image is most similar to that of Australia's, with Natural Features the strength of its General Country Image, and very few negative descriptors (11), as compared to positives (97). South Koreans describe Canada as "big" (19) and "beautiful" (14), "clean" (21) and "calm/relaxed/peaceful" (17). Top Natural Features are the "maple" (25), waterfalls, specifically "Niagara" (34), followed by "snow/winter" 
(18). And, like Australia, Canada's weakness is its PCI, with only 39 responses and 1,008 (96.3\%) blanks. "Roots Canada" received the most mentions, at 8 , with the rest of the responses scattered through the Natural Resources category (e.g. "wood"), and the Agriculture category (e.g. "beef").

Canada's TDI is not much more encouraging, with 196 responses ( $81.3 \%$ blank). The only category of noteworthy size is Geographical Place, with 148 responses, or three-quarters of the total. Topping the list is "Vancouver" (41), "Niagara" (37), and "Toronto" (19).

The next most common category, Positive Adjective, follows this nature theme with responses such as clean and big, as do the other categories. Table 16 presents a summary of the responses to the open-ended question related to Canadian images or characteristics. The most common place mention is Niagara Falls, the most common sports represent the winter (e.g. ski, hockey), and even the most common man-made feature to be mentioned - the Canadian flag - can be linked back symbolically to the maple leaf. Of note is the overwhelmingly positive tone of the responses.

Table 16: "What images or characteristics come to mind when you think of Canada?"

\begin{tabular}{|l|c|l|}
\hline Category & Percent of responses & \\
\hline Natural feature & $37.4 \%$ & Most common mentions \\
\hline Positive adjective & $24.2 \%$ & nature, maple \\
\hline Industry & $10.2 \%$ & clean, big, peaceful \\
\hline Geographic place & $9.2 \%$ & Niagara education, Vancouver, Toronto \\
\hline Sport related & $6.0 \%$ & ski, hockey \\
\hline Man-made feature & $4.2 \%$ & Canadian flag \\
\hline
\end{tabular}

${ }^{1}$ Percent is based on total number of responses (401). 


\subsubsection{South Korea's Image}

The Canadian sample provided 346 responses to describe South Korea's General Country Image, reflecting a lesser degree of familiarity than with the other subject countries. Unfortunately, the most common mentions are negative descriptors (85) making South Korea the only country to receive more negative descriptors than positive. Topping the negative list are "crowded" (18), "poor" (7), and "polluted" (7).

Yet like Japan's image, responses to South Korea's PCI (268), are higher than for its TDI (141). Its strongest category is Transportation, carried by responses for "cars" (32), as well as specific brand names, such as "Hyundai" (27) and "Kia" (16), reflecting Canadians' knowledge of South Korean car brands. "Electronics" (21) are another common response, along with a few responses for "LG" (7), "Daewoo" (6), and others scattered across the Entertainment category (e.g. "DVD", "TV", and "video game" mentions).

South Korea's TDI is relatively week, with only 141 responses and 780 (84.7\%) blanks. The only notable mention is for Seoul, with 30 responses. Most other mentions represent single-item responses spread out across categories, suggesting low knowledge of what South Korea has to offer tourists.

\subsection{Across Country Comparison of Means}

The next stage of analysis interprets the results of the scaled questions that formed the bulk of the survey instrument. Appendix E presents the statistical results for all variables, including means, standard deviations, mean standard errors, as well as skewness and kurtosis statistics. In all, there are 140 variables per sample, comprised of 
33 scale variables per country of analysis, plus 2 non-scale variables (Total number of trips, and Country information from school/media/family roots), for a total of 280 variables ( 35 variables $\mathrm{x} 4$ countries $\mathrm{x} 2$ samples).

Table 17 summarizes the means for all 35 variables by dimension, including average dimension scores to highlight relative strengths and weaknesses by country.

Examining the standard deviations listed in Appendix E reveals high variation for a number of variables. By country evaluated, the most variance is for Japan, where both South Korean and Canadian mean responses have the largest standard deviations, followed by the U.S. Mean responses for Australia have the least variance in both samples. By type of variable, country-related measures are most varied, with standard deviations above 1.7 for pleasant, trustworthy, and ideal country. Overall, the Korean sample is more homogeneous, which corresponds with the more homogeneous population, as described earlier in terms of its sociodemographics. The Canadian sample is more variable, particularly for the product-related variables ownership pride, product knowledge, and brand. However, the variable with the highest variance overall is willingness to travel, with a standard deviation greater than 1.5 in 6 out of the 8 cases.

Pair-wise T-tests were undertaken to assess the significance of the mean differences across the evaluated countries. Appendix F presents all comparisons, whereby the U.S. was paired with each of the other three countries for each sample, producing a total of six pair-wise comparisons for all 33 scale variables. The South Korean sample pairings are: US-Japan, US-Australia and US-Canada. The Canadian sample pairings are: US-Japan, US-Australia and US-South Korea. 
Table 17: Mean Scores for all Variables by Study Sample and Dimension*

\begin{tabular}{|c|c|c|c|c|c|c|c|c|}
\hline & SK-US & SK-JP & SK-AU & SK-CA & CA-US & CA-JP & CA-AU & CA-SK \\
\hline \multicolumn{9}{|c|}{ Cognitive Country Image } \\
\hline Quality of life & 5.671 & 5.273 & 5.391 & $5.556^{*}$ & 5.539 & 5.180 & $5.609^{*}$ & 4.070 \\
\hline Wealth & 5.580 & 5.348 & 5.105 & 5.223 & 5.063 & $4.951^{*}$ & 4.811 & 3.930 \\
\hline Technology level & 5.587 & $5.682 *$ & 4.630 & 4.788 & 5.582 & 5.931 & 4.498 & 4.822 \\
\hline Education & 5.041 & $4.977^{*}$ & $4.918^{*}$ & $5.049^{*}$ & 4.646 & 5.631 & $4.820^{*}$ & $4.552 *$ \\
\hline Average score & 5.47 & 5.32 & 5.01 & 5.16 & 5.208 & 5.423 & 4.935 & 4.344 \\
\hline \multicolumn{9}{|c|}{ Affective Country Image } \\
\hline Pleasant & 4.785 & 4.075 & 5.413 & 5.430 & 5.016 & $5.098 *$ & 5.699 & 4.305 \\
\hline Exciting & 5.076 & 4.458 & $4.979^{*}$ & 4.794 & 4.765 & $4.602 *$ & 5.257 & 3.993 \\
\hline Friendly & 4.171 & $4.026^{*}$ & 4.785 & 4.742 & 4.719 & $4.987 *$ & 5.379 & $4.517^{*}$ \\
\hline Safety & 3.359 & 4.504 & 5.009 & 5.206 & 3.941 & 5.124 & 5.082 & $4.157^{*}$ \\
\hline Trustworthy & 3.928 & 3.503 & 4.754 & 4.919 & 4.275 & 4.921 & 5.078 & $4.340^{*}$ \\
\hline Ideal country & 4.493 & 4.069 & 5.301 & 5.295 & 5.062 & 4.745 & 5.567 & 3.878 \\
\hline Average score & 4.30 & 4.11 & 5.04 & 5.07 & 4.630 & 4.913 & 5.534 & 4.198 \\
\hline \multicolumn{9}{|l|}{ Product Beliefs } \\
\hline Quality & 5.322 & 5.787 & 4.655 & 4.727 & 5.160 & 5.655 & 4.735 & 4.487 \\
\hline Reliability & 4.765 & 5.233 & 4.431 & 4.466 & 4.993 & 5.291 & 4.558 & 4.497 \\
\hline Workmanship & 5.224 & 5.491 & 4.217 & 4.415 & 4.752 & 5.206 & 4.385 & 4.241 \\
\hline Innovativeness & 5.078 & 5.429 & 4.105 & 4.224 & 5.114 & 5.380 & 4.137 & 4.146 \\
\hline Value for money & 4.826 & 5.149 & 4.127 & 4.238 & 4.886 & $5.107^{*}$ & 4.286 & 4.368 \\
\hline Good overall & 5.240 & 5.641 & 4.793 & 4.696 & 5.428 & $5.500^{*}$ & 4.990 & 4.182 \\
\hline Average score & 5.076 & 5.455 & 4.388 & 4.461 & 5.056 & 5.357 & 4.515 & 4.320 \\
\hline \multicolumn{9}{|l|}{ Destination Beliefs } \\
\hline Appealing scenery & 5.588 & 5.225 & 5.988 & 5.870 & 5.783 & $5.542 *$ & 6.030 & 4.817 \\
\hline Accommodations & 4.779 & $4.598^{*}$ & 4.525 & 4.464 & 5.569 & 4.868 & 5.229 & 4.123 \\
\hline Quality attractions & 5.321 & 5.075 & 5.657 & 5.597 & 5.470 & 4.791 & $5.213^{*}$ & 4.187 \\
\hline Range of activities & 5.457 & 5.170 & 5.664 & $5.411^{*}$ & 5.905 & 5.158 & 5.421 & 4.383 \\
\hline Value for money & 5.957 & 5.692 & 5.348 & 5.218 & 5.209 & 4.316 & 4.860 & 4.197 \\
\hline Good tourism dest. & 5.455 & 5.154 & 5.742 & $5.506^{*}$ & 5.660 & 5.034 & $5.810^{*}$ & 3.927 \\
\hline Average score & 5.43 & 5.15 & 5.49 & 5.36 & \begin{tabular}{|l|}
5.599 \\
\end{tabular} & 4.952 & 5.427 & 4.272 \\
\hline \multicolumn{9}{|l|}{ Product Familiarity } \\
\hline Product knowledge & 4.256 & 4.724 & 3.118 & 3.084 & 4.788 & 4.369 & 2.815 & 3.258 \\
\hline Brand recognition & 5.418 & $5.579 *$ & 3.702 & 3.789 & 5.837 & 5.182 & 3.569 & 3.970 \\
\hline Use & 4.816 & 5.213 & 3.206 & 2.997 & 5.245 & 4.633 & 3.037 & 3.505 \\
\hline Ease to find & 5.206 & 5.555 & 3.086 & 2.866 & 5.199 & $5.036^{*}$ & 2.814 & 3.990 \\
\hline Satisfaction & 4.410 & 4.910 & 3.985 & 4.068 & 5.030 & $5.043^{*}$ & 4.383 & 4.253 \\
\hline Average score & 4.821 & 5.196 & 3.419 & 3.361 & 5.219 & 4.853 & $\mathbf{3 . 3 2 4}$ & 3.795 \\
\hline \multicolumn{9}{|c|}{ Destination Familiarity } \\
\hline Country knowledge & 3.500 & 4.075 & 3.258 & 3.116 & 5.046 & 3.620 & 3.875 & 3.052 \\
\hline Trips to country & 1.280 & 1.620 & 1.130 & 1.130 & 3.445 & 1.140 & 1.166 & 1.063 \\
\hline Media, school, roots & 3.788 & 3.725 & 2.983 & 2.983 & 4.952 & 3.744 & 3.526 & 2.795 \\
\hline Average score & 2.856 & 3.140 & 2.457 & 2.410 & 4.481 & 2.835 & 2.856 & 2.303 \\
\hline \multicolumn{9}{|l|}{ Product Receptivity } \\
\hline Ownership pride & 3.296 & $3.348^{*}$ & 3.751 & 3.824 & 4.121 & $4.297 *$ & 4.553 & $4.007^{*}$ \\
\hline Open to imports & 3.677 & $3.499^{*}$ & 4.224 & 4.275 & 4.354 & 4.434* & 4.886 & $4.207^{*}$ \\
\hline Willing to buy & 4.301 & $4.484^{*}$ & 3.929 & $4.107 *$ & 5.382 & $5.332^{*}$ & 5.053 & 4.521 \\
\hline Average score & $\mathbf{3 . 7 5 8}$ & $\mathbf{3 . 7 7 7}$ & 3.968 & 4.069 & 4.619 & 4.688 & 4.831 & 4.245 \\
\hline \multicolumn{9}{|c|}{ Destination Receptivity } \\
\hline Closer ties & 5.040 & 4.533 & $4.855^{*}$ & $4.939 *$ & $4.5 \overline{41}$ & $4.538^{*}$ & 4.892 & $4.246^{*}$ \\
\hline Willing to travel & 5.118 & $5.089 *$ & 5.519 & 5.384 & 5.918 & 5.253 & $5.728 *$ & 4.373 \\
\hline Average score & 5.079 & 4.811 & 5.187 & 5.162 & 5.230 & 4.896 & 5.310 & 4.310 \\
\hline
\end{tabular}

*Indicates non-significant difference from mean for U.S. (p>.01) at $95 \%$ confidence interval 
Overall, $\mathrm{T}$ values are significant for more than three-quarters of the pair wise comparisons $(78 \%)$, meaning that the majority of mean scores are significantly different at the 0.01 level ( 155 significant; 43 non-significant; total 198). Of the remaining $22 \%$ of pairings whose means are not significantly different, most are either country-related or receptivity variables, notably education, friendly, closer ties, open to imports, ownership pride and willingness to buy. For these variables, respondent evaluations are most similar across countries. The majority of the Beliefs and Familiarity-related variable means are significantly different.

In terms of country comparisons, over half of the non-significant mean comparisons are found in the US-Japan pairing (22 out of 43 non-significant scores), meaning this country pairing is the most similar of the measured pairings. The least similar pairing is US-Australia with only eight non-significant mean differences found.

Given that the majority of mean scores are significantly different, the particular strengths and weaknesses of each country are worthy to consider, first by dimension, then by country.

\subsection{Analysis by Dimension}

Beginning with Cognitive Country Image scores, South Koreans rate the U.S. as highest, and Australia as lowest, whereas Canadians rate Japan as highest, and South Korea as lowest. And while Japan's relative strength is the technology level measure, the U.S.'s relative strength is wealth. By comparison, Canada's and Australia's strength is quality of life. 
The scores are almost reversed for Affective Country Image, in that South Koreans rate Canada and Australia as highest, significantly above the U.S. and Japan, and Canadians rate Australia on top, with the highest score for pleasant. The U.S. receives low ratings for safety, which is a relative strength for Canada. South Koreans rate the U.S. and Japan low in terms of trustworthy, and consider Australia and Canada to be more ideal countries. Canadians rate South Korea lowest on most affective measures (pleasant, exciting, friendly, and ideal country), but rate the U.S. even lower on two key measures: safety and trustworthy.

In terms of Product Beliefs, Japan is rated highest by both South Koreans and Canadians, significantly above all other test countries, particularly in terms of product quality. The results for Destination Beliefs are quite different. Here, Japan receives lower ratings, and it is Australia and the U.S. that are on top, but for different reasons. Australia's relative strength is appealing scenery, whereas the U.S. is stronger in terms of value for money.

The patterns for Product and Destination Familiarity support the findings of the open-ended response analysis - and logic - with South Koreans being most familiar with Japan, and least familiar with Canada and Australia, and Canadians being most familiar with the U.S., and least familiar with South Korea. However, the influence of familiarity on receptivity is unclear. The results suggest that South Koreans are most receptive to Canadian products, and Canadians to Australia, both in terms of product and travel. To further explore relative strengths and weaknesses, a country by country analysis follows. 


\subsubsection{The United States}

As shown in Figure 18, the U.S. mean scores for Cognitive Country items are relatively high, and higher than the scores for the Affective Country image items. The U.S. has its lowest scores in this dimension for safety and trustworthy. Both the Product and Destination Belief scores are high, with brand recognition and range of activities being the U.S.'s strongest attributes. The Product and Destination Receptivity indicators show an interesting pattern, in that both (and especially the latter) are scored high on willingness to buy U.S. products and willingness to travel to the U.S., but both are also scored low on the respondents' desire for open to imports from it and closer ties that would enable easier travel to it in the current restrictive environment.

Figure 18: Summary of Mean Scores for the U.S. by Study Dimension (based on bipolar adjective scales: 1-negative to 7-positive)

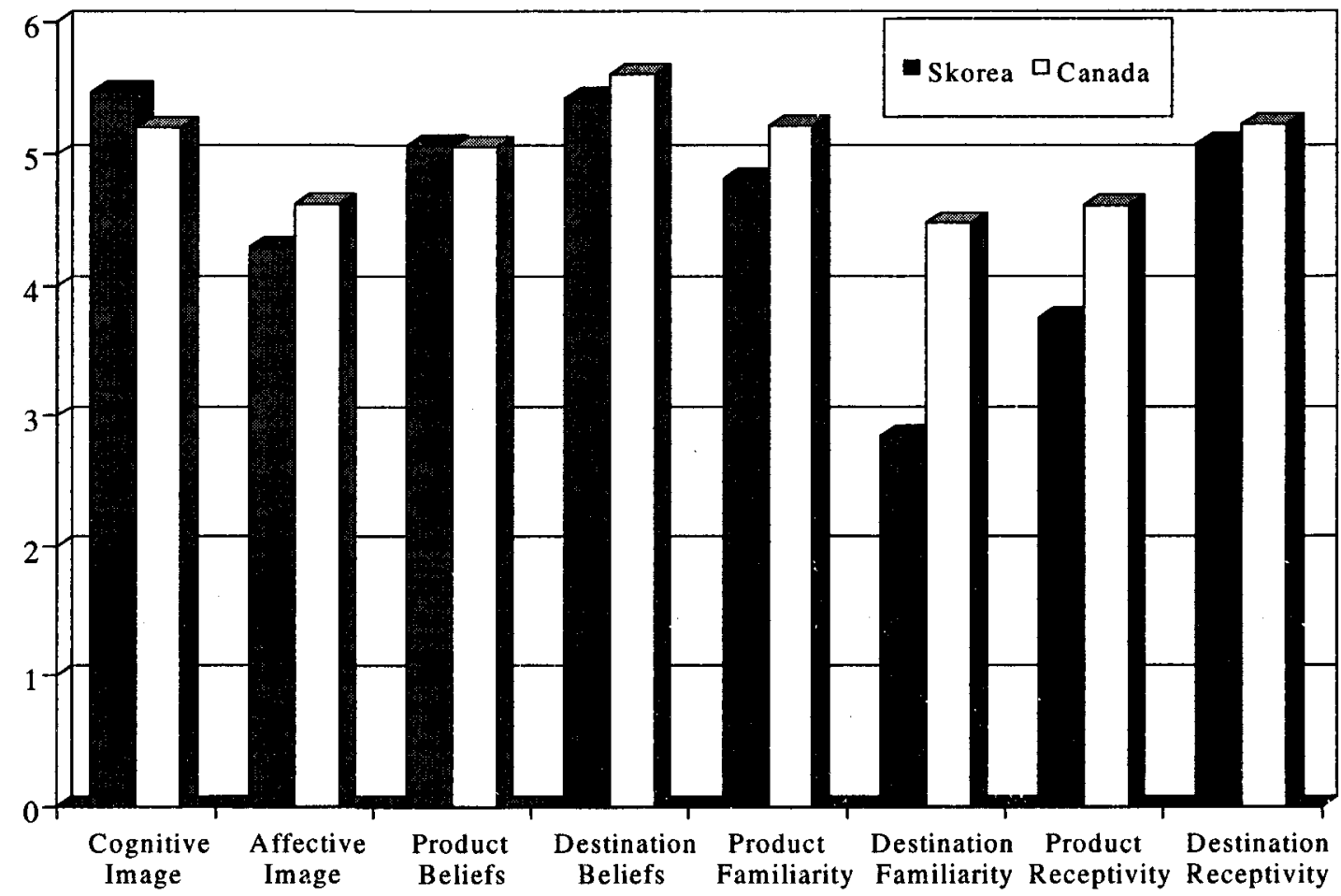


To summarize, while the U.S. is relatively strong in terms of cognitive items and product and destination beliefs, it scores lower on affective items and a desire for more products from and travel to the target country. For Canadian respondents, this might reflect potential disagreements within Canadian public opinion with recent U.S. international policies and actions (such views are widely reported almost daily in the Canadian media), as well as feelings that the levels of penetration of U.S. goods in Canada, and of Canadian travel to the U.S., are high enough and ought not to be expanded further. An expected "image factor", or what might be considered a country's "goodwill measure", appears to be at play and to be currently weakening the U.S.'s overall view in Canada.

\subsubsection{Japan}

As seen in Figure 19, Japan's strength is its Cognitive Image, particularly the technology measure. This strength follows through in ratings for Product Beliefs, yet, while Product Familiarity is also relatively high, Product Receptivity drops, particularly for South Korean respondents. It would appear that Affective measures negatively impact Receptivity. Many of the negative feelings that came out in the open-ended response analysis (e.g. "double-faced", "mean") may also be influencing ratings for Destination Receptivity, as its scores are much lower than expected, given the relatively high ratings for Destination Beliefs. For Japan, the "image factor" seems to have greater influence on receptivity than the country's technological and product quality strengths would suggest. 
Figure 19: Summary of Mean Scores for Japan by Study Dimension (based on bipolar adjective scales: 1-negative to 7-positive)

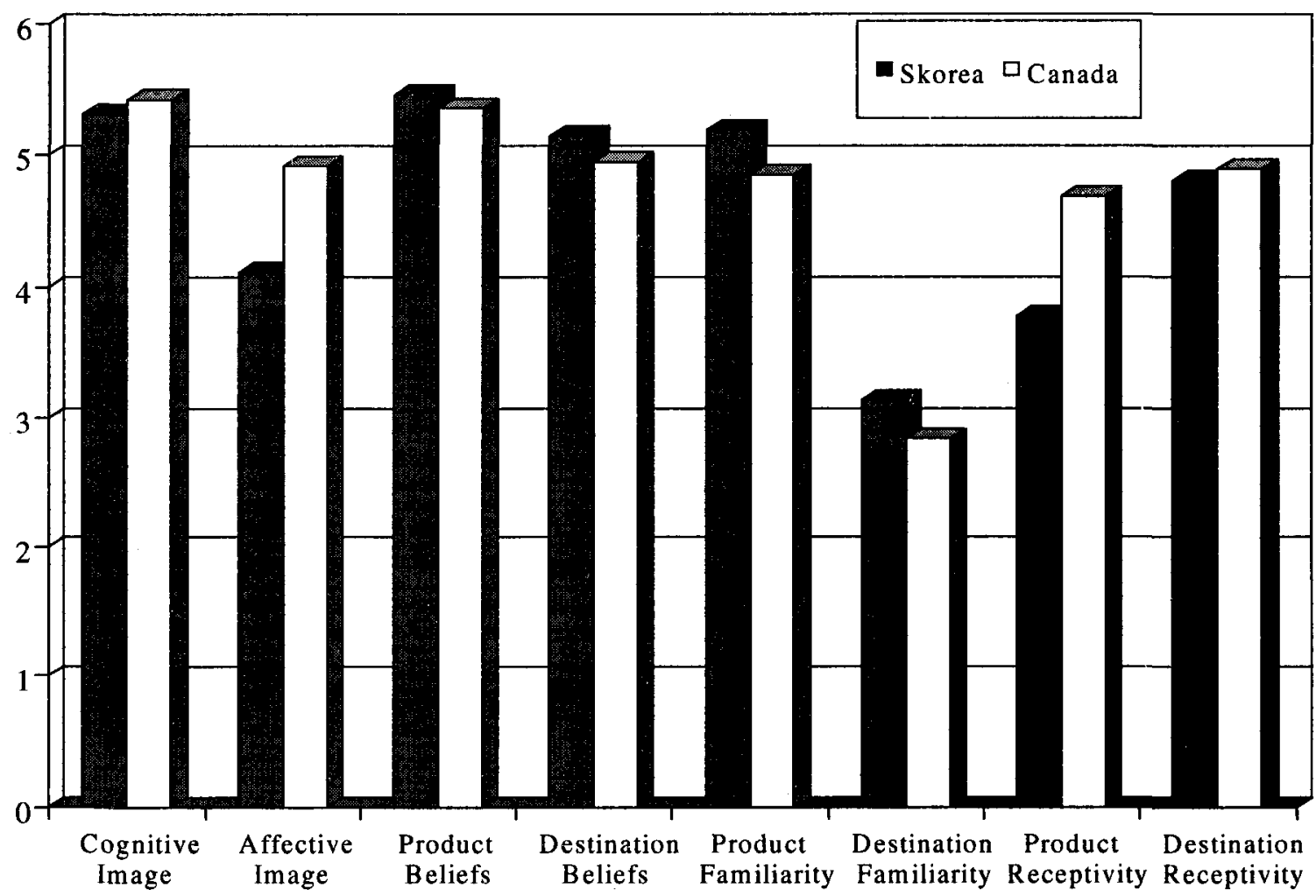

\subsection{Australia}

Australia's scores, as shown in Figure 20, seem somewhat more consistent across dimensions than for other countries, in that their strength in Destination Beliefs, for example, does seem to influence similarly high ratings in Destination Receptivity. Likewise, their low ratings in Product Beliefs seem to match their low ratings in Product Receptivity. Australia's Affective Country Image is stronger than its Cognitive Country Image, and both Product and Destination Familiarity are low, meaning few respondents knew much about Australia, nor its products. But - they would still love to visit! 
Figure 20: Summary of Mean Scores for Australia by Study Dimension (based on bi-polar adjective scales: 1-negative to 7-positive)

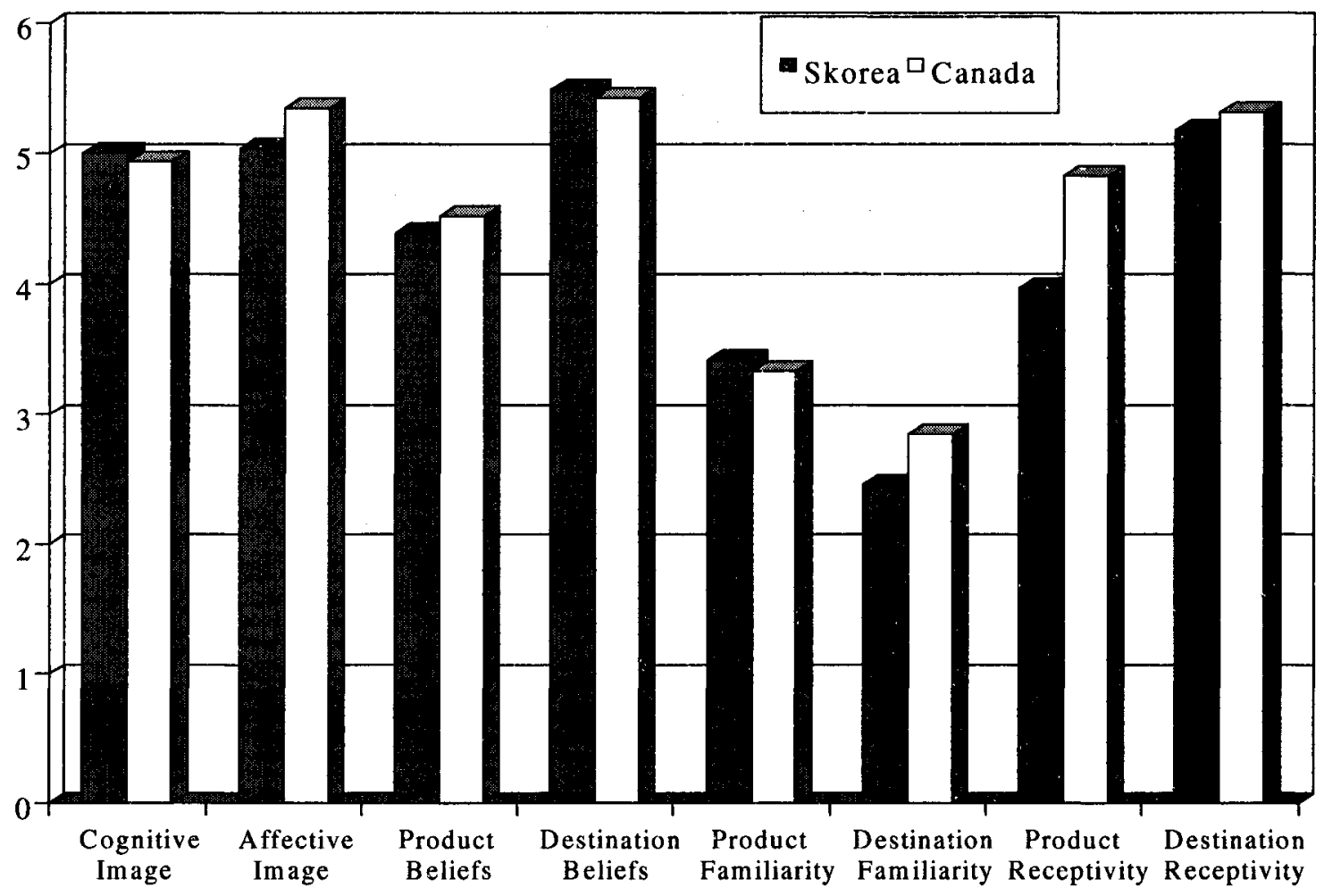

\subsubsection{Canada}

The preceding bar charts presented a comparison of South Korean and Canadian evaluations of each country. However, Canada was only evaluated by South Koreans. Thus, Canada's strengths and weaknesses are compared to the other three countries, by study dimension. The results are presented in Figure 21 . To begin, mean scores for Canada on Cognitive Country items are relatively low. Cognitive measures reflect the thoughts, knowledge and beliefs of respondents in evaluating each country. Canada ranked below the U.S. and Japan in terms of wealth and technology level, finishing just ahead of Australia. Canada's best ranking on cognitive items was for the education of residents. 
Figure 21: Summary of Mean Scores, All Countries, South Korean Sample (based on bi-polar adjective scales: 1-negative to 7-positive)

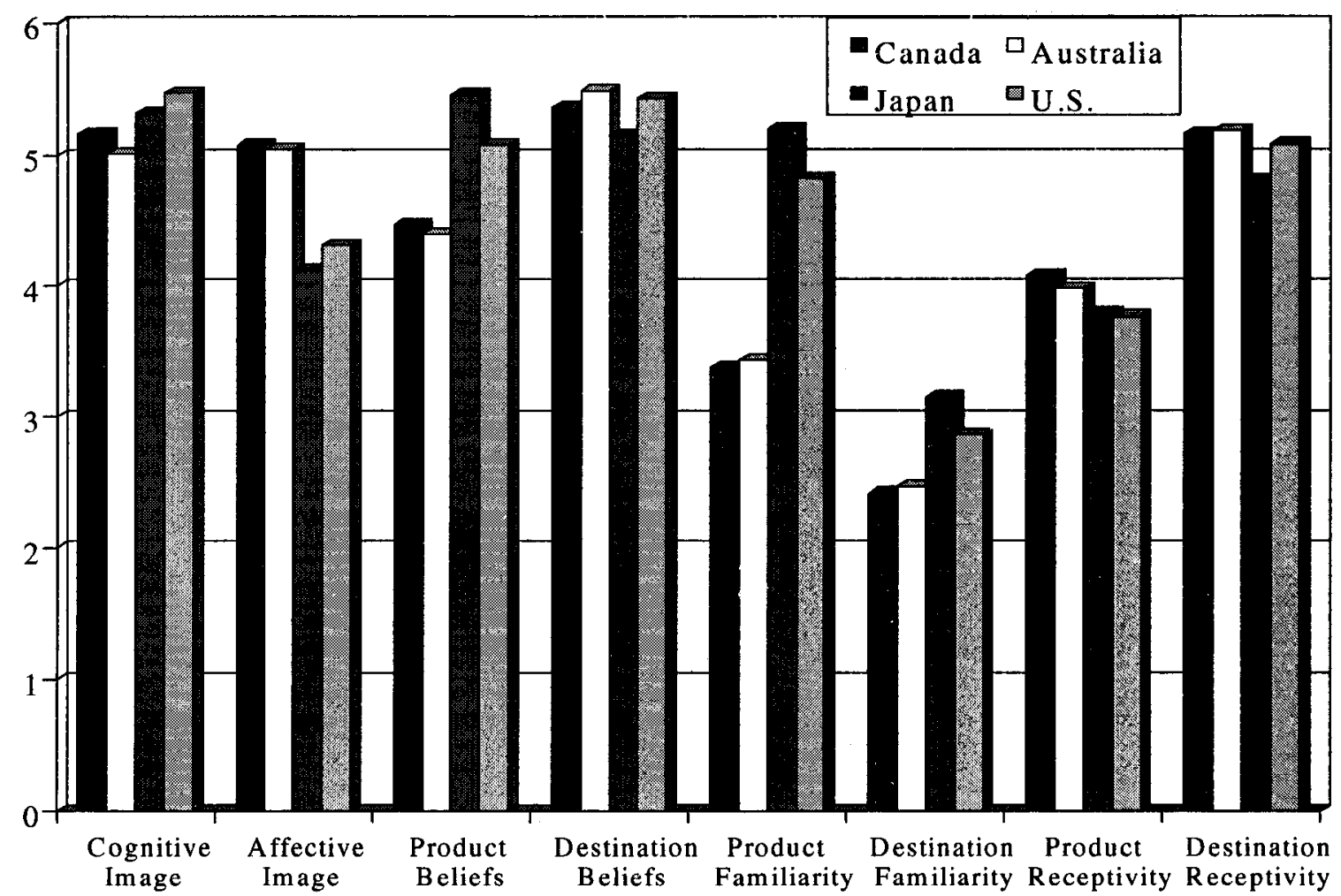

In terms of Affective Country Image items, however, Canada ranks first overall. Affective responses include emotions, feelings, moods and reactions of respondents to the test countries. This is Canada's strength, with top scores for pleasant, safety and trustworthy people. Canada ranks just below Australia in terms of friendliness, with its worst affective measure being exciting, where Canada falls to third place.

In the Product Belief dimension, ratings are relatively poor. Canada ranks third in terms of product quality, reliability, workmanship, innovativeness, value and satisfaction, below the U.S. and Japan, and just ahead of Australia. Canada's ranking in the Destination Belief dimension is a disappointing third place finish, behind Australia and the U.S., and just ahead of Japan. While Canada finishes second in terms of appealing 
scenery and quality attractions, the fourth place rating in terms of accommodations and value for money brings the overall ranking down.

Perhaps the most surprising scores are found within the Receptivity dimension. Here, despite Canada's relatively weak performance in the Product and Destination dimensions, Canada is ranked first in terms of ownership pride, and second in terms of willingness to travel to the country. To summarize, Canada is relatively weak in terms of cognitive items, such as wealth and technology level, and is strongest in terms of affective items, such as pleasant, safety and trustworthy. And despite Canada's third place ranking in terms of Product Beliefs, respondents would be most proud to own a Canadian product. Likewise, respondents are more willing to travel to Canada than the relatively weak scores for Destination Beliefs would suggest. This seemingly contradictory result is likely related to Canada's first place ranking on Affective Country Image. Here, the "image-factor" - Canada's goodwill - strengthens the overall evaluations of place image.

\subsubsection{South Korea}

Canadians rate South Korea lowest on all constructs relative to the other test countries, with the exception of Product Familiarity, which is above Australia. Yet, Australia still out-scores South Korea on Product Belief measures, despite Caradians admittedly lower familiarity with Australian products. The findings of the open-ended analysis suggest that Canadians hold quite a negative view of South Korea overall (e.g. "crowded", "poor", "polluted"). Not only are Canadians unfamiliar with South Korea, but even what they feel they do know, they rate poorly (e.g. product innovation, product 
workmanship). It would seem that a poor "image factor" or negative "goodwill" results in worse consequences than unfamiliarity.

Figure 22: Summary of Mean Scores, All Countries, Canadian Sample (based on bi-polar adjective scales: 1-negative to 7-positive)

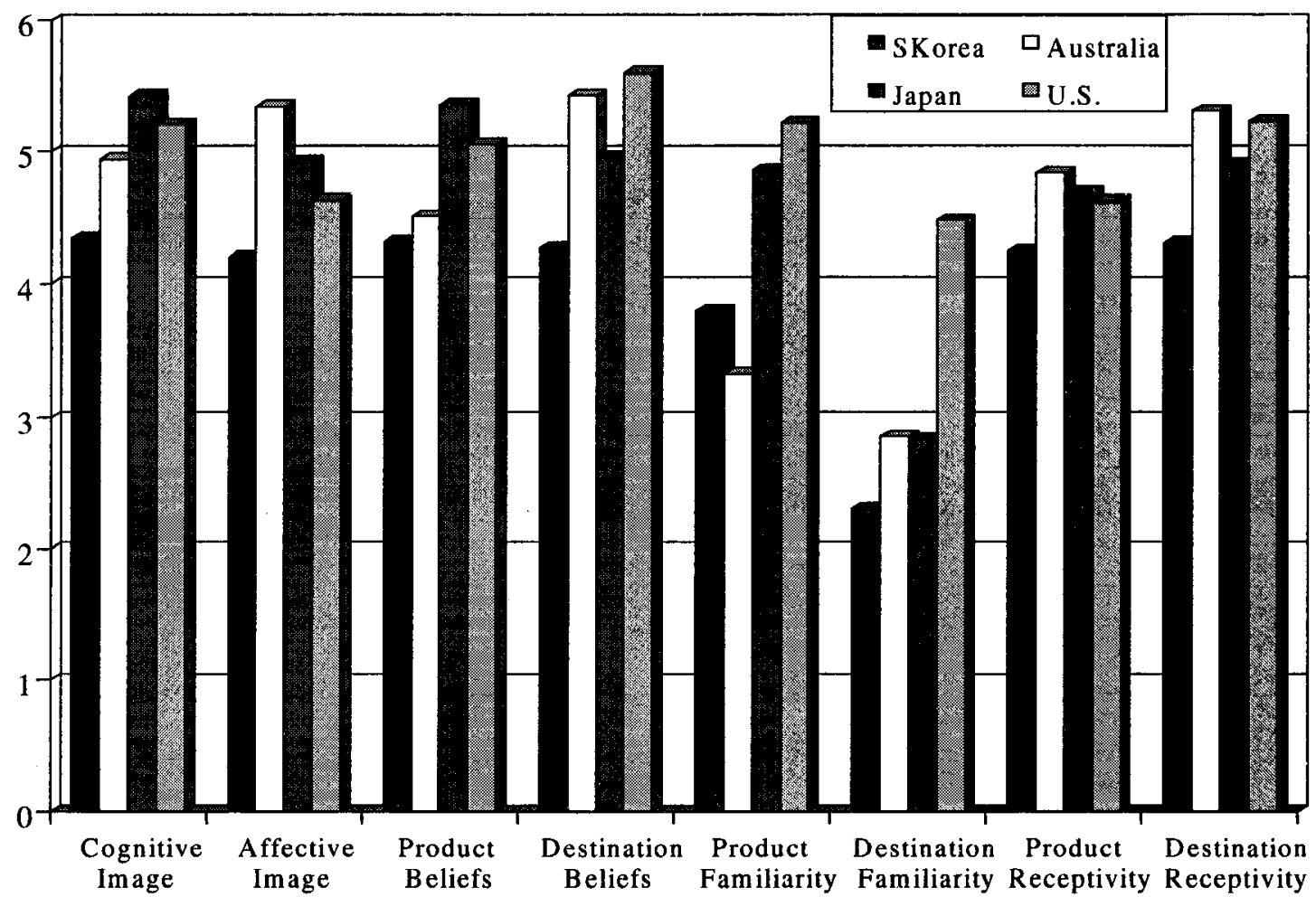

In the end, it would seem that receptivity is not directly related to any one measure, but the result of the interplay of many factors. The criss-crossing of ratings is summarized in Table 18, which provides the overall rankings of each country by dimension. With the exception of South Korea, all countries received a top rating for at least one dimension, as well as a three or four score-rating in at least one dimension, suggesting that dimensions are independent. Based on these results, it is difficult to determine which measures have the greatest influence, and where, or how. A closer 
examination of the relationships between dimensions using multivariate techniques follows.

Table 18: Country Rankings based on Mean Scores by Dimension ${ }^{1}$

\begin{tabular}{|l|c|c|c|c|c|c|c|c|}
\hline & \multicolumn{4}{|l}{ South Korea n=349 } & \multicolumn{3}{l|}{ Canada n=307 } \\
\hline & US & JP & AU & CA & US & JP & AU & SK \\
\hline Cognitive Country Image & 1 & 2 & 4 & 3 & 2 & 1 & 3 & 4 \\
\hline Affective Country Image & 3 & 4 & 2 & 1 & 3 & 2 & 1 & 4 \\
\hline Product Familiarity & 2 & 1 & 3 & 4 & 1 & 2 & 4 & 3 \\
\hline Product Beliefs & 2 & 1 & 4 & 3 & 2 & 1 & 3 & 4 \\
\hline Product Receptivity & 4 & 3 & 2 & 1 & 3 & 2 & 1 & 4 \\
\hline Destination Familiarity & 2 & 1 & 3 & 4 & 1 & 3 & 2 & 4 \\
\hline Destination Beliefs & 2 & 4 & 1 & 3 & 1 & 3 & 2 & 4 \\
\hline Destination Receptivity & 3 & 4 & 1 & 2 & 2 & 3 & 1 & 4 \\
\hline
\end{tabular}

${ }^{\mathrm{T}}$ Rankings are based on the average of mean scores by factor dimension (see Table 18)

\subsection{Exploratory Factor Analysis}

Before conducting Exploratory Factor Analysis (EFA) and Structural Equation Modeling (SEM), the adequacy of the sample data was checked for multivariate normality by assessing the univariate distributions of the means. Skewness and kurtosis measures for all the scale variables indicated tolerable symmetrical distributions, with Skewness $<3$ and kurtosis $<8$ (see Appendix E for details). However, the non-scale item, total number of trips is asymmetrically distributed, and is therefore not included in the factor analysis nor SEM. The Kaiser-Meyer-Olkin measures of sampling adequacy are all in the 0.85 to 0.882 range, and Bartlett's tests of sphericity are all significant, as shown in Table 19.

SPSS version 14.0 was used to analyze all 33 scale items, repeated for all 8 models ( $2 \times 4$ sample-target country combinations), using the principal components method of extraction and orthogonal rotation (Varimax with Kaiser normalization), so that new factors remain uncorrelated, and are more easily interpretable. Only factors 
with Eigenvalues greater than one were retained, and solutions were reached in 12 iterations or less. Detailed results are included as Appendix G. Initial pattern matrices varied from model to model, with seven to nine factors extracted, accounting for $56.3 \%$ (SK-AU) to $67.2 \%$ (CA-JP) of the total variance, with an average of $62.4 \%$.

Table 19: Sampling Adequacy and Test of Sphericity

\begin{tabular}{|c|c|c|c|c|c|c|c|c|}
\hline & $\begin{array}{l}\text { SK- } \\
\text { US }\end{array}$ & $\begin{array}{l}\text { SK- } \\
\text { JP }\end{array}$ & $\begin{array}{l}\text { SK- } \\
\text { AU }\end{array}$ & $\begin{array}{l}\text { SK- } \\
\text { CA }\end{array}$ & $\begin{array}{l}\text { CA- } \\
\text { US }\end{array}$ & $\begin{array}{l}\mathrm{CA}- \\
\mathrm{JP}\end{array}$ & $\begin{array}{l}\mathrm{CA}- \\
\mathrm{AU}\end{array}$ & $\begin{array}{l}\text { CA- } \\
\text { SK }\end{array}$ \\
\hline \multicolumn{9}{|c|}{ Kaiser-Meyer-Olkin Measure of Sampling Adequacy } \\
\hline & .866 & .876 & .850 & .865 & .885 & .882 & .872 & .875 \\
\hline \multicolumn{9}{|c|}{ Bartlett's Test of Sphericity } \\
\hline $\begin{array}{l}\text { Approx. } \\
\text { Chi- } \\
\text { Square }\end{array}$ & 4652.5 & 4959.0 & 4111.2 & 4402.9 & 4527.6 & 4784.5 & 4538.8 & 5049.7 \\
\hline df & 528 & 528 & 528 & 528 & 528 & 528 & 528 & 528 \\
\hline Sig & .000 & .000 & .000 & .000 & .000 & .000 & .000 & .000 \\
\hline
\end{tabular}

Individual factor loadings also varied, and were considered across all models in order to find the set of items with the best psychometric properties. At this stage, five items with consistently poor loadings on their respective factors, and/or high cross loadings above 0.40 on multiple factors, were dropped: exciting, reliability, good products overall, accommodation, and product knowledge. Two items loaded on factors differently than was predicted: brand recognition loaded on Product Beliefs in all cases (not Product Familiarity); and, product satisfaction loaded on Product Familiarity in most cases (not Poduct Beliefs). These items were realigned as it was felt that, logically, brand recognition could be considered as a measure of product beliefs, and product satisfaction as a measure of product use, or familiarity. Thus, the validity of measures was retained, and statistical estimation improved. 
Additionally, four items did not load on the factors they were predicted to load on, but their alternative loadings were less clear. These four items: good tourism destination, ideal country, closer ties and ownership pride, rather than being dropped, were realigned and tested through CFA in order to retain sufficient variables for the Familiarity and Receptivity factors, as the use of multiple indicators tends to be more reliable and valid. At this stage, one factor now has a single measurement item: Destination Familiarity, as measured by country knowledge. A single-variable construct can work, provided the variable is symmetrically distributed. For country knowledge, the skewness statistic included in Appendix E ranges from -0.597 to 0.549 , and the kurtosis statistic ranges from -0.905 to 0.001 , which are acceptable.

Another potential issue identified during EFA was the cross-loadings of some Cognitive Country Image items and Affective Country Image items, questioning whether these two factors are truly distinct. Because there is much theory and past empirical research that supports their separation, their distinct structure is retained. The extent of their discriminant validity will be tested further during CFA. Following the EFA analysis, there are now 27 remaining items that will be included in the CFA modelling analysis.

\subsection{Construct Validity and Reliability}

While each construct is based on theory, it must also hold statistically. Ideally, each construct is comprised of variables that correlate positively together, called convergent validity, and each construct is differentiated from the scales that comprise the other model constructs, called discriminant validity. Thus, validity measures the consistency of the constructs, but constructs must also be reliable. Reliability relates 
more to the accuracy of the construct scales, or its internal consistency. Results of the statistical tests follow.

\subsubsection{Convergent Validity}

To assess the degree to which responses are consistent across the items within each factor, Cronbach's Coefficient Alpha is used as the most common estimate of internal consistency, or convergent validity. Table 20 lists the reliability coefficients for all constructs, for all eight models. Individual alphas range from a low of 0.518 (CA-AU Product Familiarity) to a high of 0.884 (SK-JP Product Beliefs), but all aggregates are above the recommended threshold of 0.60 for SEM [Bagozzi and Yi, 1988]. While many researchers commonly use a minimum of 0.70 in CFA as a threshold [Kline, 2005, pg. 59], the SEM analysis to follow accounts for measurement error. Thus, the validity of the constructs is considered to be more than adequate at this stage.

Table 20: Summary of Reliability Tests by Construct

\begin{tabular}{|l|c|c|c|c|c|c|c|c|c|}
\hline & \multicolumn{8}{|c|}{ Reliability Coefficients (Cronbach Alphas) } \\
\cline { 2 - 9 } Model & $\begin{array}{c}\text { Cog. } \\
\text { Image }\end{array}$ & $\begin{array}{c}\text { Aff. } \\
\text { Image }\end{array}$ & $\begin{array}{c}\text { Prod. } \\
\text { Beliefs }\end{array}$ & $\begin{array}{c}\text { Dest. } \\
\text { Beliefs }\end{array}$ & $\begin{array}{c}\text { Prod. } \\
\text { Fam. }\end{array}$ & $\begin{array}{c}\text { Dest. } \\
\text { Fam. }\end{array}$ & $\begin{array}{c}\text { Prod. } \\
\text { Recep. }\end{array}$ & $\begin{array}{c}\text { Dest. } \\
\text { Recep. }\end{array}$ & $\begin{array}{c}\text { Ave. } \\
\text { A }\end{array}$ \\
\hline SK-US & .675 & .749 & .854 & .831 & .627 & & .655 & .659 & .721 \\
SK-JP & .652 & .746 & .884 & .783 & .742 & & .696 & .744 & .750 \\
SK-AU & .704 & .775 & .774 & .828 & .663 & N/A & .596 & .714 & .722 \\
SK-CA & .702 & .787 & .791 & .792 & .634 & 1 item & .628 & .727 & .723 \\
CA-US & .596 & .798 & .829 & .838 & .602 & & .671 & .740 & .729 \\
CA-JP & .699 & .855 & .859 & .806 & .684 & & .691 & .776 & .767 \\
CA-AU & .606 & .837 & .796 & .845 & .518 & & .662 & .763 & .718 \\
CA-SK & .701 & .806 & .837 & .880 & .597 & & .693 & .815 & .761 \\
Average & .667 & .794 & .828 & .825 & .633 & & .662 & .742 & .736 \\
\hline
\end{tabular}

The three lowest average scores (last row in Table 20) are 0.633 for the Product Familiarity construct, 0.662 for Product Receptivity and 0.667 for Cognitive Image. The two highest Cronbach alpha scores are 0.828 for Product Beliefs and 0.825 for 
Destination Beliefs. The two remaining constructs have satisfactory scores of 0.794 for Affective Image and 0.742 for Destination Receptivity. Individually, all alphas except one (Product Familiarity in CA-AU) are 0.6 or higher.

\subsubsection{Discriminant Validity}

Discriminant validity represents the distinctiveness of constructs, and is measured by estimating the correlations between constructs. Correlations are considered "excessively high" if greater than 0.85 [Kline, 2005, pg. 73]. Tables 21 -a to 21-h list the correlations between all constructs for the eight models. In most cases, the correlations are acceptable, and suggest discriminant validity. However, there are exceptions. In two models the correlation between Cognitive Image and Affective Image is excessively high. In the South Korea - Canada model it is 0.89 , and in the Canada - Australia model it is 0.92. In two other models the correlation between Destination Beliefs and Destination Receptivity is excessively high. In the South Korea - U.S. model it is 0.85 , and in the South Korea - Australia model it is 0.92. Lastly, in the Canada - U.S. model the correlation between Product Beliefs and Product Receptivity is 0.85 .

In cases of high correlation, collapsing constructs was considered. The separation, however, allows for the exploration of the hypothesized relationships, and is also theory-based. Therefore, constructs have not been collapsed. Additionally, no more than one excessively high correlation per model exists, and all correlations are positive, except for Product Familiarity, which displays negative correlations in half the models. In sum, there is sufficient and adequate validity, but the correlations have been noted as they will influence subsequent modelling. 
Table 21-a: Correlation Matrix of Independent Variables

South Korea Sample - U.S. Evaluation

\begin{tabular}{|l|c|c|c|c|c|c|c|}
\hline \multicolumn{1}{|c|}{ Construct } & $\begin{array}{c}\text { Cog. } \\
\text { Image }\end{array}$ & $\begin{array}{c}\text { Aff. } \\
\text { Image }\end{array}$ & $\begin{array}{c}\text { Prod. } \\
\text { Beliefs }\end{array}$ & $\begin{array}{c}\text { Dest. } \\
\text { Beliefs }\end{array}$ & $\begin{array}{c}\text { Prod. } \\
\text { Famil. }\end{array}$ & $\begin{array}{c}\text { Destin. } \\
\text { Recep. }\end{array}$ & $\begin{array}{c}\text { Prod. } \\
\text { Recep. }\end{array}$ \\
\hline Cognitive Image & 1.00 & & & & & & \\
Affective Image & $.48^{\mathrm{a}}$ & 1.00 & & & & & \\
Product Beliefs & $.62^{\mathrm{a}}$ & $.44^{\mathrm{a}}$ & 1.00 & & & & \\
Destination Beliefs & $.40^{\mathrm{a}}$ & $.37^{\mathrm{a}}$ & $.55^{\mathrm{a}}$ & 1.00 & & & \\
Product Familiarity & $.21^{\mathrm{a}}$ & $.39^{\mathrm{a}}$ & $.50^{\mathrm{a}}$ & $.18^{\mathrm{a}}$ & 1.00 & & \\
Destination Receptivity & $.48^{\mathrm{a}}$ & $.56^{\mathrm{a}}$ & $.65^{\mathrm{a}}$ & $.85^{\mathrm{a}}$ & $.34^{\mathrm{a}}$ & 1.00 & \\
Product Receptivity & $.47^{\mathrm{a}}$ & $.65^{\mathrm{a}}$ & $.71^{\mathrm{a}}$ & $.35^{\mathrm{a}}$ & $.55^{\mathrm{a}}$ & $.61^{\mathrm{a}}$ & 1.00 \\
\hline
\end{tabular}

${ }^{\mathrm{I}}$ LISREL Path Analysis using Maximum Likelihood; model converged in 21 iterations; ${ }^{\mathrm{a}} \mathrm{p}>0.01$ (2-tailed)

Table 21-b: Correlation Matrix of Independent Variables

South Korea Sample - Japan Evaluation ${ }^{1}$

\begin{tabular}{|l|c|c|c|c|c|c|c|}
\hline \multicolumn{1}{|c|}{ Construct } & $\begin{array}{c}\text { Cog. } \\
\text { Image }\end{array}$ & $\begin{array}{c}\text { Aff. } \\
\text { Image }\end{array}$ & $\begin{array}{c}\text { Prod. } \\
\text { Beliefs }\end{array}$ & $\begin{array}{c}\text { Dest. } \\
\text { Beliefs }\end{array}$ & $\begin{array}{c}\text { Prod. } \\
\text { Famil. }\end{array}$ & $\begin{array}{c}\text { Dest. } \\
\text { Recep. }\end{array}$ & $\begin{array}{c}\text { Prod. } \\
\text { Recep. }\end{array}$ \\
\hline Cognitive Image & 1.00 & & & & & & \\
Affective Image & $.53^{\mathrm{a}}$ & 1.00 & & & & & \\
Product Beliefs & $.58^{\mathrm{a}}$ & $.21^{\mathrm{a}}$ & 1.00 & & & & \\
Destination Beliefs & $.48^{\mathrm{a}}$ & $.34^{\mathrm{a}}$ & $.54^{\mathrm{a}}$ & 1.00 & & & \\
Product Familiarity & $.19^{\mathrm{a}}$ & -.08 & $.58^{\mathrm{a}}$ & $.25^{\mathrm{a}}$ & 1.00 & & \\
Destination Receptivity & $.48^{\mathrm{a}}$ & $.54^{\mathrm{a}}$ & $.57^{\mathrm{a}}$ & $.82^{\mathrm{a}}$ & $.35^{\mathrm{a}}$ & 1.00 & \\
Product Receptivity & $.60^{\mathrm{a}}$ & $.81^{\mathrm{a}}$ & $.47^{\mathrm{a}}$ & $.44^{\mathrm{a}}$ & .10 & $.75^{\mathrm{a}}$ & 1.00 \\
\hline
\end{tabular}

${ }^{1}$ LISREL Path Analysis using Maximum Likelihood; model converged in 11 iterations;

${ }^{a} \mathrm{p}>0.01$ (2-tailed)

Table 21-c: Correlation Matrix of Independent Variables

South Korea Sample - Australia Evaluation ${ }^{1}$

\begin{tabular}{|l|c|c|c|c|c|c|c|}
\hline \multicolumn{1}{|c|}{ Construct } & $\begin{array}{c}\text { Cog. } \\
\text { Image }\end{array}$ & $\begin{array}{c}\text { Aff. } \\
\text { Image }\end{array}$ & $\begin{array}{c}\text { Prod. } \\
\text { Beliefs }\end{array}$ & $\begin{array}{c}\text { Dest. } \\
\text { Beliefs }\end{array}$ & $\begin{array}{c}\text { Prod. } \\
\text { Famil. }\end{array}$ & $\begin{array}{c}\text { Dest. } \\
\text { Recep. }\end{array}$ & $\begin{array}{c}\text { Prod. } \\
\text { Recep. }\end{array}$ \\
\hline Cognitive Image & 1.00 & & & & & & \\
Affective Image & $.80^{\mathrm{a}}$ & 1.00 & & & & & \\
Product Beliefs & $.56^{\mathrm{a}}$ & $.36^{\mathrm{a}}$ & 1.00 & & & & \\
Destination Beliefs & $.47^{\mathrm{a}}$ & $.41^{\mathrm{a}}$ & $.16^{\mathrm{b}}$ & 1.00 & & & \\
Product Familiarity & -.06 & -.03 & $.14^{\mathrm{b}}$ & $-.27^{\mathrm{a}}$ & 1.00 & & \\
Destination Receptivity & $.54^{\mathrm{a}}$ & $.61^{\mathrm{a}}$ & $.15^{\mathrm{b}}$ & $.92^{\mathrm{a}}$ & $-.24^{\mathrm{a}}$ & 1.00 & \\
Product Receptivity & $.46^{\mathrm{a}}$ & $.47^{\mathrm{a}}$ & $.73^{\mathrm{a}}$ & $.17^{\mathrm{a}}$ & .13 & $.27^{\mathrm{a}}$ & 1.00 \\
\hline
\end{tabular}

${ }^{1}$ LISREL Path Analysis using Maximum Likelihood; model converged in 18 iterations; ${ }^{a} \mathrm{p}>0.01 ;{ }^{b}>0.05$ (2-tailed). 
Table 21-d: Correlation Matrix of Independent Variables

South Korea Sample - Canada Evaluation ${ }^{1}$

\begin{tabular}{|l|c|c|c|c|c|c|c|}
\hline \multicolumn{1}{|c|}{ Construct } & $\begin{array}{c}\text { Cog. } \\
\text { Image }\end{array}$ & $\begin{array}{c}\text { Aff. } \\
\text { Image }\end{array}$ & $\begin{array}{c}\text { Prod. } \\
\text { Beliefs }\end{array}$ & $\begin{array}{c}\text { Dest. } \\
\text { Beliefs }\end{array}$ & $\begin{array}{c}\text { Prod. } \\
\text { Famil. }\end{array}$ & $\begin{array}{c}\text { Dest. } \\
\text { Recep. }\end{array}$ & $\begin{array}{c}\text { Prod. } \\
\text { Recep. }\end{array}$ \\
\hline Cognitive Image & 1.00 & & & & & & \\
Affective Image & $.89^{\mathrm{a}}$ & 1.00 & & & & & \\
Product Beliefs & $.54^{\mathrm{a}}$ & $.52^{\mathrm{a}}$ & 1.00 & & & & \\
Destination Beliefs & $.49^{\mathrm{a}}$ & $.54^{\mathrm{a}}$ & $.26^{\mathrm{a}}$ & 1.00 & & & \\
Product Familiarity & $-.20^{\mathrm{a}}$ & -.09 & $.19^{\mathrm{a}}$ & $-.16^{\mathrm{b}}$ & 1.00 & & \\
Destination Receptivity & $.56^{\mathrm{a}}$ & $.57^{\mathrm{a}}$ & $.39^{\mathrm{a}}$ & $.74^{\mathrm{a}}$ & -.14 & 1.00 & \\
Product Receptivity & $.57^{\mathrm{a}}$ & $.65^{\mathrm{a}}$ & $.90^{\mathrm{a}}$ & $.27^{\mathrm{a}}$ & $.22^{\mathrm{a}}$ & $.40^{\mathrm{a}}$ & 1.00 \\
\hline
\end{tabular}

${ }^{1}$ LISREL Path Analysis using Maximum Likelihood; model converged in 16 iterations; ${ }^{a} \mathrm{p}>0.01 ;{ }^{b} \mathrm{p}>0.05$ (2-tailed)

Table 21-e: Correlation Matrix of Independent Variables Canada Sample - U.S. Evaluation ${ }^{1}$

\begin{tabular}{|l|c|c|c|c|c|c|c|}
\hline \multicolumn{1}{|c|}{ Construct } & $\begin{array}{c}\text { Cog. } \\
\text { Image }\end{array}$ & $\begin{array}{c}\text { Aff. } \\
\text { Image }\end{array}$ & $\begin{array}{c}\text { Prod. } \\
\text { Beliefs }\end{array}$ & $\begin{array}{c}\text { Dest. } \\
\text { Beliefs }\end{array}$ & $\begin{array}{c}\text { Prod. } \\
\text { Famil. }\end{array}$ & $\begin{array}{c}\text { Dest. } \\
\text { Recep. }\end{array}$ & $\begin{array}{c}\text { Prod. } \\
\text { Recep. }\end{array}$ \\
\hline Cognitive Image & 1.00 & & & & & & \\
Affective Image & $.81^{\mathrm{a}}$ & 1.00 & & & & & \\
Product Beliefs & $.59^{\mathrm{a}}$ & $.43^{\mathrm{a}}$ & 1.00 & & & & \\
Destination Beliefs & $.37^{\mathrm{a}}$ & $.31^{\mathrm{a}}$ & $.65^{\mathrm{a}}$ & 1.00 & & & \\
Product Familiarity & $.40^{\mathrm{a}}$ & $.35^{\mathrm{a}}$ & $.65^{\mathrm{a}}$ & $.47^{\mathrm{a}}$ & 1.00 & & \\
Destination Receptivity & $.58^{\mathrm{a}}$ & $.44^{\mathrm{a}}$ & $.62^{\mathrm{a}}$ & $.77^{\mathrm{a}}$ & $.52^{\mathrm{a}}$ & 1.00 & \\
Product Receptivity & $.61^{\mathrm{a}}$ & $.47^{\mathrm{a}}$ & $.85^{\mathrm{a}}$ & $.67^{\mathrm{a}}$ & $.65^{\mathrm{a}}$ & $.71^{\mathrm{a}}$ & 1.00 \\
\hline
\end{tabular}

${ }^{1}$ LISREL Path Analysis using Maximum Likelihood; model converged in 18 iterations;

${ }^{a} \mathrm{p}>0.01$ (2-tailed)

Table 21-f: Correlation Matrix of Independent Variables Canada Sample - Japan Evaluation ${ }^{1}$

\begin{tabular}{|l|c|c|c|c|c|c|c|}
\hline \multicolumn{1}{|c|}{ Construct } & $\begin{array}{c}\text { Cog. } \\
\text { Image }\end{array}$ & $\begin{array}{c}\text { Aff. } \\
\text { Image }\end{array}$ & $\begin{array}{c}\text { Prod. } \\
\text { Beliefs }\end{array}$ & $\begin{array}{c}\text { Dest. } \\
\text { Beliefs }\end{array}$ & $\begin{array}{c}\text { Prod. } \\
\text { Famil. }\end{array}$ & $\begin{array}{c}\text { Dest. } \\
\text { Recep. }\end{array}$ & $\begin{array}{c}\text { Prod. } \\
\text { Recep. }\end{array}$ \\
\hline Cognitive Image & 1.00 & & & & & & \\
Affective Image & $.80^{\mathrm{a}}$ & 1.00 & & & & & \\
Product Beliefs & $.41^{\mathrm{a}}$ & $.42^{\mathrm{a}}$ & 1.00 & & & & \\
Destination Beliefs & $.33^{\mathrm{a}}$ & $.43^{\mathrm{a}}$ & $.34^{\mathrm{a}}$ & 1.00 & & & \\
Product Familiarity & $.37^{\mathrm{a}}$ & $.46^{\mathrm{a}}$ & $.62^{\mathrm{a}}$ & $.37^{\mathrm{a}}$ & 1.00 & & \\
Destination Receptivity & $.32^{\mathrm{a}}$ & $.49^{\mathrm{a}}$ & $.41^{\mathrm{a}}$ & $.63^{\mathrm{a}}$ & $.28^{\mathrm{a}}$ & 1.00 & \\
Product Receptivity & $.45^{\mathrm{a}}$ & $.60^{\mathrm{a}}$ & $.80^{\mathrm{a}}$ & $.47^{\mathrm{a}}$ & $.65^{\mathrm{a}}$ & $.51^{\mathrm{a}}$ & 1.00 \\
\hline
\end{tabular}

${ }^{1}$ LISREL Path Analysis using Maximum Likelihood; model converged in 19 iterations; ${ }^{\mathrm{a}} \mathrm{p}>0.01$ (2-tailed) 
Table 21-g: Correlation Matrix of Independent Variables

Canada Sample - Australia Evaluation ${ }^{1}$

\begin{tabular}{|l|c|c|c|c|c|c|c|}
\hline \multicolumn{1}{|c|}{ Construct } & $\begin{array}{c}\text { Cog. } \\
\text { Image }\end{array}$ & $\begin{array}{c}\text { Aff. } \\
\text { Image }\end{array}$ & $\begin{array}{c}\text { Prod. } \\
\text { Beliefs }\end{array}$ & $\begin{array}{c}\text { Dest. } \\
\text { Beliefs }\end{array}$ & $\begin{array}{c}\text { Prod. } \\
\text { Famil. }\end{array}$ & $\begin{array}{c}\text { Dest. } \\
\text { Recep. }\end{array}$ & $\begin{array}{c}\text { Prod. } \\
\text { Recep. }\end{array}$ \\
\hline Cognitive Image & 1.00 & & & & & & \\
Affective Image & $.92^{\mathrm{a}}$ & 1.00 & & & & & \\
Product Beliefs & $.50^{\mathrm{a}}$ & $.36^{\mathrm{a}}$ & 1.00 & & & & \\
Destination Beliefs & $.43^{\mathrm{a}}$ & $.45^{\mathrm{a}}$ & $.46^{\mathrm{a}}$ & 1.00 & & & \\
Product Familiarity & -.09 & -.08 & $.33^{\mathrm{a}}$ & -.04 & 1.00 & & \\
Destination Receptivity & $.48^{\mathrm{a}}$ & $.54^{\mathrm{a}}$ & $.45^{\mathrm{a}}$ & $.75^{\mathrm{a}}$ & -.03 & 1.00 & \\
Product Receptivity & $.49^{\mathrm{a}}$ & $.58^{\mathrm{a}}$ & $.41^{\mathrm{a}}$ & $.41^{\mathrm{a}}$ & -.01 & $.52^{\mathrm{a}}$ & 1.00 \\
\hline
\end{tabular}

${ }^{1}$ LISREL Path Analysis using Maximum Likelihood; model converged in 17 iterations ${ }^{\mathrm{a}} \mathrm{p}>0.01$ (2-tailed)

Table 21-h: Correlation Matrix of Independent Variables Canada Sample - South Korea Evaluation ${ }^{1}$

\begin{tabular}{|l|c|c|c|c|c|c|c|}
\hline \multicolumn{1}{|c|}{ Construct } & $\begin{array}{c}\text { Cog. } \\
\text { Image }\end{array}$ & $\begin{array}{c}\text { Aff. } \\
\text { Image }\end{array}$ & $\begin{array}{c}\text { Prod. } \\
\text { Beliefs }\end{array}$ & $\begin{array}{c}\text { Dest. } \\
\text { Beliefs }\end{array}$ & $\begin{array}{c}\text { Prod. } \\
\text { Famil. }\end{array}$ & $\begin{array}{c}\text { Dest. } \\
\text { Recep. }\end{array}$ & $\begin{array}{c}\text { Prod. } \\
\text { Recep. }\end{array}$ \\
\hline Cognitive Image & 1.00 & & & & & & \\
Affective Image & $.81^{\mathrm{a}}$ & 1.00 & & & & & \\
Product Beliefs & $.55^{\mathrm{a}}$ & $.66^{\mathrm{a}}$ & 1.00 & & & & \\
Destination Beliefs & $.31^{\mathrm{a}}$ & $.42^{\mathrm{a}}$ & $.46^{\mathrm{a}}$ & 1.00 & & & \\
Product Familiarity & $.16^{\mathrm{b}}$ & .11 & $.44^{\mathrm{a}}$ & $.16^{\mathrm{b}}$ & 1.00 & & \\
Destination Receptivity & $.44^{\mathrm{a}}$ & $.55^{\mathrm{a}}$ & $.58^{\mathrm{a}}$ & $.64^{\mathrm{a}}$ & $.22^{\mathrm{a}}$ & 1.00 & \\
Product Receptivity & $.42^{\mathrm{a}}$ & $.62^{\mathrm{a}}$ & $.44^{\mathrm{a}}$ & $.38^{\mathrm{a}}$ & .05 & $.51^{\mathrm{a}}$ & 1.00 \\
\hline
\end{tabular}

${ }^{1}$ LISREL Path Analysis using Maximum Likelihood; model converged in 15 iterations; ${ }^{a} p>0.01 ;{ }^{b}>0.05$ (2-tailed).

The constructs are assessed further using Confirmatory Factor Analysis (CFA) to see if the variables group as proposed. Loading factors are calculated for each variable, and for each country of interest, with a target loading of 0.7 for individual variables, and a target loading of 0.5 for shared variances, or the average communality, for each construct. In cases where the results of the factor analysis indicate poor variable "fit", the construct composition is re-evaluated. 


\subsection{Confirmatory Factor Analysis}

Linear Structural Relationships (LISREL version 8.72) program is used for CFA, beginning with the PRELIS program to screen the SPSS data files and prepare matrices for analysis. A hierarchical approach toward building the final model is followed, by testing two nested models, or subsets of the final full model. For each of the eight cases, three CFA models are tested: a Product Model, containing the two country image constructs and the three product constructs; a Tourism Model, containing the two country image constructs and the two tourism constructs; and finally, a Full Model, containing the two country image constructs, the three product constructs, and the two tourism constructs. The tourism model contains one less construct than the product model because Destination Familiarity is a single-item construct, and therefore not included in the CFA.

All eight Product Models and all eight Tourism Models are included in Appendix H. Table 22 summarizes the measures of fit for the two nested models and the full models. Three measures of fit are considered. First, chi-squared is divided by degrees of freedom to produce a normed chi-square statistic (NC) that indicates reasonable model fit if less than 5.0, and a better fit if closer to 2.0 [Bollen, 1989]. In all cases the NC is less than 5.0, and is lower for the full model, ranging from 2.72 to 3.51 , suggesting that the full model with all constructs is a better fit with the data.

The Root Mean Square Error of Approximation (RMSEA) also improves. The scores for the Product and Tourism Models are around 0.10 which suggests poor fit, whereas the scores for the Full Models are all around 0.80, which suggests reasonable error of approximation [Kline, 2005, pg. 139]. Lastly, the Comparative Fit Index (CFI) is 
provided, and in the full models is greater than 0.90 , again suggesting reasonably good fit [Kline, 2005, pg. 140].

Table 22: Comparison of Product, Tourism and Full Model Fit Statistics

\begin{tabular}{|c|c|c|c|c|c|c|c|c|}
\hline & \multicolumn{4}{|c|}{ South Korea $n=349$} & \multicolumn{4}{|c|}{ Canada n=307 } \\
\hline & U.S. & Japan & Austr & Canada & U.S. & Japan & Austr & SKorea \\
\hline \multicolumn{9}{|c|}{ Product Model } \\
\hline$\chi^{2} /$ d.f. & 4.08 & 3.85 & 2.85 & 2.98 & 3.98 & $3 . \overline{67}$ & 4.05 & 4.66 \\
\hline RMSEA & .094 & .091 & .073 & .075 & .099 & .093 & .100 & .109 \\
\hline CFI & .90 & .91 & .93 & .94 & .90 & .93 & .89 & .89 \\
\hline \multicolumn{9}{|c|}{ Tourism Model } \\
\hline$\chi^{2} /$ d.f. & 3.78 & 3.39 & 3.96 & 3.48 & 5.34 & 4.06 & 6.33 & 4.61 \\
\hline RMSEA & .089 & .083 & .092 & .084 & .119 & .100 & .132 & .109 \\
\hline $\mathrm{CFI}$ & .93 & .94 & .94 & .96 & .90 & .93 & .91 & .93 \\
\hline \multicolumn{9}{|c|}{ Full Model } \\
\hline$\chi^{2} /$ d.f. & 3.32 & 3.16 & 2.72 & 2.74 & 3.51 & 3.03 & 3.77 & 3.39 \\
\hline RMSEA & .082 & .079 & .070 & .071 & .091 & .081 & .095 & .088 \\
\hline CFI & .92 & .93 & .93 & .94 & .92 & .93 & .91 & .93 \\
\hline
\end{tabular}

Now that the fit of the Full Model has been tested, the individual path coefficients, or the causal effect of factors on observed scores, are considered. The standardized coefficients are presented in Table 23 for the full CFAs for all country models. The estimates of measurement error are included in brackets. The full CFA was kept as a unidimensional measurement model meaning each measure is associated with only one construct.

CFA produced statistically significant factor loadings in excess of 0.5 , except for wealth, and the measures of Product Familiarity and Product Receptivity. The Beliefs constructs, Affective Country Image, and Destination Receptivity measures all loaded well. For some items, such as use, a low coefficient is an exception (0.36), and so the measure is maintained. However, for closer ties, more than half the coefficients are below 0.5 , and so this measure is dropped from the SEM analysis to follow. All other measures 
are retained at this stage, given that SEM takes into account measurement error. The low path scores for Product Familiarity and Product Receptivity are considered in the final analysis.

Table 23: Confirmatory Factor Analysis Loadings by Construct

\begin{tabular}{|c|c|c|c|c|c|c|c|c|c|}
\hline & \multicolumn{4}{|c|}{ South Korea $n=349$} & \multicolumn{4}{|c|}{ Canada n=307 } & \multirow{2}{*}{$\begin{array}{l}\text { Ave } \\
\mathbf{R}^{2}\end{array}$} \\
\hline & U.S. & Japan & Austr & Canada & U.S. & Japan & Austr & SKorea & \\
\hline \multicolumn{10}{|c|}{ Cognitive Country Image } \\
\hline Quality of life & $.58(.67)$ & $8(.66)$ & $.67(.56)$ & $.59(.65)$ & $.58(.67)$ & $.55(.70)$ & $.62(.62)$ & $.73(.47)$ & .38 \\
\hline Wealth & .55(.69) & $.51(.74)$ & $.54(.71)$ & $.51(.74)$ & $.33(.89)$ & $.40(.84)$ & $.35(.88)$ & $.49(.76)$ & .22 \\
\hline Technology level & $.56(.68)$ & $.52(.73)$ & $.54(.71)$ & $.64(.60)$ & $.52(.73)$ & $.66(.56)$ & $.45(.80)$ & $.52(.73)$ & .31 \\
\hline Education & $.63(.60)$ & $.64(.59)$ & $.69(.52)$ & $.72(.47)$ & $.65(.58)$ & $.81(.35)$ & $.70(.51)$ & $.70(.50)$ & .49 \\
\hline \multicolumn{10}{|c|}{ Affective Country Image } \\
\hline Pleasant & $.59(.66)$ & $.74(.46)$ & $.67(.55)$ & $.75(.44)$ & $.63(.61)$ & $.68(.54)$ & $.68(.53)$ & $.71(.49)$ & .47 \\
\hline Frien & $.62(.61)$ & $.63(.60)$ & $.63(.61)$ & $.61(.62)$ & $.73(.47)$ & $.77(.40)$ & $.72(.48)$ & $.62(.62)$ & .45 \\
\hline Safety & & $.54(.71)$ & $.71(.50)$ & $.66(.57)$ & $.67(.55)$ & $.80(.36)$ & $.79(.37)$ & $.73(.47)$ & .48 \\
\hline Trustworthy & $.82(.32)$ & $.71(.50)$ & $.71(.49)$ & $.74(.46)$ & $.81(.35)$ & $.84(.29)$ & $.82(.33)$ & $.80(.36)$ & .61 \\
\hline \multicolumn{10}{|l|}{ Product Beliefs } \\
\hline Quality & $.70(.51)$ & $.69(.53)$ & $.61(.63)$ & $.60(.63)$ & $.67(.55)$ & $.71(.50)$ & $.60(.64)$ & $.68(.53)$ & .44 \\
\hline Wo & $.72(.49)$ & $.77(.41)$ & $.60(.64)$ & $.78(.40)$ & $.71(.50)$ & $.79(.38)$ & $.69(.53)$ & $.77(.41)$ & .53 \\
\hline $\operatorname{Rec}$ & $.67(.55)$ & $.84(.29)$ & $.65(.57)$ & $.62(.62)$ & $.58(.66)$ & $.74(.45)$ & $.57(.67)$ & $.63(.60)$ & .45 \\
\hline Inn & $.78(.39)$ & $.82(.32)$ & $.73(.47)$ & $.70(.50)$ & $.64(.59)$ & $.68(.53)$ & $.69(.53)$ & $.69(.53)$ & .52 \\
\hline Value for Money & $.77(.40)$ & $.77(.41)$ & $.62(.62)$ & $.65(.58)$ & $.78(.40)$ & $.74(.46)$ & $.73(.47)$ & $.68(.54)$ & .52 \\
\hline \multicolumn{10}{|l|}{ Destination Beliefs } \\
\hline App & $.75(.44)$ & $.76(.42)$ & $.76(.42)$ & $.75(.44)$ & $.69(.52)$ & $.73(.47)$ & $\overline{58)}$ & $.75(.43)$ & .54 \\
\hline Qus & $.79(.38)$ & $.80(.35)$ & $.80(.37)$ & $.78(.38)$ & $.73(.46)$ & $.77(.41)$ & $.84(.29)$ & $.86(.25)$ & .64 \\
\hline RaI & & $84(.29)$ & $85(.27)$ & $.78(.40)$ & $.82(.33)$ & $.85(.28)$ & 23) & $.88(.23)$ & .71 \\
\hline Value for money & .59 & $.39(.85)$ & $.55(.70)$ & $.51(.74)$ & $41)$ & $.53(.72)$ & & $.73(.46)$ & .37 \\
\hline \multicolumn{10}{|c|}{ Product Familiarity } \\
\hline Use & 7) & $(.53)$ & & & & $.70(.51)$ & 31) & $.75(.45)$ & .48 \\
\hline Eas & & $.77(.41)$ & $.66(.56)$ & & & $.45(.80)$ & 66) & $.61(.63)$ & .34 \\
\hline Satisfaction & 1.0 & $.65(.58)$ & .46 & .40 & 45) & $.77(.41)$ & 92) & $.44(.80)$ & .40 \\
\hline \multicolumn{10}{|c|}{ Product Receptivity } \\
\hline Willi & $.79(.38)$ & $.66(.56)$ & $.79(.38)$ & $.68(.54)$ & $.78(.39)$ & $.85(.31)$ & $81)$ & $.42(.83)$ & .48 \\
\hline Ope & $48 c^{2}$ & $.58(.66)$ & & & & .531 & 33) & $.89(.21)$ & .36 \\
\hline & & $.59(.65)$ & & & & $.43(.82)$ & 46) & $.78(.39)$ & .22 \\
\hline Ownership pride & $.54(.71)$ & $.56(.69)$ & $.70(.51)$ & $.50(.75)$ & $.48(.77)$ & $.46(.79)$ & $.35(.88)$ & $.33(.89)$ & .25 \\
\hline \multicolumn{10}{|c|}{ Destination Receptivity } \\
\hline Willir & $.58(.66)$ & $.78(.39)$ & 47) & & & $.59(.65)$ & 48) & $.63(.61)$ & .44 \\
\hline Ideal & $.53(.72)$ & $.58(.66)$ & $.58(.66)$ & & & $.78(.39)$ & $.65(.57)$ & $.83(.31)$ & .48 \\
\hline Good destination & $.78(.39)$ & $.73(.46)$ & $.68(.54)$ & $.85(.28)$ & $.80(.36)$ & $.90(.18)$ & $.80(.35)$ & $.91(.18)$ & .66 \\
\hline
\end{tabular}

Table 23 includes the $\mathrm{R}^{2}$ values for each item, averaged across the eight CFAs, as a measure of the percentage of variance explained by the variable. For example, range of activities is very strong, accounting for $71 \%$ of the variance. The Product Belief 
measures are also strong, all accounting for approximately half the variance. The $\mathrm{R}^{2} \mathrm{~s}$ for Affective Country Image items are higher than those for Cognitive Country Image items, with the lowest explanation of variance being for wealth, at $22 \%$. Other relatively low $\mathrm{R}^{2} \mathrm{~s}$ are found in Product Receptivity (25\% for ownship pride), and the items in Product Familiarity and Destination Receptivity range from $34 \%$ for ease to find to $66 \%$ for good tourism destination. Again, the only item dropped at this stage is closer ties, given the acceptable statistical results of the CFA, and the consideration that SEM accounts for measurement error. 


\section{Chapter 7 Structural Equation Modeling Analyses and Results}

Now that the constructs have satisfied the measures of validity and reliability, the full structural equation models containing both the measurement models and the hypothesized structural relationships are estimated. SEM analysis begins with the fitting of the models to the data for each of the eight sample-target country combinations. This process required several iterations, because the models would not converge to an admissible solution when all 21 hypothesized relationships were included. To derive one "best" model that fit for each case, six paths were dropped, all of which are directly measurable through reduced formula equations, produced by LISREL for each exogenous to endogenous construct path. By eliminating the direct paths from the model, a generalizable model with reasonable fit for the eight cases was found, without losing the ability to statistically measure all 21 hypothesized relationships. Additionally, reduced form equations provide an $\mathrm{R}^{2}$ measure as an indication of the model's explanatory power, discussed later in Section 7.6. The eight IMPI models are presented as Figures 23-a to h.

The IMPI is recursive, with only unidirectional casual effects, and disturbances that are assumed to be uncorrelated. The absence of feedback loops between constructs facilitates the analysis of the model, which is not complex in terms of its structure, but does comprise a relatively large number of parameters. The model is over-identified, in that there are more observations than model parameters, thus enabling the derivation of unique estimates for each parameter. Degrees of Freedom for the model, when all 26 variables are included, equals $281: 26(27) / 2=351-70$ parameters (15 direct effects, 26 observed, 26 unobserved variances, and 3 exogenous construct covariances). To scale the latent variables, one reference parameter is set to 1.0 for each construct. 
The numbers in the models represent the Maximum Likelihood estimates of the parameters. While the unstandardized parameters are used later to test the hypotheses, the coefficients shown in the models are standardized parameters for ease of interpretation. For example, the estimated standardized path coefficient for the effect of Cognitive Country Image on Affective Country Image in the first model (SK-US) is 0.75 , meaning that an increase of one standard deviation in the Cognitive Country Image mean would result in a 0.75 increase in the Affective Country Image mean standard deviation. It is important to also consider the standard error for each parameter in order to calculate a Z-score, thereby determining whether the parameter is statistically significant or not. Due to a relatively large standard error, the Cognitive Country Image to Affective Country Image path is not significant here. On the other hand, the 0.29 parameter for the Affective Country Image to Product Receptivity path is significant. All significant model paths in Figures 23a-h are indicated by dark lines, and non-significant paths are indicated by dashed lines.

\subsection{Path Structure}

A strength of LISREL is the simultaneous modeling of both the path structure and the measurement structure of a model. The path structures are presented as Figures 23a-h, followed by an assessment of each individual country model. Then, the measurement side of the model is estimated by the standardized loading coefficients, and is summarized in Table 24. Finally, the overall fit of the models is assessed, and the hypothesized model relationships are formally tested. To begin, the structure of each model is considered. 


\subsubsection{U.S. Model - South Korea Sample (SK-US)}

The product part of the SK-US model is relatively strong, confirming the relationship of Cognitive Country Image to Product Beliefs to Product Receptivity found in past research. Product Beliefs is influenced by both Cognityyses ountry Image and Product Familiarity, which in turn influences Product Receptivity. Product Beliefs also influences Destination Receptivity. On the other hand, Affective Country Image does not have significant influence on Product Beliefs, but does influence Product Receptivity. The tourism part of the model is weaker. Neither Cognitive Country Image nor Destination Familiarity has an influence on Destination Beliefs. It is Affective Country Image that influences Destination Receptivity directly, as does Destination Beliefs. And, Destination Beliefs does not have a significant influence on Product Receptivity.

Figure 23-a: U.S. Model, South Korean Sample

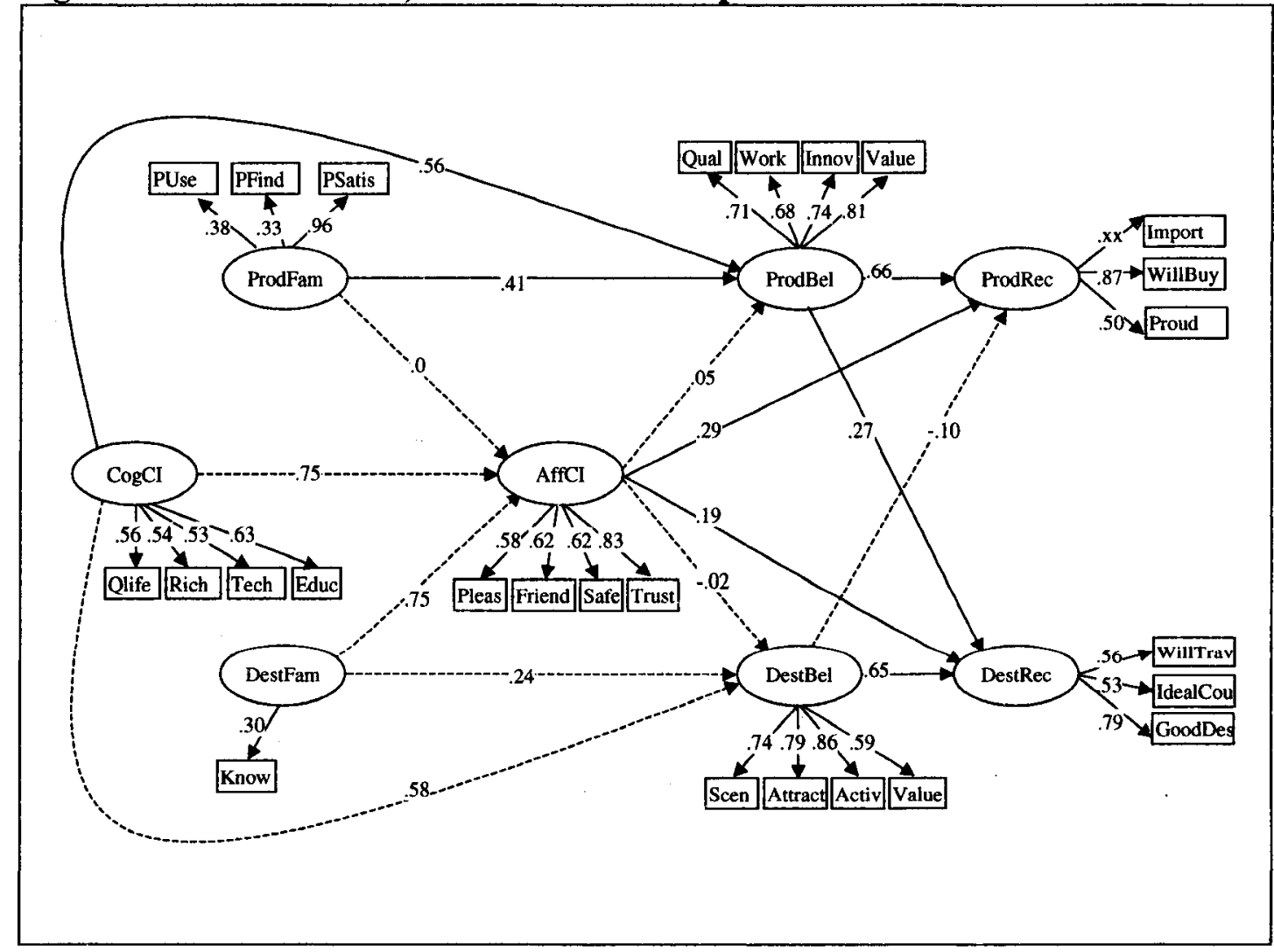




\subsubsection{Japan Model - South Korea Sample (SK-JP)}

The SK-JP model shares the same strengths as the SK-US model for the product part. Product Beliefs is influenced by both Cognitive Country Image and by Product Familiarity, which in turn influences Product Receptivity. Product Beliefs also influences Destination Receptivity. Affective Country Image has a significant influence directly on Product Receptivity, but not on Product Beliefs. The Tourism part is somewhat stronger here than was the case in the SK-US model, and more directly parallels the product side of the model. Both Cognitive Country Image and Destination Familiarity have a significant influence on Destination Beliefs, and Affective Country Image influences Destination Receptivity directly, but not Destination Beliefs. Again, Product Beliefs influences Destination Receptivity, yet Destination Beliefs does not influence Product Receptivity.

\section{Figure 23-b: Japan Model, South Korea Sample}

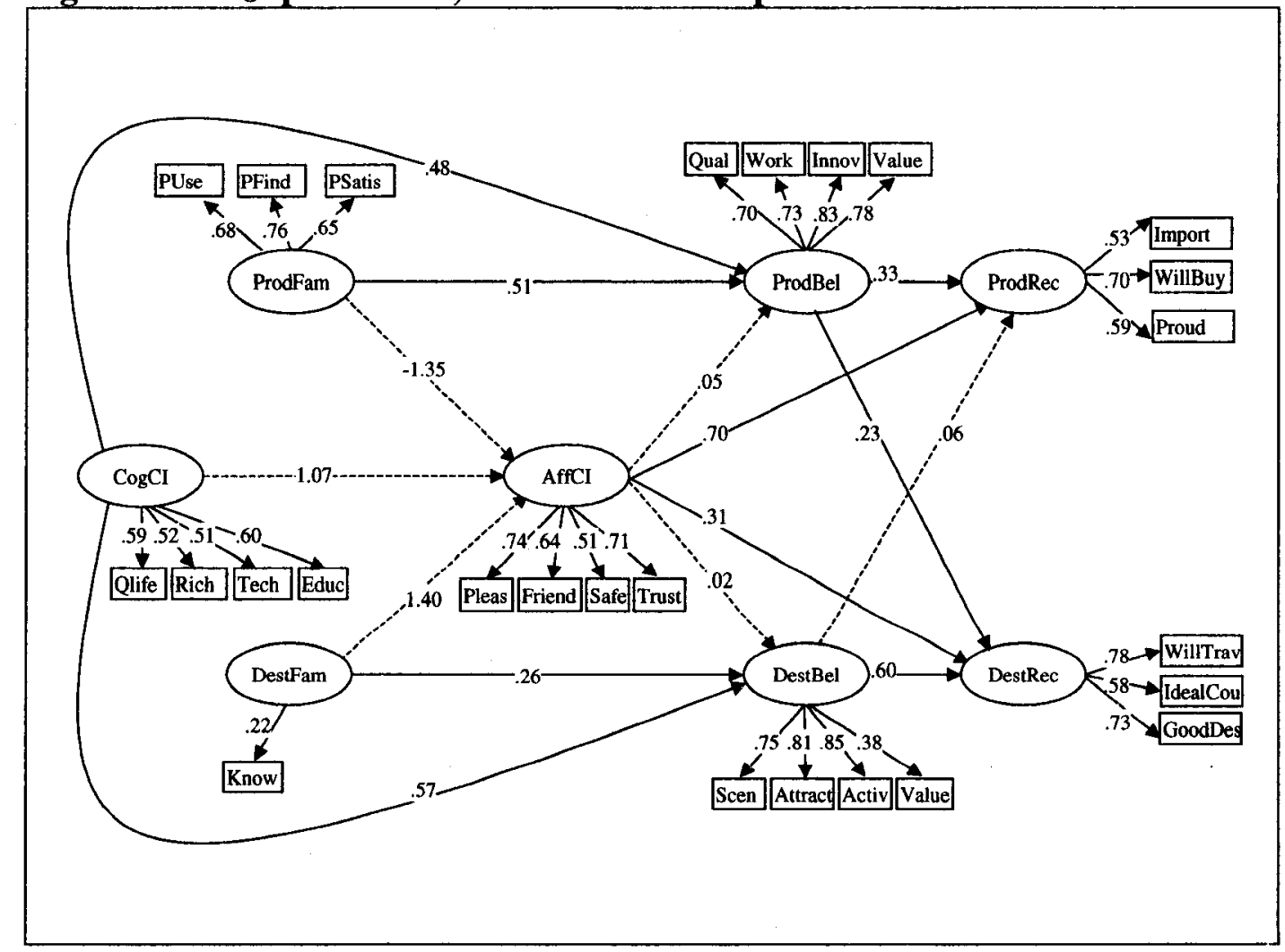




\subsubsection{Australia Model - South Korea Sample (SK-AU)}

Again, for the product part of the model, Cognitive Country Image and Product Familiarity significantly influence Product Beliefs, and Affective Country Image influences Product Receptivity, but not Product Beliefs. Yet in this model, Product Beliefs does not influence Destination Receptivity. The tourism part of the model differs as well. Cognitive Country Image influences Affective Country Image, which in turn influences Destination Receptivity. Oddly, Destination Familiarity has a negative influence on Destination Beliefs, meaning that the less one knows about Australia, the more highly one rates it as a tourism destination, suggesting the presence of an Australian "mystique".

Figure 23-c: Australia Model, South Korea Sample

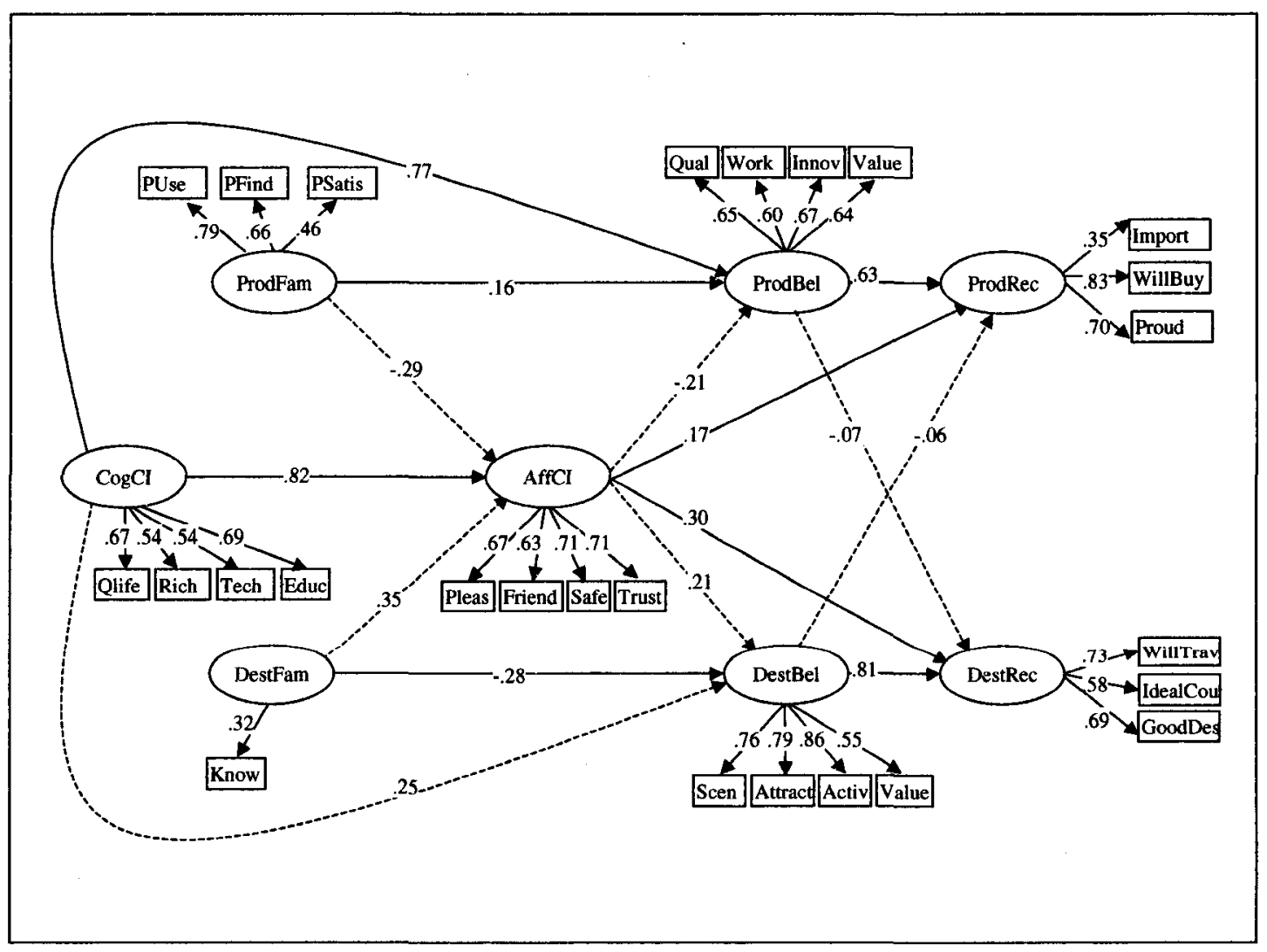




\subsubsection{Canada Model - South Korea Sample (SK-CA)}

For the SK-CA model, the influence of Cognitive Country Image on Product Beliefs is non-significant, and it is only Product Familiarity that significantly influences Product Beliefs, which in turn, influences Product Receptivity. For the tourism part, Cognitive Country Image influences Affective Country Image, which then influences Destination Receptivity. Again, Product Receptivity influences Destination Receptivity, yet Destination Beliefs does not influence Product Receptivity.

Figure 23-d: Canada Model, South Korea Sample

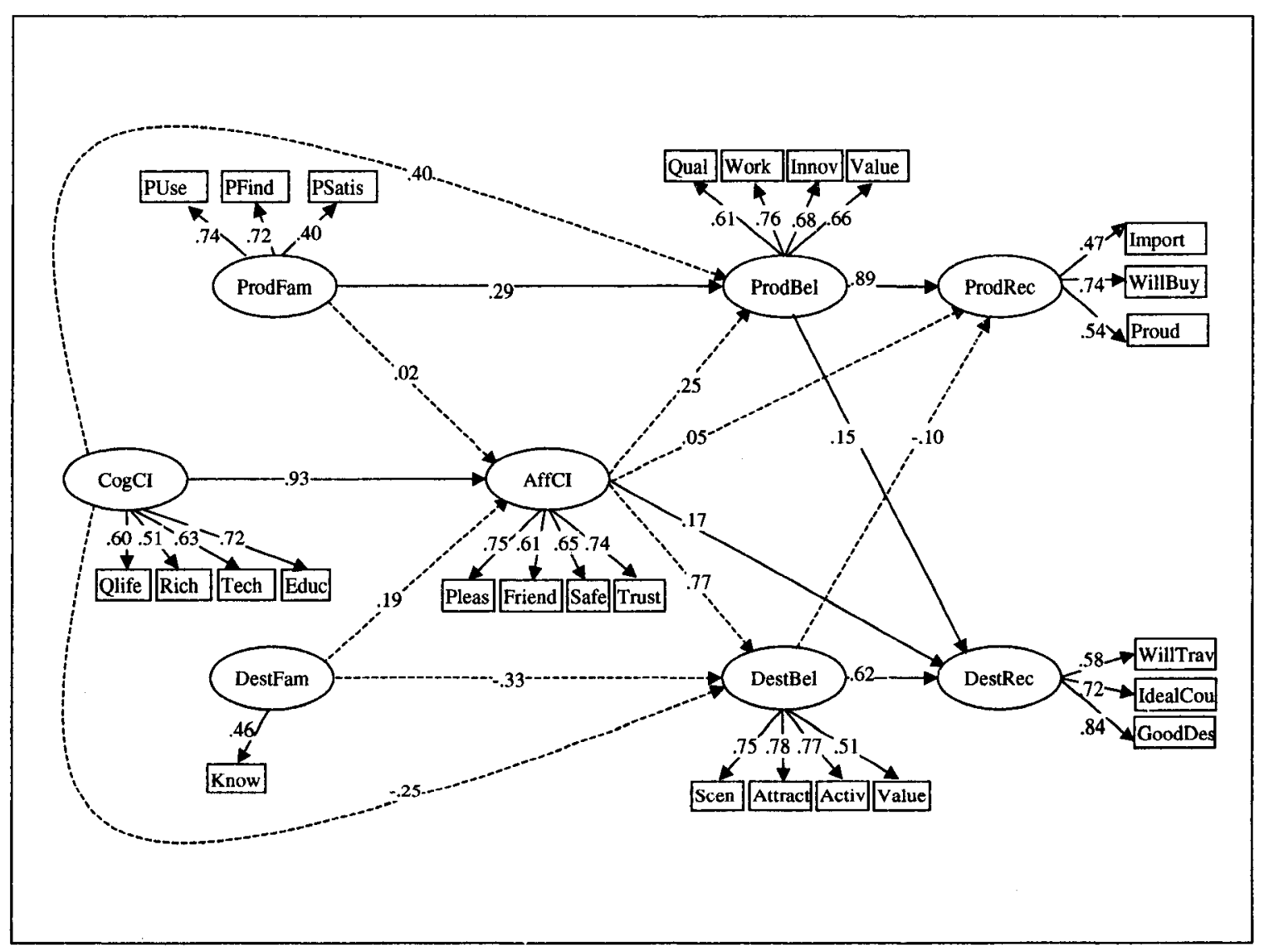




\subsubsection{U.S. Model - Canada Sample (CA-US)}

CA-US is the only model where all three paths from Cognitive Country Image - to Product Beliefs, Destination Beliefs and Affective Country Image - are significant. For the product part, however, Product Familiarity does not influence Product Beliefs, and Affective Country Image has a negative influence on Product Beliefs. Affective Country Image also has a negative influence on Destination Beliefs, meaning that Canadians rate U.S. products and destination attributes quite high, despite rating affective measures such as trust and safety quite low. Affective Country Image does have a positive influence on Destination Receptivity, and this is the first model where Destination Beliefs influences Product Receptivity, as well as Product Beliefs influencing Destination Receptivity for a dual cross-over effect.

\section{Figure 23-e: U.S. Model, Canada Sample}

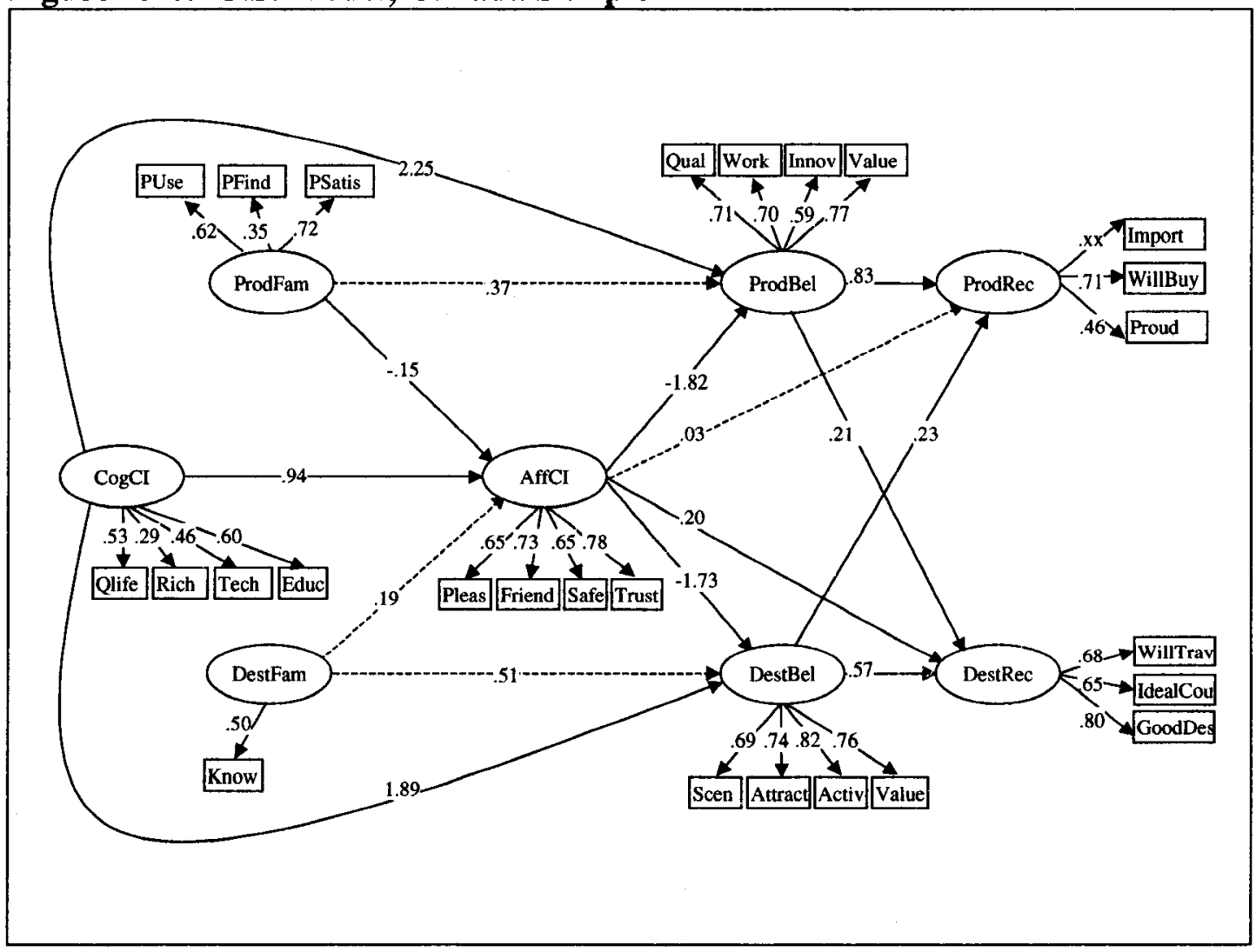




\subsubsection{Japan Model - Canada Sample (CA-JP)}

For the CA-JP model to converge, additional paths were dropped from the Destination Familiarity construct. Thus, the influence of Destination Familiarity is unmeasurable in this model. In contrast, Product Familiarity has a significant influence on both Product Beliefs and Affective Country Image. Product Beliefs in turn influences both Product Receptivity and Destination Receptivity. Cognitive Country Image significantly influences Affective Country Image, which influences both Destination Beliefs and Destination Receptivity. Destination Beliefs also influences Product Receptivity, supporting the dual cross-over effect once more.

\section{Figure 23-f: Japan Model, Canada Sample}

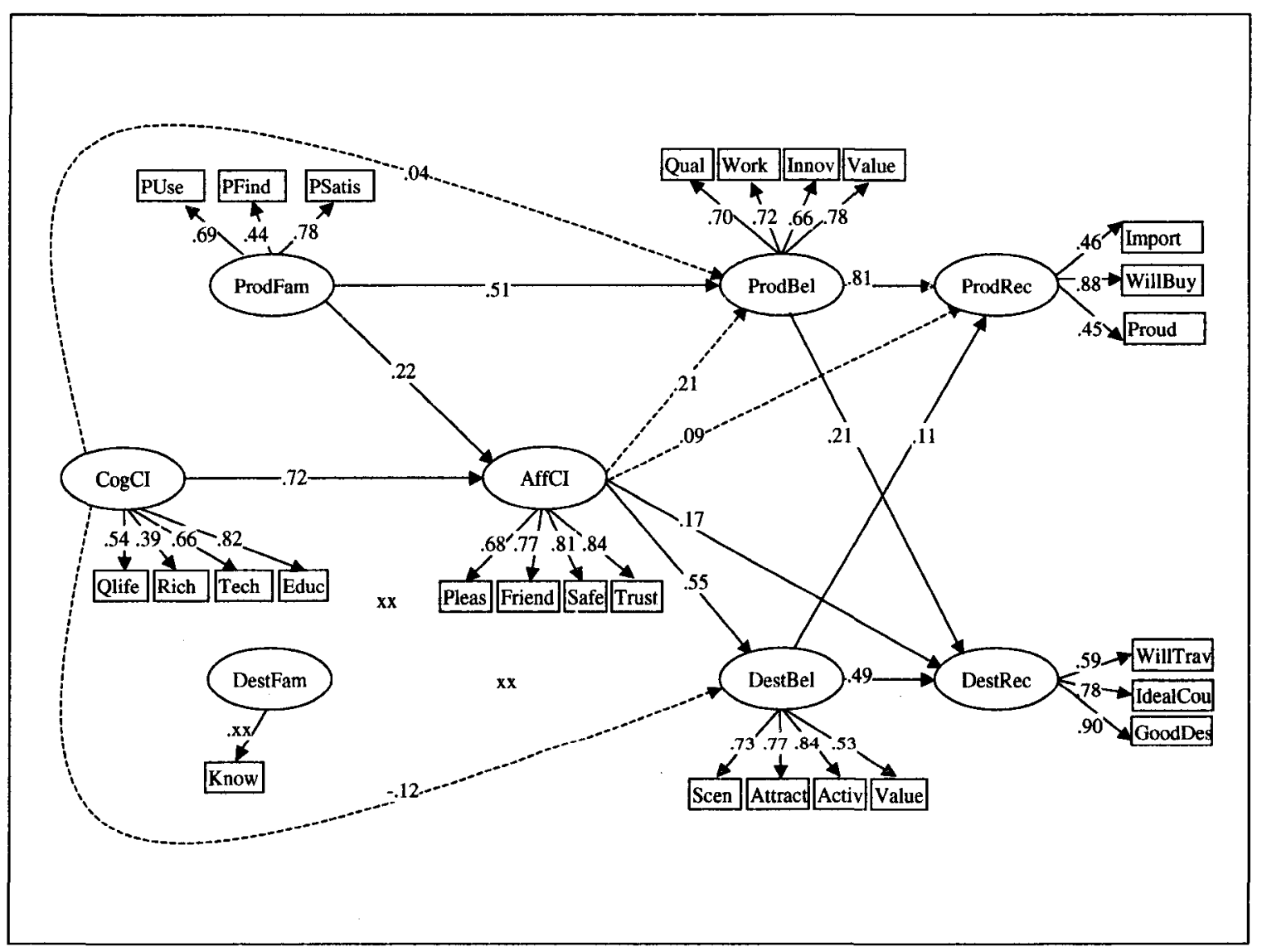




\subsubsection{Australia Model - Canada Sample (CA-AU)}

The CA-AU model is unique in that Cognitive Country Image does not significantly influence Product Beliefs, but does influence Destination Beliefs, making the tourism side the relatively stronger side of the model. The product part of the model is weaker, with only Product Beliefs and Affective Country Image influencing Product Receptivity. And here, rather than Product Beliefs influencing Destination Receptivity, it is Destination Beliefs that influences Product Receptivity.

\section{Figure 23-g: Australia Model, Canada Sample}

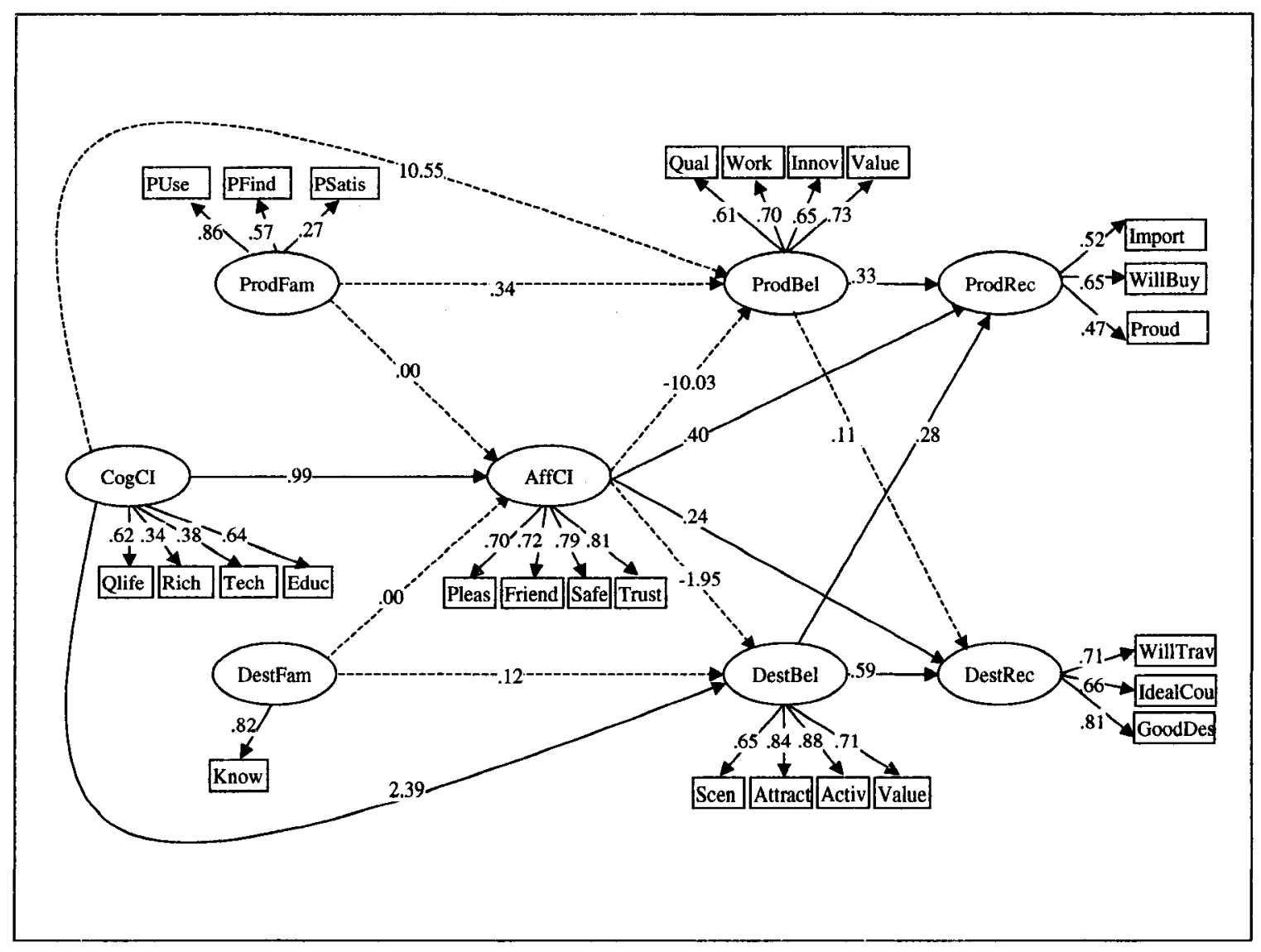




\subsubsection{South Korea Model - Canada Sample (CA-SK)}

The strongest paths in the CA-SK model are from Cognitive Country Image to Affective Country Image, and from Affective Country Image to both Product Beliefs and Destination Beliefs. Product Familiarity also influences Product Beliefs, whereas Destination Familiarity does not have any significance influence. Product Beliefs also influences Destination Receptivity, but Destination Beliefs does not influence Product Receptivity.

\section{Figure 23-h: South Korea Model, Canada Sample}

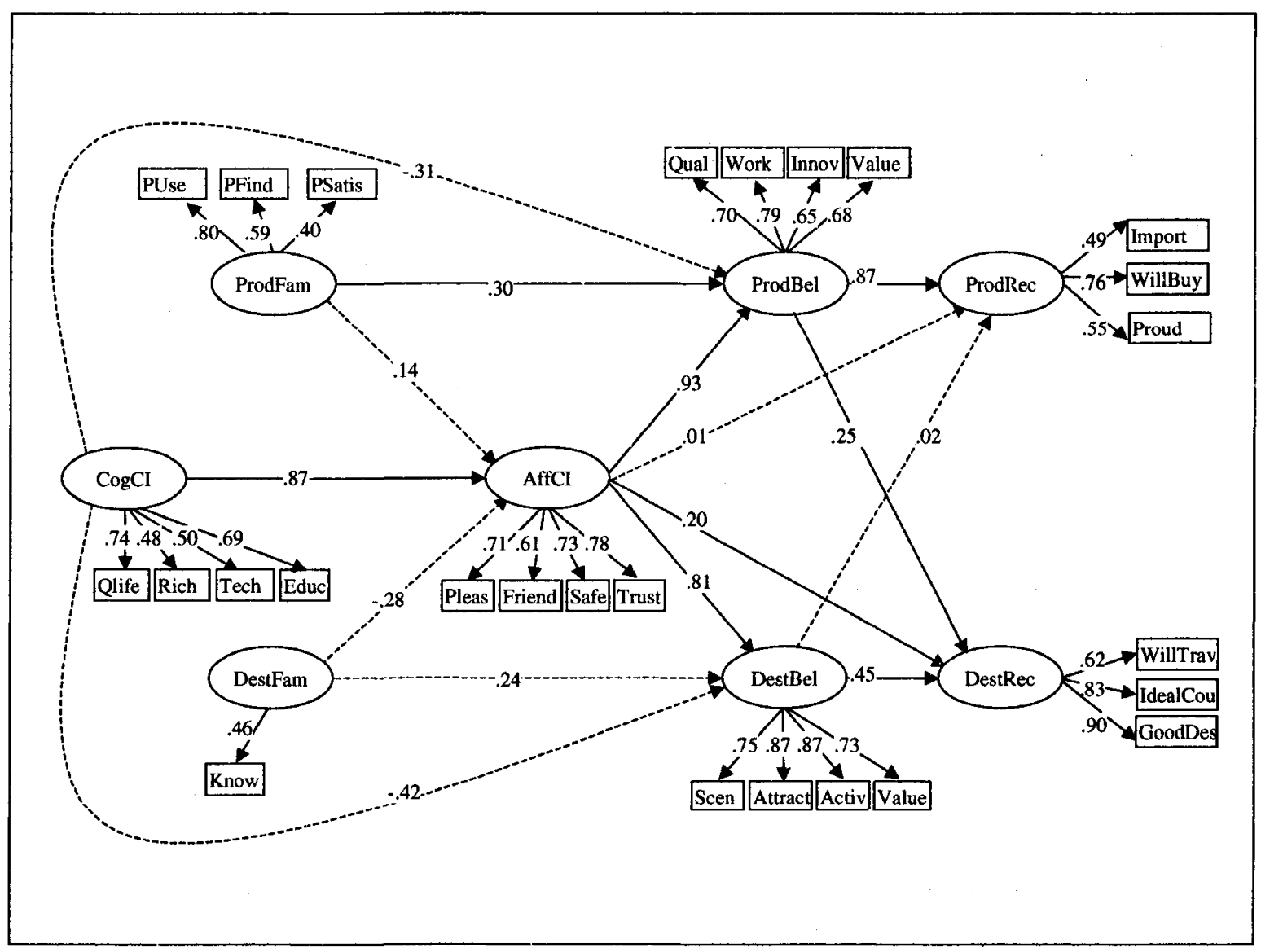




\subsection{Measurement Structure}

The measurement structure of the model is estimated by the standardized path coefficients, or factor loadings, of each observed variable to its latent construct. The loadings are presented in Table 24 for all country models. The estimates of measurement error are included in brackets. As expected, the SEM measurement results are similar to the CFA results. Table 24 also includes the $\mathrm{R}^{2}$ values for each item, averaged across the eight SEMs, as a measure of the explained variance.

Within the Cognitive Country Image construct, education is the strongest measure, loading consistently above 0.60 and accounting for $46 \%$ of variance. By comparison, wealth and technology level are weaker measures, accounting for $22 \%$ and $28 \%$ of variance respectively. Statistically, Affective Country Image, Product Beliefs and Destination Beliefs are the strongest constructs, with the majority of factor loadings above 0.60 , and $\mathrm{R}^{2}$ ranging from $37 \%$ (Destination value for money) to a high of $72 \%$ (Destination activities).

Poduct Familiarity measures are less consistent. For example, loadings for use range from a low of 0.38 (SK-US) to a high of 0.86 (CA-AU), and loadings for satisfaction range from 0.27 (CA-AU) to 0.96 (SK-US). Despite opposing results, both measures are retained in the search for a generalizable model. Likewise, country knowledge is retained as the sole measure of Destination Familiarity, despite a relatively low $\mathrm{R}^{2}$ of $23 \%$.

Product Receptivity also produced interesting results. Here, two country models, SK-US and CA-US, would not converge when open to imports was included as a measure. This reflects what would seem to be an interesting consumer dilemma for 
South Koreans and Canadians alike. While both are willing to buy American goods, and are proud to own them, they are less receptive to more imports, perhaps due to the high level of imports the U.S. already holds within both countries relative to other foreign importers.

Table 24: Structural Equation Model Variable Loadings by Construct

\begin{tabular}{|c|c|c|c|c|c|c|c|c|c|}
\hline & \multicolumn{4}{|c|}{ Korea $n=349$} & \multicolumn{4}{|c|}{ Canada $n=307$} & \multirow{2}{*}{$\begin{array}{l}\text { Ave } \\
R^{2} \\
\end{array}$} \\
\hline & U.S. & Japan & Austr & Canada & U.S. & Japan & Austr & SK & \\
\hline \multicolumn{10}{|c|}{ Cognitive Country Image } \\
\hline Quality of life & $.56(.69)$ & $.59(.66)$ & $.67(.55)$ & $.60(.64)$ & $.53(.72)$ & $.54(.71)$ & $.62(.62)$ & $.74(.46)$ & .37 \\
\hline Wealth & $.54(.70)$ & $.52(.73)$ & $.54(.71)$ & $.51(.74)$ & $.29(.91)$ & $.39(.84)$ & $.34(.88)$ & $.48(.76)$ & .22 \\
\hline Technology level & $.53(.72)$ & $.51(.74)$ & $.54(.71)$ & $.63(.60)$ & $.46(.78)$ & $.66(.57)$ & $.38(.86)$ & $.50(.75)$ & .28 \\
\hline Education & $.63(.61)$ & $.60(.64)$ & $.69(.52)$ & $.72(.48)$ & $.60(.64)$ & $.82(.33)$ & $.64(.59)$ & $.69(.52)$ & .46 \\
\hline \multicolumn{10}{|c|}{ Affective Country Image } \\
\hline Pleasant & $.58(.67)$ & $.74(.45)$ & $.67(.55)$ & $.75(.43)$ & $.65(.57)$ & $.68(.4)$ & $.70(.51)$ & $.71(.49)$ & .47 \\
\hline Friendly & $.62(61)$ & $.64(.59)$ & $.63(.60)$ & $.61(.63)$ & $.73(.46)$ & $.77(.41)$ & $.72(.48)$ & $.61(.63)$ & .45 \\
\hline Safety & $.62(.62)$ & $.51(.74)$ & $.71(.50)$ & $.65(.57)$ & $.65(.58)$ & $.81(.35)$ & $.79(.38)$ & $.73(.47)$ & .47 \\
\hline Trustworthy & $.83(.32)$ & $.71(.50)$ & $.71(.49)$ & $.74(.46)$ & $.78(.39)$ & $.84(.30)$ & $.81(.35)$ & $.78(.39)$ & .60 \\
\hline \multicolumn{10}{|l|}{ Product Beliefs } \\
\hline Quality & $.71(.50)$ & $.70(.51)$ & $.65(.57)$ & $.61(.63)$ & $.71(.50)$ & $.70(.51)$ & $.61(.63)$ & $.70(.52)$ & .45 \\
\hline Workmanship & $.68(.54)$ & $73(.46)$ & $.60(.64)$ & $.76(.43)$ & $.70(.51)$ & $.72(.47)$ & $.70(.50)$ & $.79(37)$ & .51 \\
\hline Innovativeness & $.74(.45)$ & $.83(.31)$ & $.67(.55)$ & $.68(.54)$ & $.59(.65)$ & $.66(.57)$ & $.65(.57)$ & $.65(.57)$ & .47 \\
\hline Value for Money & $.81(.35)$ & $.78(.39)$ & $.64(.59)$ & $.66(.56)$ & $.77(.41)$ & $.78(.39)$ & $.73(.47)$ & $.68(.54)$ & .54 \\
\hline \multicolumn{10}{|c|}{ Destination Beliefs } \\
\hline Appeal. scenery & $.74(.45)$ & $.75(.44)$ & $.76(.42)$ & $.75(.44)$ & $.69(52)$ & $.73(.47)$ & $.65(.48)$ & $.75(.43)$ & .53 \\
\hline Qual. attractions & $.79(.37)$ & $.81(.35)$ & $.79(.37)$ & $.78(.39)$ & $.74(45)$ & $.77(.41)$ & $.84(.30)$ & $.87(.25)$ & .64 \\
\hline Range activities & $.86(.26)$ & $.85(.27)$ & $.86(27)$ & $.77(.40)$ & $.82(.32)$ & $.84(.29)$ & $.88(.23)$ & $.87(.24)$ & .72 \\
\hline Value for money & $.59(.65)$ & $.38(.85)$ & $.55(.70)$ & $.51(.74)$ & $.76(.46)$ & $.53(.72)$ & $.71(.50)$ & $.73(.46)$ & .37 \\
\hline \multicolumn{10}{|c|}{ Product Familiarity } \\
\hline Use & $.38(.86)$ & $.68(.53)$ & $.79(.38)$ & $.74(.45)$ & $.62(.62)$ & $.69(.52)$ & $.86(.26)$ & $.80(.36)$ & .50 \\
\hline Ease to find & $.33(.89)$ & $.76(.43)$ & $.66(.57)$ & $.72(.48)$ & $.35(.88)$ & $.44(.80)$ & $.57(.68)$ & $.59(.65)$ & .33 \\
\hline Satisfaction & $.96(.07)$ & $.65(.57)$ & $.46(.79)$ & $.40(.84)$ & $.72(.48)$ & $.78(.40)$ & $.27(.93)$ & $.40(.84)$ & .39 \\
\hline \multicolumn{10}{|c|}{ Destination Familiarity } \\
\hline Coun.Knowledge & $.30(.91)$ & $.22(.95)$ & $.32(.90)$ & $.46(.79)$ & $.50(.75)$ & na & $.82(.33)$ & $.46(.79)$ & .23 \\
\hline \multicolumn{10}{|c|}{ Product Receptivity } \\
\hline Open to imports & na & $.53(.72)$ & $.35(.86)$ & $.47(.78)$ & na & $.46(.79)$ & $.52(.73)$ & $.49(.76)$ & .24 \\
\hline Willing to buy. & $.87(.25)$ & $.70(.51)$ & $.82(.31)$ & $.74(.46)$ & $.71(.50)$ & $.88(.23)$ & $.65(.58)$ & $.76(.43)$ & .59 \\
\hline Ownership pride & $.50(.75)$ & $.59(.66)$ & $.71(.51)$ & $.54(.71)$ & $.46(.78)$ & $.45(.80)$ & $.47(.77)$ & $.55(.70)$ & .29 \\
\hline \multicolumn{10}{|c|}{ Destination Receptivity } \\
\hline Willing to travel & $.56(.69)$ & $.78(.39)$ & $.73(.47)$ & $.58(.67)$ & $.68(.54)$ & $.68(.54)$ & $.71(.49)$ & $.62(.61)$ & .44 \\
\hline Ideal Country & $.53(.72)$ & $.58(.66)$ & $.58(.67)$ & $.72(.48)$ & $.65(.58)$ & $.65(.58)$ & $.66(.56)$ & $.83(.31)$ & .45 \\
\hline Good destination & $79(.37)$ & $.73(47)$ & $.69(.53)$ & $.82(.29)$ & $.80(.36)$ & $.80(.36)$ & $.81(.34)$ & $.90(.19)$ & .66 \\
\hline
\end{tabular}

Destination Receptivity is another interesting construct. The three items willing to travel, good tourism destination and ideal country were not predicted to load together 
as a measure of Destination Receptivity but they do, in fact, perform well as a final dependent measure within the model. The construct name is maintained to reflect Destination Receptivity, broader in meaning than originally intended, yet statistically, and logically, valid as a summary measure of consumer's overall destination receptiveness.

In summary, while the 26 variables performance varies across the eight models, overall they represent a good set of measures with broad applicability that can be applied in order to identify unique strengths and weaknesses. For example, the poor performance of open to imports in the U.S. models reveals an interesting consumer attitude toward American products that would not be detectable if this measure were dropped. Though this likely lowers the overall fit of the models, the variables are retained, in part based on theoretical grounds and results of past research, and in order to allow for a fuller exploration of the key relationships that are posited.

\subsection{Hypotheses Testing}

To test the study hypotheses, the structural parameters produced by the SEM analysis for each country-of-interest model are assessed in terms of their significance. Where the $z$-value of a structural parameter (equal to the ratio between a parameter estimate and its standard error) is greater than 1.96 , the paraneter is considered significant at the 0.05 level $(\mathrm{p}>0.05)$. A companion Table with $z$-values is included as Appendix I for reference. This path analysis leads to the confirmation or rejection of the 21 hypothesized model relationships. 
Table 25 includes the standardized path coefficients for all models, with an asterisk indicating those that are statistically significant. The two columns at the far right summarize the number of Significant and Non-significant paths. The interpretation of these findings either supports or does not support, the conceptual model as proposed. For most, hypothesized relationships are confirmed for some models, but not all. In such cases, individual parameter estimates and significance levels are scrutinized in terms of scale and direction, and consideration is given to the reduced form equation results.

Table 25: Path Coefficients for All Hypothesized Relationships, by Model ${ }^{1}$

\begin{tabular}{|c|c|c|c|c|c|c|c|c|c|c|c|}
\hline & & \multicolumn{4}{|c|}{ South Korea $n=349$} & \multicolumn{4}{|c|}{ Canada Models n = 307} & $\mathbf{S}$ & $\mathbf{N}$ \\
\hline Hyp & Path & US & $\mathbf{J P}$ & $\mathbf{A U}$ & $\mathbf{C A}$ & US & $\mathbf{J P}$ & $\mathbf{A U}$ & SK & & \\
\hline H1 & CogCI-AffCI & 0.75 & 1.07 & $0.82^{*}$ & $0.93^{*}$ & $0.94^{*}$ & $0.72^{*}$ & $0.99 *$ & $0.87^{*}$ & 6 & 2 \\
\hline $\mathbf{H 2}$ & CogCI-ProdBel & $0.56^{*}$ & $0.48^{*}$ & $0.77^{*}$ & 0.40 & $2.25^{*}$ & 0.04 & 10.55 & -0.31 & 4 & 4 \\
\hline H3 & ogCI-DestBel & 0.58 & $0.57 *$ & 0.25 & -0.25 & $1.89^{*}$ & $-0 . \overline{12}$ & $2.39 *$ & -0.42 & 3 & 5 \\
\hline H4 & $\mathrm{ffC}$ & 0.05 & 0.05 & -0.21 & 0.25 & $-1.82^{*}$ & 0.21 & -10.3 & $0.93^{*}$ & 2 & 6 \\
\hline H5 & Bel & -0.02 & 0.02 & 0.21 & 0.77 & $-1.73^{*}$ & $0.56^{*}$ & -1.95 & $0.81^{*}$ & 3 & 5 \\
\hline H6 & 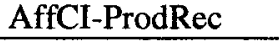 & $0.29 *$ & $0.70^{*}$ & $0.17 *$ & 0.05 & 0.03 & 0.09 & $0.40^{*}$ & 0.01 & 4 & 4 \\
\hline H7 & & $0.19 *$ & $0.31^{*}$ & $0.30^{*}$ & $0.17^{*}$ & $0.20 *$ & $0.17^{*}$ & $0.24 *$ & $0.20^{*}$ & 8 & 0 \\
\hline H8 & & $0.66^{*}$ & $0.33^{*}$ & $0.63^{*}$ & $0.89 *$ & $0.83 *$ & $0.81 *$ & $0.33^{*}$ & $0.87^{*}$ & 8 & $\mathbf{0}$ \\
\hline H9 & & $0.27^{*}$ & $0.23^{*}$ & -.070 & $0.15^{*}$ & $0.21^{*}$ & $0.21 *$ & 0.11 & $.025^{*}$ & 6 & 2 \\
\hline H10 & es & -0.10 & 0.06 & -0.06 & -0.10 & $0.23 *$ & $0.11 *$ & $0.28 *$ & 0.02 & 3 & 5 \\
\hline H11 & 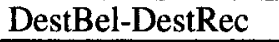 & $0.65 *$ & $0.60 *$ & $0.81 *$ & $0.62 *$ & $0.57 *$ & $0.49 *$ & $0.59 *$ & $0.45^{*}$ & 8 & $\mathbf{0}$ \\
\hline H12 & rod & $0.41^{*}$ & $0.51^{*}$ & $0.16^{*}$ & $0.29 *$ & 0.37 & $0.51^{*}$ & 0.34 & $0.30^{*}$ & 6 & 2 \\
\hline H13 & & 00 & -0.03 & -0.06 & 0.01 & $0.26^{*}$ & $0.56^{*}$ & -0.01 & 0.11 & 2 & 6 \\
\hline H14 & Prod & $0.27 *$ & -0.81 & 0.09 & $0.26^{*}$ & $0.59 *$ & $0.49^{*}$ & $0.10^{*}$ & $0.37^{*}$ & 6 & 2 \\
\hline H15 & Prod & 0.11 & -0.33 & -0.15 & 0.05 & $0.25^{*}$ & $0.21 *$ & 0.03 & 0.18 & 2 & 6 \\
\hline H16 & Destlf & 0.09 & 0.20 & -0.15 & 0.07 & -0.42 & $-\cdots$ & -0.01 & -0.34 & 0 & 7 \\
\hline H17 & Dest & 0.24 & $0.71^{*}$ & $-0.57^{*}$ & -0.33 & 0.64 & $-\cdots$ & 0.12 & 0.31 & 2 & 5 \\
\hline H18 & DestF & 0.49 & 2.80 & 0.06 & 0.10 & -0.29 & $-\cdots$ & 0.02 & -0.30 & $\mathbf{0}$ & 7 \\
\hline H19 & DestF & 0.67 & 1.69 & -0.11 & -0.11 & 0.09 & $-\cdots$ & 0.05 & -0.15 & 0 & 7 \\
\hline $\mathbf{H 2 0}$ & DestF & 0.75 & 1.40 & 0.72 & 0.27 & 0.23 & $-\cdots$ & 0.0 & -0.28 & $\mathbf{0}$ & 7 \\
\hline $\mathbf{H 2 1}$ & Prod & 0.0 & -1.35 & -0.29 & 0.02 & $-0.15^{*}$ & $0.22 *$ & 0.0 & 0.14 & 2 & 6 \\
\hline $\mathbf{H}_{22}{ }^{2}$ & CogCI - ProdRec & $0.55^{*}$ & 0.96 & $0.50^{*}$ & $0.56^{*}$ & $0.53^{*}$ & $0.26^{*}$ & $0.72^{*}$ & $0.45^{*}$ & 7 & 1 \\
\hline $\mathrm{H}_{23^{2}}$ & $\mathrm{CogCI}$ - De & $0.68^{*}$ & 0.10 & $0.54^{*}$ & $0.54^{*}$ & $0.45^{*}$ & $0.30^{*}$ & 0.56 & $0.43^{*}$ & 6 & 2 \\
\hline & RMSEA & .076 & .078 & .066 & .066 & .086 & .073 & .088 & .081 & & \\
\hline
\end{tabular}

*Statistically significant path at $\mathrm{p}>0.05$ level.

${ }^{1}$ Standardized coefficients.

${ }^{2}$ Not included in the original model, but additionally tested through reduced form equations. 
To begin, as the model posits, Cognitive Country Image is positively related to three constructs: Affective Country Image, Product Beliefs and Destination Beliefs. Cognitive Country Image is positively related to Affective Country Image in all eight models, and is significant in six. Thus, $\mathrm{H} 1$ is strongly supported. Cognitive Country Image is positively related to beliefs about its products in seven of eight models, and is significant in four, whereas Cognitive Country Image is positively related to beliefs about it as a destination in five of eight models, and is significant in three. Thus, $\mathrm{H} 2$ is moderately supported, and $\mathrm{H} 3$ is partially supported.

Next, the model posits that Affective Country Image is positively related to four constructs: Product Beliefs and Product Receptivity, and Destination Beliefs and Destination Receptivity. In both cases, the relationship from Affective Country Image to Beliefs is weaker than the relationship from Affective Country Image to Receptivity. Additionally, the influence of Affective Country Image on the product side of the model is weaker than its influence on the destination side. Affective Country Image is positively related to Product Beliefs in $\mathbf{5}$ of $\mathbf{8}$ models, yet is significant in only two (one of which is negative). Thus, $\mathrm{H} 4$ is not supported. Affective Country Image is positively related to Destination Beliefs in five of eight models, and is significant in three (one of which is negative). Thus, H5 is only partially supported. By comparison, Affective Country Image is positively related to Product Receptivity in all models, and is significant in four, moderately supporting H6. Lastly, Affective Country Image is positively related to Destination Receptivity in all models, and is significant in all, strongly supporting $\mathrm{H} 7$. 
Turning to Product Beliefs, as the model posits, Product Beliefs is positively related to two constructs: Product Receptivity and Destination Receptivity. Product Beliefs is positively and significantly related to Product Receptivity in all models. Thus, H8 is strongly supported, confirming past PCI research. Similarly, Product Beliefs is positively related to Destination Receptivity in all models, and significant in six. Thus, $\mathrm{H} 9$, the cross-over influence of product beliefs on destination receptivity, is also strongly supported.

Destination Beliefs has a similar relationship to Destination Receptivity and Product Receptivity, but the cross-over effect is weaker in this direction. Destination Beliefs is positively related to Product Receptivity in seven of eight models, and significant in four ( 1 of which is negative). Thus, H10 is moderately supported. As expected, Destination Beliefs is positively and significantly related to Destination Receptivity in all models, strongly supporting $\mathrm{H} 11$.

Looking next at Product Familiarity, the model posits that Product Familiarity is positively related to five constructs: Product and Destination Beliefs, Product and Destination Receptivity, and Affective Country Image. Only two of these relationships are strongly supported. Product Familiarity is positively and significantly related to both Product Beliefs and Product Receptivity in six models. Thus, H12 and H14 are strongly supported. Two additional hypotheses, Product Familiarity to Destination Beliefs and to Destination Receptivity, are positively related in five of eight models, and significantly related in two and three models respectively. Thus, $\mathrm{H} 13$ and $\mathrm{H} 15$ are partially supported, suggesting some additional influence from the product to destination side of the model. 
Lastly, Product Familiarity is significantly related to Affective Country Image in only one model. Thus, H16 is not supported.

Table 26: Summary of Hypotheses Support

\begin{tabular}{|l|l|l|l|}
\hline Hyp & From & To & Support \\
\hline H1 & Cognitive Country Image & Affective Country Image & Strong \\
\hline H2 & Cognitive Country Image & Product Beliefs & Moderate \\
\hline H3 & Cognitive Country Image & Destination Beliefs & Partial \\
\hline H4 & Affective Country Image & Product Beliefs & No \\
\hline H5 & Affective Country Image & Destination Beliefs & Partial \\
\hline H6 & Affective Country Image & Product Receptivity & Moderate \\
\hline H7 & Affective Country Image & Destination Receptivity & Strong \\
\hline H8 & Product Beliefs & Product Receptivity & Strong \\
\hline H9 & Product Beliefs & Destination Receptivity & Strong \\
\hline H10 & Destination Beliefs & Product Receptivity & Partial \\
\hline H11 & Destination Beliefs & Destination Receptivity & Strong \\
\hline H12 & Product Familiarity & Product Beliefs & Strong \\
\hline H13 & Product Familiarity & Destination Beliefs & Partial \\
\hline H14 & Product Familiarity & Product Receptivity & Strong \\
\hline H15 & Product Familiarity & Destination Receptivity & Partial \\
\hline H16 & Product Familiarity & Affective Country Image & No \\
\hline H17 & Destination Familiarity & Product Beliefs & No \\
\hline H18 & Destination Familiarity & Destination Beliefs & No \\
\hline H19 & Destination Familiarity & Product Receptivity & No \\
\hline H20 & Destination Familiarity & Destination Receptivity & No \\
\hline H21 & Destination Familiarity & Affective Country Image & No \\
\hline H221 & Cognitive Country Image & Product Receptivity & Strong \\
\hline H23 & Cognitive Country Image & Destination Receptivity & Strong \\
\hline Based & examination Z Z & Scores: Strong \\
\hline
\end{tabular}
\begin{tabular}{lllll}
\hline Based on examination of $Z$ scores: Strong $=9$ & Moderate $=2$ & Partial $=5$ & No $=7$
\end{tabular} Not included in the original model, but additionally tested through reduced form equations.

Similarly, the model posits that Destination Familiarity is positively related to five constructs: Destination and Product Beliefs, Destination and Product Receptivity, and Affective Country Image. None of these relationships are supported. Even the path from Destination Familiarity to Destination Beliefs, though positive in five of eight models, is only significant in two ( 1 of which is negative). Thus, H17 through $\mathrm{H} 21$ are not 
supported. Unfortunately, contributing to this result may be the relatively poor performance of Destination Familiarity, the one single-item construct of the model.

\subsection{Model Fit}

Finally, to assess the overall fit of the model, multiple measures are used, as listed in Table 27. Three measures of fit are considered. Chi-square $\left(\mathrm{X}^{2}\right)$ divided by degrees of freedom (d.f.) indicates that a model has reasonable fit if the statistic is less than four [Taylor and Todd 1995], and a better fit if closer to 2.0 [Bollen, 1989]. In all cases, the $\mathrm{NC}$ is less than 3.4, ranging from 2.51 for the SK-AU model to 3.39 for the $\mathrm{CA}-\mathrm{AU}$ model, suggesting that the models fit the data. This is supported by the RMSEA statistics that range from 0.066 to 0.088 , indicating reasonable error of approximation [Kline, 2005, pg. 139]. Lastly, the Comparative Fit Index (CFI) is greater than 0.90 in all models, again suggesting reasonably good fit [Kline, 2005, pg. 140]. The difference in the measures of fit across the models is quite minimal.

Table 27: Comparison of Final Model Fit Statistics

\begin{tabular}{|l|c|c|c|c|l|l|l|l|}
\hline & \multicolumn{4}{|l|}{ South Korea n 349 } & \multicolumn{3}{l|}{ Canada n=307 } \\
\hline & U.S. & Japan & Austr & Canada & U.S. & Japan & Austr & SKorea \\
\hline $\mathrm{X}^{2}$ & 773.99 & 881.40 & 645.80 & 708.29 & 835.77 & 742.11 & 953.15 & 843.55 \\
\hline d.f. & 257 & 281 & 257 & 281 & 257 & 261 & 281 & 281 \\
\hline $\mathrm{X}^{2}$ /d.f. & 3.01 & 3.14 & 2.51 & 2.52 & 3.25 & 2.84 & 3.39 & 3.00 \\
\hline RMSEA & .076 & .078 & .066 & .066 & .086 & .078 & .088 & .081 \\
\hline CFI & .93 & .93 & .94 & .94 & .93 & .94 & .92 & .93 \\
\hline
\end{tabular}

\subsection{Summary of Model Results}

As summarized in Table 26 , the path analysis strongly supports seven posited paths, moderately supports two, partially supports five, and does not support seven. The majority of the paths are positive, as was hypothesized, with few exceptions. 
The final results of the hypothesis testing are presented as Figure 24, with strongly supported paths indicated by dark lines, moderately supported paths by large dashed lines, partially supported paths by small dashed lines, and unsupported paths indicated by faint lines. Overall, the model fits the data reasonably well across the eight cases. One-third of the model paths represent strong relationships between constructs, one-third represent moderate or partially supported relationships, and one-third of the posited relationships are not supported.

\section{Figure 24: Final Integrated Model of Place Image}

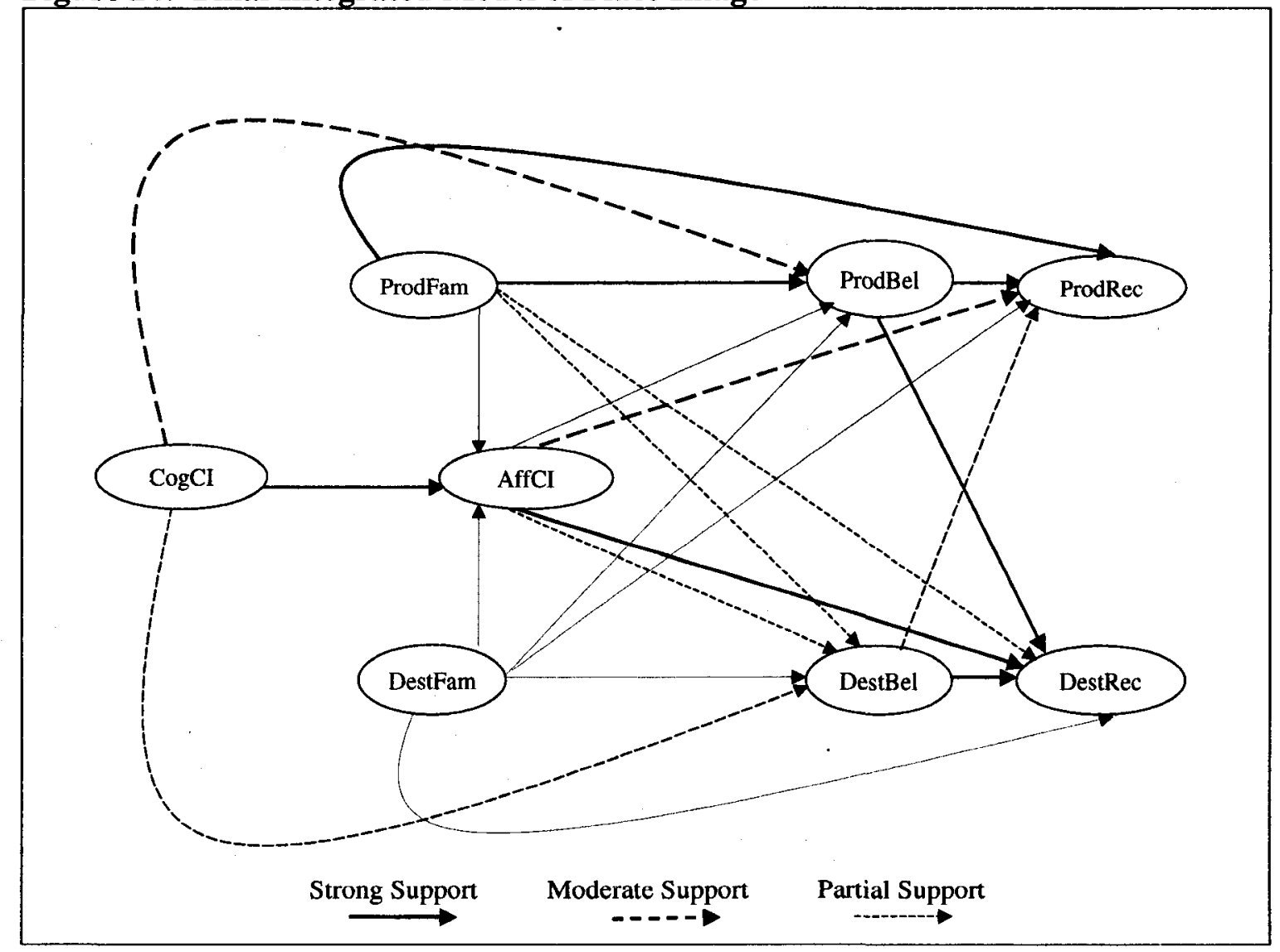

Looking more closely at the strongest relationships in Figure 24, it is evident that country image has a significant influence on consumers' beliefs and their receptivity to 
goods and travel. Though not included in the original model, the paths from Cognitive Country Image to Product Receptivity and Destination Receptivity were additionally tested. The results are included in Table 28. Cognitive Country Image has a significant influence on Product Receptivity and Destination Receptivity in seven and six cases respectively, and all are positive, thus strongly supporting both relationships. The cognitive components of country image prove particularly strong, in that they also have a strong influence on Affective Country Image, and a moderate influence on Product and Destination Beliefs. In contrast, Affective Country Image strongly influences Destination Receptivity and moderately influences Product Receptivity, and only weakly influences Destination Beliefs, but not Product Beliefs. So while Cognitive Country Image has a stronger influence on the product side of the model, Affective Country Image has a stronger influence on the destination side.

Product Beliefs is also an influential construct in the model, with significant relationships to not only Product Receptivity but to Destination Receptivity. This supports the cross-over hypothesis, that what one believes about a country's products will not only influence their receptivity to that country's goods but also their receptivity toward that country as a travel destination. Though weak, Product Familiarity also has some influence on Destination Beliefs and Receptivity.

The reverse, however, does not hold. Destination Familiarity does not influence the product side of the model at all, nor does it even influence Destination Beliefs. And unlike the strong influence of Product Beliefs on Destination Receptivity, Destination Beliefs has only a weak influence on Product Receptivity. This suggests that consumers, as marketers well know, can be rather savvy. For example, if one feels that a place is 
likely able to produce a wide range of desirable products, one is likely to also feel that such a place offers good accommodations and attractions, a good range of tourism activities, and good value for money, as well as good "scenery". All of these are characteristics of a well-developed and broad-based tourism destination, like the U.S., but are unlike "strong scenery" destinations in less-developed countries or "urban-only" destinations in more developed counterparts. On the other hand, a country's natural endowments, which add to its range of tourism offerings, may not necessarily mean that that country also is an able producer of quality products. Still, the fact that H10 was in the right direction in five cases, and significantly so in three, suggests that a cross-over relationship from destination to product is also likely, though less pronounced. In summary, the product side of the model has a stronger influence on the destination side of the model, than the reverse.

Considering the resulting paths, from country image to beliefs to receptivity, the one for PCI, concerning products, confirms the findings of many earlier studies that have reported it in the past. Since the equivalent path within the TDI context had not been tested before, its confirmation in this study points to the value of the cross-disciplinary exchange of ideas and contributes in its own right to the TDI literature. Additionally, by simultaneously testing PCI and TDI, the similarities and differences of each path are notable. Interestingly, cognitive country image has greater influence on the product side of the model, affective country image has greater influence on the destination side, and familiarity only influences product beliefs and behaviours. 


\subsection{Explanatory Power of the Model}

In addition to the analysis of the hypothesized relationships, another method of assessing the appropriateness of the model is to consider the amount of variance of the dependent variables explained or accounted for by the independent variables, or in this case, exogenous constructs. Table 28 below shows the Coefficients of Determination, or $\mathrm{R}^{2}$, based on the LISREL reduced form equations, not the structural equations. Unlike the structural equations, the reduced form equations produce $\mathrm{R}^{2}$ estimates that have similar interpretation to that of a regression equation [Joreskog, 2000].

Table 28: Reduced Form Equations $\mathbf{R}^{2}$ for Endogenous Model Constructs

\begin{tabular}{|c|c|c|c|c|c|c|c|c|c|}
\hline & \multicolumn{4}{|c|}{ South Korea $n=349$} & \multicolumn{4}{|c|}{ Canada $\mathbf{n}=\mathbf{3 0 7}$} & \\
\hline & US & JP & $\mathbf{A U}$ & CA & US & $\mathbf{J P}$ & $\mathbf{A U}$ & SK & Ave. \\
\hline Affective Image & .70 & .82 & .65 & .84 & .93 & .69 & .99 & .75 & .80 \\
\hline Product Beliefs & .63 & .60 & .38 & .41 & .72 & .42 & .39 & .37 & .49 \\
\hline Destination Beliefs & .28 & .34 & .27 & .28 & .32 & .12 & .24 & .11 & .25 \\
\hline Product Receptivity & .44 & .63 & .25 & .33 & .69 & .39 & .53 & .29 & .44 \\
\hline Destination Recep. & .46 & .51 & .36 & .30 & .42 & .18 & .34 & .20 & .35 \\
\hline
\end{tabular}

The $R^{2} s$ in Table 28 represent the amount of variance explained by the three exogenous model constructs: Cognitive Country Image, Product Familiarity and Destination Familiarity. $\mathrm{R}^{2}$ is highest for Affective Country Image, where $80 \%$ of variance is explained, reflecting the significant correlation between the Cognitive and Affective constructs. The $\mathrm{R}^{2}$ s for Product Beliefs and Product Receptivity are fairly high, at $49 \%$ and $44 \%$ respectively. The $\mathrm{R}^{2}$ is lowest for Destination Beliefs, where only $25 \%$ of the variance is explained. Here, the measurement for Destination Familiarity failed to have a significant influence, which leaves opportunity for future research to identify what factors most strongly influence Destination Beliefs. The $R^{2}$ for Destination Receptivity is higher, at $35 \%$, reflecting the stronger influence of the country image constructs directly 
on receptivity. In summary, the measures included in the model have fairly strong explanatory power, meaning that what was accounted for, largely mattered. Yet, as expected when attempting to measure such broad concepts as beliefs and behaviour, there are more influencers than have been captured in one model.

\subsection{Cross-Country Applicability}

The analysis of the eight structural model results and hypotheses suggests that differences might exist. To more rigorously test the invariance of the model to determine whether the country sampled has an influence on the structural model for the observed variables, multiple group structural equation modeling is used. Steenkamp and Baumgartner [1998] describe a process of multi-group confirmatory factor analysis to assess various aspects of measurement invariance. Consideration is given primarily to assessing configural invariance, as the goal of the study is to identify whether the model can be conceptualized in the same pattern across countries. Parameters are constrained to be equal, or allowed to vary freely across the groups. A comparison of the statistical significance of the difference in Goodness of Fit between the constrained and unconstrained models suggests that the model structure is, in fact, invariant across countries. Through constraining loadings in the null hypothesis test, described below, the model appears to also be metric invariant (measurement scales exhibit a similar interpretation across countries) and scalar invariant (responses are not obviously biased upward or downward).

The Full Information Maximum Likelihood (FIML) method in LISREL 8.7 for Windows is used to fit the measurement model to the two multivariate data sets: South 
Korea and Canada. The evaluation scores for the United States, Japan and Australia are used, first to fit each measurement model separately, and then to cross-validate the models across the two country groups. Appendix J presents the results for the U.S. test of the null hypothesis (H0), that the model is identical across sample countries (South Korea and Canada), and the alternative hypothesis test (H1), that the model is not identical across sample countries. For the H1 test, the LISREL syntax specifies that the variance and covariance parameters of the model are different across the two groups. For the H0 test, the relationships are not specified for the second country, thus it is assumed to be identical, including equal parameters, to the first country model. The H0 model fit, RMSEA $=0.083$, indicates a good fit of the "equal" or "identical" model to the data.

Table 29: Cross-Country Hypothesis Testing of Model Invariance

\begin{tabular}{|l|r|r|r|}
\hline Hypotheses & U.S. & Japan & Australia \\
\hline Alternative $(H 1): \chi^{2}$ UnEqual & $2,082.59$ & $1,997.69$ & $2,165.52$ \\
\hline Null $(H 0): \chi^{2}$ Equal & $1,892.92$ & $1,853.37$ & $1,478.22$ \\
\hline$\chi^{2}$ Difference & $\mathbf{1 8 9 . 6 7}$ & $\mathbf{1 4 4 . 3 2}$ & $\mathbf{6 8 7 . 3 0}$ \\
\hline
\end{tabular}

The test was repeated for Japan and Australia. To compare the results of the HO hypothesis, and the alternative hypothesis (H1), that the model is not identical across sample countries, the Chi-square difference is shown in Table 29 for all three tests. In all cases, the difference in chi-square supports the null hypothesis, meaning that the cross validation of the measurement model is supported by the two-country data. This finding strengthens the support of the accepted hypotheses. 


\section{Chapter 8 Discussion and Implications}

The systematic and analytical approach of studying a mix of place image components, by multiple methods, helps a place to identify its most unique attributes, its assets, and its vulnerabilities, as dominant associations emerge. Images are mental schemata that have a profound effect on buyer behaviour, since they reflect "a complex web of associations" [Hawkins, Best and Coney, 2001] among concepts, constructs, generalizations, objects, events, and feelings that "form a person's intellectual framework" [DeChenne, 1993] and that typically lead to stereotyping as consumers chunk information to make their environment more manageable [Yarhouse 2000]. Hawkins, Best and Coney [2001:343-344] note that elements are stored in an "associative network of nodes" in one's memory. Stereotyping results when dominant associations between existing nodes are applied to all objects, people, or events in a category [Stangor and Lange, 1994] or, when facts are imagined which fit each concept [DeChenne, 1993].

The associations identified in this study not only reveal an interesting picture of what the image is of each of the U.S., Japan, Australia, Canada and South Korea, but importantly, how the general country, product, and tourism components of their images are related. While the former contribution can support, quite directly, practitioners' development of place marketing strategy, the later contribution to the theoretical foundations of place image research is hopefully significant and more important in the context of this thesis. The next two sections summarize the principal findings of the study and review its limitations. This is followed by a discussion of implications of the results for academic researchers, business practitioners, and public policy makers, as well as an 
overview of implications for Canada in general and a summary of potential directions for future research.

\subsection{Summary of Results}

Tables $30 \mathrm{a}$ to $30 \mathrm{~d}$ put together the main findings of the open-ended responses, the mean analysis, and the structural relationships for each of the target countries. The strong elements that are most commonly recalled tell much about a country's image, and its distinctiveness in the consumers' mind. For Japan, it is Tokyo and Sony - geographic and product associations, that when considered with consumer evaluations that highly rate technology level and product quality attributes, form an image of a strong producer nation. In contrast, for Australia it is the kangaroos and Sydney - nature and geographic associations, combined with high consumer evaluations for pleasant, ideal, and appealing scenery attributes, to form an image of a strong tourism destination.

For the U.S., its country-level associations include "big" and "rich", combined with high evaluations for both product and tourism attributes, and a range of known brand and place mentions, to form an image of a strong, diversified nation. For Canada, it is qualities of nature and good nature that stand strong, with associations such as "beautiful" and "clean", combined with high consumer evaluations for pleasant, safe, and trustworthy attributes, to form an image of, well, the true north, strong and free - free of products it might seem. The findings suggest recognition of Canada's abundant natural resources, yet with a lack of knowledge of product development, and relatively low evaluations for built tourism product (e.g. accommodations). 
Table 30-a: Summary of Main Findings for the U.S.

\begin{tabular}{|c|c|c|}
\hline Latent Constructs & South Korean data & Canadian data \\
\hline \multicolumn{3}{|c|}{ Open-Ended Responses } \\
\hline Country Image & $\begin{array}{l}\text { Many more positives (162) than } \\
\text { negatives ( } 84 \text { ) "danger", "terror"; } \\
\text { cognitive associations such as } \\
\text { "strong", "big", "rich", "free" }\end{array}$ & $\begin{array}{l}\text { Many positives (156); also many } \\
\text { negatives (108) "danger", } \\
\text { "crime"; cognitive associations: } \\
\text { "big", "rich", as well as affective } \\
\text { associations: "friendly", "fun" }\end{array}$ \\
\hline Product Image & $\begin{array}{l}\text { Top category is clothing (113); } \\
\text { Specific brands dominate }(91.7 \%)\end{array}$ & $\begin{array}{l}\text { Most mentions, with top } \\
\text { category transportation (144); } \\
\text { Specific brands (42.5\%) }\end{array}$ \\
\hline $\begin{array}{l}\text { Tourism } \\
\text { Destination Image }\end{array}$ & $\begin{array}{l}\text { Specific ( } 96.2 \% \text { ) place names (e.g. } \\
\text { New York) and attractions (e.g. } \\
\text { Disney) most common }\end{array}$ & $\begin{array}{l}\text { Same place names (e.g. New } \\
\text { York) and attractions (e.g. } \\
\text { Disney), but fewer specific } \\
\text { mentions (68.6\%) }\end{array}$ \\
\hline \multicolumn{3}{|c|}{ Analysis of Means } \\
\hline Country Image & $\begin{array}{l}\text { Cognitive measures highest (e.g. } \\
\text { technology); Affective measures } \\
\text { lower (e.g. safety, trustworthy) }\end{array}$ & $\begin{array}{l}\text { Same Cognitive measures } \\
\text { highest and Affective measures } \\
\text { lower, but less extreme }\end{array}$ \\
\hline Product Image & $\begin{array}{l}\text { Product Beliefs strong (e.g. } \\
\text { quality); but receptivity weak (e.g. } \\
\text { imports, proud to own) }\end{array}$ & $\begin{array}{l}\text { Product Beliefs strong (e.g. good } \\
\text { overall); and strong will to buy, } \\
\text { but imports and proud to own } \\
\text { weak }\end{array}$ \\
\hline $\begin{array}{l}\text { Tourism } \\
\text { Destination Image }\end{array}$ & $\begin{array}{l}\text { Destination Beliefs strong (e.g. } \\
\text { value); and will to travel moderate }\end{array}$ & $\begin{array}{l}\text { Destination Beliefs strong (e.g. } \\
\text { lots to see and do); and will to } \\
\text { travel strong }\end{array}$ \\
\hline
\end{tabular}

\section{Structural Equation Model}

\begin{tabular}{l|l|l} 
Country Image & $\begin{array}{l}\text { CogCI } \rightarrow \text { ProdBel } \rightarrow \text { ProdRec } \\
\text { AffCI } \rightarrow \text { ProdRec (not ProdBel) } \\
\text { AffCI } \rightarrow \text { DestRec (not DestBel) }\end{array}$ & $\begin{array}{l}\text { CogCI } \rightarrow \text { ProdBel } \rightarrow \text { ProdRec } \\
\text { CogCI } \rightarrow \text { DestBel } \rightarrow \text { DestRec } \\
\text { AffCI } \rightarrow \text { ProdBel is negative } \\
\text { AffCI } \rightarrow \text { DestBel is negative } \\
\text { AffCI } \rightarrow \text { DestRec (not ProdRec) }\end{array}$ \\
\hline $\begin{array}{l}\text { Product Image } \\
\text { Deurismation Image }\end{array}$ & $\begin{array}{l}\text { ProdFam } \rightarrow \text { ProdBel } \rightarrow \text { ProdRec } \\
\text { ProdBel } \rightarrow \text { DestRec }\end{array}$ & $\begin{array}{l}\text { ProdBel } \rightarrow \text { ProdRec } \\
\text { ProdBel } \rightarrow \text { DestRec }\end{array}$ \\
\hline Summary & $\begin{array}{l}\text { DestBel } \rightarrow \text { DestRec only } \\
\text { Paths to Product Receptivity are } \\
\text { from Cognitive Image to Beliefs, } \\
\text { and Familiarity to Beliefs; Path to } \\
\text { Destination Receptivity is from } \\
\text { Affective Image }\end{array}$ & $\begin{array}{l}\text { DestBel } \rightarrow \text { DestRec } \\
\text { DestBel } \rightarrow \text { ProdRec }\end{array}$ \\
$\begin{array}{l}\text { Path to Product and Destination } \\
\text { Receptivity is from Cognitive } \\
\text { Image through Beliefs; and } \\
\text { Affective Image influences } \\
\text { Receptivity, not Beliefs }\end{array}$ \\
\hline
\end{tabular}


Table 30-b: Summary of Main Findings for Japan

\begin{tabular}{l|l|l}
\hline Latent Constructs & \multicolumn{1}{|c}{ South Korean data } & \multicolumn{1}{|c}{ Open-Ended Responses } \\
\hline Country Image & $\begin{array}{l}\text { Many positives (123) and } \\
\text { negatives (110); positives are } \\
\text { general: "clean", "strong", } \\
\text { whereas negatives are very } \\
\text { personal: "mean", "double-faced" }\end{array}$ & $\begin{array}{l}\text { Many positives (118) and } \\
\text { negatives (85); positives are } \\
\text { personal: "polite", "reserved", } \\
\text { whereas negatives are more } \\
\text { general: "crowded", "expensive" }\end{array}$ \\
\hline Product Image & $\begin{array}{l}\text { Most mentions, with top } \\
\text { categories entertainment (319) } \\
\text { and transportation (103); Top } \\
\text { survey brand is Sony (224); } \\
\text { Specific brands dominate (90\%), } \\
\text { e.g. Only 3 respond "car/auto" }\end{array}$ & $\begin{array}{l}\text { Top categories are entertainment } \\
\text { (219) and transportation (165); } \\
\text { Top survey brand is Sony (55); } \\
\text { Fewer specific brand mentions } \\
\text { (37.3\%), e.g. 78 respond } \\
\text { "car/auto" }\end{array}$ \\
\hline $\begin{array}{l}\text { Tourism } \\
\text { Destination Image }\end{array}$ & $\begin{array}{l}\text { Specific (81.3\%) place names } \\
\text { (e.g. Tokyo is the top survey } \\
\text { place mention); attractions (e.g. } \\
\text { Batbu hot spa) most common }\end{array}$ & $\begin{array}{l}\text { Same place names (e.g. Tokyo) } \\
\text { and attractions (e.g. temples), but } \\
\text { fewer specific mentions (38.6\%) }\end{array}$ \\
\hline Country Image & \multicolumn{2}{|c}{ Analysis of Means } \\
\hline Product Image & $\begin{array}{l}\text { Cognitive measures strong (e.g. } \\
\text { technology); Affective measures } \\
\text { weaker (e.g. trustworthy) }\end{array}$ & $\begin{array}{l}\text { Same cognitive measure strong } \\
\text { (e.g. technology); weak Affective } \\
\text { measure is } \text { exciting }\end{array}$ \\
\hline $\begin{array}{l}\text { Product Beliefs strongest (e.g. } \\
\text { quality); but receptivity falls (e.g. } \\
\text { imports, proud to own) }\end{array}$ & $\begin{array}{l}\text { Product Beliefs strong (e.g. } \\
\text { quality); and moderate will to buy }\end{array}$ \\
\hline $\begin{array}{l}\text { Tourism } \\
\text { Destination Image }\end{array}$ & $\begin{array}{l}\text { Destination Beliefs strong (e.g. } \\
\text { value); and will to travel close in } \\
\text { strength }\end{array}$ & $\begin{array}{l}\text { Similar pattern with Destination } \\
\text { Beliefs strong (e.g. scenery); and } \\
\text { will to travel close in strength }\end{array}$ \\
\hline
\end{tabular}

Structural Equation Model

\begin{tabular}{l|l|l}
\hline Country Image & $\begin{array}{l}\text { CogCI } \rightarrow \text { ProdBel } \rightarrow \text { ProdRec } \\
\text { CogCI } \rightarrow \text { DestBel } \rightarrow \text { DestRec } \\
\text { AffCI } \rightarrow \text { ProdRec (not ProdBel) } \\
\text { AffCI } \rightarrow \text { DestRec (not DestBel) }\end{array}$ & $\begin{array}{l}\text { CogCI } \rightarrow \text { AffCI } \rightarrow \text { DestBel } \rightarrow \\
\text { DestRec } \\
\text { CogCI } \rightarrow \text { AffCI } \rightarrow \text { DestRec }\end{array}$ \\
\hline Product Image & $\begin{array}{l}\text { ProdFam } \rightarrow \text { ProdBel } \rightarrow \text { ProdRec } \\
\text { ProdBel } \rightarrow \text { DestRec }\end{array}$ & $\begin{array}{l}\text { ProdFam } \rightarrow \text { ProdBel } \rightarrow \text { ProdRec } \\
\text { ProdBel } \rightarrow \text { DestRec }\end{array}$ \\
\hline $\begin{array}{l}\text { Tourism } \\
\text { Destination Image }\end{array}$ & DestFam $\rightarrow$ DestBel $\rightarrow$ DestRec & $\begin{array}{l}\text { DestBel } \rightarrow \text { DestRec } \\
\text { DestBel } \rightarrow \text { ProdRec }\end{array}$ \\
\hline Summary & $\begin{array}{l}\text { Paths to Product and Destination } \\
\text { Receptivity are through Cognitive } \\
\text { Image to Beliefs, and Familiarity } \\
\text { to Beliefs; Affective Image } \\
\text { influences Receptivity, not } \\
\text { Beliefs }\end{array}$ & $\begin{array}{l}\text { Path to Product Receptivity is } \\
\text { only through Familiarity to } \\
\text { Beliefs; Path to Destination } \\
\text { Receptivity is from Cognitive to } \\
\text { Affective to Beliefs and } \\
\text { Receptivity }\end{array}$ \\
\hline
\end{tabular}


Table 30-c: Summary of Main Findings for Australia

\begin{tabular}{|c|c|c|}
\hline Latent Constructs & South Korean data & Canadian data \\
\hline \multicolumn{3}{|c|}{ Open-Ended Responses } \\
\hline Country Image & $\begin{array}{l}\text { Highest category response for } \\
\text { Natural Features ( } 261) \text {, with top } \\
\text { survey feature, the kangaroo } \\
(100) \text {; Very few negatives } \\
\text { mentioned (6) }\end{array}$ & $\begin{array}{l}\text { Highest category response for } \\
\text { Natural Features ( } 302) \text {, with top } \\
\text { survey feature, the kangaroo } \\
(53) \text {; Very few negatives } \\
\text { mentioned (10) }\end{array}$ \\
\hline Product Image & $\begin{array}{l}\text { Very weak }(33) ; 96.8 \% \text { blank; } \\
\text { Few known brands }(8)\end{array}$ & $\begin{array}{l}\text { Many more responses ( } 276) \text {, } \\
\text { mostly general products }(233) \text {, } \\
\text { like agriculture (45), and } \\
\text { wine/beer }\end{array}$ \\
\hline $\begin{array}{l}\text { Tourism } \\
\text { Destination Image }\end{array}$ & $\begin{array}{l}\text { Most responses in Geographic } \\
\text { Places (144), specifically Sydney } \\
\text { (92); Also, the Sydney Opera } \\
\text { House (49) }\end{array}$ & $\begin{array}{l}\text { Most responses in Nature } \\
\text { Related (194), such as the } \\
\text { outback and beaches }\end{array}$ \\
\hline \multicolumn{3}{|c|}{ Analysis of Means } \\
\hline Country Image & $\begin{array}{l}\text { Only country where Affective } \\
\text { measures (e.g. pleasant, ideal) } \\
\text { higher than Cognitive }\end{array}$ & $\begin{array}{l}\text { Only country where Affective } \\
\text { measures (e.g. pleasant, ideal) } \\
\text { higher than Cognitive }\end{array}$ \\
\hline Product Image & $\begin{array}{l}\text { Product Beliefs lowest country } \\
\text { ratings (e.g. innovativeness); } \\
\text { Product Receptivity also low (e.g. } \\
\text { proud to own) }\end{array}$ & $\begin{array}{l}\text { Product Beliefs low (e.g. } \\
\text { innovativeness); but Product } \\
\text { Receptivity goes up (e.g. will to } \\
\text { buy) }\end{array}$ \\
\hline $\begin{array}{l}\text { Tourism } \\
\text { Destination Image }\end{array}$ & $\begin{array}{l}\text { Destination Beliefs strongest } \\
\text { feature (e.g. scenery); Receptivity } \\
\text { also high (e.g. will to travel) }\end{array}$ & $\begin{array}{l}\text { Destination Beliefs strongest } \\
\text { feature (e.g. scenery); } \\
\text { Receptivity also high (e.g. will } \\
\text { to travel) }\end{array}$ \\
\hline \multicolumn{3}{|c|}{ Structural Equation Model } \\
\hline Country Image & $\begin{array}{l}\mathrm{CogCI} \rightarrow \text { ProdBel } \rightarrow \text { ProdRec } \\
\mathrm{CogCI} \rightarrow \text { AffCI } \rightarrow \text { DestRec } \\
\mathrm{CogCI} \rightarrow \text { AffCI } \rightarrow \text { ProdRec }\end{array}$ & $\begin{array}{l}\text { CogCI } \rightarrow \text { AffCI } \rightarrow \text { ProdRec } \\
\text { CogCI } \rightarrow \text { AffCI } \rightarrow \text { DestRec }\end{array}$ \\
\hline Product Image & ProdFam $\rightarrow$ ProdBel $\rightarrow$ ProdRec & ProdBel $\rightarrow$ ProdRec only \\
\hline $\begin{array}{l}\text { Tourism } \\
\text { Destination Image }\end{array}$ & DestBel $\rightarrow$ DestRec only & $\begin{array}{l}\text { DestBel } \rightarrow \text { DestRec } \\
\text { DestBel } \rightarrow \text { ProdRec }\end{array}$ \\
\hline Summary & $\begin{array}{l}\text { Paths to Product Receptivity are } \\
\text { through Cognitive Image to } \\
\text { Beliefs, and Familiarity to Beliefs; } \\
\text { Path to Destination Receptivity } \\
\text { from Cognitive to Affective to } \\
\text { Receptivity, not Beliefs }\end{array}$ & $\begin{array}{l}\text { Path to Product and Destination } \\
\text { Receptivity is only from } \\
\text { Cognitive to Affective to } \\
\text { Receptivity, not Beliefs }\end{array}$ \\
\hline
\end{tabular}


Table 30-d: Summary of Main Findings for Canada and South Korea

\begin{tabular}{|c|c|c|}
\hline Latent Constructs & South Korean data for CANADA & Canadian data for S. KOREA \\
\hline \multicolumn{3}{|c|}{ Open-Ended Responses } \\
\hline Country Image & $\begin{array}{l}\text { Many more positives (97): } \\
\text { "beautiful", "clean", "calm"; than } \\
\text { negatives (11); Highest response } \\
\text { (150) for Natural Features: "maple", } \\
\text { "waterfalls". }\end{array}$ & $\begin{array}{l}\text { Only country to receive more } \\
\text { negative responses ( } 85 \text { ) than } \\
\text { positives (57); "crowded", "poor", } \\
\text { "polluted" }\end{array}$ \\
\hline Product Image & $\begin{array}{l}\text { Very weak (39); } 96.3 \% \text { blank; Few } \\
\text { known brands (11) }\end{array}$ & $\begin{array}{l}\text { Many PCI responses (268); mostly } \\
\text { transportation (80), e.g. "cars"; and } \\
\text { entertainment (62); e.g. "electronics" }\end{array}$ \\
\hline $\begin{array}{l}\text { Tourism Destination } \\
\text { Image }\end{array}$ & $\begin{array}{l}\text { TDI responses (196) higher than } \\
\text { PCI; Majority in Geographic Places } \\
\text { (148), specifically Vancouver (41), } \\
\text { Niagara (37), Toronto (19) }\end{array}$ & $\begin{array}{l}\text { Fewer TDI responses ( } 141) \text {, with the } \\
\text { only notable response being "Seoul" } \\
\text { (30) }\end{array}$ \\
\hline \multicolumn{3}{|c|}{ Analysis of Means } \\
\hline Country Image & $\begin{array}{l}\text { Cognitive measures are relatively } \\
\text { low (e.g. technology), but Affective } \\
\text { is the highest of the countries (e.g. } \\
\text { pleasant, safe, trustworthy) }\end{array}$ & $\begin{array}{l}\text { Lowest country ratings for Cognitive } \\
\text { (e.g. wealth) and Affective Image } \\
\text { measures (e.g. ideal) }\end{array}$ \\
\hline Product Image & $\begin{array}{l}\text { Product Beliefs are rated poorly, } \\
\text { behind the U.S. and Japan (e.g. } \\
\text { innovation); yet, first in terms of } \\
\text { Product Receptivity (e.g. proud to } \\
\text { own) }\end{array}$ & $\begin{array}{l}\text { Lowest country ratings for Product } \\
\text { Beliefs (e.g. good overall, } \\
\text { innovative) and Receptivity (e.g. will } \\
\text { to buy); above Australia only in } \\
\text { terms of Familiarity }\end{array}$ \\
\hline $\begin{array}{l}\text { Tourism Destination } \\
\text { Image }\end{array}$ & $\begin{array}{l}\text { Destination Beliefs also rated } \\
\text { poorly, behind the U.S. and } \\
\text { Australia (e.g. accommodation, } \\
\text { value); move to } 2^{\text {nd }} \text { in terms of } \\
\text { Receptivity (e.g. will to travel) }\end{array}$ & $\begin{array}{l}\text { Lowest country ratings for } \\
\text { Destination Beliefs (e.g. good } \\
\text { overall), and for Familiarity and } \\
\text { Receptivity (e.g. closer ties) }\end{array}$ \\
\hline \multicolumn{3}{|c|}{ Structural Equation Model } \\
\hline Country Image & CogCI $\rightarrow$ AffCI $\rightarrow$ DestRec & $\begin{array}{l}\mathrm{CogCI} \rightarrow \text { AffCI } \rightarrow \text { ProdBel } \rightarrow \\
\text { ProdRec } \\
\text { CogCI } \rightarrow \text { AffCI } \rightarrow \text { DestBel } \rightarrow \\
\text { DestRec } \\
\text { CogCI } \rightarrow \text { AffCI } \rightarrow \text { DestRec }\end{array}$ \\
\hline Product Image & $\begin{array}{l}\text { ProdFam } \rightarrow \text { ProdBel } \rightarrow \text { ProdRec } \\
\text { ProdBel } \rightarrow \text { DestRec }\end{array}$ & $\begin{array}{l}\text { ProdFam } \rightarrow \text { ProdBel } \rightarrow \text { ProdRec } \\
\text { ProdBel } \rightarrow \text { DestRec }\end{array}$ \\
\hline $\begin{array}{l}\text { Tourism Destination } \\
\text { Image }\end{array}$ & DestBel $\rightarrow$ DestRec only & DestBel $\rightarrow$ DestRec only \\
\hline Summary & $\begin{array}{l}\text { Path to Product Receptivity only } \\
\text { through Product Familiarity to } \\
\text { Beliefs; Path to Destination } \\
\text { Receptivity from Cognitive to } \\
\text { Affective to Receptivity, not Beliefs }\end{array}$ & $\begin{array}{l}\text { Path to Product and Destination } \\
\text { Receptivity is from Cognitive to } \\
\text { Affective to Beliefs and to } \\
\text { Receptivity }\end{array}$ \\
\hline
\end{tabular}


While there remain some gaps in the place image picture, the results of the IMPI have a number of valuable implications for practitioners responsible for product and/or tourism marketing, for public managers responsible for place-related policy development, and notably, for academics interested in place-related research.

\subsection{Limitations}

Complex studies of causal relationships involving multiple variables, while informationally rich, can also be fraught with limitations. Thus, a sound foundation in theory and a rigorous methodology are important and served as guiding principles to this endeavor. The hypothesized relationships between country image, beliefs and behavioural constructs are based on an extensive review of existing literature in two vast streams of research, namely PCI and TDI. However, the combination of PCI- and TDIrelated constructs in one model is a first attempt through this study, and as such, empirical results of the model application are interpreted with caution. Even strong statistical evidence is limited by contextual study boundaries. Here, boundaries were established through the selection of specific countries, measurements, and respondents.

By the very nature of image, of product and of tourism, there is much more left out of a model than can feasibly be put in. This said, the selected constructs are reflective of the study objective, which must be kept in mind. The primary research goal was to develop and test a model of place image that encompasses evaluations of both products and tourism. For this reason, evaluations are at a global level of products and destinations in general, without specifying particular product categories, seasons or brands, and of country origin in general, without reference to country-of-manufacture, 
country-of-design, or other such hybrid product levels. The approach of using such global-level measures is the most common in both PCI and TDI research, and it is felt that this general level of evaluation has enabled the main constructs of interest to be adequately measured, and relationships to be assessed, thereby meeting the study objectives. It is recognized that relationships would vary at a more micro level - of specific products, brands, places - beyond the scope of the current study, but worthy of future investigation. Furthermore, to enable the simultaneous examination of country, product, and tourism images with a single research instrument it was necessary to use fewer scales in measuring each than in typical studies that address only one of these three components. However, the scales used were drawn from existing studies which had previously validated their use, and the results suggest that no substantive information was lost because of the somewhat abbreviated scales.

A particular limitation in the current study was the relatively poor performance of Destination Familiarity, the only single-item construct in the model. Additional measures of tourism-related familiarity would not only enhance this construct, but would likely improve the overall performance of the model.

\subsection{Implications and Benefits}

The goal of this study is to enrich place marketing theory by developing an effective model to encompass measures of both product and travel related images, based on an extensive analysis of the literature in both PCI and TDI. The specific study benefits, outlined in Chapter 1 and summarized here, are fourfold. First, each stream of research benefits from advances found in the other. Second, the model application 
represents the first full test of these two key aspects of place image within the same study. Third, the model is tested in two countries, assessing the images of four countries in each case, thus enabling the examination of eight distinct applications. Lastly, based on the empirical tests, policy and strategy implications are identified for Canada's country image, selected as a primary country of investigation because of the researcher's origin and interest. However, it must be noted that by applying the findings in the Canada case, the wider applicability of the IMPI is directly illustrated, thereby providing additional support for the generalizability of the model. To effectively link the study results with the specific objectives, the academic, practitioner and public policy benefits are summarized as follows.

\subsubsection{For Academic Researchers}

The fundamental benefit of the study is the contribution of the Integrated Model of Place Image to marketing research theory. The IMPI enables an exploration and understanding of the relationships between product and destination beliefs and behaviours. Given the multi-faceted complexity of "place", finding one invariant model was a challenge. It required a lengthy questionnaire to evaluate four countries, capturing 9,429 open-ended responses and measuring a sufficient number of items for each country. The initial scales had 33 items in total, which, through factor analysis, were reduced to 26 due to poor psychometric properties of some items. Then, in order for the IMPI to converge in all eight applications, a few additional items were dropped on a selective basis (e.g. more imports in SK-US, country knowledge in CA-JP). Next, the model was 
subjected to a cross-nation test of invariance, with the statistical results indicating that the model is invariant, though marginally so.

The resulting IMPI, comprising eight constructs and 26 variables, is presented as Figure 25. The figure includes the fifteen main paths tested in this study that received, at minimum, partial support in one part of the model. For example, while the path from Destination Familiarity to Product Beliefs was not supported, the one from Product Familiarity to Destination Beliefs was supported. Thus, both directional paths would be worthy of testing in future applications of the IMPI. On the other hand, neither Product nor Destination Familiarity to Affective Country Image was supported. Thus, these paths are not included in Figure 25. The resulting set of measures provides a framework for analysis of any place of interest, thereby contributing to both the theoretical foundations, and practical analysis of place image.

Academic researchers in each field can benefit from research advances found in the other. First, a new construct, titled Destination Beliefs, as distinct from the associated Country Image, was developed as part of the IMPI, helping to untangle a concept that has been treated very weakly so far in the TDI field. This distinction enables the exploration of new relationships between a country's image and beliefs about that country as a travel destination. Additionally, several Country Image dimensions that are common in PCI are new to TDI, such as quality of life and technology level, as well as the Product Belief dimensions of quality, workmanship, innovativeness and value for money. 
Figure 25: Integrated Model of Place Image with Relationships and Measures

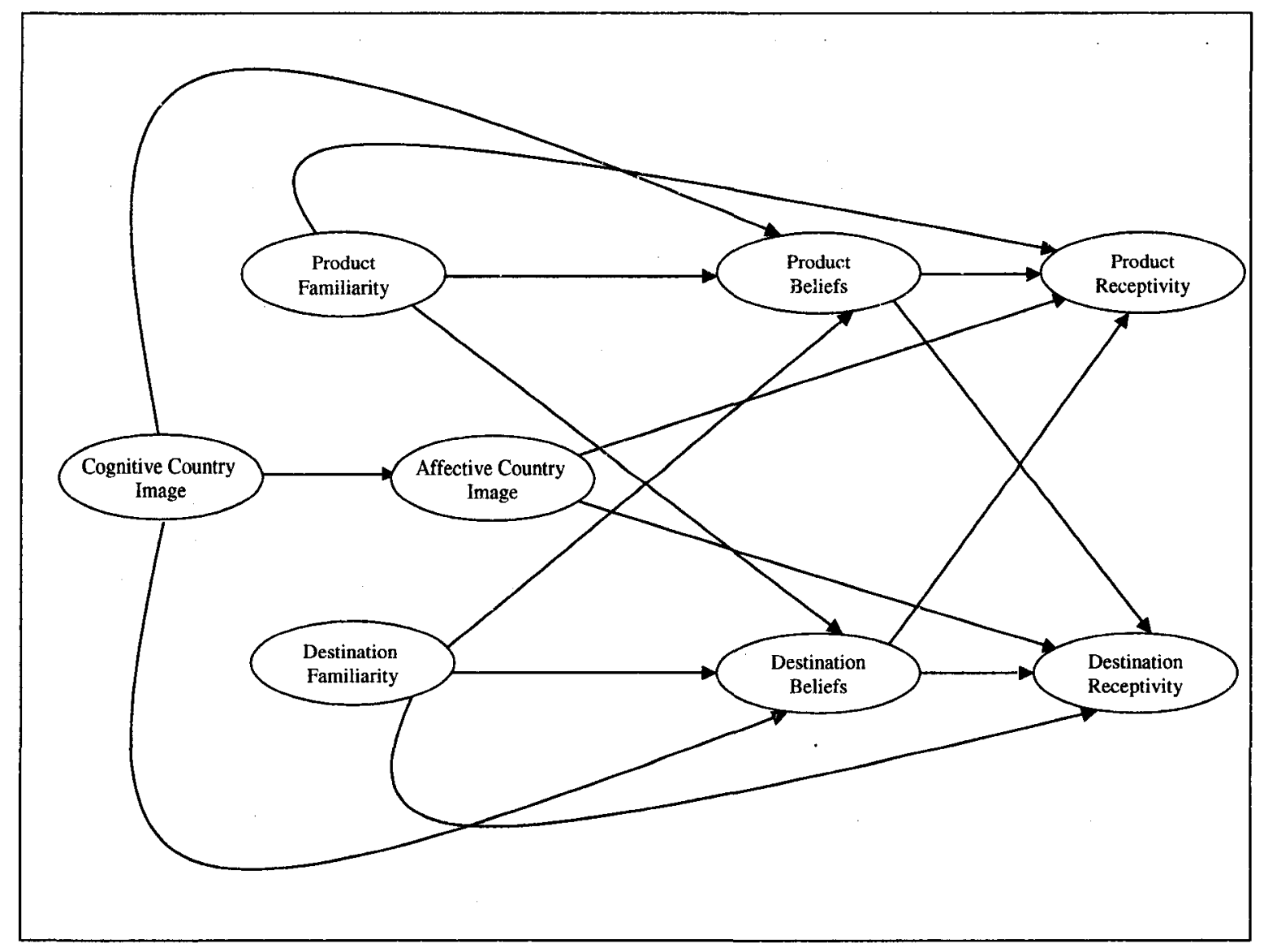

\begin{tabular}{|c|c|c|c|}
\hline $\begin{array}{l}\text { Cognitive } \\
\text { Country } \\
\text { Image }\end{array}$ & $\begin{array}{l}\text { - } \text { Quality of life } \\
\text { - Wealth } \\
\text { - Technology level } \\
\text { - Education }\end{array}$ & $\begin{array}{l}\text { Affective } \\
\text { Country } \\
\text { Image }\end{array}$ & $\begin{array}{ll}\text { - } & \text { Pleasant } \\
\text { - } & \text { Friendly } \\
\text { - } & \text { Safe } \\
\text { - } & \text { Trustworthy }\end{array}$ \\
\hline $\begin{array}{l}\text { Product } \\
\text { Beliefs }\end{array}$ & $\begin{array}{l}\text { - } \text { Quality } \\
\text { - Workmanship } \\
\text { - Innovativeness } \\
\text { - Value for money }\end{array}$ & $\begin{array}{l}\text { Destination } \\
\text { Beliefs }\end{array}$ & $\begin{array}{l}\text { - } \text { Appealing scenery } \\
\text { - Quality attractions } \\
\text { - Lots to see and do } \\
\text { - } \quad \text { Value for money }\end{array}$ \\
\hline $\begin{array}{l}\text { Product } \\
\text { Familiarity }\end{array}$ & $\begin{array}{ll}\text { - } & \text { Use } \\
\text { - } & \text { Ease to find } \\
\text { - } & \text { Satisfaction }\end{array}$ & $\begin{array}{l}\text { Destination } \\
\text { Familiarity }\end{array}$ & $\begin{array}{l}\text { - Country } \\
\text { knowledge }\end{array}$ \\
\hline $\begin{array}{l}\text { Product } \\
\text { Receptivity }\end{array}$ & $\begin{array}{l}\text { Ownership pride } \\
\text { - Open to imports } \\
\text { - Willingness to } \\
\text { buy }\end{array}$ & $\begin{array}{l}\text { Destination } \\
\text { Receptivity }\end{array}$ & $\begin{array}{l}\text { Willingness to } \\
\text { travel } \\
\text { - Good destination } \\
\text { - Ideal country }\end{array}$ \\
\hline
\end{tabular}


Another significant enhancement to TDI theory gained from the merger of PCI practice is the conceptualization of place image as a predictor of consumer behaviour. While much of the TDI research to date has focused on image formation, by contrast, PCI has focused on the link between country image and purchase decision-making. Methodologically, TDI research also benefits from the application of Structural Equations Modeling techniques that are found more commonly in PCI studies. Rather than the still-common descriptive assessment of a destination's tourism image, SEM, as applied here, has enabled the relationships between image, beliefs and behaviour to be explored more fully.

PCI theory benefits from the different conceptualizations of place image gained from the merger of TDI practice. Affective dimensions of Country Image found in TDI but new to PCI include, pleasant, as well as the Destination Belief dimensions, linked to PCI for the first time. Methodologically, PCI research also benefits from the adoption of unstructured techniques to capture a more holistic image of place (e.g. "what images come to mind when you think of products from X?'), which are seen more commonly in TDI. A potential enrichment to PCI, not fully captured in this study but worthy of future investigation, is the treatment and measurement in TDI of familiarity at three levels: organic, induced and complex.

\subsubsection{For Practitioners}

Practitioners in each stream benefit from the findings of the model application itself. First, exporters of products made in Canada and South Korea will find the results of interest when preparing strategies to enter the other's market. The comparison of one 
country's image to that of competitors (e.g. Japan, the U.S., and Australia) helps international marketers to better position their products. The country selections provide for comparison to economic leaders, such as Japan and the U.S., as well as Australia, considered a "middle-power" nation, like Canada. The results can guide exporters to determine whether a global marketing and product distribution strategy will be effective, or whether attitudes toward their country's products necessitate a more local strategy. An understanding of place image helps direct decisions related to branding, packaging, advertising, retail distribution and sourcing. Both tourism and product marketers in Canada and South Korea can strengthen image-based branding strategies based on the identification of image strengths and weaknesses by market.

Not only are consumer evaluations of product and destination strengths and weaknesses useful to marketers of individual products and places, but the similarities and differences in the pattern of relationships can guide strategy development at a more macro level. Cognitive Country Image plays a significant role, influencing both product and destination beliefs and receptivity. The role of affect is more distinct, having greater influence directly on receptivity, and on tourism destination beliefs, whereas familiarity has greater influence on product beliefs.

A country's cognitive image associations influence foreign consumers' beliefs of that country's products, whereas a country's affective image associations influence foreign consumers' receptivity to that country's products. The pattern for travel destination perceptions, by contrast, is weaker from that country's cognitive image associations to foreign consumers' beliefs about that country as a travel destination, and 
stronger from that country's affective image associations to consumers' beliefs and receptivity to travel there.

The influence of familiarity is also different across the paths. Knowledge of a foreign destination does not affect consumers' perceptions of a country's products, neither directly nor indirectly. And while consumers familiarity with foreign products does not directly affect their perceptions of that country as a travel destination (Product Familiarity $\rightarrow$ Destination Beliefs not significant), the former does influence destination receptivity indirectly through product beliefs (Product Familiarity $\rightarrow$ Product Beliefs $\rightarrow$ Destination Receptivity). In other words, a consumer who is familiar with a country's products will evaluate that country's products more positively, and will be more receptive to the idea of travelling there.

It is consumer beliefs that exhibit the stronger cross-over effects than familiarity, particularly in the direction from product beliefs to destination receptivity. The influence of destination beliefs on the receptivity to that country's products, though weaker, is still evident (Destination Beliefs $\rightarrow$ Product Receptivity weakly significant).

\subsubsection{For Public Policy}

Public policy makers, particularly at the national level, benefit from the simultaneous assessment of consumer perspectives on products and travel, and the identification of overarching dimensions of image to support a country branding strategy. The study identifies strengths and weaknesses in terms of both cognitive and affective image dimensions, to identify not only a country's attributes of quality, but the symbolic and emotional aspects of country image, thereby capturing a deeper essence of place. As 
stated earlier, a country must find its je ne sais quoi to symbolize and make its image globally competitive. The U.S. has the Statue of Liberty; Australia, the kangaroo; and, Japan has Sony. Canada may very well have its best global symbol in its red maple leaf strong roots from which to grow.

The process of developing place branding strategies that require integration across sectors can be compared to the development of a corporate brand. The place equates to the corporate brand, with the tourism and product sectors as sub-brands. The common dimension of the place's corporate image would be the cognitive elements (quality of life, technology, education, wealth) that influence both product and travel paths. Affective image associations play a "corporate" role as well, but with greater influence on the travel than the product sub-sector. And because the cross-over effect is stronger from the product to travel side than vice-versa, the corporate place brand should first and foremost strengthen its cognitive country elements.

\subsubsection{For Canada}

For Canada, the study findings raise important dynamics that should be addressed. Canada's "corporate" strength is its affective associations more so than its cognitive associations. These affective strengths position Canada well as a desireable travel destination, which in fact it is. Yet, its relatively weak cognitive associations devalue its PCI. Additionally, by strengthening cognitive associations, TDI would be even further enhanced. By way of example, Anholt's (2007b) Nation Brand Index finds Canada's strength to be its governance, a cognitive association that boosts Canada's overall study ranking. Affective associations are by no means to be overlooked, as they can directly 
influence country receptivity. However, as the IMPI results illustrate, cognitive associations influence beliefs, which most strongly and directly influence receptivity.

To consider the implications of the findings for Canada, it is necessary to begin with the country's current image. Canada is viewed extremely positively, characterized as "beautiful", "clean", and "calm". South Korean consumers are familiar with a few Canadian destinations, namely Vancouver and Toronto, as well as with iconic symbols of Canada's nature, such as the maple leaf and Niagara Falls. Canada is seen as pleasant and trustworthy, and scores highly on safety, quite a positive TDI overall. But, Canada is not seen as innovative, and its PCI is vague, at best. To strengthen its country image, Canada needs to focus more on cognitive associations, where it does rank well globally in terms of measures of wealth (e.g. relatively high GNP, low unemployment, resource-rich), education (e.g. high standards, low illiteracy), technology (e.g. technological infrastructure, innovations) and quality of life (e.g. relatively low crime rate, high standard of living).

The global mind-shift has been unfavourable to Canada as a travel destination. The country's prime travelers, the Americans, seem to have adopted a "been there, done that" attitude towards Canada [Canadian Tourism Commission, 2007b] and more and more are heading to newer destinations. Canada's global ranking has fallen from $10^{\text {th }}$ to $12^{\text {th }}$ place over the last two decades, and China, Australia, Turkey and Greece have moved ahead. Canada needs to consider the influence of its global image in the foreign market, and how it might be strengthened, and more effectively communicated. To do so, image must first be understood. 
Anholt describes Canada as "...the best largely unexploited brand in the world, almost universally admired, positively angelic and almost too perfect" [Canadian Tourism Commission, 2006, p.31]. The affective strengths make Canada very likeable, and this is not a quality to be lost. However, for Canada to be seen as a stronger competitor in the global game, it must link its strengths more directly to its cognitive capabilities. Attributes of trustworthiness and safety carry huge value, particularly in today's environment where the cases of unsafe exports from China of pet food and toys have brought new focus on and awareness of the "made in" label. Not only would Canada's product exports stand to benefit from enhanced concentration on capabilities and skills - from innovation to education - the highly competitive tourism market requires much more than fine scenery to attract the savvy global traveler. And even fine scenery, though undoubtedly a Canadian strength, is far from unique. Destination websites from all corners of the globe abound in amazing images of landscapes, vistas and appealing "eye-candy". Where Canada falls short in the evaluative comparisons to the U.S., Japan and Australia is on measures of accommodation and value for money suggesting that it is the development side of Canada's tourism industry that requires greater attention to issues of product quality and value in order to improve Canada's TDI. A stronger country and product image would support this.

For Canadian producers, country image plays an influential and positive role in buyer decision making that, if incorporated in marketing strategy, could help to address the perception of relatively low product capabilities. Given that Canada's affective strengths can directly influence buyer receptivity, producers would benefit from associating their products with Canadian attributes, such as trustworthiness and safety, 
the top-of-mind positives of beautiful, clean and calm, and the strong associations with Canada's nature. Of course, product quality improvements may very well be necessary, but if strategically integrated with elements of place equity, issues of unfamiliarity with Canadian products may also be overcome.

To achieve synergistic benefits, producers and tourism marketers might consider more strategic alliances. In tourism, alliances are common with traditional tourism partners (e.g. destination marketing organizations, hotels) and celebrity spokespeople (e.g. singers, movie stars), and producers tend to focus within their particular sector. By forming non-traditional alliances across tourism, industry and innovators in sectors ranging from technology to transportation, greater benefits from Canada's place equity would be gained.

Niagara Falls is the honeymoon capital of the world. Its beauty has led to global recognition. But what of Niagara's harnessing of incredible water power, and recognition for its industrial capabilities? In 1922, the Sir Adam Beck Niagara Generating Station, built by $2000 \mathrm{men}$, became the largest power generator in the world, and the Hydro Electric Power Commission the largest utility in the world. Today, Niagara continues as not only one of the world's greatest sources of hydroelectric power, but as an exemplar of industrial innovation. The re-constructed Ontario Power Generation is building the Niagara tunnel - using the largest hard rock boring machine in the world - to create a massive channel under the City of Niagara Falls that will generate an additional 1.6 billion kilowatt hours of power [Ontario Power Generation, 2007].

Like Niagara Falls, perhaps the beauty of Canada's image overshadows the capabilities of the nation. Yet, Canada's natural assets shine all the more brighter when 
lit by the competencies and power of its people. As with a person's intellectual framework that combines cognitive, affective and conative elements to form an image, the stronger a country's sub-sector associations, the stronger the image framework. Attention to Canada's weaker links would strengthen the connections and the whole.

\subsubsection{For Future Research}

Beyond the SEM analysis of PCI and TDI paths and relationships, the crossnation investigation summarized in Figures 30a-d suggests differences between South Korean and Canadian consumers that point to an inter-play of not only country image factors, but cultural factors that seem to implicate image formation and consumer behaviour.

From the initial analysis of the open-ended responses, two differences in the manner in which the sampled populations responded are notable. First, South Koreans are much more likely to mention specific product brands and specific geographic places than Canadians, who are more likely to mention general product and destination-related features. For example, $90.2 \%$ of South Koreans mention a specific brand for Japan's PCI, compared to $37.6 \%$ of Canadians. This difference is underscored by the product responses in the transportation category, where Canadians mention some brands, such as Honda (36) and Toyota (35), but are more likely to simply mention the "auto/car" (78) general category. In contrast, almost all South Koreans mention a brand, with only three respondents stating "auto/car".

The pattern is similar for the TDI responses. South Koreans mention specific Japanese places or attractions $81.4 \%$ of the time, as compared to $39.1 \%$ of Canadians. 
The pattern is also similar for the other study countries. South Koreans mention U.S. product brands $92.3 \%$ of the time, and specific places or attractions $97.2 \%$ of the time, whereas Canadians' specific mentions are only $42.9 \%$ and $68.9 \%$ respectively.

While familiarity may partially explain why South Koreans mention more specifics for Japan than Canadians, the familiarity argument does not hold when South Koreans also mention more specifics for the U.S. than Canadians do. Therefore, it is more likely that this is a result of distinct east-west cultural differences in image processing and recall. Canadians seem more likely to "chunk" several associations in multi-brand categories into one, larger node (e.g. Toyota, Honda and Acura become "cars"), known as the "summary effect" in schema theory - e.g., a frequent recall of hierarchically-dominant categories instead of their components. South Koreans, by contrast, recall specific brands, places and attractions, and do not display the same tendency to "chunk" as Canadians. And where South Koreans are unfamiliar with a country's products, as is the case with Australia, and therefore cannot recall specific brands, very few responses are given (total of 33 for PCI). Canadians, however, will still respond (total of 276 for $\mathrm{PCI}$ ), with general associations that seem more readily recalled (e.g. "beer", "sheep"). These differences point to opportunities for future research to focus on cross-cultural investigations of chunking mechanisms, which are widely recognized as particularly important in modern markets where product complexity, the availability of various similar brands, and a lack of time on the part of consumers for indepth product comparisons, mean that country, product category, or other higher-order images may be transposed to evaluate individual brands. 
A second notable difference that may be attributable to culture, in the pattern of open-ended responses by the two sampled populations, is the tendency for South Koreans to respond at a personal level when stating a negative (e.g. "double-faced" and "mean" for Japan) and at a general level when stating a positive (e.g. "clean" and "economic power", again for Japan). Canadians, in contrast, tend to respond more impersonally when stating a negative (e.g. "crowded" and "expensive") and personally when stating a positive (e.g. "polite" and "reserved"). This may reflect the collectivistic nature of South Koreans to attribute positives to the group and negatives to the individual, whereas Canadians' more individualistic nature attributes positives to the individual and negatives to the group [de Mooij, 2004].

This pattern holds for the other study countries as well, where Canadians are more likely to use personal traits to describe Americans and Australians as "fun" and "friendly" than South Koreans. Knight and Calantone's [2000] research of country image effects in Asia also raised the issue of cultural traits, specifically collectivism, that implicate consumer behaviour. There may also be cultural differences in terms of cognitive and affective processing by Canadians and South Koreans, the influence of which can be seen in the cross-nation SEM analysis. These findings again suggest a fertile ground for future studies, especially among researchers dealing with such issues as global consumer acculturation, ethnicity, ethnocentrism and animosity, and international rivalries that are accentuated in the context of highly competitive global markets.

When the results of the hypothesis tests are considered by sample, differences are apparent in terms of the relative strength of cognition, affect and familiarity. For the Canadian sample, the cognitive influence is strongly linked to affect. Affective country 
image also has a strong influence in the model, particularly on the destination side, and less so on the product side, while familiarity has negligible influence. For the Korean sample, cognition also has a strong influence, but more so on beliefs than on affect, and affective country image is weaker, limited in influence to the destination side of the model. The dimension with greater influence for the South Korean respondents is familiarity, particularly in terms of its influence on product beliefs. It would seem that South Koreans' evaluations are based more on what they know about a place or product, with less affective influence than the Canadian evaluations are subject to. This likely reflects South Koreans' collectivistic tendency to place great significance on relationships, group membership, and what is known, whereas Canadians tend to place greater significance on an individual's own personality.

The distinction holds significant ramifications for marketing, suggesting that relationship-based communication might be more effective in South Korea, or perhaps more generally, Asian markets, while a more personal style might be better suited to Canada, and other western markets. While this study has bridged the two sub-fields of PCI and TDI, further bridging into the cultural behaviour field is an area recommended for future study.

\subsection{Conclusions}

Today's consumer shops the global market almost as commonly as today's researcher references it. Globality is reality. Consumers in Canada, South Korea, and points between and beyond have access to a range of foreign products, and no longer is the range limited to French wine, Italian fashion and German cars. We now drive to the 
grocery store in our Korean Hyundai, wearing clothes manufactured in China and Ugg boots from Australia, and have access to an international potpourri of foods - from African spices and Asian vegetables to European soup mixes and South American nuts. We then proceed home to an evening spent on-line, where the world's music, movies, news and events enter our daily lives as casually as we click. This expansive exposure creates innumerable associations in the consumer's mind, that mix, match and blend together to create a metamorphic image of place.

It is hoped that the development of the IMPI, a new theoretical model of place image will contribute to place branding efforts in many settings, applied to many places, products and situations, to enhance TDI and PCI theory, and to further our understanding of place, product and tourism destination relationships. 


\section{Bibliography}

Aaker, David A., Kumar, Vinod, and Day, George S. (1995), Marketing Research, John Wiley \& Sons, Toronto

Aaker, D.A. and Joachimsthaler, E. (2000), Brand Leadership, The Free Press, NY

Abratt, R. (1989) "A new approach to the corporate image management process", Journal of Marketing Management, Vol. 5 (1), pp. 63-76

Agresti, Alan (1996) An Introduction to Categorical Data Analysis, John Wiley \& Sons, Toronto

Ahmed, Zafar U. (1991) "The influence of the components of a state's tourist image on product positioning strategy”, Tourism Management, December, pp. 331-340

Andersen, V., Prentice, R. and Guerin, S. (1997) "Imagery of Denmark among visitors to Danish fine arts exhibitions in Scotland", Tourism Management, Vol. 18, (7), pp. 453464

Anderssen, P. and Colberg, R.T. (1973) "Multivariate analysis in travel research: A tool for travel package design and market segmentation", Proceedings of the Fourth Annual Conference, Sun Valley, Idaho, Travel Research Association

Andreassen, T.W. and Lindestad, B. (1998), "Customer loyalty and complex services: the impact of corporate image on quality, customer satisfaction and loyalty for customers with varying degrees of service expertise", International Journal of Service Industry Management, Vol. 9 (1), pp. 7-23

Anholt, Simon (2007a), Competitive Identity: The New Brand Management for Nations, Cities and Regions, Palgrave Macmillan

Anholt, Simon (2007b) "Nation Brand Index", http://www.nationbrandindex.com

Anholt, Simon (2004) "Where is place branding heading?" Place Branding, Vol. 1 (1), p.11

Anholt, Simon (2002) "Nation branding: a continuing theme", forward, Journal of Brand Management, Vol. 10 (1), pp. 59-60

Askegaard, Soren and Ger, G. (1998) "Product-country images: toward a contextualized approach", European Advances in Consumer Research, Vol. 3, pp. 50-58

Awaritefe, Onome Daniel (2004) "Destination image differences between prospective and actual tourists in Nigeria", Journal of Vacation Marketing, Vol. 10 (3), pp. 264-282 
Babin, L.A. and Burns, A.C. (1997), "Effects of print ad pictures and copy containing instructions to imagine on mental imagery that mediates attitudes", Journal of Advertising, Vol. XXVI (3), p. 33

Bagozzi and Yi (1988), "On the evaluation of structural equation models", Academy of Marketing Science, Vol. 16 (1), pp. 74-95

Balmer, J.M.T. (1998), "Corporate identity and the advent of corporate marketing", Journal of Marketing Management, Vol. 14, pp. 963-996

Balmer, J.M.T. and Gray, E.R. (2003), "Corporate brands: What are they? What of them?" European Journal of Marketing, Vol. 37 (7/8), pp. 972-997

Baloglu, Seyhmus (2001) "Image variations of Turkey by familiarity index: informational and experiential dimensions", Tourism Management, Vol. 22, pp. 127-133

Baloglu, Seyhmus and Brinberg, David (1997) "Affective images of tourism destinations", Journal of Travel Research, Vol. 35 (4), pp. 11-15

Baloglu, Seyhmus and Mangaloglu, Mehmet (2001) "Tourism destination images of Turkey, Egypt, Greece and Italy as perceived by US-based tour operators and travel agents", Tourism Management, Vol. 22, pp. 1-9

Baloglu, Seyhmus and McCleary, Ken W. (1999a) "A model of destination image formation", Annals of Tourism Research, Vol. 26 (4), pp. 868-897

Baloglu, Seyhmus and McCleary, Ken W. (1999b) "U.S. international pleasure travelers' images of four Mediterranean destinations: a comparison of visitors and nonvisitors", Journal of Travel Research, Vol. 38, November, pp. 144-152

Beaman, Jay G., Huan, Tzung-Cheng, and Beaman, Jeff P. (2004) "Tourism surveys: sample size, accuracy, reliability and acceptable error", Journal of Travel Research, Vol. 43, August, pp. 67-74

Beerli, Asuncion and Martin, Josefa D. (2004a) "Factors influencing destination image", Annals of Tourism Research, Vol. 31 (3), pp. 657-681

Beerli, Asuncion and Martin, Josefa D. (2004b) "Tourists' characteristics and the perceived image of tourist destinations: a quantitative analysis - a case study of Lanzarote, Spain", Tourism Management, Vol. 25, pp. 623-636

Bigne, J. Enrique, Sanchez, M. Isabel and Sanchez, Javier (2001) "Tourism image, evaluation variables and after purchase behaviour: inter-relationship", Tourism Management, Vol. 22, pp. 607-616 
Bilkey, Warren J. and Nes, Erik (1982) "Country-of-Origin effects on product evaluations", Journal of International Business Studies, Vol. 8, Spring/Summer, pp. 8999

Bojanic, David C. (1991) "The use of advertising in managing destination image", Tourism Management, December, pp. 352-355

Bollen, Kenneth, A. (1989), Structural Equations with Latent Variables, Wiley, Toronto

Boulding, K.E. (1956), The Image: Knowledge in Life and Science, University of Michigan Press, Ann Arbor

Brisles, R.W. (1970), "Back translation for cross-cultural research", Journal of CrossCultural Psychology, vol. 1 (3), pp. 185-216

Brown, T.J. (1998), "Corporate associations in marketing: antecedents and consequences", Corporate Reputation Review, Vol. 1 (3), pp. 215-233

Burns, A.C., Biswas, A. and Babin, L.A. (1993), "The operation of visual imagery as a mediator of advertising effects", Journal of Advertising, Vol. XXII (2), pp. 71-84

Cai, Liping A. (2002) "Cooperative branding for rural destinations", Annals of Tourism Research, Vol. 29 (3), pp. 720-742

Canadian Trade Commissioner Service (2004) "Tourism Sector Profile - South Korean", International Trade Canada, http://www.infoexport.gc.ca, Ottawa

Canadian Tourism Commission (2007a), South Korea Consumer and Travel Trade Research Project Summary Report, CTX, Vancouver

Canadian Tourism Commission (2007b), http://www.corporate.canada.travel./en/ca

Canadian Tourism Commission (2006), Strategic Plan 2007-2011, Canadian Tourism Commission, Vancouver, September 2006

Canadian Tourism Commission (2003), Strategic Plan 2003-2005, Canadian Tourism Commission, Ottawa

Cattin, Philippe, Jolibert, Alain, and Lohnes, Colleen (1982) "A cross-cultural study of 'Made-In' concepts”, Journal of International Business Studies, Winter, pp. 131-141

Chao, P. (1993) "Partitioning country-of-origin effects: consumer evaluations of a Hybrid product, Journal of International Business Studies, Vol. 24 (2), pp. 291-306

Chaudhary, Manjula (2000) "India's image as a tourist destination - a perspective of foreign tourists", Tourism Management, Vol. 21, pp. 293-297 
Chen, Joseph S. and Hsu, Cathy H.C. (2000) "Measurement of Korean tourists' perceived images of overseas destinations", Journal of Travel Research, Vol. 38 (4), pp. 411-416

Choi, W.M, Chan A, Wu J. (1999) "A qualitative and quantitative assessment of Hong Kong's image as a tourist destination", Tourism Management, Vol. 20, pp. 361-365

Chon, Kye-Sung (1991) "Tourism destination image modification process: Marketing implications", Tourism Management, March, pp. 68-72

Chon, Kye-Sung (1990) "The role of destination image in tourism: a review and discussion", The Tourist Review, No. 2, pp. 2-9

Coshall, John T. (2000) "Measurement of tourists images: the repertory grid approach", Journal of Travel Research, Vol. 39 (1), pp. 85-89

Crompton, John, L. (1979) "An assessment of the image of Mexico as a vacation destination and the influence of geographical location upon that image", Journal of Travel Research, Vol. 17 (4), pp. 18-23

Crompton, John L. and Kim, Seoung-Seop (2001) "The influence of cognitive distance in vacation choice", Annals of Tourism Research, Vol. 28 (2), pp. 512-516

Crompton, John, L., Fakeye, Paul C., Lue, Chi-Chuan (1992) "Positioning: the example . of the lower Rio Grande Valley in the winter long stay destination market", Journal of Travel Research, Vol. 31(2), pp. 20-27

Czinkota, Michael R. and Ronkainen, Ilkka A. (2002) International Marketing, Harcourt, Inc., Florida

d'Astous, Alain and Ahmed, Sadrudin (1999) "The importance of country images in the formation of consumer product perceptions", International Marketing Review, Vol. 16 (2), pp. 108-125

Day, Jonathon, Skidmore, Sarita and Koller, Theadora (2002) "Image selection in destination positioning: a new approach", Journal of Vacation Marketing, Vol. 8 (2), pp. $177-186$

DeChenne, David (1993), "Schema Theory, Educational Applications, and a Model for Teaching" The History Teacher, 26(2), 175-189

DeMooij, Marieke (2004), Consumer Behavior and Culture: Consequences for Global Marketing and Advertising, Sage Publications, thousand Oaks

Dichter, E. (1985), "What's in an image", Journal of Consumer Marketing, Vol. 2 (1), pp. $75-81$ 
Dichter, Ernest (1962) "The world customer", Harvard Business Review, Vol. 40 (4), pp. $113-122$

Dodds, W.B., Monroe, K.B. and Grewal, D. (1991), "Effects of price, brand, and store information on buyers' product evaluations", Journal of Marketing Research, Vol. XXVIII, August, pp. 307-319

Dolan, Conor V. (1994), "Factor analysis of variables with 2, 3, 5 and 7 response categories: a comparison of categorical variable estimates using simulated data", British Journal of Mathematical and Statistical Psychology, Vol. 47, pp.3309-3326

Dowling, G.R. (1986), "Managing your corporate images", Industrial Marketing Management, Vol. 15 (2), pp. 109-115

Driscoll, Angie, Lawson, Rob and Niven, Brian (1994) "Measuring tourists' destination perceptions", Annals of Tourism Research, Vol. 21 (3), pp. 499-511

Echtner, Charlotte M. and Ritchie, J.R. Brent (1993) "The measurement of destination image: an empirical assessment", Journal of Travel Research, Vol. 31 (4), pp. 2-13

Echtner, Charlotte M. and Ritchie, J.R. Brent (1991) "The meaning and measurement of destination image", Journal of Tourism Studies, Vol. 2 (2), pp. 2-12

Ekinci, Yuksel (2003) "From destination image to destination branding: an emerging area of research", e-Review of Tourism Research, Vol. 1 (2), pp. 21-24

Elliot, Statia (2004) "The role of image in marketing", $\mathrm{PhD}$ Comprehensive, Carleton University, Ottawa

Erickson, Gary, Johansson, Johny and Chao, Paul (1984), "Image variables in multiattribute product evaluations: country-of-origin effects", Journal of Consumer Research, Vol. 11 (2), pp. 694-699

Essoussi, Leila Hamzaoui and Merunka, Dwight (2007), "Consumers' product evaluations in emerging markets: Does country of design, country of manufacture, or brand image matter?", International Marketing Review, Vol. 24 (4), pp. 409-426

Faircloth, J.B., Capella, L.M. and Alford, B.L. (2001), "The effect of brand attitude and brand image on brand equity", Journal of Marketing, Summer, p. 61-74

Fakeye, P.C. and Crompton, J.L. (1991) "Image differences between prospective, firsttime and repeat visitors to the Lower Rio Grande Valley", Journal of Travel Research, Vol. 30 (2), pp. 10-16

Fishbein, Martin (1967), "Attitude and the prediction of behavior" in Readings in Attitude Theory and Measurement, Fishbein, Martin (ed.), Wiley, N.Y., pp. 477-492 
Fombrun, C. and Shanley, M. (1990), "What's in a name? Reputation building and corporate strategy", Academy of Management Journal, 33 (2), pp. 233-258

Fornell, Claes and Bookstein, Fred L. (1982) "Two structural equation models: LISREL and PLS applied to consumer exit-voice theory", Journal of Marketing Research, Vol. 11 , pp. $440-52$

Framke, Wolfgang (2002) "The destination as a concept: A discussion of the businessrelated perspective versus the socio-cultural approach in tourism theory", $\underline{\text { Scandinavian }}$ Journal of Hospitality and Tourism, Vol. 2 (2), pp. 92-108

Gallarza, Martina G., Saura, Irene Gil and Garcia, Haydee Calderon (2002) "Destination image: towards a conceptual framework", Annals of Tourism Research, Vol. 29 (1), pp. 56-78

Gartner, William C. (1993) "Image formation process" in Communication and Channel Systems in Tourism Marketing, Ulysal, M. and Fesenmaier, D.R., (eds.), Haworth Press, NY, pp. 191-215

Gartner, William C. (1989) "Tourism image: attribute measurement of state tourism products using multidimensional techniques", Journal of Travel Research, Vol. 28 (2), pp. $16-20$

Gartner, William C. (1986) "Temporal influences on image change", Annals of Tourism Research, vol. 13,pp. 635-644

Gartner, William C. and Hunt, J.D. (1987) "An analysis of state image change over a twelve-year period (1971-1983)", Journal of Travel Research, Vol. 26 (2), pp. 15-19

Gnoth, Juergen (2002) "Leveraging export brands through a tourism destination brand" Journal of Brand Management, Vol. 9 (4-5), pp. 262-280

Gnoth, Juergen (1998) "Branding tourism destinations", Annals of Tourism Research, Vol. 25 (3), pp. 758-760

Goeldner, Charles R. and Ritchie, J.R. Brent (2003) Tourism Principles, Practices, Philosophies, $9^{\text {th }}$ Ed., John Wiley \& Sons, NJ

Gonzalez, Ana M. and Bello, Laurentino (2002) "The construct "lifestyle" in market segmentation: the behaviour of tourist consumers", European Journal of Marketing, Vol. $36(1 / 2)$, pp. $51-85$

Goodrich, J.N. (1978) "The relationship between preferences for and perceptions of vacation destinations", Journal of Travel Research, Vol. 17 (2), pp. 8-13 
Graeff, T.R. (1996), "Using promotional messages to manage the effects of brand and self-image on brand evaluations", Journal of Consumer Marketing, Vol. 13 (3), pp. 4-18

Granzin, Kent L. and Olsen, Janeen E. (1998), "Americans' choice of domestic over foreign products: a matter of helping behaviour?" Journal of Business Research, Vol. 43, pp. $39-54$

Gronroos, C. (1984) "A service quality model and its marketing implications", European Journal of Marketing, Vol. 18 (4), pp. 36-44

Grunig, J.E. (1993), "Image and substance: from symbolic to behavioural relationships", Public Relations Review, Vol. 19 (2), pp. 121-139

Gunn, C. (1972) Vacationscape: Designing Tourist Regions, Bureau of Business Research, University of Texas, Austin

Gunn, C. with Var, Turgut (2002) Tourism_Planning: Basics, Concepts, Cases, $4^{\text {th }}$ Ed., Routeledge, NY

Haahti, Antti (1986) "Finland's competitive position as a destination", Annals of Tourism Research, Vo. 13, pp. 11-35

Haahti, Antti and Yavas, Ugur (1983) "Tourists perceptions of Finland and selected European countries as travel destinations”, European Journal of Marketing, Vol. 17 (2), pp. $34-42$

Han, C. Min (1990) "Testing the role of country image in consumer choice behaviour", European Journal of Marketing, Vol. 24 (6), pp. 24-40

Han, C. Min (1989) “Country image: halo or summary construct?”, Journal of Marketing Research, Vol. 26, May, pp. 222-229

Han, C. Min and Terpstra, Vern (1988) "Country-of-origin effects for uni-national and bi-national products”, Journal of International Business Studies, Vol. 19 (2), pp. 235-255

Hankinson, Graham (2004a) "Relational network brands: towards a conceptual model of place brands", Journal of Vacation Marketing, Vol. 10 (2), pp. 109-121

Hankinson, Graham (2004b) "The brand images of tourisin destinations: a study of the saliency of organic images", Journal of Product \& Brand Management, Vol. 13 (1), pp. 6-14

Hatch, M.J. and Schultz, M. (2003), "Bringing the corporation into corporate branding", European Journal of Marketing, Vol. 37 (7-8), pp. 1041-1064 
Hatch, M.J. and Schultz, M. (1997), "Relations between organizational culture, identity and image", European Journal of Marketing, Vol. 31 (5/6), pp. 356-365

Häubl, G. (1996), "A Cross-national investigation of the effects of country of origin and brand name on the evaluation of a new car", International Marketing Review, 13 (5), 7697

Hawkins, Del I., Roger J. Best, and Kenneth A. Coney (2001), Consumer Behavior: Building Marketing Strategy, McGraw-Hill Higher Education, $8^{\text {th }}$ ed.

Henderson, Joan C. (2000) "Selling places: the new Asia-Singapore brand", Journal of Tourism Studies, Vol. 11 (1), pp. 36-44

Heslop, L.A., Nadeau, J., O'Reilly, N. and Luk, P. (2005) "Climbing new heights: Lessons from Mount Everest on PCI and TDI convergence", Administrative Sciences Association of Canada Conference Proceedings, Banff, Alberta

Heslop, L.A., Papadopoulos, N., Dowdles, M., Wall, M. and Compeau, D. (2004) "Who controls the purse strings? A study of consumers' and retail buyers' reactions in an America's FTA environment", Journal of Business Research, Vol. 57, pp. 1177-1188

Heslop, L.A., Papadopoulos, M., Wall, M. N., Dowdles and Compeau, D. (2001) "Modeling consumer views of AFTA countries and their product" Marketing, Administrative Sciences Association of Canada, London, Ontario

Heslop, Louise, Papadopoulos, Nicolas and Bourk, Margie (1998) "An interregional and intercultural perspective on subcultural differences in product evaluations", Canadian Journal of Administrative Sciences, Vol. 15 (2), pp. 113-127

Heslop, Louise A. and Papadopoulos, Nicolas (1993) "But who knows where or when: reflections on the images of countries and their products" in Product-Country Images: Impact and Role in International Marketing, Papadopoulos, Nicolas and Heslop, Louise (eds.), International Business Press, NY, pp. 39-75

Heslop, Louise, Papadopoulos, Nicolas, and Bamossy, Gary (1993) "Country and product perceptions: measurement scales and image interactions", European Advances in Consumer Research, Vol. 1, pp. 198-205

Hofstede, G. (2001) Culture's Consequences (2 ${ }^{\text {nd }}$ ed.), Thousand Oaks, CA

Howard, J.A. and Sheth, J.N. (1969), "A theory of buyer behavior", in Marketing Classics: A Selection of Influential Articles, Enis, B.M. and Cox, K.K., eds. (1991) $7^{\text {th }}$ Ed., Allyn and Bacon, Massachusetts 
Hsu, Cathy H.C., Wolfe, Kara and Kang, Soo K. (2004) "Image assessment for a destination with limited comparative advantages", Tourism Management, Vol. 25, pp. $121-126$

Hui, Tak Kee and Wan, Tai Wai David (2003) "Singapore's image as a tourist destination", International Journal of Tourism Research, Vol. 5, pp. 305-313

Hulland, John (1998) "The effects of country-of-brand and brand name on product evaluation and consideration: a cross-country comparison", Journal of International Consumer Marketing, Vol. 11 (1), pp. 23-40

Hunt, J.D. (1975) "Image as a factor in tourism development", Journal of Travel Research, Vol. 13 (3), pp. 1-7

Jaffe, Eugene D. and Nebenzahl, Israel D. (2006) National Image and Competitive Advantage: The Theory and Practice of Country-of-Origin Effect, Copenhagen Business School Press, Copenhagen, $2^{\text {nd }}$ ed.

Jaffe, Eugene D. and Nebenzahl, Israel D. (1984) "Alternative questionnaire formats for country image studies", Journal of Marketing Research, Vol. 21, November, pp. 463-471 Jenkins, Olivia H. (2003) "Photography and travel brochures: the circle of representation", Tourism Geographies, Vol. 5 (3), pp. 305-328

Jenkins, Olivia H. (1999) "Understanding and measuring tourist destination images", International Journal of Tourism Research, Vol. 1, pp. 1-15

Joppe, Marion (2003) "Optimizing tourism destination development in Canada", International Journal of Contemporary Hospitality Management, Vol. 15 (6), pp. 308311

Joppe, Marion, Martin, David W. and Waalen, Judith (2001) "Toronto's image as a destination: a comparative importance-satisfaction analysis by origin of visitor", Journal of Travel Research, Vol. 39, February, pp. 252-260

Joreskog, Karl G. (2000) "Interpretation of $\mathrm{R}^{2}$ Revisited", University of Alabama LISREL listserv @ http://bama.ua.edu/cgi-bin/wa, January 3, 2000

Keller, K. (1998) Strategic Brand Management: Building, Measuring, and Managing Brand Equity, Prentice-Hall, Upper Saddle River, NJ

Kennedy, S.H. (1977), "Nurturing Corporate Images", European Journal of Marketing, Vol. 11 (3), pp. 119-164

Kim, Chung Koo and Chung, Jay Young (1997) "Brand popularity, country image and market share: an empirical study”, Journal of International Business Studies, Vol. 28 (2), pp. 361-386 
Kim, Hyounggon and Richardson, Sarah L. (2003) "Motion picture impacts on destination images", Annals of Tourism Research, Vol. 30 (1), pp. 216-237

Kim, Seong-Seop, Crompton, John L. and Botha, Christel (2000) "Responding to competition: a strategy for Sun/Lost City, South Africa", Tourism Management, Vol. 21, pp. 33-41

Klein, Jill Gabrielle, Ettenson, Richard and Morris, Marlene D. (1998) "The animosity model of foreign product purchase: an empirical test in the People's Republic of China", Journal of International Consumer Marketing, Vol. 10 (4), pp. 69-92

Kline, (2005), Principles and Practice of Structural Equation Modeling, The Guilford Press, New York

Knight, Gary and Calantone, Roger (2000) "A flexible model of consumer country-oforigin perceptions", International Marketing Review, Vol. 17 (2), pp. 127-145

Ko, Dung-Woo and Park, Suk-Hee (2002) "The relative importance of the cognitive image associated with the affective image in tourism destinations", International Journal of Tourism Sciences, Vol. 2 (1), pp. 121-130

Ko, Dung-Woo and Park, Suk-Hee (2000) "Five aspects of tourism image: a review", International Journal of Tourism Sciences, Vol. 1 (1), pp. 79-92

Kotler, Philip, Bowen, John and Makens, James (2003) Marketing for Hospitality and Tourism, $3^{\text {rd }}$ Ed., Prentice Hall, NJ

Kotler, Philip, Hamlin, M.A., Rein, I. and Haider, D.H. (2002) Marketing Asian Places, John Wiley \& Sons, Singapore

Kotler, Philip, Jatusripitak, Somkid and Maesincee, Suvit (1997) The Marketing of Nations, The Free Press, NY

Kotler, Philip, Haider, D. and Rein, I. (1993) Marketing Places, Macmillan, Inc., Ontario

Laroche, M., Papadopoulos, N., Heslop, L. and Bergeron, J. (2003) "Effects of subcultural differences on country and product evaluations", Journal of Consumer Behaviour, Vol. 2 (3), pp. 232-247

Laws, Eric, Scott, Noel and Parfitt, Nick (2002) "Synergies in destination image management: a case study and conceptualisation", International Journal of Tourism Research, Vol. 4, pp. 39-55

Leigh, J.H. and Gabel, T.G. (1992), "Symbolic interactionism: its effects on consumer behavior and implications for marketing strategy", Journal of Consumer Marketing, Vol. 9 (1), p. 27 
Leisen, Birgit (2001) "Image segmentation: the case of a tourism destination", Journal of Services Marketing, Vol. 15 (1), pp. 49-66

Li, W.K. and Wyer, Jr.R.S. (1994) "The role of country-of-origin in product evaluations: informational and standard-of-comparison effects", Journal of Consumer Psychology, Vol. 3, pp. 187-212

Li, Xiang et al., (2004) "A comparison of two methodologies in measuring image", TTRA

Liefeld, John P. (1993) "Review and meta-analysis of effect size" in Product-Country Images: Impact and Role in International Marketing, Papadopoulos, Nicolas and Heslop, Louise, A. (eds.), International Business Press, NY, pp. 179-195

Liefeld, John, Heslop, Louise, Papadopoulos, Nicolas and Wall, Marjorie (1996) "Dutch consumer use of intrinsic, country-of-origin, and price cues in product evaluation and choice", Journal of International Consumer Marketing, Vol. 9, (1), pg. 57

Likert, Rensis and Hayes, Samuel P. (1957), Some Applications of Behavioural Research, Unesco, France

MacInnis, D.J. and Price, L.L. (1987), "The role of imagery in information processing: review and extensions", Journal of Consumer Research, Vol. 13, March, pp. 473-491

MacKay, Kelly J. and Couldwell, Christine M. (2004) "Using visitor-employed photography to investigate destination image", Journal of Travel Research, Vol. 42 (4), pp. 390-397

MacKay, Kelly J. and Fesenmaier, Daniel R. (2000) "An exploration of cross-cultural destination image assessment", Journal of Travel Research, Vol. 38 (4), pp. 417-23

MacKay, Kelly J. and Fesenmaier, Daniel R. (1997) "Pictorial element of destination in image formation", Annals of Tourism Research, Vol. 24 (3), pp. 537-565

MacKenzie, Scott B. (2001) "Opportunities for improving consumer research through latent variable structural equation modeling", Journal of Consumer Research, Vol. 28, pp. $159-166$

Malhotra, N., Agarwal, J. and Peterson, M. (1996) "Methodological issues in crosscultural marketing research: A state0ofOthe-art review", International Marketing Review, Vol. 13 (5), pp. 7-43.

Martineau, P. (1958) "Sharper focus for the corporate image", Harvard Business Review, Nov/Dec., pp. $49-58$ 
Mayo, E.J. (1973) "Regional images and regional travel behaviour", Proceedings of the Fourth Annual Conference, Sun Valley, Idaho, Travel Research Association

Meenaghan, T. (1995), "The role of advertising in brand image development", Journal of Product and Brand Management, Vol. 4 (4), pp. 23-34

Melissen, J. (2004) "Where is place branding heading?" Place Branding, Vol. 1 (1), pp.26-27

Meyers-Levy, J. and Malaviya, P. (1999), "Consumers' processing of persuasive advertisements: an integrative framework of persuasion theories", Journal of Marketing, Vol. 63, Special, pp. 45-60

Miller, D.W., Hadjimarcou, J. and Miciak, A. (2000), "A scale for measuring advertisement-evoked mental imagery", Journal of Marketing Communications, Vol. 6, pp. $1-20$

Miller, G.A. (1956), "The magical number seven plus or minus two: some limits on our capacity to process information", Psychological Review, Vol. 63, pp. 81-97

Morgan, Nigel, Pritchard, Annette and Piggott, Rachel (2003) "Destination branding and the role of the stakeholders: the case of New Zealand", Journal of Vacation Marketing, Vol. 9 (3), pp. 285-299

Morgan, Nigel, Pritchard, Annette and Pride, Roger, eds. (2002) Destination Branding: Creating the Unique Destination Proposition, Butterworth-Heinemann, Oxford

Morgan, Nigel and Pritchard, Annette (1998) Tourism Promotion and Power, Creating Images, Creating Identities, John Wiley \& Sons

Mossberg, Lena and Kleppe, I.A. (2005) "Country and destination image - different or similar image concepts?” Service Industries Journal, Vol. 24 (4), pp. 493-503

Murphy, Peter, Pritchard, Mark P. and Smith, Brock (2000) "The destination product and its impact on traveller perceptions", Tourism Management, Vol. 21, pp. 43-52

Nagashima, Akira (1970) "A comparison of Japanese and U.S. attitudes toward foreign products”, Journal of Marketing, Vol. 34, January, pp. 68-74

Narayana, Chem L. (1981) "Aggregate images of American and Japanese products: Implications on international marketing", Columbia Journal of World Business, Summer (16), pp. 68-74

Nebenzahl, Isreal and Jaffe, Eugene (1996) "Measuring the joint effect of brand and country image in consumer evaluation of global products" International Marketing Review Vol. 13 (4) pp. 5-22 
Nebenzahl, Isreal, Jaffe, Eugene and Lampert, Shlomo (1997) "Towards a theory of country image effect on product evaluation", Management International Review, Vol. 37 (1), pp. 27-49

Nelson, B.H. (1962), "Seven principles in image formation", Journal of Marketing, Vol. 26, pp. 67-71

Nes, Erik and Bilkey, Warren (1993) "A multi-cue test of country-of-origin theory" in Product-Country Images: Impact and Role in International Marketing, Papadopoulos, Nicolas and Heslop, Louise A. (eds.), International Business Press, Binghamton, NY, pp. $179-195$

Nguyen, N. and LeBlanc, G. (2002), "Contact personnel, physical environment and the perceived corporate image of intangible services by new clients", International Journal of Service Industry Management, Vol. 13 (3/4), pp. 242-263

O'Leary, Sinead and Deegan, Jim (2003) "People, pace, place: qualitative and quantitative images of Ireland as a tourism destination in France", Journal of Vacation Marketing, Vol. 9 (3), pp. 213-226

Obermiller, Carl and Spangenberg, Eric (1989) "Exploring the effects of country of origin labels: an information processing framework", Advances in Consumer Research, Vol. 16, pp. 454-459

Ontario Power Generation (2007), http://www.opg.com/power/hydro/new_projects/ntp/index.asp

Oppermann, Martin (1996) "Convention destination images: analysis of association meeting planners' perceptions", Tourism Management, Vol. 17 (3), pp. 175-182

Orbaiz, Luisa Villanueva and Papadopoulos, Nicolas (2003) "Toward a model of consumer receptivity of foreign and domestic products", Journal of International Consumer Marketing, Vol. 15 (3), pp. 101-126

Panitz, E. (1988), "Distributor image and marketing strategy", Industrial Marketing Management, Vol. 17 (4), pp. 315-323

Papadopoulos, Nicolas (2004) "Place branding: evolution, meaning and implications", Place Branding, Vol. 1 (1), pp. 36-49

Papadopoulos, Nicolas (1993) "What product and country images are and are not" in Product-Country Images: Impact and Role in International Marketing, Papadopoulos, Nicolas and Heslop, Louise A. (eds.), International Business Press, NY, pp. 3-38 
Papadopoulos, Nicolas and Butt, Irfan (2005) "The use of structural modeling in international marketing: a review and analysis", Administrative Sciences Association of Canada (ASAC), International Business Division

Papadopoulos, Nicolas and Heslop, Louise A., eds. (1993) Product-Country Images: Impact and Role in International Marketing, International Business Press, NY

Papadopoulos, Nicolas and Heslop, Louise A. (1986) "Travel as a correlate of product and country images", in Muller, T. (ed.) Marketing, Vol. 7, Administrative Sciences Association of Canada, Marketing Division, Whistler, Canada, May, pp. 191-200

Papadopoulos, Nicolas and Heslop, Louise A. (1989) "As others see us: the image of Canadian products abroad", Canadian Business Review, Winter, pp. 27-31

Papadopoulos, Nicolas and Heslop, Louise A. (2000) "Countries as brands" Ivey Business Journal, Nov/Dec., pp. 1-7

Papadopoulos, Nicolas and Heslop, Louise (2002) "Country equity and country branding: problems and prospects" Journal of Brand Management Vol. 9 (4/5) pp. 294-314

Papadopoulos, N., Heslop, L.A. and Bamossy, G. (1994) "An international comparative analysis of consumer attitudes toward Canada and Canadian products", Canadian Journal of Administrative Sciences, Vol. 11 (3), pp. 224-240

Papadopoulos, N., Heslop, L.A. and Bennett, D. (1993) "National image correlates of product stereotypes: a study of attitudes towards East European countries", European Advances in Consumer Research, Vol. 1, pp. 206-213

Papadopoulos, N., Marshall, J., Heslop, L.A., Avlonitis, G., Bliemel, F., Graby, F. (1988) "Strategic implications of product and country images: a modeling approach", Proceedings of the $41^{\text {st }}$ E.S.O.M.A.R. Marketing Research Congress, Lisbon, pp. 69-90

Pappu, Ravi, Quester, Pascale G. and Cooksey, Ray W. (2007), "Country image and consumer-based brand equity: relationships and implications for international marketing", Journal of International Business Studies, Vol. 38 (5), pp. 726-746

Parameswaran, Ravi and Pisharodi, R. Mohan (2002) "Assimilation effects in country image research” International Marketing Review, Vol. 19 (3), pp. 259-278

Pearce, Phillip L. (1982) "Perceived changes in holiday destinations", Annals of Tourism Research, Vol. 9, pp. 145-164

Pechlander, Herald, Zehrer, Anita, Matzler, Kurt and Abfalter, Dagmar (2004), "A ranking of international tourism and hospitality journals", Journal of Travel Research, Vol. 42, May, pp. 328-332 
Peterson, Robert and Jolibert, Alain (1995) "A meta-analysis of country-of-origin effects", Journal of International Business Studies, Vol. 26, pp. 883-900

Petroshius, S.M. and Monroe, K.B. (1987), "Effect of product-line pricing characteristics on product evaluations", Journal of Consumer Research, Vol. 13, March, pp. 511-519

Phelps, Angela (1986) "Holiday destination image - the problem of assessment: An example developed in Menorca", Tourism Management, September, pp. 168-180

Pike, Steven (2002) "Destination image analysis - a review of 142 papers from 1973 to 2000”, Tourism Management, Vol. 23, pp. 541-549

Pike, Steven and Ryan, Chris (2004) "Destination positioning analysis through a comparison of cognitive, affective and conative perceptions", Journal of Travel Research, Vol. 42 (4), pp. 333-343

Poiesz (1989), “The image concept”, Journal of Economic Psychology, Vol. 10, pp. 457472

Poon, Wai-Yin (1999) "Bayesian analysis of square ordinal-ordinal tables", British Journal of Mathematical and Statistical Psychology, Vol. 52, pp. 111-124

Reisinger, Yvette and Turner, Lindsay (1999) "Structural equation modeling with Lisrel: application in tourism", Tourism Management, Vol. 20 (1) pp. 71-88

Rezende-Parker, Aline M., Morrison, Alastair M. and Ismail, Joseph A. (2003) "Dazed and confused? An exploratory study of the image of Brazil as a travel destination", Journal of Vacation Marketing, Vol. 9 (3), pp. 243-259

Richardson, Sarah L. and Crompton, John L. (1988) “Cultural variations in perceptions of vacation attributes", Tourism Management, June, pp. 128-136

Ritchie, J.R. Brent (1996) "Beacons of light in an expanding universe: an assessment of the state-of-the-art in tourism marketing/marketing research", Journal of Travel \& Tourism Marketing, Vol. 5 (4), pp. 49-84

Roth, Martin and Romeo, Jean (1992) "Matching product category and country image perceptions: a framework for managing country-of-origin effect", Journal of International Business Studies, Vol. 23 (3), pp. 477-497

Schindler, R.M. and Kibarian, T.M. (2001), "Image communicated by the use of 99 endings in advertised prices", Journal of Advertising, Vol. XXX (4), pp. 95-99

Schneider, Ingrid and Sonmez, Sevil (1999) "Exploring the touristic image of Jordan", Tourism Management, Vol. 20, pp. 539-542 
Schooler, Robert D. (1971) "Bias phenomena attendant to the marketing of foreign goods in the U.S.", Journal of International Business Studies, Vol. 2 (1), pp. 71-80

Schooler, Robert D. (1965) "Product bias in the Central American Common Market", Journal of Marketing Research Vol. II, November, pp. 394-397

Scott, L.M. (1994), "Images in advertising: the need for a theory of visual rhetoric", Journal of Consumer Research, Vol. 21 (2), pp. 252-273

Selby, Martin and Morgan, Nigel J. (1996) "Reconstructing place image: a case study of its role in destination market research", Tourism Management, Vol. 17 (4), pp. 287-294

Shimp, Terrence and Sharma, Subhash (1987) "Consumer ethnocentrism: construction and validation of the CETSCASLE", Journal of Marketing Research, Vol. 24, August, pp. 280-289

Sirakaya, Ercan, Sonmez, Sevil F. and Choi, Hwan-Suk (2001) "Do destination images really matter? Predicting destination choices of student travellers", Journal of Vacation Marketing, Vol. 7 (2), pp. 125-142

Sirgy, M. Joseph and Su, Chenting (2000) "Destination image, self-congruity and travel behaviour: toward an integrative model", Journal of Travel Research, Vol. 38 (4), pp. 340-353

Smith, Malcolm C. and MacKay, Kelly J. (2001) "The organization of information in memory for pictures of tourist destinations: are there age-related differences?", Journal of Travel Research, Vol. 39, February, pp. 261-266

Spector, A.J. (1961), "Basic Dimensions of the corporate image", Journal of Marketing, Vol. 25 (6), pp. 47-51

Stangor, Charles, and James E. Lange (1994), "Mental Representations of Social Groups: Advances in Understanding Stereotypes and Stereotyping", Advances in Experimental Social Psychology, Vol. 26, pp. 357-416

Statistics/Industry Canada (2007) <http://strategis.ic.gc.ca>; IMF http://www.inf.org/external/data/htm; InfoExport <http://www.infoexport.gc.ca

Steenkemp, J.B. and Baumgartner, Hans (1998) "Assessing measurement invariance in cross-national consumer research", Journal of Consumer Research, Vol. 25 (1), pp. 78-90

Steenkemp, J.B. and Wedel, M. (1991), "Segmenting retail markets on store image using a consumer-based methodology", Journal of Retailing, Vol. 67 (3), p. 300

Stevens, James P. (2002), Applied Multivariate Statistics for the Social Sciences, $4^{\text {th }}$ Ed., Lawrence Erlbaum Assoc., NJ 
Stuart, H. (1999), "Towards a definitive model of the corporate identity management process", Corporate Communications: An International Journal, Vol. 4 (4), pp. 200-207

Suh, Yong K. and Gartner, William C. (2004) "Perceptions in international urban tourism: an analysis of travelers to Seoul, Korea", Journal of Travel Rescarch, Vol. 43, pp. 39-45

Tan, C.T. and Farley, J.U. (1987) "The impact of cultural patterns on cognition and intention in Singapore", Journal of Consumer Research, Vol. 13, March, pp. 540-544

Tapachai, Nirundon and Waryszak, Robert (2000) "An examination of the role of beneficial image in tourist destination selection", Journal of Travel Research, Vol. 39 (1), pp. $37-44$

Tasci, Asli D.A. and Gartern, William C. (2007), "Destination image and its functional relationships", Journal of Travel Research, Vol. 45 (4), pp. 413-425

Taylor, S. and Todd, P.A. (1995) Understanding Information Technology Usage: A Test of competing models Information Systems Research, 6, 144-76

Thakor, Mrugank and Kohli, Chiranjeev (1996) "Brand origin: conceptualization and review", Journal of Consumer Marketing, Vol. 13 (3), pp. 27-42

Thang, D.C.L. and Tan, B.L.B. (2003) "Linking consumer perception to preference of retail stores: an empirical assessment of the multi-attributes of store image", Journal of Retailing and Consumer Services, Vol. 10 (4), pp. 193-200

Therkelsen, Anette (2003) "Imagining places: image formation of tourists and its consequences for destination promotion", Scandinavian Journal of Hospitality \& Tourism, Vol. 3 (2), pp. 134-150

Twitchell, J.B. (2000), Twenty Ads that Shook the World, Crown Publishers, NY

Tyler, W.D. (1957), "The image, the brand, and the consumer", Journal of Marketing, October, pp. 162-165

Um, Seoho and Crompton, John L. (1992) "The roles of perceived inhibitors and facilitators in pleasure travel destination decisions", Journal of Travel Research, Vol. 30 (3), pp. 18-25

Uysal, Muzaffer and Fesenmaier, Daniel R., eds., (1993) Communication and Channel Systems in Tourism Marketing, Haworth Press, NY

Van Ittersum, Koert, Candel, Math J.J.M. and Meulenberg, Mathew T.G. (2003), "The Influence of the Image of a Product's Region of Origin on Product Evaluation", Journal of Business Research, Vol. 56, pp. 215-226 
Van Raaij, W. Fred and Francken, Dick A. (1984) "Vacation decisions, activities and satisfactions", Annals of Tourism Research, Vol. 11, pp. 101-112

Verlegh, Peeter and Steenkamp, Jan-Benedict (1999) "A review and meta-analysis of country-of-origin research", Journal of Economic Psychology", Vol. 20, pp. 521-546

Vogt, Christine A. and Andereck, Kathleen L. (2003) "Destination perceptions across a vacation", Journal of Travel Research, Vol. 41 (4), pp. 348-354

Ward, Stephen V. (1998) Selling Places: The Marketing and Promotion of Towns and Cities 1850-2000, Routledge, NY

White, Christopher F. (2004) "Destination image: to see or not to see?", International Journal of Contemporary Hospitality Management, Vol. 16 (5), pp. 309-314

Woodside, Arch G. and Lysonski, Steven (1989) "A general model of traveler destination choice", Journal of Travel Research, Spring, pp. 8-14

World Tourism Organization (2003) Tourism Market Trends

Yarhouse, Mark A. (2000), "Review of Social Cognition Research on Stereotyping: Application to Psychologists Working with Older Adults", Journal of Clinical Psychology, Vol. 6 (2), pp.121-131

Zapata, Jose Angel Ibanez and Martinez, Theodore Luque (2002) "An explanatory model of the effects caused by country-of-origin image on consumer attitudes: The moderating role of product category knowledge", in Salah S. Hassan, Enrique Bigne, and J.S. (Vic) Johar, Proceedings, Multicultural Marketing Conference, The Academy of Marketing Science, Valencia, Spain, Vol. IV-B

Zhang, Yong (1997) "Country-of-origin effect: the moderating function of individual difference in information processing", International Marketing Review, Vol. 14 (4), pp. 266-287 


\section{APPENDIX A}

\section{Image, Tourism Destination Image and Product Country Image Related Terminology}

\section{Conceptualizations of Image 1960 to 2005}

The widely researched concept of image has produced a range of definitions, divided here into three types [Ko and Park, 2000]. First, image is often defined as a composite structure, encompassing terms such as beliefs, ideas, impressions, emotions, knowledge, and prejudices. Second, image is sometimes defined in structural terms, using attitudinal components, particularly cognitive and affective components. Third, image is frequently defined in holistic terms as an overall impression or representation. Additionally, conceptualizations specific to product-country image are listed.

\section{A.1. TDI Composite Structure}

Barich and Kotler [1991, p.95]; "We use the term image to represent the sum of beliefs, attitudes and impressions that a person or group has of an object. The object may be a company, product, brand, place or person. The impression may be true or false, real or imagined. Right or wrong, images guide and shape behaviour."

Cai [2002. p.723]; "Set in tourism, the image of a destination brand can be defined as perceptions about the place as reflected by the associations held in tourist memory."

Calantone, et al. [1989]; Perceptions of potential tourist destinations. 
Chon [1990, p.4]; "An image is the set of meanings by which an object is known and through which people describe, remember and relate to it. That is, image is the net result of the interaction of a person's beliefs, ideas, feelings and impressions about an object."

Crompton [1979, p.18]; "An image may be defined as the sum of beliefs, ideas and impressions that a person has of a destination."

Day, et al. [2002. p.177]; "Image has two meanings: to describe the perceptions of a place, and as an alternate word for photo of a place."

Dowling [1986, p.110] "An image is the set of meanings by which an object is known and through which people describe, remember and relate to it. That is it is the net result of the interaction of a person's beliefs, ideas, feelings and impressions about an object."

Gartner [1989, p.16]; "State tourism image is a complex combination of various products and associated attributes."

Gartner and Hunt [1987, p.16]; "State tourism image is defined as the impressions that a person or persons hold about a state in which they do not reside."

Hunt [1975, p.1]; "the perceptions held by potential visitors about an area". 
Jaffe and Nebenzahl [2001]; image comprises the subjective perceptions of a person about an object; beliefs, ideas and impressions are mental images that may or may not be congruent with objectively defined attributes of the object. A country name, like a brand name, is an abstract symbol that generates common perceptions and images that join together a broad range of products and services which, despite their diversity, have some common desirable or undesirable attributes.

Jenkins [1999, p.2]; "Each person's image of a particular place is unique, comprising their own memories, association and imaginations of a particular place."

Kotler, et al. [2002, p.229]; "We define a place's image as the sum of beliefs, ideas and impressions that people have of that place. Images represent a simplification of a large number of associations and pieces of information connected with the place. They are the product of the mind trying to process and frame huge amounts of data about a place."

Lawson and Baud Bovy [1977]; a destination image is the expression of all objective knowledge, impressions, prejudice, imaginations and emotional thoughts an individual or group might have of a particular place.

MacKay and Fesenmaier [1997, p.538]; “A destination's image is a composite of various products (attractions) and attributes woven into a total impression. Differences in meaning, number, and importance of dimensions may occur. Both attention to, and 
exclusion of, certain destination attributes or symbols can play a part in how destination promotions are perceived."

Murphy, et al. [2000, pp.44-45]; "The image is a sum of associations and pieces of information connected to a destination, which would include multiple components of the destination and personal perception."

Phelps (1986); Perceptions or impressions of a place.

Richardson and Crompton (1988); Perceptions of vacation attributes.

Tapachai and Waryszak [2000, p.38]; "perceptions or impressions of a destination held by tourists with respect to the expected benefit or consumption values including functional, social, emotional, epistemic, and conditional benefits of a destination. These perceptions/impressions in turn lead to the decision to visit a country as a vacation destination."

Tourism Canada [1989]; How a country is perceived relative to others.

\section{A.2. TDI Structural Definitions}

Bigne, Sanchez and Sanchez [2001, p.607]; "the image of a destination consists of the subjective interpretation of reality made by the tourist." 
Echtner and Ritchie [1991, p.8]; "Destination image is defined as not only the perceptions of individual destination attributes but also the holistic impression made by the destination. Destination image consist of functional characteristics, concerning the more tangible aspects of the destination, and psychological characteristics, concerning the more intangible aspects. Furthermore, destination images can be arranged on a continuum ranging from traits which can be commonly used to compare all destinations to those which are unique to very few destinations."

Embacher and Buttle [1989]; image is comprised of the ideas or conceptions held individually or collectively of the destination under investigation. Image may comprise both cognitive and evaluative components.

Gartner [1993, p.193]; "Destination images are formed by three distinctly different but hierarchically interrelated components: cognitive, affective and conative."

Keller [1998]; Brand image is defined as the perceptual beliefs about a brand's attribute, benefit, and attitude associations held in consumer memory ...the basis for an overall evaluation of, or attitude toward, the brand.

\section{A.3. TDI Overall Impression}

Ahmed [1991, p.331]; "a state's tourist image is tourists' mental picture of a particular state. A given image is what tourists as buyers 'see' and 'feel' when the state or its attractions come to mind as a place suited for the pursuit of leisure." 
Boulding [1956, p.14] "Images can only be compared with images. They can never be compared with any outside reality...For any individual organism or organization, there are no such things as 'facts'. There are only messages filtered through a changeable value system."

Dichter [1985, p.75]; "The concept of image can be applied to a political candidate, a product, a country. It describes not individual traits or qualities, but the total impression an entity makes on the minds of others. It is a most powerful influence in the way people perceive things, and should be a crucial concept in shaping our marketing, advertising, and communication efforts. Thus, more attention must be paid to the overall impression, the melody of an advertising or marketing campaign, rather than to its specific claims. An image is not anchored in just objective data and details. It is the configuration of the whole field of the object, the advertising, and most important, the customer's disposition and the attitudinal screen through which he observes."

Ekinci [2003, p.22]; "an individual's mental picture of a place based on their knowledge and other global impressions."

Faircloth, Capella and Alford [2001, p.62] "brand image, which is a holistic construct formed from a gestalt of all the brand associations related to the brand, is different from brand attitude, which is a consumer's overall evaluation of the brand." 
Fakeye and Crompton [1991, p.10]; "Image is the mental construct developed by a potential tourist on the basis of a few selected impressions among the flood of total impression; it comes into being through a creative process in which these impressions are elaborated, embellished, and ordered. Image is the total perception of a destination that is formed by processing information from various sources over time."

Grunig [1993, p.126] "image is an umbrella term covering all of the communication activities and their effects that occur between an organization and its publics -- at least as the concept of image is used in public relations. In another sense, image defines the symbolic relationships among organization and public relationships that occur strictly through communicative interaction."

Gunn [2002, p.226]; "place is the mental construct of the temporal-spatial experience as the individual ascribes meaning to settings, through environmental perception and cognition."

Hatch and Schultz [1997, p.359]; “Organizational image is a holistic and vivid impression held by an individual or a particular group towards an organization and is the result of sense-making by the group and communication by the organization of a fabricated and projected picture of itself."

Spector [1961, p.47]; “The sum total of their perceptions of the corporation's personality characteristics is what we refer to as the corporate image." 


\section{A.4. Product Country Image}

Bilkey and Nes [1982], Han [1989]; Country image is defined as consumers' general perceptions of quality for products made in a given country.

Heslop et al. [2004, p.1178]; "the impact of country image on the response of consumers to products from a country has been termed the country-or-origin or product-country image (PCI) effect."

Kim and Chung [1997, p. 367]; "Country images, built up over long periods, are intangible assets that make a positive contribution to market sales or share by influencing the effectiveness of marketing variables on sales."

Nagashima [1970, p.68]; "the picture, the reputation, the stereotype that businessmen and consumers attach to products of a specific country. This image is created by such variables as representative products, national characteristics, economic and political background, history, and traditions."

Narayana [1981, p.32]; "the aggregate image for any particular country's product refers to the entire connotative field associated with that country's product offerings, as perceived by consumers" 
Roth and Romeo [1992, p.480]; "Country image is the overall perception consumers form of products from a particular country, based on their prior perceptions of the country's production and marketing strengths and weaknesses."

Papadopoulos and Heslop [1993, p.xxi]; "Some call it "The BMW Effect": the aura, the feelings, the correlations, the mystique - the "image" with which producers attempt to imbue their products and/or which consumers perceive in relation to them. A product can draw its image from its design, its performance, and many other characteristics, but also from its brand name and the name of its producer and its country-of-origin."

Papadopoulos et al. [1993, p. 206]; PCI refers to the "image which consumers are assumed to conjure up when exposed to information about where a product was made, assembled, designed, or conceived. This can be found in a product's advertising, packaging, brand or manufacturer's name, made-in label, etc.”

Papadopoulos and Butt [2005, p.2]; “Country Origin refers to the effects of a country's image on buyers attitudes and behaviours toward its products."

\section{A.5. Definitions of Tourism Related Terminology}

Tourism The World Tourism Organization defines tourism as the activity of people who are leaving their home for more than 24 hours to stay at a destination for leisure or recreation before they return home (Gnoth, 2002). 
Destinations are typically places with some form of actual or perceived boundary, such as the physical boundary of an island, political boundaries, or even market-crafted boundaries (Kotler, et al., 2003).

Destinations are seen as units at several geographical levels, but without distinct geographical boundaries, and as images resulting from social practice; a commercial junction based on tourist visits. The destination is a narrative created by marketing: it is a place structured by processes and experienced through social actions, and it 'exists' at various geographical levels, but it is never a place with clear boundaries. The sum of interests, activities, facilities, infrastructure and attractions create the identity of a place the destination. It has a static dimension - the place- and a dynamic dimension - the mix and agglomeration of agents and products/services, varying with the tourists' historically changing demand. When the tourist visits a place he creates his own tourist space. The industry, as part of the tourists' space for social action, creates an economic space. These spaces differ, but each has its origin in images promoted by the marketing mediation of a place called the destination (Framke, 2002).

Tourism as an industry occurs at 'destination areas' - areas with different natural and/or man-made features, which attract non-local visitors (or tourists) for [a variety] activities (Georgulas, 1970 in Framke, 2002).

The geographical unit visited by a tourist may be a self-contained center, a village or a town or a city, a district or a region, an island, a country or a continent. This 
geographical unit may be described as the tourist destination. The tourist destination, however defined geographically, provides a convenient focus for the examination of the tourist movement and of its manifold impact and significance. (Burkart and Medlik, 1974 in Framke, 2002).

At a destination there is a mix of interdependent elements. The elements are interdependent, because in order to produce a satisfying vacation experience, all elements must be present: attractions, facilities, infrastructure, transportation, hospitality (Mill and Morrison, 1992 in Framke, 2002).

A tourist destination is defined a geographical area which exhibits landscape and cultural characteristics and which is in a position to offer a tourism product, which means a wide range of facilities in transport, accommodation and food, and at least one outstanding activity of experience (Jensen, Hansen and Metz, 1993 in Framke, 2002).

A destination can be described as a dynamic whole, consisting of three resource bases: the attraction base, the facility base, and the demand base (Jensen, 2001 in Framke, 2002).

It is proposed to define a destination as an amalgam of products and services available in one location, that can draw visitors from beyond its spatial confines (Murphy, et al., 2000). 
A tourism destination is a package of tourism facilities and services, which like any other consumer product, is composed of a number of multi-dimensional attributes (Ritchie, 1993).

Destination branding can be defined as selecting a consistent element mix to identify and distinguish it through positive image building. (Cai, 2002).

Destination visitor image the stereotypic image of the kind of people who typically visit a given destination (Sirgy and $\mathrm{Su}, 2000$ ).

Positioning involves creating the appropriate image of the product in the minds of the consumers in the targeted markets (Echtner and Ritchie, 1993). 


\section{APPENDIX B}

Product Country Image Dimensions

\begin{tabular}{|c|c|c|}
\hline Study & PCI Dimensions & Product/Brand Dimensions \\
\hline $\begin{array}{l}\text { Nagashima [1970, } \\
\text { 1977]* }\end{array}$ & $\begin{array}{l}\text { Price \& Value } \\
\text { Service \& Engineering } \\
\text { Advertising \& Reputation } \\
\text { Design \& Style } \\
\text { Consumers' Profile }\end{array}$ & NA \\
\hline White [1979]* & $\begin{array}{l}\text { Expensive } \\
\text { Price } \\
\text { Technicality } \\
\text { Quality } \\
\text { Workmanship } \\
\text { Inventiveness } \\
\text { Selection } \\
\text { Serviceability } \\
\text { Advertising } \\
\text { Durability } \\
\text { Reliability } \\
\text { Brand Recognition } \\
\end{array}$ & NA \\
\hline Narayana [1981]* & $\begin{array}{l}\text { Quality } \\
\text { Recognition } \\
\text { Prestige } \\
\text { Production Form } \\
\text { Expensiveness } \\
\text { Popularity } \\
\text { Functionality } \\
\end{array}$ & NA \\
\hline $\begin{array}{l}\text { Cattin, Jolibert \& } \\
\text { Lohness [1982]* }\end{array}$ & $\begin{array}{l}\text { Pricing } \\
\text { Reliability } \\
\text { Workmanship } \\
\text { Technicality } \\
\text { Performance } \\
\end{array}$ & NA \\
\hline $\begin{array}{l}\text { Jaffe \& Nebenzahl } \\
{[1984]^{*}}\end{array}$ & $\begin{array}{l}\text { Product-technology } \\
\text { Marketing } \\
\text { Price }\end{array}$ & NA \\
\hline $\begin{array}{l}\text { Johansson \& Nebenzhal } \\
\text { [1986]* }\end{array}$ & $\begin{array}{l}\text { Economy } \\
\text { Status } \\
\end{array}$ & NA \\
\hline Han \& Terpstra [1988]* & $\begin{array}{l}\text { Technical Advancements } \\
\text { Prestige } \\
\text { Workmanship } \\
\text { Economy } \\
\text { Serviceability } \\
\text { Overall }\end{array}$ & $\begin{array}{l}\text { Technical Advancements } \\
\text { Prestige } \\
\text { Workmanship } \\
\text { Economy } \\
\text { Serviceability } \\
\text { Overall } \\
\end{array}$ \\
\hline Han [1990] & Technological Advance & Overall Quality \\
\hline
\end{tabular}




\begin{tabular}{|c|c|c|}
\hline & $\begin{array}{l}\text { Prestige value } \\
\text { Workmanship } \\
\text { Price } \\
\text { Serviceability } \\
\end{array}$ & Brand Rating \\
\hline Roth \& Romeo [1992] & $\begin{array}{l}\text { Design } \\
\text { Workmanship } \\
\text { Prestige } \\
\text { Innovativeness }\end{array}$ & $\begin{array}{l}\text { Design } \\
\text { Workmanship } \\
\text { Prestige } \\
\text { Innovativeness }\end{array}$ \\
\hline Chao [1993] & NA & $\begin{array}{l}\text { Product Quality } \\
\text { (workmanship, reliability, } \\
\text { durability, quality) } \\
\text { Design Quality } \\
\text { (innovativeness, } \\
\text { exclusiveness, stylishness) }\end{array}$ \\
\hline $\begin{array}{l}\text { Papadopoulos, Heslop } \\
\text { and Bennett [1993] }\end{array}$ & $\begin{array}{l}\text { Stable } \\
\text { Rich } \\
\text { Democratic } \\
\text { An Ideal Country } \\
\text { Active } \\
\text { Know a lot about } \\
\text { I Like } \\
\text { Industrialized } \\
\text { Educated } \\
\text { Western culture } \\
\text { Safe } \\
\text { Many rights } \\
\text { Peaceful } \\
\text { Trustworthy } \\
\text { Individualistic } \\
\text { Favour Investment In } \\
\text { Welcome Immigration from } \\
\text { Aligned with } \\
\text { Hardworking } \\
\text { Should have closer ties with } \\
\end{array}$ & $\begin{array}{l}\text { Know a lot about } \\
\text { Recognizable brands } \\
\text { Easy to find } \\
\text { Good after sales service } \\
\text { Inexpensive } \\
\text { Good value } \\
\text { Proud to own } \\
\text { Attractive } \\
\text { Innovative } \\
\text { Technical advancement } \\
\text { Reliable } \\
\text { Workmanship } \\
\text { Satisfaction } \\
\text { Quality } \\
\text { Good Overall } \\
\text { Willingness to Buy }\end{array}$ \\
\hline $\begin{array}{l}\text { Nebenzahl and Jaffe } \\
\text { [1996] }\end{array}$ & \begin{tabular}{|l} 
Known \\
Reliability \\
Price \\
Performance \\
Exclusivity \\
Quality \\
Innovativeness \\
Proud to show \\
Technology \\
Like-dislike \\
Service \\
Assortment
\end{tabular} & \begin{tabular}{|l} 
Known \\
Reliability \\
Price \\
Performance \\
Exclusivity \\
Quality \\
Innovativeness \\
Proud to show \\
Technology \\
Like-dislike \\
Service \\
Assortment
\end{tabular} \\
\hline
\end{tabular}




\begin{tabular}{|l|l|l|}
\hline Heslop, Papadopoulos, & Political stability & Reliability \\
Comples, Wall, & Individual rights \& freedoms & Workmanship \\
Quality of life & Durability \\
& Role in world politics & Quality \\
& Environment controls & Attractiveness \\
& Technology level & Innovativeness \\
& Stability of economy & Technology level \\
& Wealth & Variety \\
& Education level & Recognizable brand names \\
& Industriousness & Ease of finding \\
& Work ethic & Knowledge of products \\
& Individualism & Value \\
& Trustworthiness & Rating compared to others \\
& Friendliness & Proud to own \\
& Likeability & Overall satisfaction \\
& Alignment with country & Willingness to buy \\
& Political \& Economic ties & \\
& Immigration from country & \\
& Investment in country & \\
& Investment from country & \\
& Exports to country \\
& Imports from country & \\
\hline
\end{tabular}

*Studies from 1970 to 1988 from Roth and Romeo [1992, p.481] 


\section{APPENDIX C}

A Comparison of TDI and PCI Research Streams

Table C-1: A Chronology of PCI and TDI Research Milestones

\begin{tabular}{|c|c|c|c|}
\hline \multicolumn{2}{|r|}{ PCI } & \multicolumn{2}{|r|}{ TDI } \\
\hline Author(s) & Study Focus & Author(s) & Study Focus \\
\hline $\begin{array}{l}\text { Schooler } \\
(1965)\end{array}$ & $\begin{array}{l}1^{\text {st }} \text { published PCI work: } \\
\text { an empirical } \\
\text { examination of product } \\
\text { stereotyping among } \\
\text { consumers. }\end{array}$ & $\begin{array}{l}\text { Olsson } \\
(1965)\end{array}$ & $\begin{array}{l}1^{\text {st }} \text { key study of place } \\
\text { images in relation to } \\
\text { influence on trayel } \\
\text { behaviour. }\end{array}$ \\
\hline \begin{tabular}{|l} 
Lillis \& \\
Narayana \\
(1974)
\end{tabular} & $\begin{array}{l}\text { Interdisciplinary: } \\
\text { connected marketing, } \\
\text { social psychology and } \\
\text { political science re: } \\
\text { national stereotyping. }\end{array}$ & \begin{tabular}{|l|} 
Hunt \\
$(1971$, \\
$1975)$
\end{tabular} & $\begin{array}{l}\text { Ground breaking research } \\
\text { of image as a factor in } \\
\text { tourism and tourism } \\
\text { development. }\end{array}$ \\
\hline $\begin{array}{l}\text { Nagashima } \\
(1977)\end{array}$ & $\begin{array}{l}\text { Semantic Differential: } \\
\text { popularized } \\
\text { methodology of scales } \\
\text { to study product } \\
\text { country-of-origin } \\
\text { effects. }\end{array}$ & $\begin{array}{l}\text { Crompton } \\
\text { (1977) }\end{array}$ & $\begin{array}{l}\text { Systems Model: the } \\
\text { tourist's destination } \\
\text { selection process, role of } \\
\text { image and perceived } \\
\text { constraints. }\end{array}$ \\
\hline $\begin{array}{l}\text { Johanasson } \\
(1977)\end{array}$ & $\begin{array}{l}\text { Multivariate Studies: } \\
\text { advanced PCI research } \\
\text { from descriptive to multi } \\
\text { analysis of attitudes and } \\
\text { beliefs of hybrid } \\
\text { products. }\end{array}$ & $\begin{array}{l}\text { Goodrich } \\
(1978)\end{array}$ & $\begin{array}{l}\text { Multidimensional Scaling } \\
\text { new method to investigate } \\
\text { influence of image on } \\
\text { destination selection. }\end{array}$ \\
\hline \begin{tabular}{|l} 
Bilkey \& \\
Ness \\
$(1982)$
\end{tabular} & $\begin{array}{l}\text { Literature Review: much } \\
\text { referenced review and } \\
\text { critique of early PCI } \\
\text { work that greatly } \\
\text { influenced future } \\
\text { research. }\end{array}$ & $\begin{array}{l}\text { Haahti \& } \\
\text { Yavas } \\
\text { (1983) }\end{array}$ & $\begin{array}{l}\text { Measurement of tourists' } \\
\text { perceptions of selected } \\
\text { countries as travel } \\
\text { destinations. }\end{array}$ \\
\hline $\begin{array}{l}\text { Han } \\
(1989)\end{array}$ & $\begin{array}{l}\text { Country/Product Image } \\
\text { Interface: explored the } \\
\text { correlation of country/ } \\
\text { product, and introduced } \\
\text { the "halo" and } \\
\text { "summary" constructs. }\end{array}$ & $\begin{array}{l}\text { Gartner } \\
(1989)\end{array}$ & $\begin{array}{l}\text { Perceptual ratings of } \\
\text { activities and attractions: } \\
\text { positioned tourism } \\
\text { destinations according to } \\
\text { subjective perceptions of } \\
\text { image attributes. } \\
\end{array}$ \\
\hline $\begin{array}{l}\text { Darling \& } \\
\text { Kraft (1996) }\end{array}$ & $\begin{array}{l}\text { Longitudinal } \\
\text { Perspective: tracked PCI } \\
\text { over several points in } \\
\text { time and related to } \\
\text { international trade } \\
\text { trends. }\end{array}$ & $\begin{array}{l}\text { Fakeye \& } \\
\text { Crompton } \\
\text { (1991) }\end{array}$ & $\begin{array}{l}\text { Destination Image Stages: } \\
\text { involved an evolution of } \\
\text { destination image in its } \\
\text { nature and complexity } \\
\text { towards the ideal; varies } \\
\text { with visitor experience. }\end{array}$ \\
\hline
\end{tabular}




\begin{tabular}{|l|l|l|l|}
\hline $\begin{array}{l}\text { Papadopoulos } \\
\text { \& Heslop } \\
(1993)\end{array}$ & $\begin{array}{l}1^{\text {st }} \text { book on country-of- } \\
\text { origin; compiled the } \\
\text { state-of-the-art research } \\
\text { and theory to-date, } \\
\text { paving the way for } \\
\text { future work. }\end{array}$ & $\begin{array}{l}\text { Echtner \& } \\
\text { Ritchie } \\
(1993)\end{array}$ & $\begin{array}{l}\text { Image Attribute } \\
\text { Dimensions: } \\
\text { measurement comprised } \\
\text { attribute-based vs. holistic } \\
\text { images, functional, } \\
\text { psychological, unique, and } \\
\text { common characteristics. }\end{array}$ \\
\hline $\begin{array}{l}\text { Papadopoulos } \\
\text { \& Heslop } \\
(2002)\end{array}$ & $\begin{array}{l}\text { Inventory and taxonomy } \\
\text { of PCI research; } \\
\text { catalogued 766 works to } \\
\text { portray the scope and } \\
\text { depth of field. }\end{array}$ & $\begin{array}{l}\text { Pike } \\
(2002)\end{array}$ & $\begin{array}{l}\text { Reference Guide of TDI } \\
\text { research: review of 142 } \\
\text { works to identify context, } \\
\text { method and focus of } \\
\text { previous studies. }\end{array}$ \\
\hline
\end{tabular}

Adapted and expanded from Papadopoulos and Heslop [1993] and Ritchie [1996]

Table C-2: Summary of PCl and TDI Research Themes

\begin{tabular}{|c|c|}
\hline PCI Themes & TDI Themes \\
\hline $\begin{array}{l}\text { 1. Assessment and Measurement } \\
\text { of PCI } \\
\text { The most common focus of } \\
\text { research, representing about } 25 \% \\
\text { of published works, these are } \\
\text { mostly descriptive studies that } \\
\text { assess the image of one or more } \\
\text { countries from the perspective of } \\
\text { another. }\end{array}$ & $\begin{array}{l}\text { 1. Assessment and Measurement of TDI } \\
\text { Over half of TDI studies deal with } \\
\text { measurement, either as an empirical } \\
\text { study to assess a particular TDI, or } \\
\text { empirical and theoretical, addressing } \\
\text { measurement issues (e.g. Echtner and } \\
\text { Ritchie 1993). }\end{array}$ \\
\hline $\begin{array}{l}\text { 2. Consumer Nationalism } \\
\text { The next most common focus, } \\
\text { about } 14 \% \text { of published works, is } \\
\text { ethnocentrism studies and } \\
\text { research of domestic goods versus } \\
\text { imports (Papadopoulos, Heslop, } \\
\text { Bamossy 1990). }\end{array}$ & $\begin{array}{l}\text { 2. Active and Passive Role of Residents } \\
\text { The role of residents has received some } \\
\text { attention from two perspectives: first, } \\
\text { residents' image of their own place as } \\
\text { compared to visitors; second, residents' } \\
\text { role as part of the image (Echtner and } \\
\text { Ritchie 1991). }\end{array}$ \\
\hline $\begin{array}{l}\text { 3. Consumer Characteristics } \\
\text { About } 10 \% \text { of published works } \\
\text { consider PCI from the point-of- } \\
\text { view of various consumer } \\
\text { segments, and the relation of } \\
\text { image to behaviour (e.g. } \\
\text { Johansson and Nebenzahl 1986). }\end{array}$ & $\begin{array}{l}\text { 3. Destination Image Formation Process } \\
\text { About one third of TDI studies deal } \\
\text { with the structure and formation of } \\
\text { image, either as a static relation (e.g. } \\
\text { between image and destination choice) } \\
\text { or as a dynamic, complex process (e.g. } \\
\text { Chon, Baloglu and Gartner). }\end{array}$ \\
\hline $\begin{array}{l}\text { 4. Integrating PCI With Other } \\
\text { Cues } \\
\text { About } 9 \% \text { of published works } \\
\text { attempt to measure the importance } \\
\text { of PCI effects in relation to other } \\
\text { cues such as brand name and price }\end{array}$ & $\begin{array}{l}\text { 4. Distance and TDI Change Over Time } \\
\text { Fewer studies deal with these variables. } \\
\text { An exception is Crompton (relation } \\
\text { between location and image 1979; } \\
\text { influence of length of stay 1991). } \\
\text { Others have considered the influence of }\end{array}$ \\
\hline
\end{tabular}




\begin{tabular}{|l|l|}
\hline $\begin{array}{l}\text { (e.g. intrinsic and extrinsic cues, } \\
\text { Han 1988). }\end{array}$ & $\begin{array}{l}\text { repeat visits, with few true longitudinal } \\
\text { studies (e.g. Gartner \& Hunt 1987). }\end{array}$ \\
\hline $\begin{array}{l}\text { 5. Strategic Implications for } \\
\text { Marketing }\end{array}$ & $\begin{array}{l}\text { 5. Destination Image Management } \\
\text { Policies } \\
\text { Fewer works have dealt with the } \\
\text { implications of findings for } \\
\text { advertising, promotions and other } \\
\text { marketing elements. } \\
\text { way with management issues in terms } \\
\text { of strategy development, positioning } \\
\text { and promotion (e.g. works of Ritchie, } \\
\text { Haahti and Han). }\end{array}$ \\
\hline $\begin{array}{l}\text { 6. Other Elements of PCI } \\
\text { About 7\% of published works } \\
\text { consider PCI's effect on industrial } \\
\text { purchases. Other elements of PCI } \\
\text { receive less focus, such as PCI } \\
\text { effects across nations, sub- } \\
\text { nationally, and in terms of foreign } \\
\text { direct investment decisions. }\end{array}$ & $\begin{array}{l}\text { 6. Conceptualization and Dimensions } \\
\text { Almost half of TDI studies deal with its } \\
\text { definition and delimitation. Yet, } \\
\text { without consensus (from Hunt 1971 to } \\
\text { Gallarza2001). Echtner and Ritchie } \\
\text { (1993) proposed 3 axes of TDI: } \\
\text { functional/psychological, common/ } \\
\text { unique, and holistic/attribute-based. }\end{array}$ \\
\hline
\end{tabular}

Baughn and Yaprak [1993], Papadopoulos and Heslop [2002], Gallarza, Saura and Garcia [2001] 
Table C-3: Comparison of Common Attributes of PCI and TDI Studies

\begin{tabular}{|c|c|c|c|}
\hline Constructs & PCI Variables & Subjects & TDI Variables \\
\hline \begin{tabular}{|l|} 
Product \\
Integrity
\end{tabular} & $\begin{array}{l}\text { Workmanship } \\
\text { Reliability } \\
\text { Quality } \\
\text { Appearance } \\
\text { Technically Advanced } \\
\text { Innovativeness }\end{array}$ & Attractions & $\begin{array}{l}\text { Safety } \\
\text { Transportation } \\
\text { Accommodation } \\
\text { Landscape, surroundings } \\
\text { Originality } \\
\text { Nature } \\
\text { Gastronomy } \\
\text { Climate } \\
\text { Cultural attractions } \\
\text { Nightlife and entertainment } \\
\text { Shopping facilities } \\
\text { Sport facilities }\end{array}$ \\
\hline Price & $\begin{array}{l}\text { Value for money } \\
\text { Price level } \\
\text { Service } \\
\text { Good products }\end{array}$ & \begin{tabular}{|l} 
Value \\
\end{tabular} & $\begin{array}{l}\text { Price, value, cost } \\
\text { Service quality }\end{array}$ \\
\hline $\begin{array}{l}\text { Market } \\
\text { Presence }\end{array}$ & $\begin{array}{l}\text { Variety } \\
\text { Recognized brands } \\
\text { Know a lot } \\
\text { Easy to find }\end{array}$ & $\begin{array}{l}\text { Market } \\
\text { Info }\end{array}$ & $\begin{array}{l}\text { Various activities } \\
\text { Information available } \\
\text { Accessibility }\end{array}$ \\
\hline Response & $\begin{array}{l}\text { Normally buy } \\
\text { Have what I like } \\
\text { Products for me } \\
\text { Satisfaction } \\
\text { Proud to own } \\
\text { Willing to buy }\end{array}$ & $\begin{array}{l}\text { Motivation } \\
\text { Response }\end{array}$ & $\begin{array}{l}\text { Relaxation vs Massific } \\
\text { Excitement/adventure } \\
\text { Satisfaction }\end{array}$ \\
\hline $\begin{array}{l}\text { Advance- } \\
\text { ment }\end{array}$ & $\begin{array}{l}\text { Technological } \\
\text { advancement } \\
\text { Overall wealth } \\
\text { Population's education } \\
\text { Refined taste } \\
\text { Stability }\end{array}$ & Knowledge & $\begin{array}{l}\text { Learning new things } \\
\text { Enriching myself } \\
\text { Experiencing new places }\end{array}$ \\
\hline People & $\begin{array}{l}\text { Trustworthy } \\
\text { Likable } \\
\text { Hard working } \\
\text { Rich/Poor }\end{array}$ & Social & $\begin{array}{l}\text { Resident's Receptiveness } \\
\text { Social interaction } \\
\text { Meeting people } \\
\text { Developing close } \\
\text { friendships }\end{array}$ \\
\hline Links & $\begin{array}{l}\text { Want closer ties } \\
\text { Want more imports } \\
\text { Want more investment } \\
\text { Alignment }\end{array}$ & Prestige & $\begin{array}{l}\text { Going places my friends } \\
\text { have not } \\
\text { Telling my friends about } \\
\text { my trip }\end{array}$ \\
\hline
\end{tabular}

Adapted from Papadopoulos and Heslop [2000] for PCI; Baloglu and McCleary [1999] and Gallarza, Saura and Garcia [2001] for TDI 
Table C-4: Comparison of PCI and TDI Findings

\begin{tabular}{|c|c|c|}
\hline Summary of PCI Findings & Linkages & Summary of TDI Findings \\
\hline $\begin{array}{l}\text { Place images are powerful } \\
\text { influencers }\end{array}$ & & $\begin{array}{l}\text { Cognitive, Affective and/or } \\
\text { evaluative elements }\end{array}$ \\
\hline $\begin{array}{l}\text { Effects vary depending on the } \\
\text { situation }\end{array}$ & & \begin{tabular}{|l|} 
Collective images vs \\
personal impressions
\end{tabular} \\
\hline $\begin{array}{l}\text { Origin images affect price } \\
\text { expectations }\end{array}$ & & $\begin{array}{l}\text { Selective images vs } \\
\text { additive images }\end{array}$ \\
\hline $\begin{array}{l}\text { PCIs appear to consist of } 7 \\
\text { key constructs }\end{array}$ & & $\begin{array}{l}\text { Need of a Multidisciplinary } \\
\text { focus on TDI }\end{array}$ \\
\hline $\begin{array}{l}\text { Buyers distinguish between } \\
\text { origin of design, assembly, } \\
\text { etc. }\end{array}$ & & $\begin{array}{l}\text { Images are a } \\
\text { multi-item construct }\end{array}$ \\
\hline $\begin{array}{l}\text { Product classes are related to } \\
\text { a country's global product } \\
\text { image }\end{array}$ & & $\begin{array}{l}\text { Static and Dynamic } \\
\text { Structure of TDI }\end{array}$ \\
\hline $\begin{array}{l}\text { Buyers distinguish between } \\
\text { product and national images }\end{array}$ & & $\begin{array}{l}\text { TDI varies across people } \\
\text { (segmentation) }\end{array}$ \\
\hline $\begin{array}{l}\text { PCI may shift slowly or } \\
\text { quickly over time }\end{array}$ & & $\begin{array}{l}\text { TDI involves comparisons } \\
\text { among objects (positioning) }\end{array}$ \\
\hline $\begin{array}{l}\text { Effect of 'buy domestic' } \\
\text { campaigns is unclear }\end{array}$ & & $\begin{array}{l}\text { Time and distance } \\
\text { affects TDI }\end{array}$ \\
\hline
\end{tabular}

Papadopoulos and Heslop [2000] for PCI; and, Gallarza, Saura and Garcia [2002] for TDI 


\section{APPENDIX D}

\section{Select PCI and TDI Structural Models}

Table D-1: PCI Structural Modeling

\begin{tabular}{|c|c|c|c|c|c|c|c|c|}
\hline Author & Year & Measures & $\begin{array}{l}\# \\
\text { Places }\end{array}$ & $\begin{array}{l}\text { \#Pro } \\
\text { ducts }\end{array}$ & $\begin{array}{l}\text { Subjects/ } \\
\text { selection }\end{array}$ & Size & Method & Paths \\
\hline $\begin{array}{l}\text { 1. Papa- } \\
\text { dopoulos, } \\
\text { et al. }\end{array}$ & 1988 & $\begin{array}{l}\text { Country beliefs } \\
\text { Product beliefs } \\
\text { Familiarity } \\
\text { Product evaluation } \\
\text { Buyer behaviour }\end{array}$ & $\begin{array}{l}4 \text { country } \\
\text { samples; } \\
2 \text { origins }\end{array}$ & 1 & $\begin{array}{l}\text { Consumers } \\
\text { systematic }\end{array}$ & $\begin{array}{l}\text { Ave206 } \\
\text { Tt11110 }\end{array}$ & $\begin{array}{l}\text { SEM/ } \\
\text { LISREL }\end{array}$ & $\begin{array}{l}4 \\
\text { sup- } \\
\text { port } \\
\text { for all }\end{array}$ \\
\hline 2. Haubl & 1996 & $\begin{array}{l}\text { Eval.of country-AFF. } \\
\text { Eval.of country- } \\
\text { COG. } \\
\text { CI in product class } \\
\text { Brand image/attitude } \\
\text { Appearance } \\
\text { Product sector beliefs } \\
\text { Product specific } \\
\text { beliefs } \\
\text { Product feature eval. } \\
\text { Intent to buy }\end{array}$ & $\begin{array}{l}2 \text { country } \\
\text { samples; } \\
1 \text { origin }\end{array}$ & 1 & $\begin{array}{l}\text { Consumers } \\
\text { quota }\end{array}$ & $\begin{array}{l}\text { Ave311 } \\
\text { Ttl } 622\end{array}$ & $\begin{array}{l}\text { SEM/ } \\
\text { LISREL }\end{array}$ & $\begin{array}{l}17 \\
\text { sup- } \\
\text { port } \\
\text { for } \\
\text { most }\end{array}$ \\
\hline $\begin{array}{l}\text { 3. Klein, et } \\
\text { al. }\end{array}$ & 1998 & $\begin{array}{l}\text { Country image } \\
\text { Economic } \\
\text { development } \\
\text { People affect } \\
\text { Political development } \\
\text { Ethnocentrism } \\
\text { Animosity-war } \\
\text { Animosity-economic } \\
\text { Animosity } \\
\text { Product judgements } \\
\text { Willingness to buy } \\
\text { Product ownership }\end{array}$ & 1 & 1 & $\begin{array}{l}\text { Consumers } \\
\text { convenience }\end{array}$ & 244 & $\begin{array}{l}\text { SEM/ } \\
\text { LISREL }\end{array}$ & $\begin{array}{l}9 \\
\text { near } \\
\text { sup- } \\
\text { port } \\
\text { for all }\end{array}$ \\
\hline $\begin{array}{l}\text { 4. Knight } \\
\text { and } \\
\text { Calantone }\end{array}$ & 2000 & $\begin{array}{l}\text { Country } \\
\text { Image(people) } \\
\text { Countrylmage(produ } \\
\text { ct) } \\
\text { Product beliefs } \\
\text { Attitude to purchase }\end{array}$ & $\begin{array}{l}\text { 2country } \\
\text { samples; } 1 \\
\text { origin }\end{array}$ & 1 & $\begin{array}{l}\text { Consumer } \\
\text { and students } \\
\text { samples } \\
\text { convenience }\end{array}$ & $\begin{array}{l}\text { Ave } 305 \\
\text { Ttl } 914\end{array}$ & $\begin{array}{l}\text { SEM/ } \\
\text { EQS }\end{array}$ & $\begin{array}{l}3 \\
\text { near } \\
\text { sup- } \\
\text { port } \\
\text { for all }\end{array}$ \\
\hline $\begin{array}{l}\text { 5. Heslop, } \\
\text { et al. }\end{array}$ & 2001 & $\begin{array}{l}\text { People description } \\
\text { Country description } \\
\text { People competence } \\
\text { Country competence } \\
\text { Ethnocentrism } \\
\text { Country relationship } \\
\text { Product beliefs } \\
\text { Familiarity } \\
\text { Product evaluation } \\
\text { Willingness to buy } \\
\end{array}$ & $\begin{array}{l}1 \text { country } \\
\text { sample; } \\
5 \text { origins }\end{array}$ & 1 & $\begin{array}{l}\text { Consumers } \\
\text { systematic }\end{array}$ & 312 & $\begin{array}{l}\text { SEM/ } \\
\text { PLS }\end{array}$ & $\begin{array}{l}15 \\
\text { sup- } \\
\text { port } \\
\text { for } \\
\text { most }\end{array}$ \\
\hline $\begin{array}{l}\text { 6. Zapata } \\
\text { and } \\
\text { Martinez }\end{array}$ & 2002 & $\begin{array}{l}\text { Country image } \\
\text { Product beliefs } \\
\text { Attitude to purchase }\end{array}$ & 1 & 1 & $\begin{array}{l}\text { Consumers } \\
\text { quota }\end{array}$ & 900 & $\begin{array}{l}\text { SEM/ } \\
\text { LISREL }\end{array}$ & $\begin{array}{l}3 \\
\text { near } \\
\text { sup- } \\
\text { port } \\
\text { for all }\end{array}$ \\
\hline
\end{tabular}




\begin{tabular}{|c|c|c|c|c|c|c|c|c|}
\hline $\begin{array}{l}\text { 7. Parames- } \\
\text { waran and } \\
\text { Pisharodi }\end{array}$ & 2002 & $\begin{array}{l}\text { GenCounAttributes: } \\
\text { People } \\
\text { Similarity } \\
\text { GenProdAtttributes: } \\
\text { Desireable } \\
\text { Distribution } \\
\text { Undesireable } \\
\text { ProductAttributes } \\
\text { Intent to buy }\end{array}$ & $\begin{array}{l}1 \text { country } \\
\text { sample; } 2 \\
\text { origins }\end{array}$ & 2 & $\begin{array}{l}\text { Consumers } \\
\text { systematic }\end{array}$ & 678 & $\begin{array}{l}\text { SEM/ } \\
\text { LISREL }\end{array}$ & $\begin{array}{l}17 \\
\text { near } \\
\text { sup- } \\
\text { port } \\
\text { for all }\end{array}$ \\
\hline $\begin{array}{l}\text { 8. Orbaiz } \\
\text { and Papa- } \\
\text { dopoulos }\end{array}$ & 2003 & $\begin{array}{l}\text { Country image } \\
\text { Country affect } \\
\text { Ethnocentrism } \\
\text { Product beliefs } \\
\text { Familiarity } \\
\text { Willingness to buy }\end{array}$ & $\begin{array}{l}\text { 1country } \\
\text { sample; } 3 \\
\text { origins }\end{array}$ & 1 & $\begin{array}{l}\text { Consumers } \\
\text { systematic }\end{array}$ & 198 & $\begin{array}{l}\text { SEM/ } \\
\text { EQS }\end{array}$ & $\begin{array}{l}9 \\
\text { near } \\
\text { sup- } \\
\text { port } \\
\text { for all }\end{array}$ \\
\hline $\begin{array}{l}\text { 9. Heslop, } \\
\text { et al. }\end{array}$ & 2004 & $\begin{array}{l}\text { People description } \\
\text { Country description } \\
\text { People competence } \\
\text { Country competence } \\
\text { Country evaluation } \\
\text { Country relationship } \\
\text { Product beliefs } \\
\text { Familiarity } \\
\text { Product evaluation } \\
\text { Willingness to buy }\end{array}$ & $\begin{array}{l}1 \text { country } \\
\text { sample; } \\
5 \text { origins }\end{array}$ & 1 & $\begin{array}{l}\text { Retailers } \\
\text { systematic }\end{array}$ & 147 & $\begin{array}{l}\text { SEM/ } \\
\text { PLS }\end{array}$ & $\begin{array}{l}15 \\
\text { sup- } \\
\text { port } \\
\text { for } \\
\text { most }\end{array}$ \\
\hline $\begin{array}{l}\text { 10. Papa- } \\
\text { dopoulos } \\
\text { and Butt }\end{array}$ & 2005 & $\begin{array}{l}\text { Country beliefs } \\
\text { People affect } \\
\text { Desired interaction } \\
\text { Country image } \\
\text { Product beliefs } \\
\text { Familiarity } \\
\text { Product evaluation } \\
\end{array}$ & $\begin{array}{l}\text { 1country } \\
\text { sample; } 2 \\
\text { origins }\end{array}$ & 1 & $\begin{array}{l}\text { Consumers } \\
\text { systematic }\end{array}$ & 436 & $\begin{array}{l}\text { SEM/ } \\
\text { EQS }\end{array}$ & $\begin{array}{l}6 \\
\text { near } \\
\text { sup- } \\
\text { port } \\
\text { for all }\end{array}$ \\
\hline
\end{tabular}

Adapted from Papadopoulos and Butt [2005] 
Table D-2: TDI Structural Models

\begin{tabular}{|c|c|c|c|c|c|c|c|c|}
\hline Author & Year & Measures & \# Places & $\begin{array}{l}\text { \#Prod- } \\
\text { ucts }\end{array}$ & $\begin{array}{l}\text { Subjects/ } \\
\text { selection }\end{array}$ & Size & Method & Paths \\
\hline $\begin{array}{l}\text { 1. Baloglu } \\
\text { and } \\
\text { McCleary }\end{array}$ & $\begin{array}{l}1999 \\
\text { (a) }\end{array}$ & $\begin{array}{l}\text { Variety of info (9) } \\
\text { Info source (4) } \\
\text { Age (1) } \\
\text { Education (1) } \\
\text { Motivations (17) } \\
\text { Cognitive } \\
\text { evaluation (14) } \\
\text { Affective } \\
\text { evaluation (4) } \\
\text { Overall image (1) }\end{array}$ & $\begin{array}{l}4 \\
\text { countries: } \\
\text { Turkey } \\
\text { Greece } \\
\text { Italy } \\
\text { Egypt }\end{array}$ & $\begin{array}{l}1 \\
\text { tourism } \\
\text { in } \\
\text { general }\end{array}$ & $\begin{array}{l}\text { Prospec- } \\
\text { tive } \\
\text { travellers } \\
\text { NTO } \\
\text { mailing list }\end{array}$ & $\begin{array}{l}448 \\
\text { (res- } \\
\text { ponse } \\
\text { rate } \\
31 \% \text { ) } \\
716 \\
\text { total }\end{array}$ & $\begin{array}{l}\text { Re- } \\
\text { gression }\end{array}$ & $\begin{array}{l}8 \\
\text { support } \\
\text { for all; } \\
2 \text { strong; } \\
3 \text { mod; } \\
3 \text { part }\end{array}$ \\
\hline $\begin{array}{l}2 . \\
\text { Murphy, } \\
\text { Pritchard, } \\
\text { and Smith }\end{array}$ & 2000 & \begin{tabular}{|l|} 
Environment (5) \\
Infrastructure (3) \\
Quality (2) \\
Value (4) \\
Intention to return \\
$(2)$ \\
\end{tabular} & $\begin{array}{l}1 \text { city: } \\
\text { Victoria, } \\
\text { B.C. }\end{array}$ & $\begin{array}{l}1 \\
\text { tourism } \\
\text { in } \\
\text { general }\end{array}$ & $\begin{array}{l}\text { Visitors } \\
\text { Drawn } \\
\text { from exit } \\
\text { survey data } \\
\text { set }\end{array}$ & 610 & PLS & $\begin{array}{l}7 \\
\text { support } \\
\text { for all }\end{array}$ \\
\hline $\begin{array}{l}3 . \\
\text { Bigne, } \\
\text { Sanchez, } \\
\text { and } \\
\text { Sanchez }\end{array}$ & 2001 & $\begin{array}{l}\text { Image (1) } \\
\text { Quality (1) } \\
\text { Satisfaction (1) } \\
\text { Return (1) } \\
\text { Recommend (1) } \\
\end{array}$ & \begin{tabular}{|l|}
2 \\
resorts in \\
Spain
\end{tabular} & $\begin{array}{l}1 \\
\text { tourism } \\
\text { in } \\
\text { general }\end{array}$ & $\begin{array}{l}\text { Visitors } \\
\text { Con- } \\
\text { venience } \\
\text { and Quota }\end{array}$ & 514 & LISREL & $\begin{array}{l}9 \\
\text { support } \\
\text { for all; } \\
7 \text { full } \\
2 \text { part } \\
\end{array}$ \\
\hline $\begin{array}{l}\text { 4. Beerli } \\
\text { and } \\
\text { Martin }\end{array}$ & $\begin{array}{l}2004 \\
\text { (a) }\end{array}$ & $\begin{array}{l}\text { Cognitive image } \\
(24) \\
\text { Affecitve image (2) } \\
\text { Overall image (1) } \\
\text { Sources of info (9) } \\
\text { Import of sources } \\
\text { Motivations (19) } \\
\text { Experience (2) } \\
\text { Socio demos (Age, } \\
\text { Education, Social } \\
\text { class, } \\
\text { Country of origin) } \\
\text { by ANOVA }\end{array}$ & $\begin{array}{l}1 \\
\text { Lanzarote, } \\
\text { Canary } \\
\text { Islands, } \\
\text { Spain }\end{array}$ & $\begin{array}{l}1 \\
\text { tourism } \\
\text { in } \\
\text { general }\end{array}$ & $\begin{array}{l}\text { Visitors: } \\
1^{\text {st }} \text { timers } \\
\text { and } \\
\text { repeaters } \\
\text { Con- } \\
\text { venience } \\
\text { and Quota } \\
\text { at airport }\end{array}$ & 616 & $\begin{array}{l}\text { Re- } \\
\text { gression }\end{array}$ & $\begin{array}{l}11 \\
\text { support } \\
\text { for all; } \\
4 \text { mod; } \\
7 \text { part }\end{array}$ \\
\hline $\begin{array}{l}\text { 5. Beerli } \\
\text { and } \\
\text { Martin }\end{array}$ & $\begin{array}{l}2004 \\
\text { (b) }\end{array}$ & $\begin{array}{l}\text { Cognitive image } \\
(24) \\
\text { Affective image (2) } \\
\text { Overall image (1) } \\
\text { Motivations (19) } \\
\text { Experience (1) } \\
\text { Socio demos (Age, } \\
\text { Education, Social } \\
\text { class, } \\
\text { Country of origin) } \\
\text { by ANOVA } \\
\end{array}$ & $\begin{array}{l}1 \\
\text { Lanzarote, } \\
\text { Canary } \\
\text { Islands, } \\
\text { Spain }\end{array}$ & $\begin{array}{l}1 \\
\text { tourism } \\
\text { in } \\
\text { general }\end{array}$ & $\begin{array}{l}\text { Visitors: } \\
1^{\text {st }} \text { timers } \\
\text { and } \\
\text { repeaters } \\
\text { Con- } \\
\text { venience } \\
\text { and Quota } \\
\text { at airport }\end{array}$ & 616 & \begin{tabular}{|l|} 
Re- \\
gression
\end{tabular} & $\begin{array}{l}7 \\
\text { support } \\
\text { for all; } \\
3 \text { mod; } \\
4 \text { part }\end{array}$ \\
\hline $\begin{array}{l}\text { 6. Heslop, } \\
\text { et al. }\end{array}$ & 2005 & $\begin{array}{l}\text { Country } \\
\text { Competence(3) } \\
\text { People } \\
\text { Competence(3) } \\
\text { Country } \\
\text { Description(3) } \\
\text { People } \\
\end{array}$ & $\begin{array}{l}1 \\
\text { Nepal }\end{array}$ & $\begin{array}{l}1 \\
\text { tourism }\end{array}$ & $\begin{array}{l}\text { Visitors } \\
\text { Con- } \\
\text { venience at } \\
\text { attractions }\end{array}$ & 307 & LISREL & $\begin{array}{l}10 \\
\text { support } \\
\text { for all }\end{array}$ \\
\hline
\end{tabular}




\begin{tabular}{|l|l|l|l|l|l|l|l|}
\hline & Description(3) & & & & & \\
Natural & Environment(3) & & & & & \\
Built & Environment(3) & & & & & \\
Destination Eval & & & & & & \\
Desired Links(5) & & & & & & & \\
Travel & & & & & & \\
\hline
\end{tabular}


APPENDIX E

Variable Descriptive Statistics

Table E.1: Scale Item Descriptive Statistics - Korean Sample

Variable Mean Std. Mean Skew. Skew. Kurt. Kurt.

Stat. Dev. StdErr. Stat. StdErr. Stat. StdErr.

\begin{tabular}{|c|c|c|c|c|c|c|c|}
\hline \multicolumn{8}{|c|}{ Country-Related: U.S. } \\
\hline CbQlifeU & 5.671 & 1.1352 & .0608 & -1.222 & .131 & 2.550 & .260 \\
\hline CaPleasU & 4.785 & 1.4082 & .0754 & -.500 & .131 & 143 & .260 \\
\hline bWealtU & 5.580 & 1.1836 & .0634 & -.914 & .131 & 1.271 & .260 \\
\hline CaExcitU & 5.076 & 1.3218 & .0708 & .929 & .131 & .983 & .260 \\
\hline CbTechU & 5.587 & 1.4121 & .0756 & -1.277 & .131 & 1.335 & .260 \\
\hline CaFrienU & 4.171 & 1.5545 & .0832 & -.112 & .131 & -.737 & .260 \\
\hline CbEducU & 5.041 & 1.2358 & .0661 & -.454 & .131 & 117 & .260 \\
\hline CaSafeU & 3.359 & 1.6483 & .0882 & .554 & .131 & -.397 & .260 \\
\hline CaTrustU & 3.928 & 1.4376 & .0770 & .087 & .131 & -.354 & .260 \\
\hline CkKnowU & 3.500 & 1.4778 & .0791 & .105 & .131 & -.524 & .260 \\
\hline CrTiesU & 5.040 & 1.4075 & .0753 & -.588 & .131 & .063 & .260 \\
\hline PrImprtU & 3.677 & 1.5846 & .0848 & .084 & .131 & -.603 & .260 \\
\hline CaIdealU & 4.493 & 1.6279 & .0871 & -.523 & .131 & -.287 & .260 \\
\hline CkInfoU & 3.788 & 1.5844 & .0848 & .352 & .131 & -.261 & .260 \\
\hline \multicolumn{8}{|c|}{ Country-Related: Japan } \\
\hline CbQlifeJ & 5.273 & 1.2788 & .0685 & -.995 & .131 & 1.287 & .260 \\
\hline CaPleasJ & 4.075 & 1.7271 & .0925 & -.126 & .131 & -.872 & .260 \\
\hline CbWealtJ & 5.348 & 1.2305 & .0659 & -.855 & .131 & .938 & .260 \\
\hline CaExcitJ & 4.458 & 1.4603 & .0782 & -.229 & .131 & -.508 & .260 \\
\hline CbTechJ & 5.682 & 1.3865 & .0742 & -1.458 & .131 & 2.138 & .260 \\
\hline CaFrienJ & 4.026 & 1.6771 & .0898 & -.192 & .131 & -.849 & .260 \\
\hline CbEducJ & 4.977 & 1.2385 & .0663 & -.549 & .131 & .382 & .260 \\
\hline CaSafeJ & 4.504 & 1.5927 & .0853 & -.334 & .131 & -.724 & .260 \\
\hline CaTrustJ & 3.503 & 1.7158 & 0918 & .265 & 131 & -.772 & .260 \\
\hline CkKnowJ & 4.075 & 1.6523 & .0884 & -.058 & .131 & -.762 & .260 \\
\hline CrTiesJ & 4.533 & 1.5236 & .0816 & -.434 & .131 & -.307 & .260 \\
\hline PrImprtJ & 3.499 & 1.6057 & 0860 & 139 & 131 & -.616 & .260 \\
\hline CaIdealJ & 4.069 & 1.7132 & 0917 & -.212 & 131 & -.691 & .260 \\
\hline CkInfoJ & 3.725 & 1.3967 & .0748 & .273 & .131 & -.016 & .260 \\
\hline \multicolumn{8}{|c|}{ Country-Related: Australia } \\
\hline CbQlifeA & 5.391 & 1.1342 & .0607 & -.624 & .131 & 618 & .260 \\
\hline CaPleasA & 5.413 & 1.1506 & .0616 & -.760 & .131 & 1.163 & .260 \\
\hline CbWealtA & 5.105 & 1.0697 & .0573 & -.382 & .131 & .376 & .260 \\
\hline CaExcitA & 4.979 & 1.2919 & .0692 & -.717 & .131 & .608 & .260 \\
\hline CbTechA & 4.630 & 1.2679 & .0679 & -.338 & .131 & .088 & .260 \\
\hline CaFrienA & 4.785 & 1.3153 & .0704 & -.465 & .131 & .294 & .260 \\
\hline CbEducA & 4.918 & 1.2453 & .0667 & -.534 & .131 & .366 & .260 \\
\hline CaSafeA & 5.009 & 1.2188 & .0652 & -.438 & .131 & .342 & .260 \\
\hline CaTrustA & 4.754 & 1.1883 & .0636 & -.236 & .131 & . 186 & .260 \\
\hline
\end{tabular}




\begin{tabular}{|c|c|c|c|c|c|c|c|}
\hline CkKnowA & 3.258 & 1.5306 & .0819 & .375 & .131 & -.280 & .260 \\
\hline CrTiesA & 4.855 & 1.1729 & .0628 & -.337 & .131 & .391 & .260 \\
\hline PrImprtA & 4.224 & 1.3580 & .0727 & -.295 & .131 & .201 & .260 \\
\hline CaIdealA & 5.301 & 1.3158 & .0704 & -.622 & .131 & .465 & .260 \\
\hline CkInfoA & 2.983 & 1.3687 & .0733 & .336 & .131 & .123 & .260 \\
\hline \multicolumn{8}{|c|}{ Country-Related: Canada } \\
\hline CbQlifeX & 5.556 & 1.1137 & .0596 & -.989 & .131 & 1.901 & .260 \\
\hline CaPleasX & 5.430 & 1.0427 & .0558 & -.540 & .131 & .928 & .260 \\
\hline CbWealtX & 5.223 & 1.1445 & .0613 & -.862 & .131 & 1.538 & .260 \\
\hline CaExcitX & 4.794 & 1.3900 & .0744 & -.587 & .131 & .154 & .260 \\
\hline CbTechX & 4.788 & 1.3471 & .0721 & -.254 & .131 & -.410 & .260 \\
\hline CaFrienX & 4.742 & 1.3175 & .0705 & -.432 & .131 & -.003 & .260 \\
\hline CbEducX & 5.049 & 1.2155 & .0651 & -.577 & .131 & .480 & .260 \\
\hline CaSafeX & 5.206 & 1.2507 & .0669 & -.752 & .131 & .701 & .260 \\
\hline CaTrustX & 4.919 & 1.2126 & .0649 & -.272 & .131 & -.160 & .260 \\
\hline CkKnowX & 3.116 & 1.5232 & .0815 & .549 & .131 & .001 & .260 \\
\hline CrTiesX & 4.939 & 1.2477 & .0668 & -.465 & .131 & .346 & .260 \\
\hline PrImprtX & 4.275 & 1.3443 & .0720 & -.150 & .131 & -.006 & .250 \\
\hline CaIdealX & 5.295 & 1.2423 & .0665 & -.528 & .131 & .509 & .260 \\
\hline CkInfoX & 2.983 & 1.3936 & .0746 & .525 & .131 & .583 & .260 \\
\hline \multicolumn{8}{|c|}{ Product-Related: U.S. } \\
\hline PbQualU & 5.322 & 1.1037 & .0591 & -.380 & .131 & .261 & .260 \\
\hline PbReliaU & 4.765 & 1.3883 & .0743 & -.526 & .131 & .013 & .260 \\
\hline PfKnowU & 4.256 & 1.4505 & .0776 & -.148 & .131 & -.442 & .260 \\
\hline PbWorkU & 5.224 & 1.1327 & .0606 & -.450 & .131 & .261 & .260 \\
\hline PfBrandU & 5.418 & 1.2421 & .0665 & -.590 & .131 & -.056 & .260 \\
\hline PbInnovU & 5.078 & 1.2786 & .0684 & -.437 & .131 & .033 & .260 \\
\hline PbValueU & 4.826 & 1.3082 & .0700 & -.394 & .131 & -.022 & .260 \\
\hline PrWilByU & 4.301 & 1.5194 & .0813 & -.084 & .131 & -.438 & .260 \\
\hline PfUseU & 4.816 & 1.4406 & .0771 & -.533 & .131 & .013 & .260 \\
\hline PfFindU & 5.206 & 1.5473 & .0828 & -.751 & .131 & .114 & .260 \\
\hline PbSatisU & 4.410 & 1.3996 & .0749 & -.368 & .131 & .020 & .260 \\
\hline PbProudU & 3.296 & 1.5091 & .0808 & .254 & .131 & -.321 & .260 \\
\hline PbGoodU & 5.240 & 1.1582 & .0620 & -.740 & .131 & 1.415 & .260 \\
\hline \multicolumn{8}{|c|}{ Product-Related: Japan } \\
\hline PbQualJ & 5.787 & 1.1042 & .0591 & -1.065 & .131 & 2.069 & .260 \\
\hline PbReliaJ & 5.233 & 1.5106 & .0809 & -.944 & .131 & .514 & .260 \\
\hline PfKnowJ & 4.724 & 1.4617 & .0782 & -.445 & .131 & -.125 & .260 \\
\hline PbWorkJ & 5.491 & 1.3901 & .0744 & -1.283 & .131 & 1.807 & .260 \\
\hline PfBrandJ & 5.579 & 1.3202 & .0707 & -1.231 & .131 & 1.715 & .260 \\
\hline PbInnovJ & 5.429 & 1.4807 & .0793 & -1.173 & .131 & 1.295 & .260 \\
\hline PbValueJ & 5.149 & 1.3940 & .0746 & -.993 & .131 & 1.106 & .260 \\
\hline PrWilByJ & 4.484 & 1.5926 & .0853 & -.405 & .131 & -.296 & .260 \\
\hline PfUse.J & 5.213 & 1.3521 & .0724 & -.814 & .131 & .535 & .260 \\
\hline PfFindJ & 5.555 & 1.4344 & .0768 & -1.136 & .131 & 1.144 & .260 \\
\hline PbSatisJ & 4.910 & 1.4022 & .0751 & -.776 & .131 & .670 & .260 \\
\hline
\end{tabular}




\begin{tabular}{|c|c|c|c|c|c|c|c|}
\hline PbProudJ & 3.348 & 1.5152 & .0811 & .114 & .131 & -.460 & .260 \\
\hline PbGoodJ & 5.641 & 1.2536 & .0671 & -1.269 & .131 & 2.469 & .260 \\
\hline \multicolumn{8}{|c|}{ Product-Related: Austrailia } \\
\hline PbQualA & 4.655 & 1.0968 & .0587 & -.025 & .131 & 1.255 & .260 \\
\hline PbReliaA & 4.431 & 1.1053 & .0592 & -.215 & .131 & 1.151 & .260 \\
\hline PfKnowA & 3.118 & 1.5325 & .0820 & .179 & .131 & -.577 & .260 \\
\hline PbWorkA & 4.217 & 1.1462 & .0614 & -.195 & .131 & 1.099 & .260 \\
\hline PfBrandA & 3.702 & 1.3329 & .0713 & -.075 & .131 & .235 & .260 \\
\hline PbInnovA & 4.105 & 1.1029 & .0590 & .006 & .131 & 1.055 & .260 \\
\hline PbValueA & 4.127 & 1.1058 & .0592 & -.025 & .131 & 1.079 & .260 \\
\hline PrWilByA & 3.929 & 1.2506 & .0669 & -.120 & .131 & .461 & .260 \\
\hline PfUseA & 3.206 & 1.5970 & .0855 & .131 & .131 & -.736 & .260 \\
\hline PfFindA & 3.086 & 1.4705 & .0787 & .308 & .131 & -.232 & .260 \\
\hline PbSatisA & 3.985 & 1.0840 & .0580 & -.283 & .131 & 1.304 & .260 \\
\hline PbProudA & 3.751 & 1.2967 & .0694 & -.147 & .131 & .612 & .260 \\
\hline PbGoodA & 4.793 & 1.1685 & .0625 & -.289 & .131 & .786 & .260 \\
\hline \multicolumn{8}{|c|}{ Product-Related: Canada } \\
\hline PbQualX & 4.727 & 1.1274 & .0603 & -.255 & .131 & 1.183 & .260 \\
\hline PbReliaX & 4.466 & 1.1834 & .0633 & -.207 & .131 & .550 & .260 \\
\hline PfK & 3.084 & 1.5780 & .0845 & .355 & .131 & -.537 & .260 \\
\hline PbWorkX & 4.415 & 1.1708 & .0627 & -.091 & .131 & .833 & .260 \\
\hline PfBrandX & 3.789 & 1.3759 & .0737 & -.001 & .131 & -.115 & .260 \\
\hline PbInnovX & 4.224 & 1.1257 & .0603 & .129 & .131 & .432 & .260 \\
\hline PbV & 4.238 & 1.1318 & .0606 & -.002 & .131 & .698 & .260 \\
\hline ByX & 4.107 & 1.2320 & .0659 & -.252 & .131 & .448 & .260 \\
\hline PfUseX & 2.997 & 1.6790 & .0899 & .334 & .131 & -.835 & .260 \\
\hline PfFindX & 2.866 & 1.4561 & .0779 & .437 & .131 & -.418 & .260 \\
\hline PbSatisX & 4.068 & 1.1415 & .0611 & -.496 & .131 & 1.223 & .260 \\
\hline $\mathbf{P b P}$ & 24 & 1.2837 & .0687 & -.363 & .131 & .555 & .260 \\
\hline PbGoodX & 4.696 & 1.3002 & .0696 & -.251 & .131 & .225 & .260 \\
\hline \multicolumn{8}{|c|}{ Tourism-Related: U.S. } \\
\hline TbScene & 5.588 & 1.2498 & .0669 & -.984 & .131 & 1.304 & .260 \\
\hline TbAccomU & 4.779 & 1.5822 & .0847 & -.424 & .131 & -.469 & .260 \\
\hline & 5.321 & 1.4027 & .0751 & -.888 & .131 & .591 & .260 \\
\hline TbActivU & 5.457 & 1.3623 & .0729 & -1.019 & .131 & 1.058 & .260 \\
\hline TbValueU & 5.957 & 1.1274 & .0604 & -1.378 & .131 & 2.741 & .260 \\
\hline TrWilTrU & 5.118 & 1.5182 & .0813 & -.683 & .131 & .059 & .260 \\
\hline TbGoodU & 5.455 & 1.1730 & .0628 & -.729 & .131 & 1.007 & .260 \\
\hline TkTripsU & 1.28 & .760 & .041 & 3.584 & .131 & 15.642 & .260 \\
\hline \multicolumn{8}{|c|}{ Tourism-Related: Japan } \\
\hline TbSceneJ & 5.225 & 1.4308 & .0766 & -.786 & .131 & .418 & .260 \\
\hline TbAccomJ & 4.598 & 1.6502 & .0883 & -.370 & .131 & -.623 & .260 \\
\hline TbAttraJ & 5.075 & 1.4344 & .0768 & -.615 & .131 & .103 & .260 \\
\hline TbActivJ & 5.170 & 1.4572 & .0780 & -.792 & .131 & .349 & .260 \\
\hline lueJ & 5.692 & 1.4582 & .0781 & -1.074 & .131 & .547 & .260 \\
\hline TrWilTrJ & 5.089 & 1.6507 & .0884 & -.748 & .131 & -.035 & .260 \\
\hline
\end{tabular}




\begin{tabular}{|c|c|c|c|c|c|c|c|}
\hline TbGoodJ & 5.154 & 1.3510 & .0723 & -.622 & .131 & .315 & .260 \\
\hline TkTripsJ & 1.62 & 1.293 & .069 & 2.626 & .131 & 6.661 & .260 \\
\hline \multicolumn{8}{|c|}{ Tourism-Related: Australia } \\
\hline TbSceneA & 5.988 & 1.0907 & .0584 & -1.113 & .131 & 1.326 & .260 \\
\hline TbAccomA & 4.525 & 1.6198 & .0867 & -.229 & .131 & -.698 & .260 \\
\hline TbAttraA & 5.657 & 1.2830 & .0687 & -1.067 & .131 & 1.231 & .260 \\
\hline TbActivA & 5.664 & 1.2794 & .0685 & -1.044 & .131 & 1.167 & .260 \\
\hline TbValueA & 5.348 & 1.3141 & .0703 & -.774 & .131 & .400 & .260 \\
\hline TrWilTrA & 5.519 & 1.3923 & .0745 & -.930 & 131 & .690 & .260 \\
\hline TbGoodA & 5.742 & 1.1919 & .0638 & -.936 & .131 & .996 & .260 \\
\hline TkTripsA & 1.13 & .491 & .026 & 6.734 & .131 & 64.897 & .260 \\
\hline \multicolumn{8}{|c|}{ Tourism-Related: Canada } \\
\hline TbSc & 5.870 & 1.1685 & .0625 & -1.102 & .131 & 1.577 & .260 \\
\hline TbAcc & 4.464 & 1.5787 & .0845 & -.208 & .131 & -.661 & .260 \\
\hline TbAttraX & 5.597 & 1.2583 & .0674 & -.917 & .131 & .937 & .260 \\
\hline TbActivX & 5.411 & 1.3380 & .0716 & -.844 & .131 & .729 & .260 \\
\hline TbValueX & 5.278 & 1.3057 & .0699 & -.668 & .131 & .357 & .260 \\
\hline TrWilTrX & 5.384 & 1.3723 & .0735 & -.577 & .131 & -.168 & .260 \\
\hline TbGoodX & 5.506 & 1.2611 & .0675 & -.666 & .131 & .338 & .260 \\
\hline TkTripsX & 1.13 & .520 & .028 & 6.225 & .131 & 53.421 & .260 \\
\hline
\end{tabular}

N=349; Minimum=1; Maximum=7. 
Table E.2: Scale Item Descriptive Statistics - Canadian Sample

\begin{tabular}{|c|c|c|c|c|c|c|c|}
\hline Variable & $\begin{array}{r}\text { Mean } \\
\text { Stat. }\end{array}$ & $\begin{array}{l}\text { Std. } \\
\text { Dev. }\end{array}$ & $\begin{array}{r}\text { Mean } \\
\text { StdErr. }\end{array}$ & $\begin{array}{r}\text { Skew. } \\
\text { Stat. }\end{array}$ & $\begin{array}{r}\text { Skew. } \\
\text { StdErr. }\end{array}$ & $\begin{array}{l}\text { Kurt. } \\
\text { Stat. }\end{array}$ & $\begin{array}{r}\text { Kurt. } \\
\text { StdErr. }\end{array}$ \\
\hline \multicolumn{8}{|c|}{ Country-Related: U.S. } \\
\hline CbQlifeU & 5.539 & 1.1576 & .0661 & -.879 & .139 & .897 & .277 \\
\hline CaPleasU & 5.016 & 1.2458 & .0711 & -.542 & 139 & -.053 & .277 \\
\hline CbWealtU & 5.063 & 1.4186 & .0810 & -.375 & 139 & -.452 & .277 \\
\hline CaExcitU & 4.765 & 1.5020 & .0857 & -.332 & 139 & -.484 & .277 \\
\hline CbTechU & 5.582 & 1.6725 & .0955 & -1.264 & .139 & .624 & .277 \\
\hline CaFrienU & 4.719 & 1.4347 & .0819 & -.419 & 139 & -.158 & .277 \\
\hline CbEducU & 4.646 & 1.3058 & .0745 & -.384 & .139 & .256 & .277 \\
\hline CaSafeU & 3.941 & 1.4585 & .0832 & -.012 & 9 & -.352 & .277 \\
\hline CaTrustU & 4.275 & 1.2717 & .0726 & -.280 & .139 & .217 & .277 \\
\hline CkKnowU & 5.046 & 1.5897 & .0907 & -.597 & .139 & -.382 & .277 \\
\hline CrTie & 4.541 & 1.6874 & .0963 & -.392 & & -.452 & 277 \\
\hline PrIn & 4.354 & 1.4728 & .0841 & -.178 & & -.141 & .277 \\
\hline CaIdealU & 5.062 & 1.5306 & .0874 & -.794 & .139 & .303 & 277 \\
\hline CkInfoU & 4.952 & 1.4944 & .0853 & -.243 & .139 & -.469 & .277 \\
\hline \multicolumn{8}{|c|}{ Country-Related: Japan } \\
\hline CbQlifeJ & 5.180 & 1.3804 & .0788 & -.889 & 139 & .820 & .277 \\
\hline $\mathbf{C a P}$ & 5.098 & 1.3661 & .0780 & -.736 & & .412 & 277 \\
\hline CbW & 4.951 & 1.3865 & .0791 & -.444 & .1 & -.211 & 277 \\
\hline CaExcitJ & 4.602 & 1.5220 & .0869 & -.486 & .1 & -.092 & 277 \\
\hline CbTechJ & 5.931 & 1.6973 & .0969 & -1.660 & & 1.611 & 277 \\
\hline Cal & 4.987 & 1.5508 & .0885 & -.613 & & -.262 & 277 \\
\hline Cbl & 5.631 & 1.3948 & .0796 & -1.276 & & 1.467 & 277 \\
\hline CaSafeJ & 5.124 & 1.4226 & .0812 & -.549 & .1 & -.207 & 277 \\
\hline CaTrustJ & 4.921 & 1.4143 & .0807 & -.718 & .1 & .509 & 277 \\
\hline CkK & 3.620 & 1.7766 & 1014 & .279 & & -.782 & 277 \\
\hline Cr1 & 4 & 53 & .0785 & -.384 & & .324 & 277 \\
\hline PrIn & 4.434 & 1.5197 & .0867 & -.374 & .1 & .277 & .277 \\
\hline CaIdealJ & 4.745 & 1.4551 & .0830 & -.519 & .1 & .084 & 277 \\
\hline CkInfoJ & 3.744 & 1.5358 & .0877 & -.388 & .139 & -.604 & 277 \\
\hline \multicolumn{8}{|c|}{ Country-Related: Australia } \\
\hline $\mathbf{C b C}$ & 5.609 & 1.0983 & .0627 & -.817 & .139 & .792 & 277 \\
\hline & 5.699 & 1.1 & .0666 & -1.099 & .1 & 1.720 & .277 \\
\hline $\mathrm{CbV}$ & 4.811 & 1.1786 & .0673 & -.267 & .1 & .273 & 277 \\
\hline CaEx & 5.257 & 1.3010 & .0743 & -.480 & .1 & -.264 & .277 \\
\hline $\mathbf{C b T}$ & 4.498 & 1.2983 & .0741 & -.141 & & -.085 & .277 \\
\hline & & 1.4462 & .0825 & -1.010 & & .826 & . 277 \\
\hline $\mathrm{Cl}$ & 4.820 & 1.1925 & .0681 & -.346 & .1 & .320 & .277 \\
\hline CaSafeA & 5.082 & 1.3564 & .0774 & -.553 & .139 & .038 & 277 \\
\hline CaTrustA & 5.078 & 1.2368 & .0706 & -.578 & .139 & .446 & 277 \\
\hline CkKnowA & 3.875 & 1.7445 & .0996 & -.057 & .139 & -.905 & 277 \\
\hline & 4.892 & 1.3808 & .0788 & -.367 & .139 & -.346 & .277 \\
\hline PrImprtA & 4.886 & 1.3921 & .0795 & -.423 & .139 & -.084 & .277 \\
\hline
\end{tabular}




\begin{tabular}{|c|c|c|c|c|c|c|c|}
\hline CaIdealA & 5.567 & 1.1596 & .0662 & -.658 & .139 & .386 & .277 \\
\hline CkInfoA & 3.526 & 1.5874 & .0906 & -.015 & .139 & -.593 & .277 \\
\hline \multicolumn{8}{|c|}{ Country-Related: South Korea } \\
\hline CbQlifeX & 4.070 & 1.4389 & .0821 & -.209 & .139 & -.485 & .277 \\
\hline CaPleasX & 4.305 & 1.2910 & .0737 & -.291 & .139 & 200 & .277 \\
\hline CbWealtX & 3.930 & 1.3474 & .0769 & -.314 & .139 & -.208 & .277 \\
\hline CaExcitX & 3.993 & 1.2783 & .0730 & .069 & .139 & .472 & .277 \\
\hline CbTechX & 4.822 & 1.5228 & .0869 & -.455 & .139 & -.340 & .277 \\
\hline CaFrienX & 4.517 & 1.2484 & .0713 & -.388 & .139 & .436 & .277 \\
\hline CbEducX & 4.552 & 1.2419 & .0709 & -.300 & .139 & .179 & .277 \\
\hline CaSafeX & 4.157 & 1.2855 & .0734 & -.176 & .139 & .390 & .277 \\
\hline CaTrustX & 4.340 & 1.2278 & .0701 & -.207 & .139 & .446 & .277 \\
\hline CkKnowX & 3.052 & 1.6756 & .0956 & .416 & .139 & -.650 & .277 \\
\hline CrTiesX & 4.246 & 1.3331 & .0761 & -.319 & .139 & .595 & .277 \\
\hline PrImprtX & 4.207 & 1.4271 & .0814 & -.221 & .139 & .143 & .277 \\
\hline CaIdealX & 3.787 & 1.3871 & .0792 & -.272 & .139 & .071 & .277 \\
\hline CkInfoX & 2.795 & 1.5798 & .0902 & .394 & .139 & -.752 & .277 \\
\hline \multicolumn{8}{|c|}{ Product-Related: U.S. } \\
\hline PbQualU & 5.160 & 1.4040 & .0801 & -.821 & .139 & .418 & .277 \\
\hline PbReliaU & 4.993 & 1.4211 & .0811 & -.655 & .139 & .081 & .277 \\
\hline PfKnowU & 4.788 & 1.6161 & .0922 & -.508 & .139 & -.399 & .277 \\
\hline PbWorkU & 4.752 & 1.2539 & .0716 & -.222 & .139 & -.025 & .277 \\
\hline PfBrandU & 5.837 & 1.3208 & .0754 & -1.256 & .139 & 1.205 & .277 \\
\hline PbInnovU & 5.114 & 1.3874 & .0792 & -.687 & .139 & .466 & .277 \\
\hline PbValueU & 4.886 & 1.2667 & .0723 & -.367 & .139 & -.056 & .277 \\
\hline PrWilByU & 5.382 & 1.4555 & .0831 & -1.026 & .139 & .814 & .277 \\
\hline PfUseU & 5.245 & 1.4782 & .0844 & -.655 & .139 & -.243 & .277 \\
\hline PfFindU & 5.199 & 1.6616 & .0948 & -.664 & .139 & -.500 & .277 \\
\hline PbSatisU & 5.030 & 1.3488 & .0770 & -.448 & .139 & -.028 & .277 \\
\hline PbProudU & 4.121 & 1.6215 & .0925 & -.039 & .139 & -.625 & .277 \\
\hline PbGoodU & 5.428 & 1.1950 & .0682 & -.816 & .139 & .979 & .277 \\
\hline \multicolumn{8}{|c|}{ Product-Related: Japan } \\
\hline PbQualJ & 5.655 & 1.4724 & .0840 & -1.169 & .139 & .815 & .277 \\
\hline PbReliaJ & 5.291 & 1.6120 & .0920 & -.797 & .139 & -.211 & .277 \\
\hline PfKnowJ & 4.359 & 1.6796 & .0959 & -.271 & .139 & -.587 & .277 \\
\hline PbWorkJ & 5.206 & 1.4753 & .0842 & -.587 & .139 & -.305 & .277 \\
\hline PfBrandJ & 5.182 & 1.6723 & .0954 & -.760 & .139 & -.317 & .277 \\
\hline PbInnovJ & 5.380 & 1.6148 & .0922 & -.901 & .139 & .036 & .277 \\
\hline PbValueJ & 5.107 & 1.5376 & .0878 & -.654 & .139 & -.087 & .277 \\
\hline PrWilByJ & 5.332 & 1.5148 & .0865 & -.804 & .139 & .087 & .277 \\
\hline PfUseJ & 4.633 & 1.6279 & .0929 & -.431 & .139 & -.435 & .277 \\
\hline PfFindJ & 5.036 & 1.6276 & .0929 & -.539 & .139 & -.462 & .277 \\
\hline PbSatisJ & 5.043 & 1.4780 & .0844 & -.716 & .139 & .089 & .277 \\
\hline PbProudJ & 4.297 & 1.7225 & .0983 & -.140 & .139 & -.740 & .277 \\
\hline PbGoodJ & 5.500 & 1.3376 & .0763 & -.952 & .139 & .722 & .277 \\
\hline 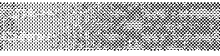 & & Prod & & $\theta x$ & & & 2 \\
\hline
\end{tabular}




\begin{tabular}{|c|c|c|c|c|c|c|c|}
\hline PbQualA & 4.735 & 1.1615 & .0663 & -.022 & .139 & .369 & .277 \\
\hline PbReliaA & 4.558 & 1.2317 & .0703 & .050 & .139 & .298 & .277 \\
\hline PfKnowA & 2.815 & 1.6206 & .0925 & .522 & .139 & -.544 & .277 \\
\hline PbWorkA & 4.385 & 1.1075 & .0632 & .351 & .139 & 1.064 & .277 \\
\hline PfBrandA & 3.569 & 1.5139 & .0864 & .050 & .139 & -.338 & .277 \\
\hline PbInnovA & 4.137 & 1.1251 & .0642 & .141 & .139 & 1.869 & .277 \\
\hline PbValueA & 4.286 & .9556 & .0545 & .707 & .139 & 2.241 & .277 \\
\hline PrWilByA & 5.053 & 1.4316 & .0817 & -.605 & .139 & .026 & .277 \\
\hline PfUseA & 3.037 & 1.6135 & .0921 & .245 & .139 & -.970 & .277 \\
\hline PfFindA & 2.814 & 1.4946 & .0853 & .423 & .139 & -.613 & .277 \\
\hline PbSatisA & 4.383 & 1.0586 & .0604 & .426 & .139 & 1.488 & .277 \\
\hline PbProudA & 4.553 & 1.4074 & .0803 & -.152 & .139 & .108 & .277 \\
\hline PbGoodA & 4.990 & 1.2432 & .0710 & -.134 & .139 & .053 & .277 \\
\hline \multicolumn{8}{|c|}{ Product-Related: South Korea } \\
\hline PbQualX & 4.487 & 1.4234 & .0812 & -.425 & .139 & -.056 & .277 \\
\hline PbReliaX & 4.497 & 1.3600 & .0776 & -.177 & .139 & -.066 & .277 \\
\hline PfKnowX & 3.258 & 1.6782 & .0958 & .275 & .139 & -.692 & .277 \\
\hline PbWorkX & 4.241 & 1.2092 & .0690 & -.172 & .139 & .602 & .277 \\
\hline PfBrandX & 3.970 & 1.5368 & .0877 & -.183 & .139 & -.485 & .277 \\
\hline PbInnovX & 4.146 & 1.4229 & .0812 & -.213 & .139 & -.029 & .277 \\
\hline PbValueX & 4.368 & 1.3579 & .0775 & -.155 & .139 & .056 & .277 \\
\hline PrWilByX & 4.521 & 1.5142 & .0864 & -.397 & .139 & -.209 & .277 \\
\hline PfUseX & 3.505 & 1.6649 & .0950 & .115 & .139 & -.781 & .277 \\
\hline PfFindX & 3.990 & 1.5519 & .0886 & -.089 & .139 & -.333 & .277 \\
\hline PbSatisX & 4.253 & 1.1820 & .0675 & -.049 & .139 & .936 & .277 \\
\hline PbProudX & 4.007 & 1.2654 & .0722 & -.159 & .139 & .777 & .277 \\
\hline PbGoodX & 3.927 & 1.5140 & .0864 & -.135 & .139 & -.189 & .277 \\
\hline \multicolumn{8}{|c|}{ Tourism-Related: U.S. } \\
\hline TbSceneU & 5.783 & 1.3206 & .0754 & -1.419 & .139 & 2.232 & .277 \\
\hline TbAccomU & 5.569 & 1.5786 & .0901 & -1.322 & .139 & 1.114 & .277 \\
\hline TbAttraU & 5.470 & 1.6019 & .0914 & -1.134 & .139 & .596 & .277 \\
\hline TbActivU & 5.905 & 1.3723 & .0783 & -1.637 & .139 & 2.516 & .277 \\
\hline TbValueU & 5.209 & 1.4392 & .0821 & -.550 & .139 & -.199 & .277 \\
\hline TrWilTrU & 5.918 & 1.5135 & .0864 & -1.579 & .139 & 1.838 & .277 \\
\hline TbGoodU & 5.660 & 1.2817 & .0731 & -1.209 & .139 & 1.676 & .277 \\
\hline TkTripsU & 3.445 & 2.2067 & .1259 & .692 & .139 & -1.117 & .277 \\
\hline \multicolumn{8}{|c|}{ Tourism-Related: Japan } \\
\hline TbSceneJ & 5.542 & 1.4915 & .0851 & -1.107 & .136 & 1.065 & .277 \\
\hline TbAccomJ & 4.868 & 1.4470 & .0826 & -.457 & .139 & -.023 & .277 \\
\hline TbAttraJ & 4.791 & 1.6428 & .0938 & -.391 & .139 & -.453 & .277 \\
\hline TbActivJ & 5.158 & 1.6011 & .0914 & -.660 & .139 & -.116 & .277 \\
\hline TbValueJ & 4.316 & 1.5222 & .0869 & -.048 & .139 & -.240 & .277 \\
\hline TrWilTrJ & 5.253 & 1.8271 & .1043 & -.907 & .139 & -.127 & .277 \\
\hline TbGoodJ & 5.034 & 1.4276 & .0815 & -.617 & .139 & .069 & .277 \\
\hline TkTripsJ & 1.140 & .4358 & .0249 & 4.481 & .139 & 27.447 & .277 \\
\hline
\end{tabular}




\begin{tabular}{lrrrrrrr} 
TbSceneA & 6.030 & 1.3367 & .0763 & -1.542 & .139 & 2.188 & .277 \\
TbAccomA & 5.229 & 1.4610 & .0834 & -.588 & .139 & -.202 & .277 \\
TbAttraA & 5.213 & 1.5534 & .0887 & 1.5534 & .139 & -.140 & .277 \\
TbActivA & 5.421 & 1.6124 & .0920 & -.946 & .139 & .198 & .277 \\
TbValueA & 4.860 & 1.4051 & .0802 & -.297 & .139 & -.133 & .277 \\
TrWilTrA & 5.728 & 1.7001 & .0970 & -1.416 & .139 & 1.207 & .277 \\
TbGoodA & 5.810 & 1.1999 & .0685 & -.732 & .139 & -.245 & .277 \\
TkTripsA & 1.166 & .4189 & .0239 & 2.858 & .139 & 9.791 & .277 \\
\hline TbSceneX & 4.817 & 1.4674 & .0838 & -.415 & .139 & .061 & .277 \\
TbAccomX & 4.123 & 1.2788 & .0730 & -.102 & .139 & .394 & .277 \\
TbAttraX & 4.187 & 1.2879 & .0735 & .024 & .139 & .551 & .277 \\
TbActivX & 4.383 & 1.4652 & .0836 & -.123 & .139 & -.126 & .277 \\
TbValueX & 4.197 & 1.2621 & .0720 & -.044 & .139 & .626 & .277 \\
TrWilTrX & 4.373 & 1.9628 & .1120 & -.304 & .139 & -.935 & .277 \\
TbGoodX & 3.927 & 1.5140 & .0864 & -.135 & .139 & -.189 & .277 \\
TkTripsX & 1.063 & .2412 & .0138 & 3.646 & .139 & 11.391 & .277 \\
\hline
\end{tabular}

$\mathrm{N}=307$; Minimum=1; Maximum=7. 


\section{APPENDIX $\mathrm{F}$}

Test of Mean Difference Significance

Table F: Paired T's to Test Significance of Mean Differences*

\begin{tabular}{|c|c|c|c|c|c|c|c|}
\hline \multirow{2}{*}{$\begin{array}{c}\text { Variable/ } \\
\text { Pair }\end{array}$} & & \multicolumn{3}{|c|}{ S. Korean Sample $(n=349)$} & \multicolumn{3}{|c|}{ Canadian Sample ( $\mathrm{n}=307)$} \\
\hline & & US- JP & US-AU & US-CA & US- JP & US-AU & US-CA \\
\hline \multicolumn{8}{|c|}{ Country-Related } \\
\hline \multirow[t]{3}{*}{ CbQlife } & $\mathbf{r}=$ & .415 & $.279^{\circ}$ & .279 & .156 & 290 & .113 \\
\hline & $\mathbf{t}=$ & 5.666 & 3.836 & 1.696 & 3.800 & -.910 & 14.787 \\
\hline & $\mathbf{p}=$ & .000 & .000 & $.091^{*}$ & .000 & $.363^{*}$ & .000 \\
\hline \multirow[t]{3}{*}{ CaPleas } & $\mathbf{r}=$ & .131 & .264 & .258 & .222 & 147 & .113 \\
\hline & $\mathbf{t}=$ & 6.375 & -7.500 & -7.926 & -.877 & -7.591 & 7.380 \\
\hline & $\mathbf{p}=$ & .000 & .000 & .000 & $.381 *$ & .000 & .000 \\
\hline \multirow{3}{*}{ CbWealt } & $\mathbf{r}=$ & .325 & .345 & .245 & .328 & .373 & .086 \\
\hline & $t=$ & 3.096 & 6.864 & 4.697 & 1.207 & 3.006 & 10.616 \\
\hline & $\mathbf{p}=$ & .002 & .000 & .000 & $.228^{*}$ & .003 & .000 \\
\hline \multirow{3}{*}{ CaExcit } & $\mathbf{r}=$ & .254 & .233 & .235 & .207 & .356 & .159 \\
\hline & $t=$ & 6.776 & 1.113 & 3.142 & 1.493 & -5.396 & 7.466 \\
\hline & $\mathbf{p}=$ & .000 & $.267 *$ & .002 & $.136^{*}$ & .000 & .000 \\
\hline \multirow[t]{3}{*}{ CbTech } & $\mathbf{r}=$ & .278 & .232 & .222 & .354 & .133 & .206 \\
\hline & $t=$ & -1.060 & 10.735 & 8.660 & -3.195 & 9.610 & 6.603 \\
\hline & $\mathbf{p}=$ & $.290 *$ & .000 & .000 & .002 & .000 & .000 \\
\hline \multirow[t]{3}{*}{ CaFrien } & $r=$ & .152 & .287 & .312 & .240 & .183 & .114 \\
\hline & $t=$ & 1.287 & -6.649 & -6.292 & -2.547 & -6.280 & 1.979 \\
\hline & $p=$ & $.199 *$ & .000 & .000 & $.011 *$ & .000 & $.049 *$ \\
\hline \multirow[t]{3}{*}{ CbEduc } & $r=$ & .350 & .346 & .323 & .144 & .246 & .115 \\
\hline & $t=$ & .845 & 1.615 & -.112 & -9.762 & -1.988 & .972 \\
\hline & $\mathbf{p}=$ & $.399 *$ & $.107 *$ & $.911^{*}$ & .000 & $.048^{*}$ & $.332 *$ \\
\hline \multirow[t]{3}{*}{ CaSafe } & $\mathbf{r}=$ & .170 & .171 & .228 & .116 & .210 & .021 \\
\hline & $\mathbf{t}=$ & -10.244 & -16.435 & -18.882 & -11.132 & -11.218 & -1.961 \\
\hline & $\mathbf{p}=$ & .000 & .000 & .000 & .000 & .000 & $.051^{*}$ \\
\hline \multirow[t]{3}{*}{ CaTrust } & $\mathbf{r}=$ & .176 & .271 & .374 & .285 & .220 & .237 \\
\hline & $t=$ & 3.897 & -9.670 & -12.394 & -7.030 & -8.978 & -.733 \\
\hline & $p=$ & .000 & .000 & .000 & .000 & .000 & $.464 *$ \\
\hline \multirow[t]{3}{*}{ CkKnow } & $\mathbf{r}=$ & .212 & .337 & .322 & .085 & .384 & .058 \\
\hline & $\mathbf{t}=$ & -5.451 & 2.608 & 4.110 & 10.945 & 11.056 & 15.584 \\
\hline & $\mathbf{p}=$ & .000 & .009 & .000 & .000 & .000 & .000 \\
\hline \multirow[t]{3}{*}{ CrTies } & $\mathbf{r}=$ & .289 & .269 & .292 & .179 & .226 & .133 \\
\hline & $t=$ & 5.414 & 2.210 & 1.191 & .027 & -3.197 & 2.580 \\
\hline & $\mathbf{p}=$ & .000 & $.028^{*}$ & $.235^{*}$ & $.978^{*}$ & .002 & $.010^{*}$ \\
\hline \multirow{3}{*}{ PrImprt } & $\mathbf{r}=$ & .433 & .422 & .342 & .342 & .257 & .242 \\
\hline & $t=$ & 1.965 & -6.409 & -6.607 & -.818 & -5.329 & 1.447 \\
\hline & $\mathbf{p}=$ & $.050^{*}$ & .000 & .000 & $.414^{*}$ & .000 & $.149 *$ \\
\hline \multirow[t]{3}{*}{ CaIdeal } & $\mathbf{r}=$ & .496 & .311 & 290 & .245 & .138 & .190 \\
\hline & $t=$ & 4.711 & -8.642 & -8.625 & 3.027 & -4.947 & 11.159 \\
\hline & $p=$ & .000 & .000 & .000 & .003 & .000 & .000 \\
\hline
\end{tabular}




\begin{tabular}{|c|c|c|c|c|c|c|c|}
\hline \multicolumn{8}{|c|}{ Product-Related } \\
\hline \multirow[t]{3}{*}{ PbQual } & $\mathbf{r}=$ & .393 & .218 & .368 & .237 & .248 & .057 \\
\hline & $t=$ & -7.151 & 9.057 & 8.864 & -4.881 & 4.694 & 7.315 \\
\hline & $\mathbf{p}=$ & .000 & .000 & .000 & .000 & .000 & .000 \\
\hline \multirow[t]{3}{*}{ PbRelia } & $\mathbf{r}=$ & .381 & .222 & .243 & .263 & .375 & .148 \\
\hline & $t=$ & -5.409 & 3.977 & 3.508 & -2.821 & 5.114 & 4.793 \\
\hline & $\mathbf{p}=$ & .000 & .000 & .001 & .005 & .000 & .000 \\
\hline \multirow[t]{3}{*}{ PfKnow } & $\mathbf{r}=$ & .331 & .100 & .166 & .458 & .036 & .139 \\
\hline & $t=$ & -5.188 & 10.621 & 11.189 & 4.278 & 15.393 & 12.401 \\
\hline & $\mathbf{p}=$ & .000 & .000 & .000 & .000 & .000 & .000 \\
\hline \multirow[t]{3}{*}{ PbWork } & $\mathbf{r}=$ & .217 & .189 & .183 & .203 & .286 & .164 \\
\hline & $\mathbf{t}=$ & -3.137 & 12.972 & 10.262 & -4.596 & 4.533 & 5.616 \\
\hline & $\mathbf{p}=$ & .002 & .000 & .000 & .000 & .000 & .000 \\
\hline \multirow[t]{3}{*}{ PfBrand } & $\mathbf{r}=$ & .326 & .030 & -.042 & .247 & .027 & .008 \\
\hline & $t=$ & -2.019 & 17.867 & 16.082 & 6.177 & 20.057 & 16.203 \\
\hline & $\mathbf{p}=$ & $.044 *$ & .000 & .000 & .000 & .000 & .000 \\
\hline \multirow{3}{*}{ PbInnov } & $\mathbf{r}=$ & .211 & .155 & .202 & .332 & .136 & .208 \\
\hline & $\mathbf{t}=$ & -3.775 & 11.695 & 10.470 & -2.671 & 10.296 & 9.593 \\
\hline & $\mathbf{p}=$ & .000 & .000 & .000 & .008 & .000 & .000 \\
\hline \multirow[t]{3}{*}{ PbValue } & $r=$ & .255 & .187 & .239 & .238 & .285 & .094 \\
\hline & $t=$ & -3.660 & 8.444 & 7.272 & -2.225 & 7.780 & 5.137 \\
\hline & $\mathbf{p}=$ & .000 & .000 & .000 & $.027^{*}$ & .000 & .000 \\
\hline \multirow[t]{3}{*}{ PrWilBy } & $r=$ & .334 & .295 & .275 & .345 & .364 & .175 \\
\hline & $\mathbf{t}=$ & -1.905 & 4.192 & 2.171 & .516 & 3.545 & 7.908 \\
\hline & $\mathbf{p}=$ & $.058 *$ & .000 & $.031 *$ & $.606 *$ & .000 & .000 \\
\hline \multirow[t]{3}{*}{ PfUse } & $r=$ & .292 & -.036 & -.057 & .214 & -.029 & -.054 \\
\hline & $t=$ & -4.460 & 13.742 & 14.943 & 5.501 & 17.431 & 13.343 \\
\hline & $\mathbf{p}=$ & .000 & .000 & .000 & .000 & .000 & .000 \\
\hline \multirow[t]{3}{*}{ PfFind } & $r=$ & .336 & -.039 & -.024 & .245 & -.092 & -.008 \\
\hline & $\mathbf{t}=$ & -3.782 & 18.203 & 20.331 & 1.415 & 17.903 & 9.285 \\
\hline & $\mathbf{p}=$ & .000 & .000 & .000 & $.158 *$ & .000 & .000 \\
\hline \multirow[t]{3}{*}{ PbSatis } & $r=$ & .381 & .058 & .147 & .203 & .297 & .178 \\
\hline & $\mathbf{t}=$ & -5.988 & 4.620 & 3.831 & -.128 & 7.829 & 8.356 \\
\hline & $\mathbf{p}=$ & .000 & .000 & .000 & $.899 *$ & .000 & .000 \\
\hline \multirow[t]{3}{*}{ PbProud } & $\mathbf{r}=$ & .338 & .321 & .374 & .266 & .230 & .215 \\
\hline & $\mathbf{t}=$ & -.555 & -5.175 & -6.269 & -1.529 & -4.019 & 1.091 \\
\hline & $\mathbf{p}=$ & $.579 *$ & .000 & .000 & $.127^{*}$ & .000 & $.276^{*}$ \\
\hline \multirow[t]{3}{*}{ PbGood } & $r=$ & .409 & .227 & .354 & .250 & .336 & .053 \\
\hline & $\mathbf{t}=$ & -5.706 & 5.765 & 7.246 & -0.816 & 5.460 & 12.262 \\
\hline & $\mathbf{p}=$ & .000 & .000 & .000 & $.415^{*}$ & .000 & .000 \\
\hline \multirow{4}{*}{ TbScene } & & & ourism & lated & & & \\
\hline & $\mathbf{r}=$ & .283 & .441 & .394 & .335 & .352 & .246 \\
\hline & $t=$ & 4.217 & -6.004 & -3.941 & 2.599 & -2.859 & 9.867 \\
\hline & $\mathbf{p}=$ & .000 & .000 & .000 & $.010^{*}$ & .005 & .000 \\
\hline \multirow[t]{2}{*}{ TbAccom } & $\mathbf{r}=$ & .420 & .459 & .418 & .366 & .460 & .234 \\
\hline & $\mathbf{t}=$ & 1.945 & 2.851 & 3.458 & 7.198 & 3.762 & 14.199 \\
\hline
\end{tabular}




\begin{tabular}{|c|c|c|c|c|c|c|c|}
\hline & $p=$ & $.053^{*}$ & .005 & .001 & .000 & .000 & .000 \\
\hline \multirow[t]{3}{*}{ TbAttra } & $r=$ & .270 & .332 & .377 & .310 & .269 & .136 \\
\hline & $\mathbf{t}=$ & 2.674 & -4.039 & -3.465 & 6.240 & 2.359 & 11.750 \\
\hline & $\mathbf{p}=$ & .008 & .000 & .001 & .000 & $.019 *$ & .000 \\
\hline \multirow[t]{3}{*}{ TbActiv } & $r=$ & .247 & .378 & .432 & .337 & .366 & .187 \\
\hline & $t=$ & 3.093 & -2.623 & .592 & 7.591 & 5.012 & 14.726 \\
\hline & $\mathbf{p}=$ & .002 & .009 & $.554 *$ & .000 & .000 & .000 \\
\hline \multirow[t]{3}{*}{ TbValue } & $\mathbf{r}=$ & .371 & .355 & .352 & .260 & .348 & .162 \\
\hline & $\mathbf{t}=$ & 3.554 & 8.151 & 9.101 & 8.678 & 3.755 & 10.111 \\
\hline & $\mathbf{p}=$ & .001 & .000 & .000 & .000 & .000 & .000 \\
\hline \multirow[t]{3}{*}{ TrWilTr } & $r=$ & .187 & .395 & .345 & .151 & .236 & .116 \\
\hline & $\mathbf{t}=$ & .272 & -4.664 & -2.987 & 5.317 & 1.671 & 11.593 \\
\hline & $\mathbf{p}=$ & $.786^{*}$ & .000 & .003 & .000 & $.096^{*}$ & .000 \\
\hline \multirow[t]{3}{*}{ TbGood } & $r=$ & .378 & .334 & .489 & .120 & .250 & .093 \\
\hline & $\mathbf{t}=$ & 3.979 & -3.932 & -0.771 & 6.089 & -1.735 & 16.060 \\
\hline & $p=$ & .000 & .000 & $.441^{*}$ & .000 & $.084 *$ & .000 \\
\hline- & & & & & & 80 & 2 \\
\hline
\end{tabular}

* Difference not significant as $\mathrm{p}>0.01$ at $95 \%$ Confidence Interval (excluding cases analysis by analysis). 
APPENDIX G Exploratory Factor Analysis Initial Pattern Matrices Table G-1: South Korean Sample -U.S. Construct Study: Initial Pattern Matrix ${ }^{1}$

\begin{tabular}{|c|c|c|c|c|c|c|c|c|}
\hline & 1 & 2 & 3 & 4 & 5 & 6 & 7 & 8 \\
\hline & Dest Bel & Prod Bel & Aff Imag & Prod Rec & Prod Fam & Cog Imag & Dest Rec & Dest Fam \\
\hline TbScene & .759 & & & & & & & \\
\hline TbAcom & .222 & & & & .591 & & & \\
\hline TbAttra & .770 & & & & & & & \\
\hline TbActiv & .808 & & & & & & & \\
\hline TbValue & .645 & & & & & & & \\
\hline TrWilTr & .645 & & & & & & & \\
\hline TbGood & -.668 & & & & & & & \\
\hline PbQual & & 504 & & & & & & \\
\hline PbRelia & & - 389 & & & .534 & & & \\
\hline PbWork & & $=.782$ & & & & & & \\
\hline PfBrand & & -.725 & & & & & & \\
\hline PbInnov & & -802 & & & & & & \\
\hline PbValue & & $\begin{array}{r}604 \\
6\end{array}$ & & & & & & \\
\hline PbGood & & $=.365$ & & & & & & \\
\hline CaPleas & & & .450 & & & & & \\
\hline CaExcit & & & 086 & & & .684 & & \\
\hline CaSafe & & & .752 & & & & & \\
\hline CaFrien & & & .738 & & & & & \\
\hline CaTrust & & & 732 & & & & & \\
\hline Caldeal & & & $\begin{array}{r}462 \\
\end{array}$ & & & & & \\
\hline PrImprt & & & & $=.712$ & & & & \\
\hline PrWilBy & & & & .605 & & & & \\
\hline PbProud & & & & .759 & & & & \\
\hline PfUse & & & & & .730 & & & \\
\hline PfFind & & & & & $\begin{array}{r}-686 \\
\end{array}$ & & & \\
\hline PbSatis & & & & & $\begin{array}{r}.560 \\
\end{array}$ & & & \\
\hline PfKnow & & & & & $\begin{array}{r}.098 \\
\end{array}$ & & .625 & \\
\hline CbQlife & & & & & & $=.414$ & .589 & \\
\hline CbWealt & & & & & & .692 & & \\
\hline CbTech & & & & & & $\begin{array}{r}.337 \\
-\quad .3\end{array}$ & .650 & \\
\hline CbEduc & & & & & & $=.553$ & & \\
\hline CrTies & & & & & & & 5.594 & \\
\hline CkKnow & & & & & & & & .695 \\
\hline$m$ & & & Ex & 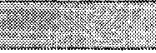 & E & 15 & $5=$ & 2 \\
\hline Eigens & 3.8 & 3.4 & 2.8 & 2.4 & 2.3 & 2.2 & 1.8 & 1.4 \\
\hline$\% \mathrm{Var}$ & 11.6 & 10.4 & 8.5 & 7.3 & 7.0 & 6.6 & 5.5 & 4.2 \\
\hline Cum \% & 11.6 & 22.0 & 30.5 & 37.8 & 44.8 & 51.4 & 57.0 & 61.2 \\
\hline
\end{tabular}

${ }^{\mathrm{T}}$ Extraction Method: Principal Component Analysis. Orthogonal Rotation Method:

Varimax with Kaiser Normalization. Rotation converged in 9 iterations.

Kaiser-Meyer-Olkin Measure of Sampling Adequacy $\quad .866$

Bartlett's Test of Sphericity: Approx. Chi-Square

4652.509

Degrees of freedom

528

Significance

.000 
Table G-2: South Korean Sample -Japan Construct Study: Initial Pattern Matrix ${ }^{1}$

\begin{tabular}{|c|c|c|c|c|c|c|c|}
\hline & 1 & 2 & 3 & 4 & 5 & 6 & 7 \\
\hline & Prod Bel & Aff Imag & Dest Bel & Cog Imag & Prod Fam & $\operatorname{Rec}$ & Dest Fam \\
\hline PbQual & .584 & & & & & & \\
\hline PbRelia & .244 & & & & 377 & & \\
\hline PbWork & .773 & & & & & & \\
\hline PfBrand & .747 & & & & & & \\
\hline PbInnov & .780 & & & & & & \\
\hline PbValue & .730 & & & & & & \\
\hline PbProud & .148 & .630 & & & & & \\
\hline PbGood & .442 & & & & & & \\
\hline CaPleas & & 679 & & & & & \\
\hline CaExcit & & 153 & & .433 & & & \\
\hline CaFrien & & .570 & & & & & \\
\hline CaSafe & & 512 & & & & & \\
\hline CaTrust & & .752 & & & & & \\
\hline CaIdeal & & .476 & & & & & \\
\hline TbScene & & & .742 & & & & \\
\hline TbAcom & & & .068 & & & .469 & \\
\hline TbAttra & & & 804 & & & & \\
\hline TbActiv & & & 813 & & & & \\
\hline TbValue & & & .471 & & & & \\
\hline TbGood & & & .582 & & & & \\
\hline CbQlife & & & & .614 & & & \\
\hline CbWealt & & & & .537 & & & \\
\hline CbTech & & & & .658 & & & \\
\hline CbEduc & & & & .627 & & & \\
\hline PfUse & & & & & .802 & & \\
\hline PfFind & & & & & .709 & & \\
\hline PbSatis & & & & & .723 & & \\
\hline PfKnow & .581 & & & & .103 & & \\
\hline TrWilTr & & & .651 & & & 188 & \\
\hline PrWilBy & & .532 & & & & .218 & \\
\hline CkKnow & & & & & & & $\begin{array}{r}.789 \\
\end{array}$ \\
\hline CrTies & & .509 & & & & & \\
\hline PrImprt & & .703 & & & & & \\
\hline$x=$ & $x=$ & & 3 & & & menes & 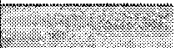 \\
\hline Eigens & 4.2 & 3.8 & 3.6 & 2.6 & 2.4 & 1.5 & 1.4 \\
\hline$\% \mathrm{Var}$ & 12.7 & 11.7 & 10.9 & 7.9 & 7.1 & 4.4 & 4.4 \\
\hline Cum \% & 12.7 & 24.4 & 35.3 & 43.2 & 50.3 & 54.8 & 59.1 \\
\hline
\end{tabular}

${ }^{1}$ Extraction Method: Principal Component Analysis. Orthogonal Rotation Method:

Varimax with Kaiser Normalization. Rotation converged in 9 iterations.

Kaiser-Meyer-Olkin Measure of Sampling Adequacy $\quad .876$

Bartlett's Test of Sphericity: Approx. Chi-Square — 4959.026

Degrees of freedom $\quad 528$

Significance $\quad .000$ 
Table G-3: South Korean Sample - Australia Construct Study: Initial Pattern Matrix $^{1}$

\begin{tabular}{|c|c|c|c|c|c|c|c|}
\hline & 1 & 2 & 3 & 4 & 5 & 6 & 7 \\
\hline & Dest Bel & Prod Bel & Aff Imag & Cog Imag & Prod Fam & $\operatorname{Rec}$ & Dest Fam \\
\hline TbScene & 734 & & & & & & \\
\hline TbAcom & 082 & & & .672 & & & \\
\hline TbAttra & .798 & & & & & & \\
\hline TbActiv & .854 & & & & & & \\
\hline TbValue & $=.652$ & & & & & & \\
\hline TrWilTr & . 721 & & & & & .112 & \\
\hline TbGood & .665 & & & & & & \\
\hline PbQual & & .625 & & & & & \\
\hline PbRelia & & .114 & & & & .464 & \\
\hline PfKnow & & $=.436$ & & & .170 & & \\
\hline PbWork & & 0.697 & & & & & \\
\hline PfBrand & & .684 & & & & & \\
\hline PbInnov & & $\begin{array}{r}732 \\
\end{array}$ & & & & & \\
\hline PbValue & & .613 & & & & & \\
\hline PbProud & & -495 & & & & & \\
\hline PbGood & & $=460$ & & & & & \\
\hline CaPleas & & & .647 & & & & \\
\hline CaExcit & & & .139 & .575 & & & \\
\hline CaFrien & & & .752 & & & & \\
\hline CaSafe & & & .607 & & & & \\
\hline CaTrust & & & .766 & & & & \\
\hline CaIdeal & .534 & & .380 & & & & \\
\hline CbQlife & & & & .495 & & & \\
\hline CbWealt & & & & 592 & & & \\
\hline CbTech & & .497 & & .113 & & & \\
\hline CbEduc & & & .572 & 183 & & & \\
\hline PfUse & & & & & $10-1772$ & & \\
\hline PfFind & & & & & i. 772 & & \\
\hline PbSatis & & & & & .668 & & \\
\hline CrTies & & & .479 & & & .200 & \\
\hline PrImprt & & & & & & .616 & \\
\hline PrWilBy & & & & & & .534 & \\
\hline CkKnow & & & & & & & $=720$ \\
\hline$x=2$ & & 20. & 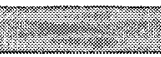 & & 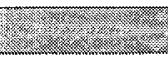 & 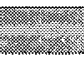 & 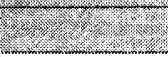 \\
\hline Eigens & 4.1 & 3.9 & 3.3 & 2.2 & 1.9 & 1.7 & 1.5 \\
\hline$\% \mathrm{Var}$ & 12.4 & 11.7 & 10.1 & 6.5 & 5.9 & 5.1 & 4.6 \\
\hline Cum \% & 12.4 & 24.1 & 34.2 & 40.7 & 46.6 & 51.7 & 56.3 \\
\hline
\end{tabular}

${ }^{\mathrm{T}}$ Extraction Method: Principal Component Analysis. Orthogonal Rotation Method: Varimax with Kaiser Normalization. Rotation converged in 9 iterations.

Kaiser-Meyer-Olkin Measure of Sampling Adequacy $\quad .850$ Bartlett's Test of Sphericity: Approx. Chi-Square 
Table G-4: South Korean Sample - Canada Construct Study: Initial Pattern Matrix $^{1}$

\begin{tabular}{|c|c|c|c|c|c|c|c|c|c|}
\hline & 1 & 2 & 3 & 4 & 5 & 6 & 7 & 8 & 9 \\
\hline & Cog Imag & Prod Bel & Dest Bel & Aff Imag & Prod Fam & Rec & \begin{tabular}{|l|} 
Dest Fam \\
\end{tabular} & & \\
\hline CbQlife & .605 & & & & & & & & \\
\hline CbWealt & .566 & & & & & & & & \\
\hline CbTech & 558 & & & & & & & & \\
\hline CbEduc & .695 & & & & & & & & \\
\hline PbQual & & .554 & & & & & & & \\
\hline PbRelia & & 331 & & & & & & .530 & \\
\hline PbWork & & $=.777$ & & & & & & & \\
\hline PfBrand & & .761 & & & & & & & \\
\hline PbInnov & & 710 & & & & & & & \\
\hline PbValue & & 581 & & & & & & & \\
\hline PrWilBy & & .669 & & & & .113 & & & \\
\hline PbGood & & $=207$ & & .761 & & & & & \\
\hline PbProud & & .495 & & & & & & & \\
\hline TbScene & & & .768 & & & & & & \\
\hline TbAcom & & & .044 & & & & & .822 & \\
\hline TbAttra & & & .821 & & & & & & \\
\hline TbActiv & & & .799 & & & & & & \\
\hline TbValue & & & 528 & & & & & & \\
\hline TrWilTr & & & .700 & & & .224 & & & \\
\hline TbGood & & & 4.451 & .696 & & & & & \\
\hline CaPleas & .691 & & & -.237 & & & & & \\
\hline CaExcit & 342 & & & .116 & & & & & .587 \\
\hline CaFrien & .560 & & & .012 & & & & & \\
\hline CaSafe & 704 & & & .032 & & & & & \\
\hline CaTrust & .614 & & & 108 & & & & & \\
\hline CaIdeal & & & & .720 & & & & & \\
\hline PfUse & & & & & -1.758 & & & & \\
\hline PfFind & & & & & $=.802$ & & & & \\
\hline PbSatis & & & & & $\begin{array}{r}.621 \\
\end{array}$ & & & & \\
\hline PfKnow & & & & & $-\quad 334$ & & 648 & & \\
\hline CrTies & & & & & & .599 & & & \\
\hline PrImprt & & & & & & .674 & & & \\
\hline CkKnow & & & & & & & 770 & & \\
\hline & 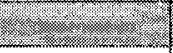 & 6 & & $=$ & 2 & & & 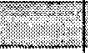 & 5 \\
\hline Eigens & 3.9 & 3.8 & 3.4 & 2.1 & 1.9 & 1.6 & 1.5 & 1.3 & 1.2 \\
\hline$\% \mathrm{Var}$ & 11.9 & 11.4 & 10.3 & 6.5 & 5.8 & 4.7 & 4.7 & 4.0 & 3.8 \\
\hline Cum \% & 11.9 & 23.3 & 33.5 & 40.0 & 45.8 & 50.6 & 55.2 & 59.2 & 63.0 \\
\hline
\end{tabular}

${ }^{T}$ Extraction Method: Principal Component Analysis. Orthogonal Rotation Method:

Varimax with Kaiser Normalization. Rotation converged in 9 iterations.

Kaiser-Meyer-Olkin Measure of Sampling Adequacy $\quad .865$

Bartlett's Test of Sphericity: Approx. Chi-Square $\quad 4402.923$

Degrees of freedom $\quad 528$

Significance $\quad .000$ 
Table G-5: Canadian Sample - U.S. Construct Study: Initial Pattern Matrix ${ }^{1}$

\begin{tabular}{|c|c|c|c|c|c|c|c|c|}
\hline & 1 & 2 & 3 & 4 & 5 & 6 & 7 & 8 \\
\hline & Dest Bel & \begin{tabular}{|l|} 
Aff Imag \\
\end{tabular} & Prod Bel & Prod Fam & Cog Imag & \begin{tabular}{|l|} 
Prod Rec \\
\end{tabular} & Dest Rec & Dest Fam \\
\hline & & & & & & & & \\
\hline TbScene & .650 & & & & & & & \\
\hline TbAcom & $\begin{array}{r}-393 \\
\end{array}$ & & & & & & & \\
\hline TbAttra & .763 & & & & & & & \\
\hline TbActiv & 839 & & & & & & & \\
\hline TbValue & .755 & & & & & & & \\
\hline TrWilTr & .729 & & & & & & .148 & \\
\hline TbGood & .567 & & & & & & & \\
\hline CaPleas & & .649 & & & & & & \\
\hline CaExcit & & 023 & & & .689 & & & \\
\hline CaFrien & & .748 & & & & & & \\
\hline CaSafe & & .656 & & & & & & \\
\hline CaTrust & & $\begin{array}{r}-778 \\
\end{array}$ & & & & & & \\
\hline PbQual & & & .300 & .517 & & & & \\
\hline PbRelia & & & .205 & .591 & & & & \\
\hline PfKnow & & & .619 & .165 & & & & \\
\hline PbWork & & & .652 & & & & & \\
\hline PfBrand & & & .710 & & & & & \\
\hline PbInnov & & & .741 & & & & & \\
\hline PbValue & & & .612 & & & & & \\
\hline PrWilBy & & & .491 & & & .211 & & \\
\hline PbProud & & & .349 & & & & & \\
\hline PbGood & .459 & & $\begin{array}{r}-309 \\
\end{array}$ & & & & & \\
\hline PfUse & & & & .711 & & & & \\
\hline PfFind & & & & 291 & & & & .754 \\
\hline PbSatis & & & & $=.712$ & & & & \\
\hline CbQlife & & & & & 518 & & & \\
\hline CbWealt & & & & & 8.800 & & & \\
\hline CbTech & & .538 & & & -0.017 & & & \\
\hline CbEduc & & .662 & & & $\begin{array}{r}-\quad 090 \\
\end{array}$ & & & \\
\hline CrTies & & & & & & .806 & & \\
\hline PrImprt & & & & & & .833 & & \\
\hline CaIdeal & & 298 & & & & & 396 & \\
\hline CkKnow & & & & & .270 & & & -.206 \\
\hline - 20 & & & & & 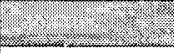 & $2=5=$ & 20 & 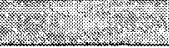 \\
\hline Eigens & 4.4 & 3.6 & 3.3 & 2.6 & 2.2 & 1.8 & 1.5 & 1.4 \\
\hline$\%$ Var & 13.3 & 10.9 & 10.0 & 7.8 & 6.8 & 5.5 & 4.6 & 4.4 \\
\hline Cum \% & 13.3 & 24.2 & 34.2 & 42.0 & 48.8 & 54.3 & 58.9 & 63.2 \\
\hline
\end{tabular}

${ }^{\mathrm{T}}$ Extraction Method: Principal Component Analysis. Orthogonal Rotation Method:

Varimax with Kaiser Normalization. Rotation converged in 10 iterations.

Kaiser-Meyer-Olkin Measure of Sampling Adequacy $\quad .885$

Bartlett's Test of Sphericity: Approx. Chi-Square

Degrees of freedom 
Table G-6: Canadian Sample - Japan Construct Study: Initial Pattern Matrix

\begin{tabular}{|c|c|c|c|c|c|c|c|c|c|}
\hline \multirow{2}{*}{ and } & \multirow{3}{*}{\begin{tabular}{c|}
1 \\
Prod Bel \\
\end{tabular}} & \multirow{2}{*}{2} & & & & & & & \\
\hline & & & 3 & 4 & 5 & 6 & 7 & 8 & 9 \\
\hline & & Aff Imag & Dest Bel & Dest Fam & Prod Fam & $\operatorname{Rec}$ & Cog Imag & & \\
\hline & & & & & & & & & \\
\hline PbQual & .702 & & & & & & & & \\
\hline PbRelia & .572 & & & & & & & & \\
\hline PbWork & 7.767 & & & & & & & & \\
\hline PfBrand & .743 & & & & & & & & \\
\hline PbInnov & .707 & & & & & & & & \\
\hline PbValue & .749 & & & & & & & & \\
\hline PbProud & $=-290$ & & & & & & & & .640 \\
\hline PbGood & 470 & & & .585 & & & & & \\
\hline PrWilBy & $=:-713$ & & & & & .240 & & & \\
\hline CaPleas & & .637 & & & & & & & \\
\hline CaExcit & & $=\frac{.031}{1}$ & & & & & & .760 & \\
\hline CaFrien & & .761 & & & & & & & \\
\hline CaSafe & & 720 & & & & & & & \\
\hline CaTrust & & . 734 & & & & & & & \\
\hline CaIdeal & & $2=.251$ & & .767 & & & & & \\
\hline TbScene & & & .706 & & & & & & \\
\hline TbAcom & & & 282 & & & & & .384 & \\
\hline TbAttra & & & $=.786$ & & & & & & \\
\hline TbActiv & & & $=.814$ & & & & & & \\
\hline TbValue & & & .680 & & & & & & \\
\hline TrWilTr & & & $=732$ & & & .059 & & .106 & \\
\hline TbGood & & & .426 & .726 & & & & & \\
\hline CkKnow & & & & .441 & & & & & \\
\hline PfUse & & & & & $=.738$ & & & & \\
\hline PfFind & & & & & 750 & & & & \\
\hline PbSatis & .417 & & & & .478 & & & & \\
\hline PfKnow & & & & & .380 & & .448 & & \\
\hline CrTies & & & & & & .802 & & & \\
\hline PrImprt & & & & & & 9770 & & & \\
\hline CbQlife & & & & & & & .539 & & \\
\hline CbWealt & & & & & & & .736 & & \\
\hline CbTech & & .670 & & & & & $2=124$ & & \\
\hline CbEduc & & .788 & & & & & $(-1.129$ & & \\
\hline 8 & & & 8 & & 62 & 8 & 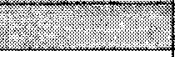 & 2 & 2. \\
\hline Eigens & 4.7 & 4.0 & 3.5 & 2.1 & 1.9 & 1.8 & 1.5 & 1.5 & 1.2 \\
\hline$\% \mathrm{Var}$ & 14.1 & 12.0 & 10.6 & 6.4 & 5.7 & 5.5 & 4.6 & 4.6 & 3.6 \\
\hline Cum \% & 14.1 & 26.1 & 36.7 & 43.1 & 48.8 & 54.3 & 59.0 & 63.6 & 67.2 \\
\hline
\end{tabular}

${ }^{T}$ Extraction Method: Principal Component Analysis. Orthogonal Rotation Method:

Varimax with Kaiser Normalization. Rotation converged in 12 iterations.

Kaiser-Meyer-Olkin Measure of Sampling Adequacy $\quad .882$

Bartlett's Test of Sphericity: Approx. Chi-Square

Degrees of freedom

4784.501

Significance

528

.000 
Table G-7: Canadian Sample - Australia Construct Study: Initial Pattern Matrix ${ }^{1}$

\begin{tabular}{|c|c|c|c|c|c|c|c|c|}
\hline & 1 & 2 & 3 & 4 & 5 & 6 & 7 & 8 \\
\hline & Prod Bel & Aff Imag & Dest Bel & Dest Rec & Cog Imag & Prod Fam & Prod Rec & Dest Fam \\
\hline & & & & & & & & \\
\hline PbQual & .560 & & & & & & & \\
\hline PbRelia & .586 & & & & & & & \\
\hline PfKnow & .443 & & & & & .321 & & \\
\hline PbWork & .696 & & & & & & & \\
\hline PfBrand & -.665 & & & & & & & \\
\hline PbInnov & $\begin{array}{r}.707 \\
\end{array}$ & & & & & & & \\
\hline PbValue & 9718 & & & & & & & \\
\hline PrWilBy & $\begin{array}{r}.410 \\
\end{array}$ & & & & & & .147 & \\
\hline PbGood & .392 & & & .657 & & & & \\
\hline PbSatis & 565 & & & & & .192 & & \\
\hline CaPleas & & 609 & & & & & & \\
\hline CaExcit & & .202 & & & .742 & & & \\
\hline CaFrien & & 732 & & & & & & \\
\hline CaSafe & & .748 & & & & & & \\
\hline CaTrust & & .765 & & & & & & \\
\hline TbScene & & & $=.551$ & & & & & \\
\hline TbAcom & & & .154 & & .405 & & & \\
\hline TbAttra & & & .833 & & & & & \\
\hline TbActiv & & & .864 & & & & & \\
\hline TbValue & & & -719 & & & & & \\
\hline TrWilTr & & & .718 & .302 & & & & \\
\hline TbGood & & & .362 & 745 & & & & \\
\hline Caldeal & & .186 & & .791 & & & & \\
\hline CbQlife & & .617 & & & $\begin{array}{r}142 \\
\end{array}$ & & & \\
\hline CbWealt & & & & & .761 & & & \\
\hline CbTech & & .481 & & & -.185 & & & \\
\hline CbEduc & & .720 & & & $\begin{array}{r}-024 \\
\end{array}$ & & & \\
\hline PfUse & & & & & & .757 & & \\
\hline PfFind & & & & & & 782 & & \\
\hline CrTies & & & & & & & .808 & \\
\hline PrImprt & & & & & & & 822 & \\
\hline PbProud & .198 & & & & & & $\quad 343$ & \\
\hline CkKnow & & & & & & & & .591 \\
\hline 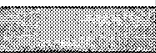 & 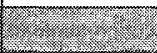 & 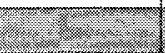 & 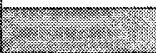 & 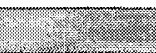 & $x^{2}=2$ & 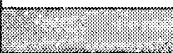 & 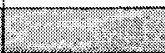 & $5=2$ \\
\hline Eigens & 4.0 & 3.8 & 3.5 & 2.7 & 1.9 & 1.9 & 1.8 & 1.4 \\
\hline$\%$ Var & 12.2 & 11.5 & 10.5 & 8.3 & 5.8 & 5.8 & 5.4 & 4.4 \\
\hline Cum $\%$ & 12.2 & 23.7 & 34.2 & 42.5 & 48.3 & 54.0 & 59.4 & 63.8 \\
\hline
\end{tabular}

${ }^{\mathrm{T}}$ Extraction Method: Principal Component Analysis. Orthogonal Rotation Method:

Varimax with Kaiser Normalization. Rotation converged in 9 iterations.

Kaiser-Meyer-Olkin Measure of Sampling Adequacy $\quad .872$

Bartlett's Test of Sphericity: Approx. Chi-Square $\quad 4538.757$

Degrees of freedom $\quad 528$

Significance $\quad .000$ 
Table G-8: Canadian Sample - South Korea Construct Study: Initial Pattern Matrix $^{1}$

\begin{tabular}{|c|c|c|c|c|c|c|c|c|}
\hline & 1 & 2 & 3 & 4 & 5 & 6 & 7 & 8 \\
\hline & Prod Bel & Dest Bel & Aff Imag & Dest Rec & Prod Rec & Cog Imag & Prod Fam & Dest Fam \\
\hline PbQual & .615 & & & & & & & \\
\hline PbRelia & $\begin{array}{r}521 \\
\end{array}$ & & & & & & & \\
\hline PbWork & .744 & & & & & & & \\
\hline PfBrand & .639 & & & & & & & \\
\hline PbInnov & 605 & & & & & & & \\
\hline PbValue & $=703$ & & & & & & & \\
\hline PrWilBy & .741 & & & & .224 & & & \\
\hline PbProud & $\begin{array}{r}555 \\
\end{array}$ & & & & & & & \\
\hline PbGood & .349 & & & .683 & & & & \\
\hline PbSatis & $=.444$ & & & & & & 349 & \\
\hline TbScene & & .792 & & & & & & \\
\hline TbAcom & & $=.358$ & & .397 & & & & \\
\hline TbAttra & & -815 & & & & & & \\
\hline TbActiv & & .856 & & & & & & \\
\hline TbValue & & .793 & & & & & & \\
\hline CaPleas & & & 202 & & .427 & & & \\
\hline CaExcit & & & .017 & & & .583 & & \\
\hline CaFrien & & & -581 & & & & & \\
\hline CaSafe & & & .603 & & & & & \\
\hline CaTrust & & & $=.541$ & & & & & \\
\hline TrWilTr & & .658 & & 346 & & & & \\
\hline TbGood & & .415 & & $\quad .677$ & & & & \\
\hline Caldeal & & & .183 &.$\quad .770$ & & & & \\
\hline CrTies & & & & & .851 & & & \\
\hline PrImprt & & & & & .791 & & & \\
\hline CbQlife & & & .464 & & & .458 & & \\
\hline CbWealt & & & & & & .731 & & \\
\hline CbTech & & & 743 & & & -.003 & & \\
\hline CbEduc & & & 801 & & & .164 & & \\
\hline PfUse & & & & & & & .776 & \\
\hline PfFind & & & & & & & .804 & \\
\hline PfKnow & & & & & & & .274 & .696 \\
\hline CkKnow & & & & & & & & .585 \\
\hline- & & $=0$ & $=0$ & & 0 & & - & 2 \\
\hline Eigens & 4.3 & 3.9 & 3.0 & 2.4 & 2.4 & 2.3 & 1.8 & 1.5 \\
\hline$\%$ Var & 13.1 & 11.8 & 9.0 & 7.2 & 7.2 & 6.9 & 5.5 & 4.7 \\
\hline Cum \% & 13.1 & 24.8 & 33.8 & 41.1 & 48.3 & 55.1 & 60.7 & 65.4 \\
\hline
\end{tabular}

TExtraction Method: Principal Component Analysis. Orthogonal Rotation Method:

Varimax with Kaiser Normalization. Rotation converged in 8 iterations.

Kaiser-Meyer-Olkin Measure of Sampling Adequacy $\quad .875$

Bartlett's Test of Sphericity: Approx. Chi-Square

Degrees of freedom 


\section{APPENDIX H Confirmatory Factor Analysis}

Figure H-1: CFA, South Korea Sample-U.S. Evaluation, Product Side of Model

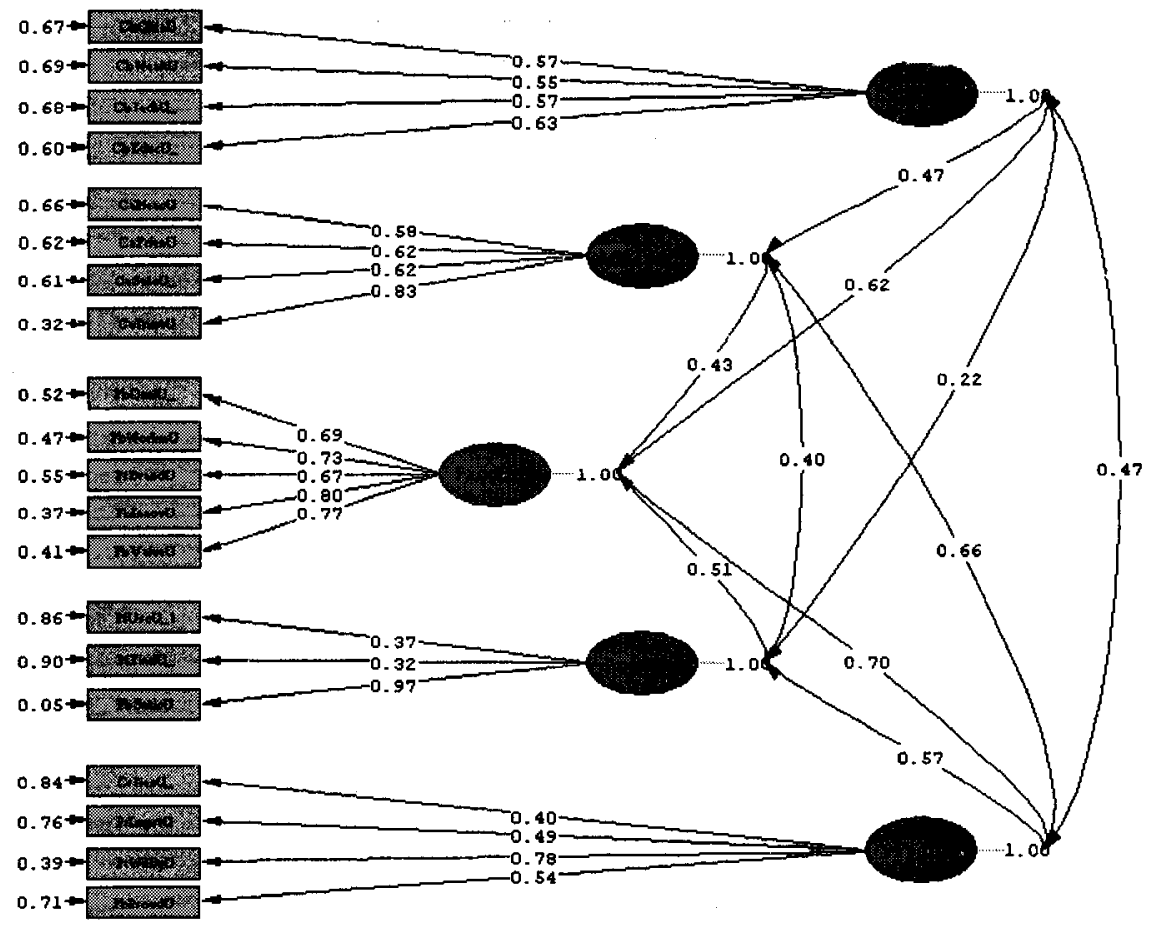

Ch1-Square $=652.72, d f=160, p-v a l u e=0.00000, \operatorname{RMSEA}=0.094$

Figure H-2: CFA, South Korea Sample-U.S. Evaluation, Tourism Side of Model

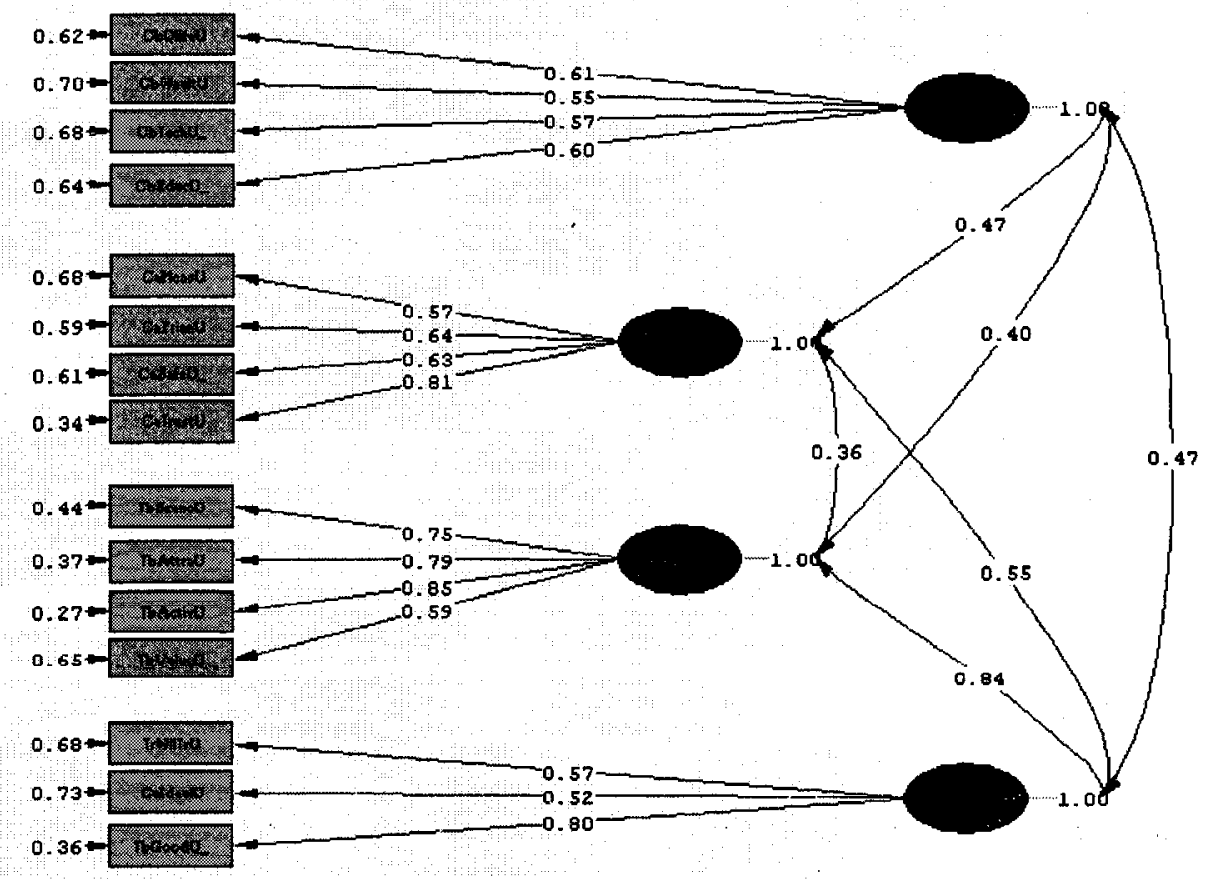

Ch1-square $=317.69, d f=84, p$-value $=0.00000$, RMSEA $=0.089$ 
Figure H-3: CFA, South Korea Sample-Japan Evaluation, Product Side of Model

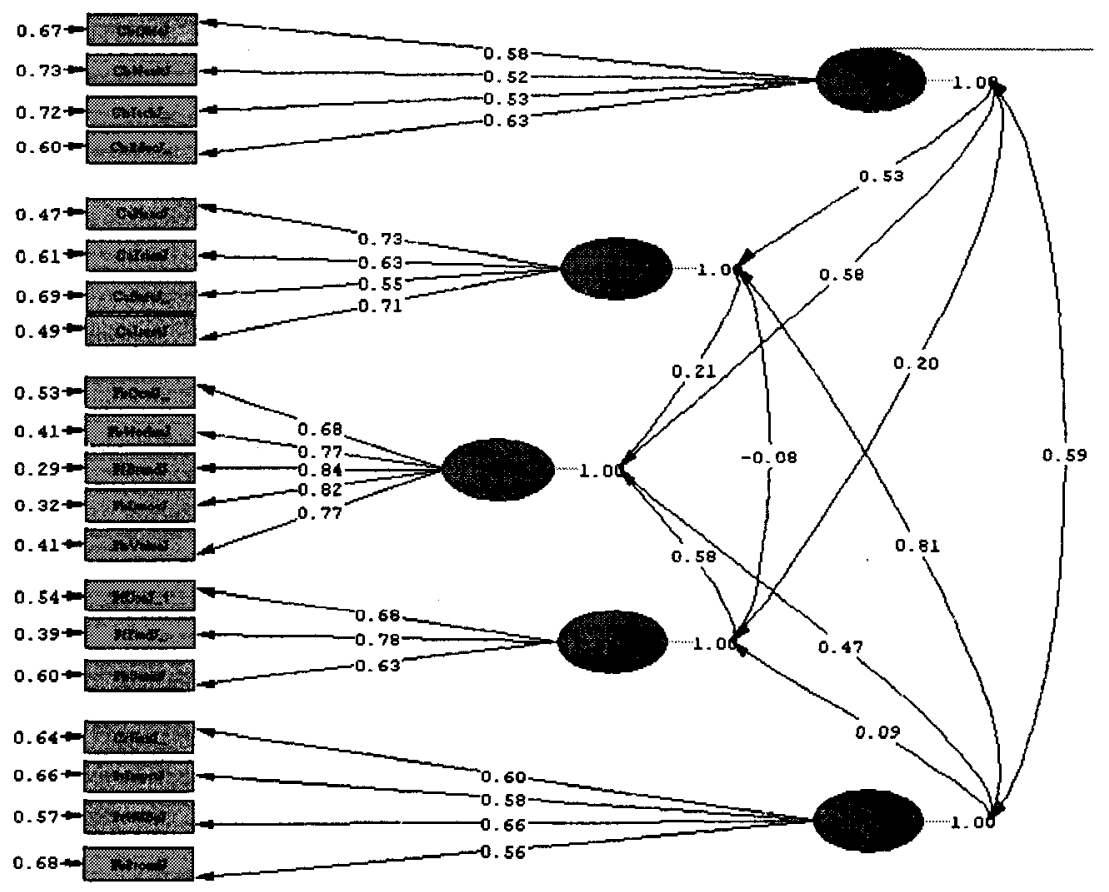

Chi-square $=616.29, d f=160, P-v a l u e=0.00000$, RMSEA $=0.091$

Figure H-4: CFA, South Korea Sample-Japan Evaluation, Tourism Side of Model

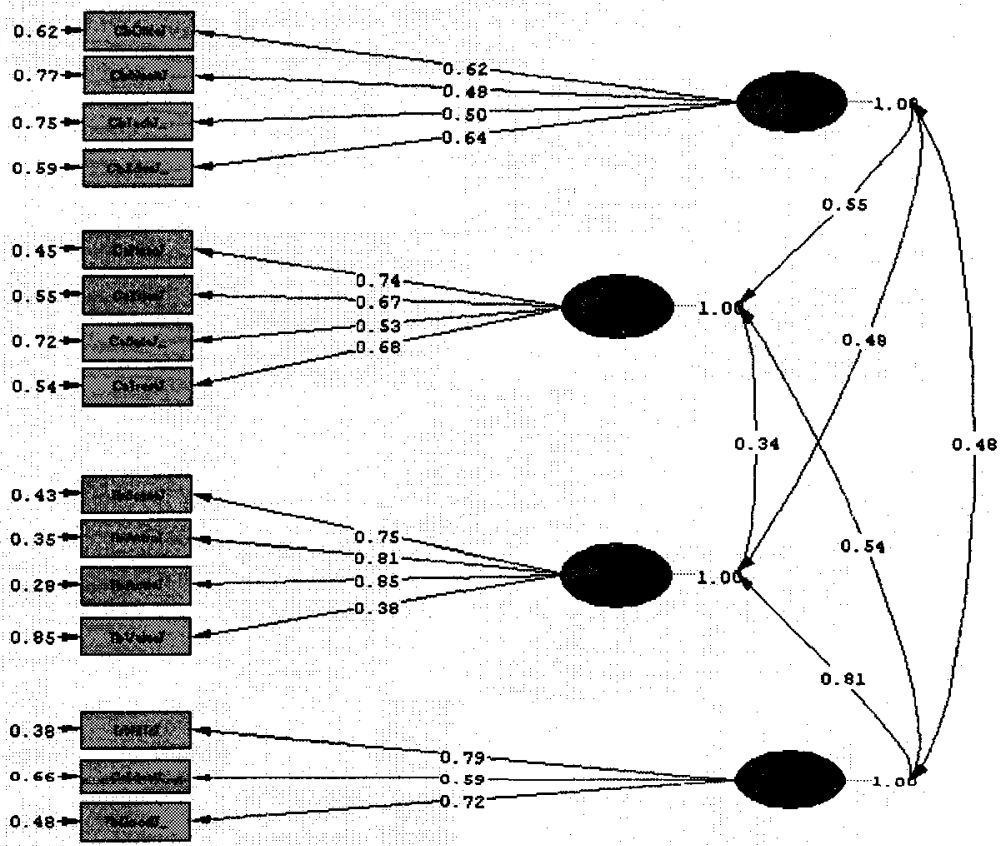

Chi-Square $=285.11, d f=84, P$-value $=0.00000$, RMSEA $=0.083$ 
Figure H-5: CFA, South Korea Sample- Australia Evaluation, Product Side of Model

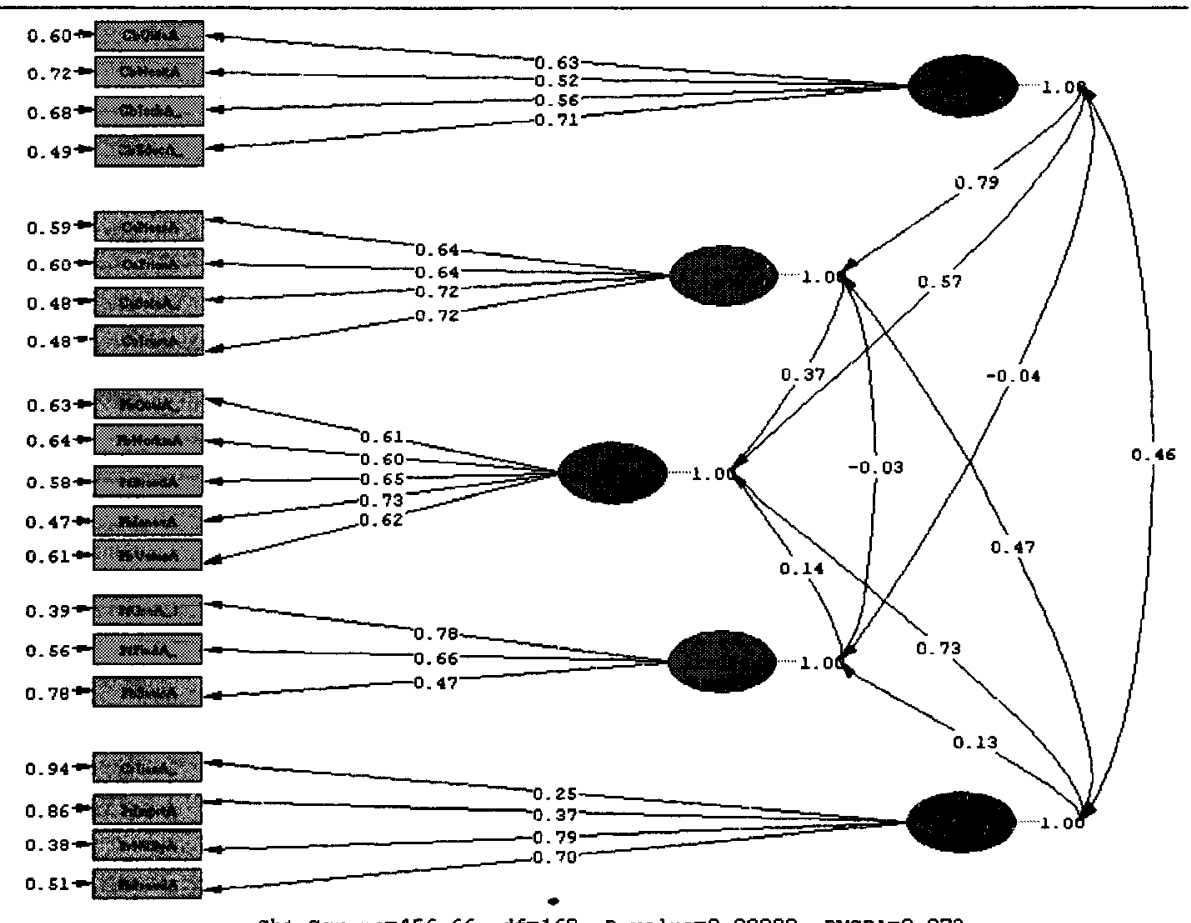

Ch1-Square $=456.66, d f=160, p$-value $=0.00000$, RMSEA $=0.073$

Figure H-6: CFA, South Korea Sample-Australia Evaluation, Tourism Side of Model

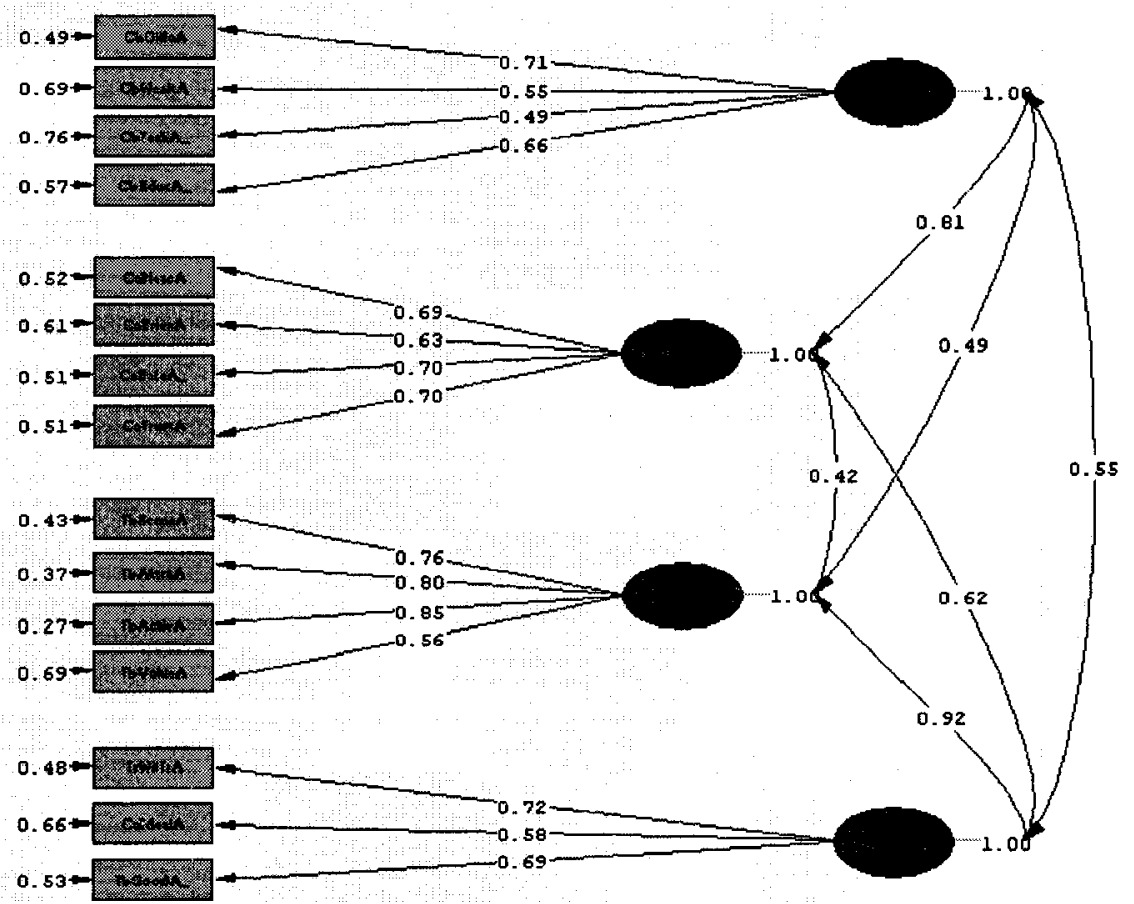


Figure H-7: CFA, South Korea Sample-Canada Evaluation, Product Side of Model

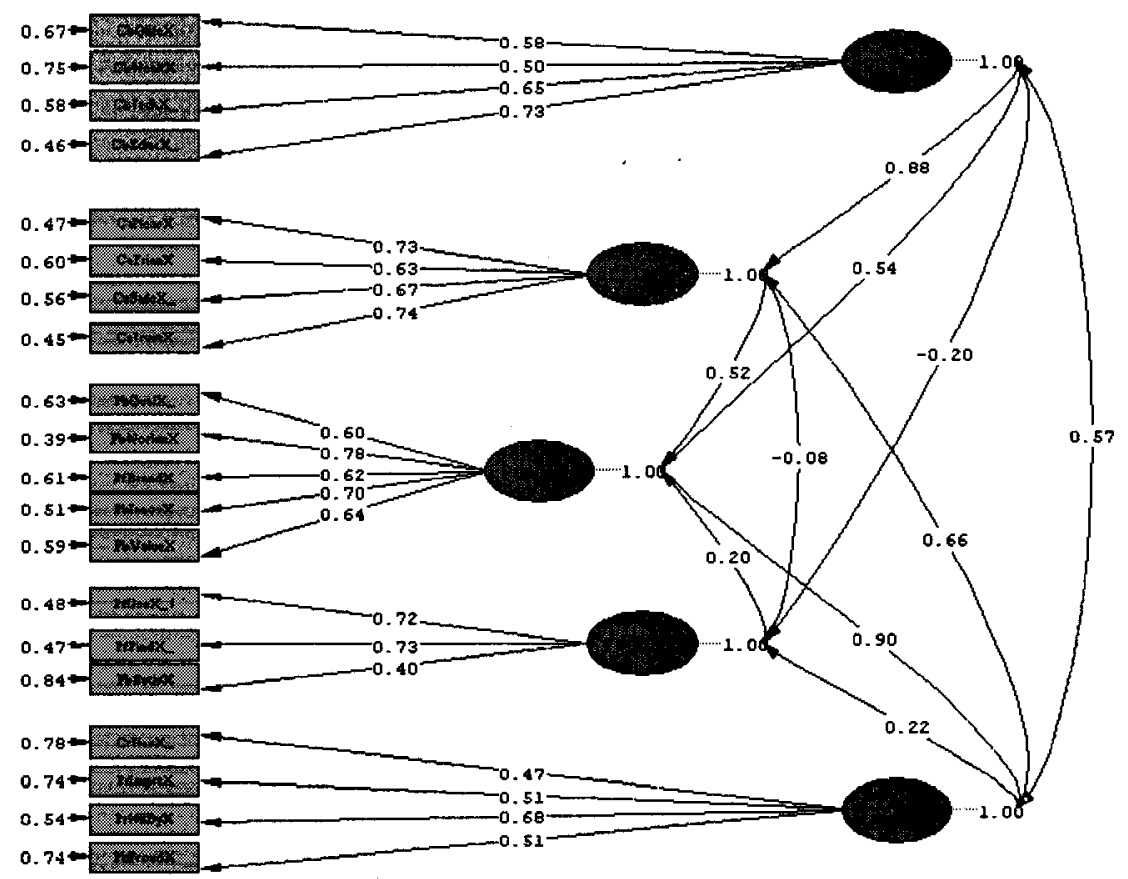

Chi-Square $=476.26, \mathrm{df}=160, \mathrm{p}$-value $=0.00000, \mathrm{RMSEA}=0.075$

Figure H-8: CFA, South Korea Sample-Canada Evaluation, Tourism Side of Model

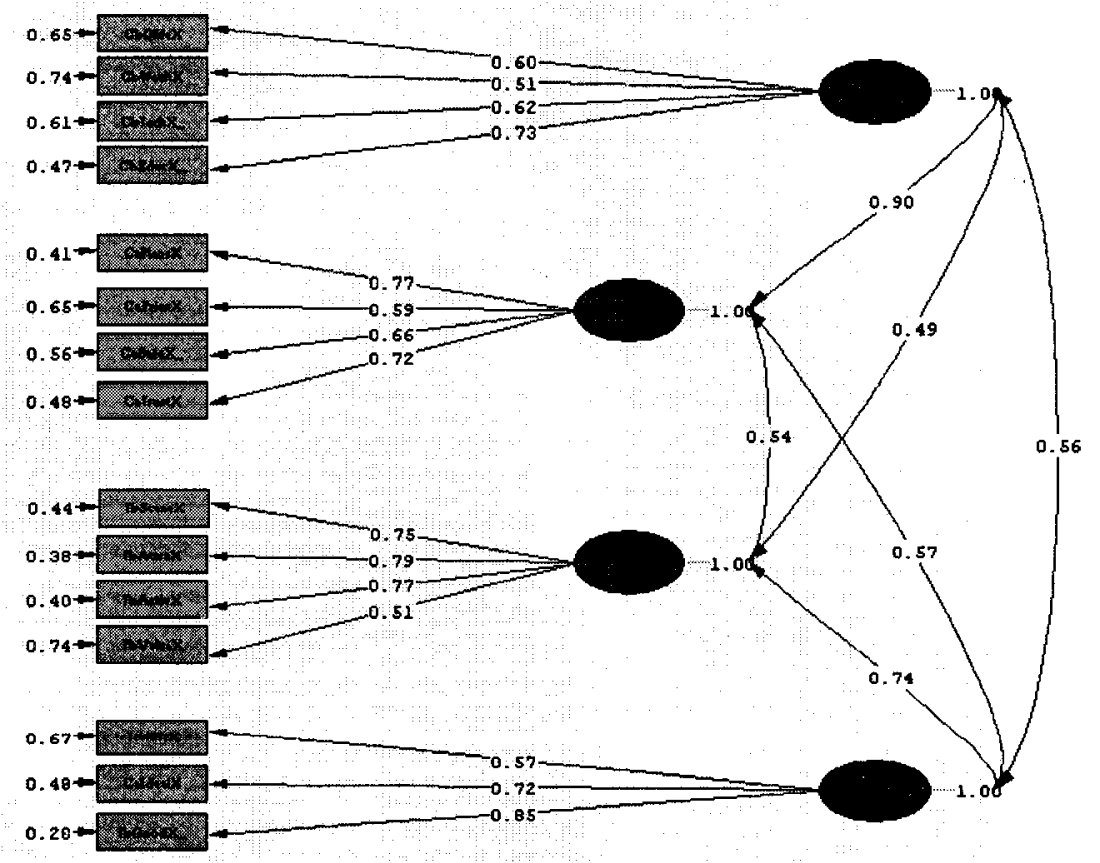

Chi-square $=292.03, \mathrm{df}=84, \mathrm{P}-\mathrm{value}=0.00000, \mathrm{RMSEA}=0.084$ 
Figure H-9: CFA, Canada Sample-U.S. Evaluation, Product Side of Model

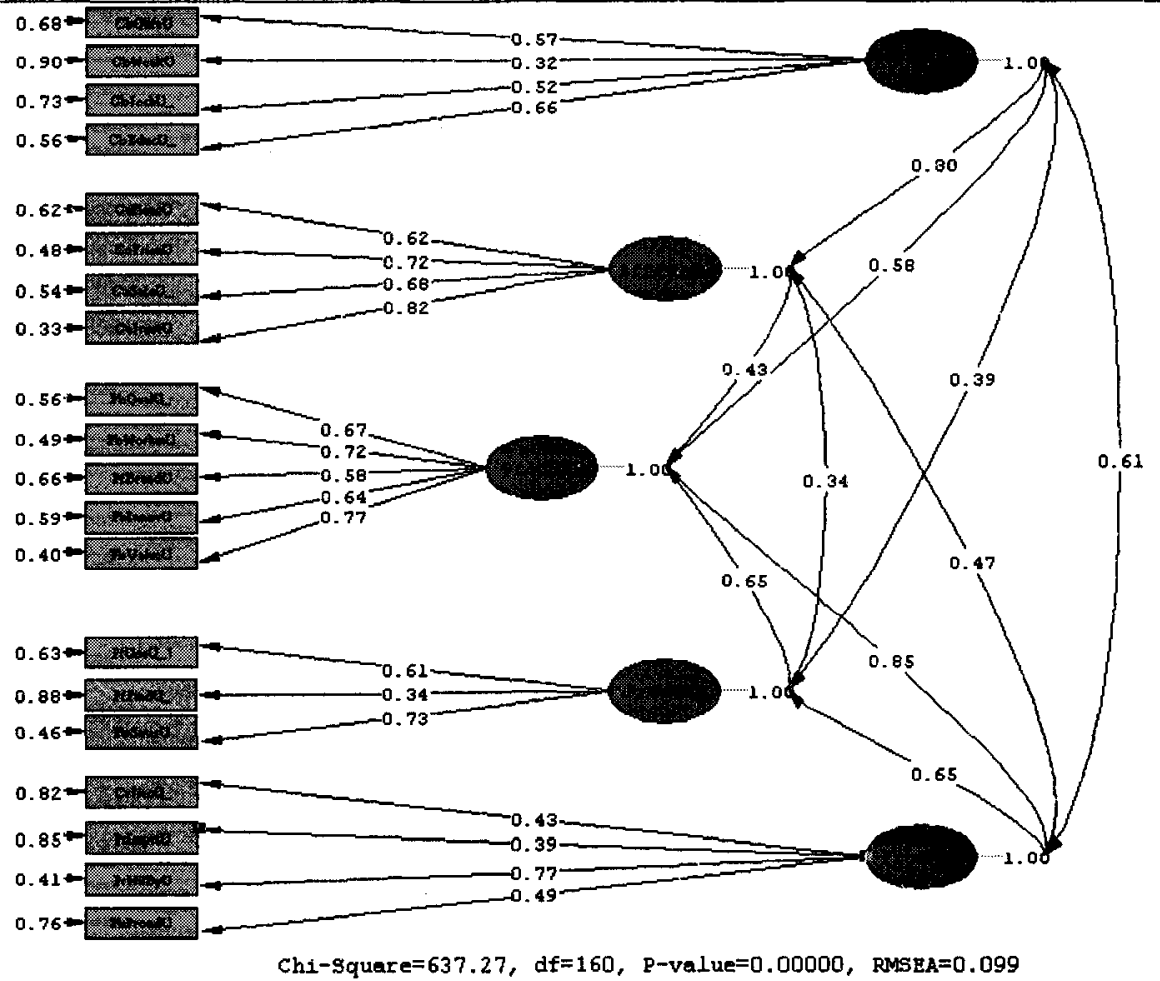

Figure H-10: CFA, Canada Sample-U.S. Evaluation, Tourism Side of Model

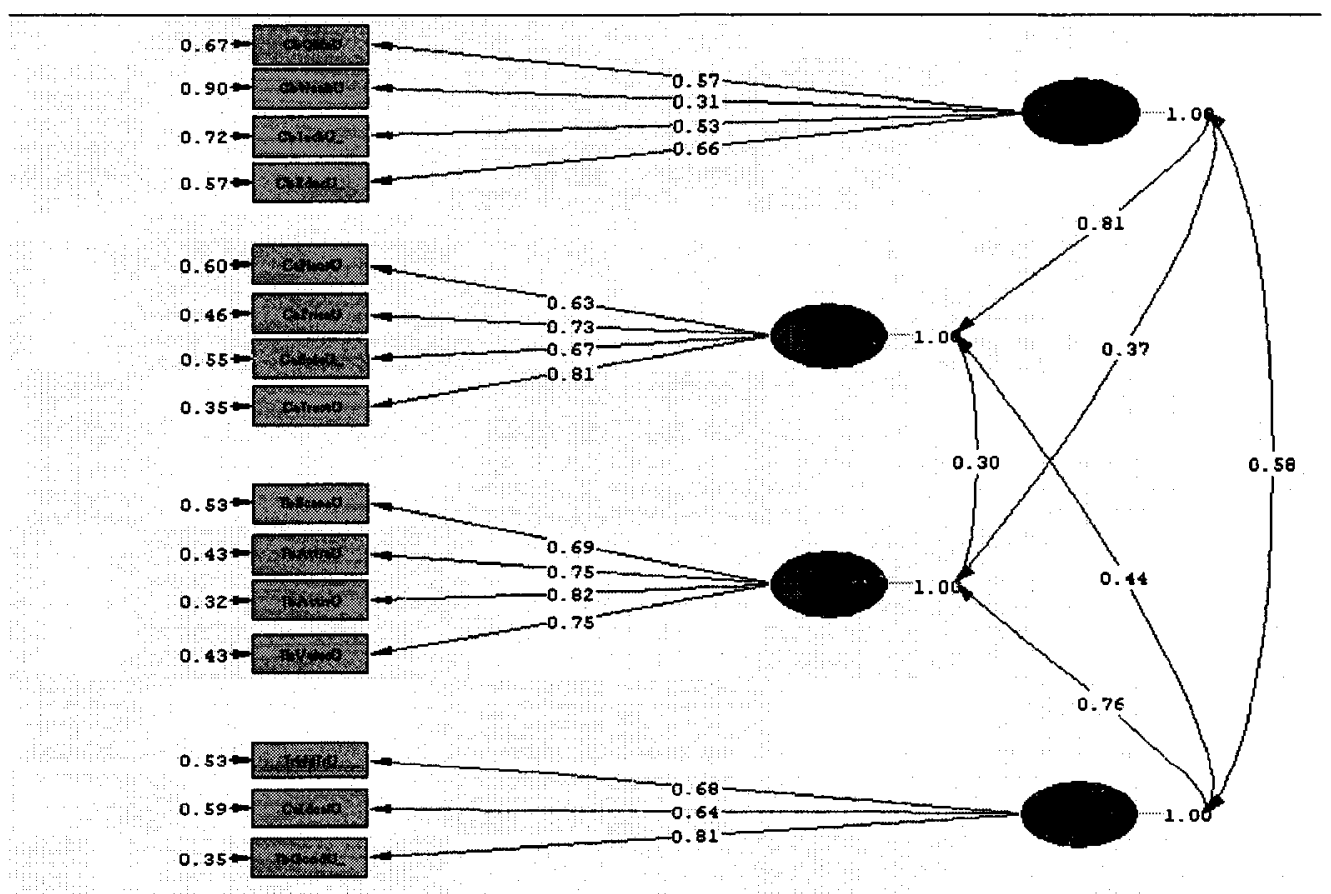

$\mathrm{Ch}_{1}-$ Squar $=448.78, \mathrm{df}=84, \mathrm{Z}-\mathrm{value}=0.00000, \mathrm{RMSER}=0.119$ 
Figure H-11: CFA, Canada Sample-Japan Evaluation, Product Side of Model

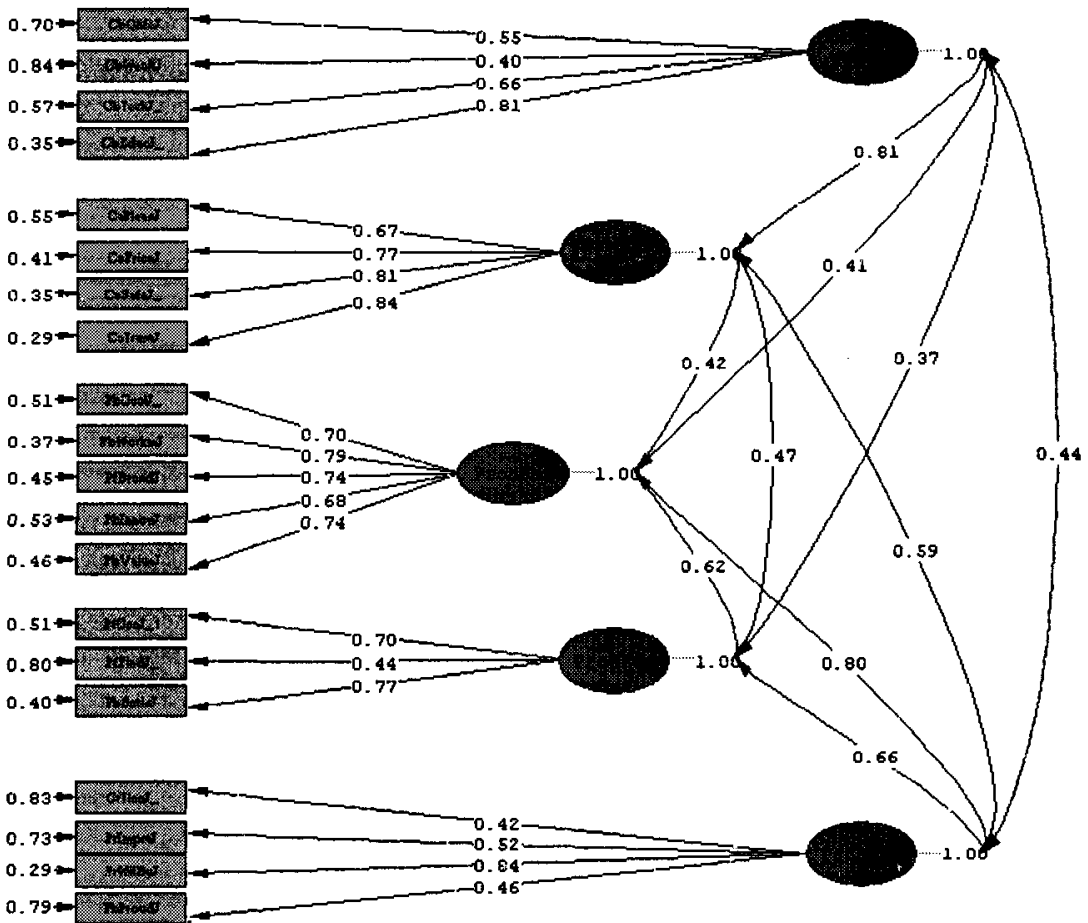

Chi-Square $=587.45, \mathrm{df}=160, \mathrm{p}$-value $=0.00000, \mathrm{RMSEA}=0.093$

Figure H-12: CFA, Canada Sample-Japan Evaluation, Tourism Side of Model

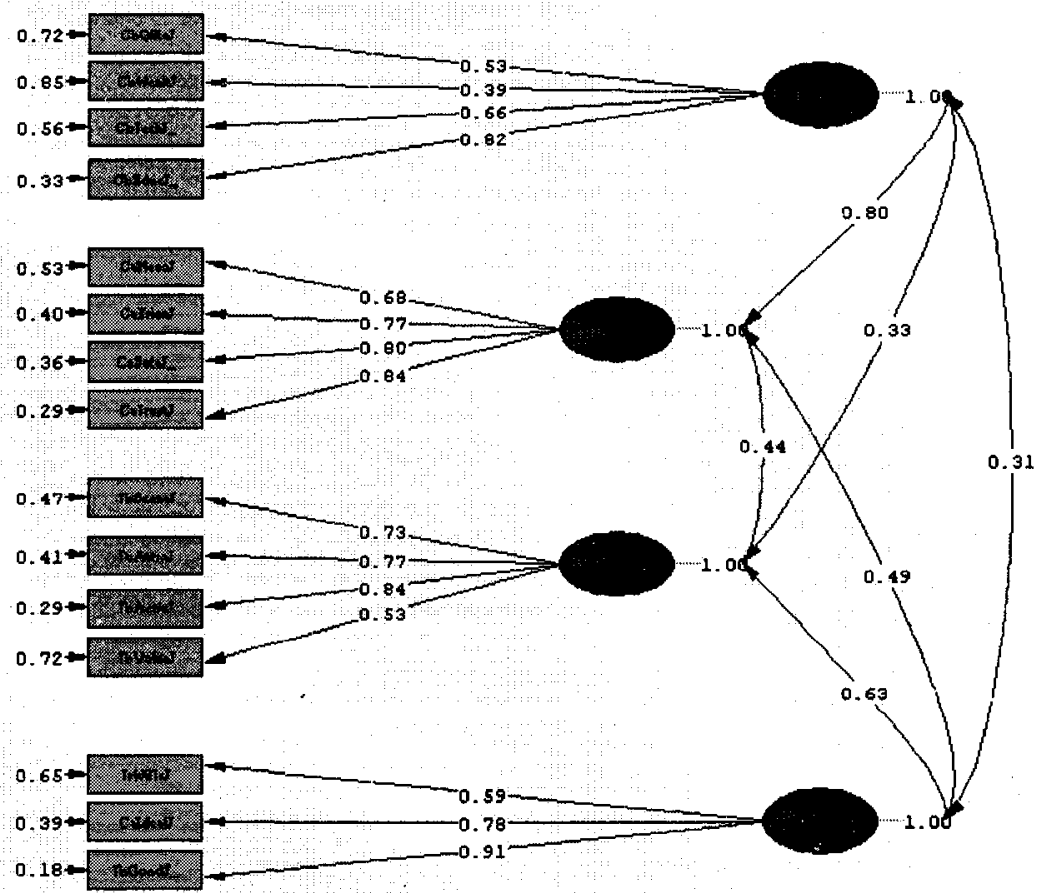

Ch1-square $=341,20, d f=84, p$-value $=0.00000, \quad \mathrm{mMgBA}=0.100$ 
Figure H-13: CFA, Canada Sample-Australia Evaluation, Product Side of Model

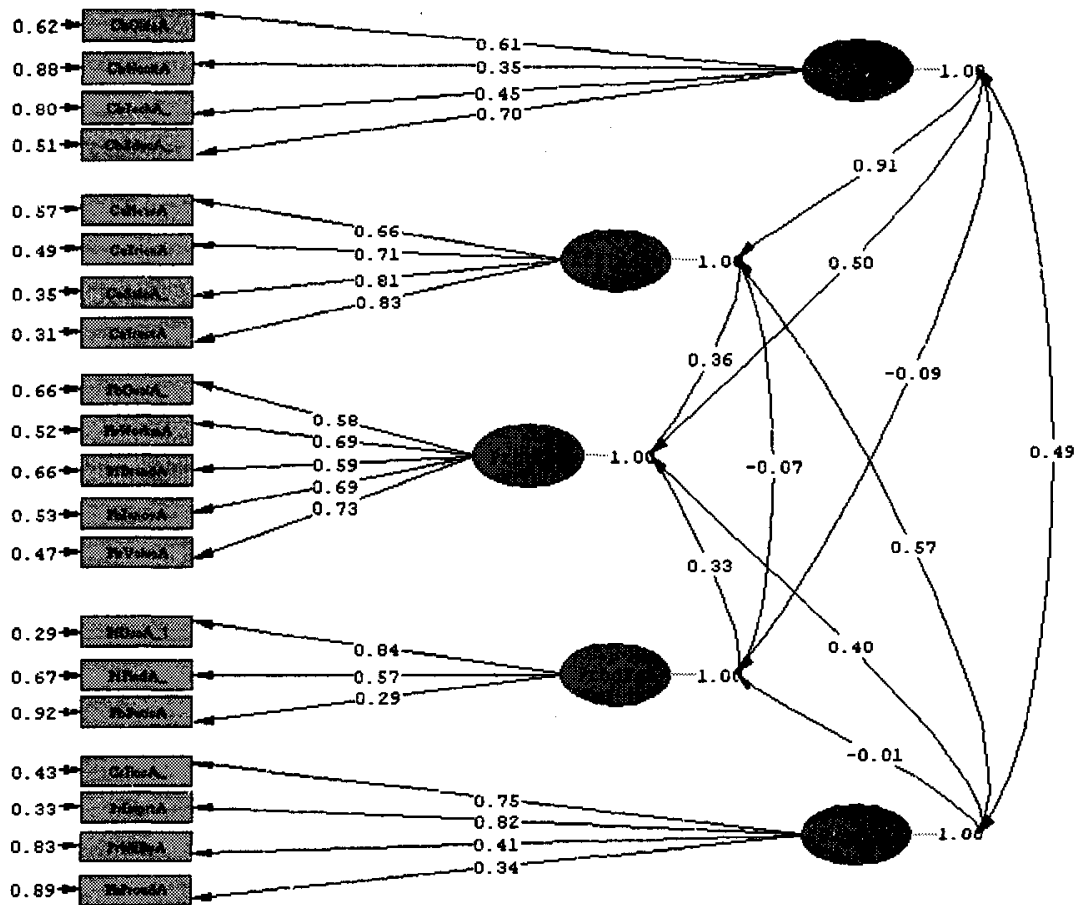

Chi-Square $=647.60, d f=160, p-v a l u e=0.00000$, RMSEA $=0.100$

Figure H-14: CFA, Canada Sample-Australia Evaluation, Tourism Side of Model

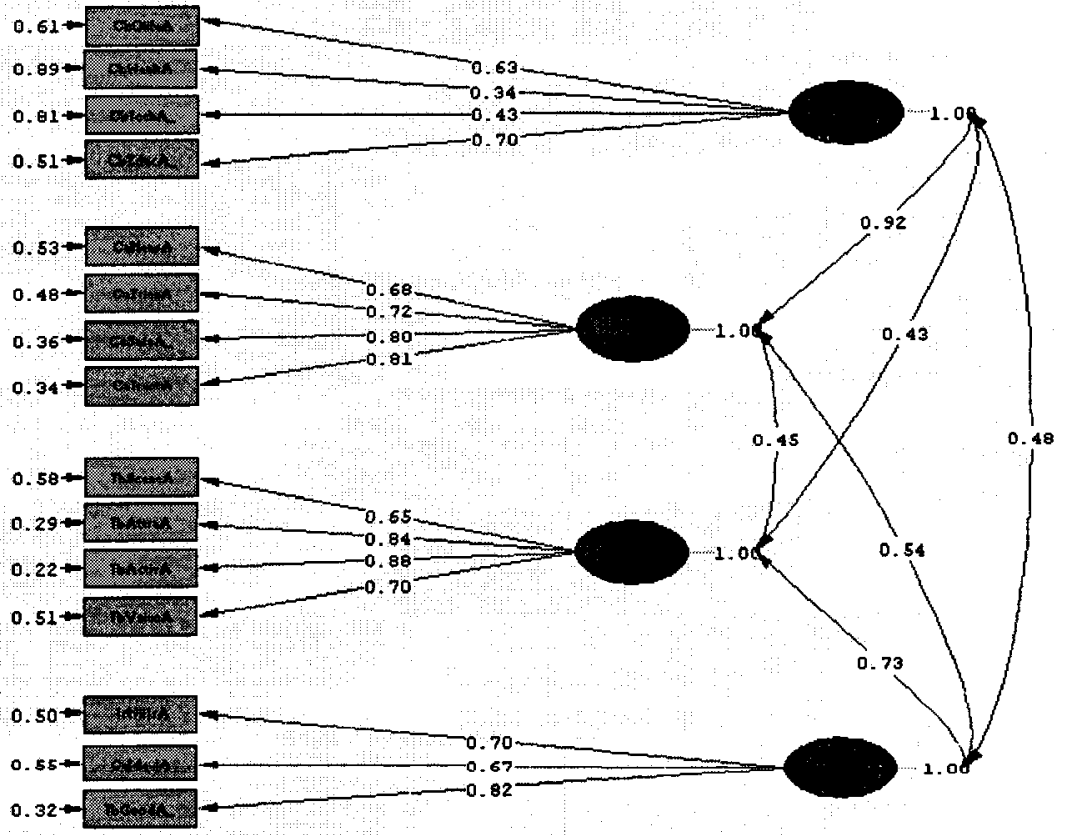

$c h i-$ Square $=532.07, d f=84, p-$ value $=0.00000, \quad R M B E A=0.132$ 
Figure H-15: CFA, Canada Sample-South Korea Evaluation, Product Side of Model

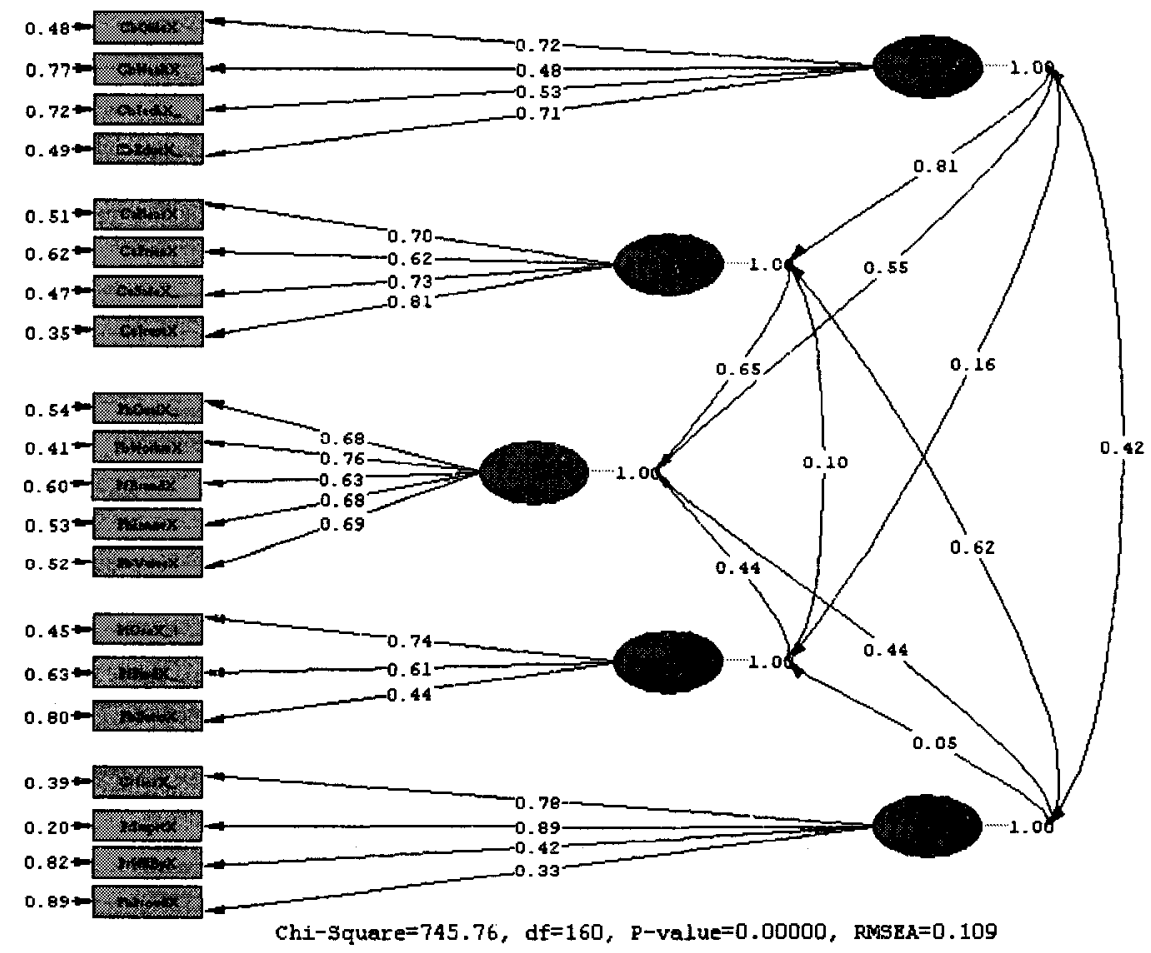

Figure H-16: Confirmatory Factor Analysis, Canada Sample-South Korea Evaluation, Tourism Side of Model

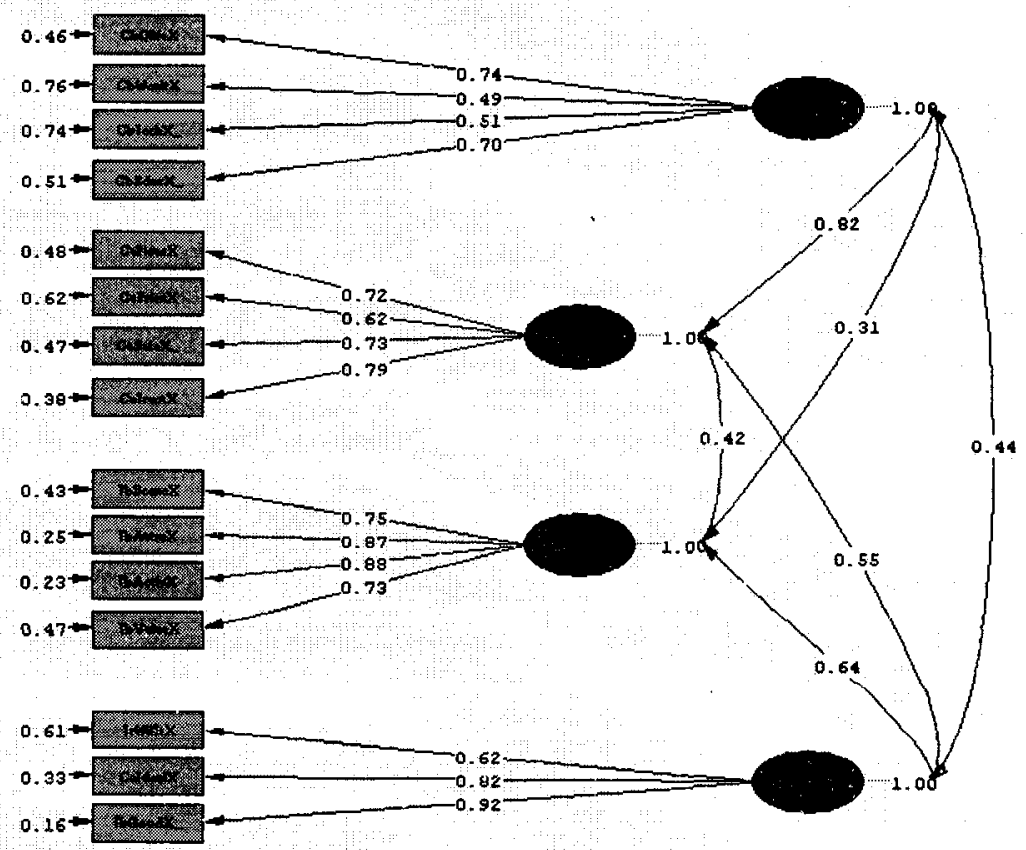

Chi-square $=387.02, d f=84$, p-value $=0.00000$, RMSER $=0.109$ 


\section{APPENDIX I}

\section{Hypothesis Testing for all Model Paths}

Table I: Z Scores for all Hypothesized Relationship by Model

\begin{tabular}{|c|c|c|c|c|c|c|c|c|c|c|c|}
\hline & & \multicolumn{4}{|c|}{ South Korea Models for: } & \multicolumn{4}{|c|}{ Canada Models for: } & \multirow[b]{2}{*}{$\mathrm{s}^{1}$} & \multirow[b]{2}{*}{$\mathbf{N}$} \\
\hline Hyp & Path & US & $\mathbf{J P}$ & $\mathbf{A U}$ & CD & US & $\mathbf{J P}$ & $\mathbf{A U}$ & SK & & \\
\hline H1 & CogCI-AffCI & 1.62 & 0.62 & 5.50 & 11.91 & 8.82 & 9.50 & 3.12 & 9.63 & 6 & $\mathbf{2}$ \\
\hline H2 & CogCI-ProdBel & 7.74 & 5.88 & 4.64 & 1.69 & 2.58 & 0.32 & 0.60 & -1.83 & 4 & 4 \\
\hline H3 & CogCI-DestBel & 1.75 & 4.54 & 1.51 & -0.57 & 3.66 & -0.88 & 2.12 & -1.91 & 3 & 5 \\
\hline H4 & AffCI-ProdBel & 0.72 & 0.73 & -1.31 & 1.08 & -2.15 & 1.56 & -0.57 & 5.19 & 2 & 6 \\
\hline H5 & AffCI-DestBel & -.04 & 0.21 & 1.25 & 1.79 & -3.01 & 3.84 & -1.82 & 3.79 & 3 & 5 \\
\hline H6 & AffCI-ProdRec & 4.22 & 7.20 & 2.29 & 0.50 & 0.38 & 1.41 & 4.45 & 0.07 & 4 & 4 \\
\hline H7 & AffCI-DestRec & 2.96 & 5.52 & 4.70 & 2.07 & 3.17 & 2.34 & 3.66 & 2.34 & 8 & $\overline{0}$ \\
\hline H8 & ProdBel-ProdRec & 9.12 & 4.59 & 7.48 & 6.27 & 7.42 & 6.55 & 3.46 & 6.04 & 8 & 0 \\
\hline H9 & ProdBel-DestRec & 4.14 & 4.26 & -1.32 & 2.12 & 2.52 & 3.09 & 1.59 & 3.07 & 6 & 2 \\
\hline H10 & DestBel-ProdRec & -1.82 & 0.87 & \begin{tabular}{|l|}
-0.96 \\
\end{tabular} & \begin{tabular}{|l|}
-1.38 \\
\end{tabular} & 2.61 & 1.97 & 3.15 & 0.25 & 4 & 4 \\
\hline H11 & DestBel-DestRec & 7.86 & 9.16 & 11.21 & 7.11 & 6.39 & 6.16 & 7.09 & 6.54 & 8 & 0 \\
\hline H12 & ProdFam-ProdBel & 5.82 & 7.73 & 2.31 & 3.97 & 1.82 & 6.29 & 0.56 & 4.36 & 6 & 2 \\
\hline H13 & ProdFam-DestBel & 0 & -0.17 & -0.23 & 0.21 & 2.42 & 2.78 & \begin{tabular}{|l|}
-0.07 \\
\end{tabular} & 0.71 & 3 & 5 \\
\hline H14 & ProdFam-ProdRec & 2.03 & -0.29 & 1.34 & 3.59 & 4.05 & 5.61 & 2.70 & 2.17 & 6 & 2 \\
\hline H15 & ProdFam-DestRec & 1.34 & -0.26 & -0.27 & 0.91 & 3.01 & 4.33 & 0.53 & 1.20 & 2 & 6 \\
\hline H16 & DestFam-ProdBel & 0.53 & 0.28 & -0.27 & 0.76 & \begin{tabular}{|l|}
-1.45 \\
\end{tabular} & - & -0.05 & \begin{tabular}{|l|}
-0.96 \\
\end{tabular} & \begin{tabular}{|l|}
0 \\
\end{tabular} & 7 \\
\hline H17 & DestFam-DestBel & 0.57 & 2.38 & -3.09 & -1.33 & 1.49 & - & 0.06 & 1.91 & 2 & 5 \\
\hline H18 & DestFam-ProdRec & 0.71 & 0.31 & 0.45 & 1.03 & -1.20 & - & 0.06 & \begin{tabular}{|l|}
-0.94 \\
\end{tabular} & 0 & 7 \\
\hline H19 & DestFam-DestRec & 1.09 & 0.41 & -0.09 & -0.80 & 0.67 & - & 0.06 & \begin{tabular}{|l|}
-0.53 \\
\end{tabular} & $\mathbf{0}$ & 7 \\
\hline$\widehat{H 20}$ & DestFam-AffCI & 0.77 & 0.31 & 0.27 & 1.10 & $1 . \overline{38}$ & - & 0.05 & -0.96 & 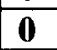 & 7 \\
\hline H21 & ProdFam-AffCI & 0 & -0.35 & -0.25 & 0.20 & -2.25 & 3.55 & 0.07 & 0.73 & 2 & 6 \\
\hline H22 & CogCI-ProdRec & 3.57 & 0.78 & 7.88 & 6.01 & 5.29 & 3.57 & \begin{tabular}{|l|}
4.49 \\
\end{tabular} & 4.71 & 7 & 1 \\
\hline $\mathbf{H 2 3}$ & CogCI-DestRec & 4.63 & 1.39 & 6.62 & 7.92 & 5.79 & 4.73 & 1.89 & 5.70 & 6 & 2 \\
\hline & RMSEA & .076 & .078 & .066 & .066 & .086 & .078 & .088 & .081 & & \\
\hline
\end{tabular}

${ }^{\mathrm{T}} \mathrm{Z}$ Scores are statistically significant if they exceed the critical value of $+/-1.96$ at the .05 level 
APPENDIX J

Model Invariance Test

Figure J-1: Null Hypothesis Test of Equality for S. Korean \& Canadian US Models

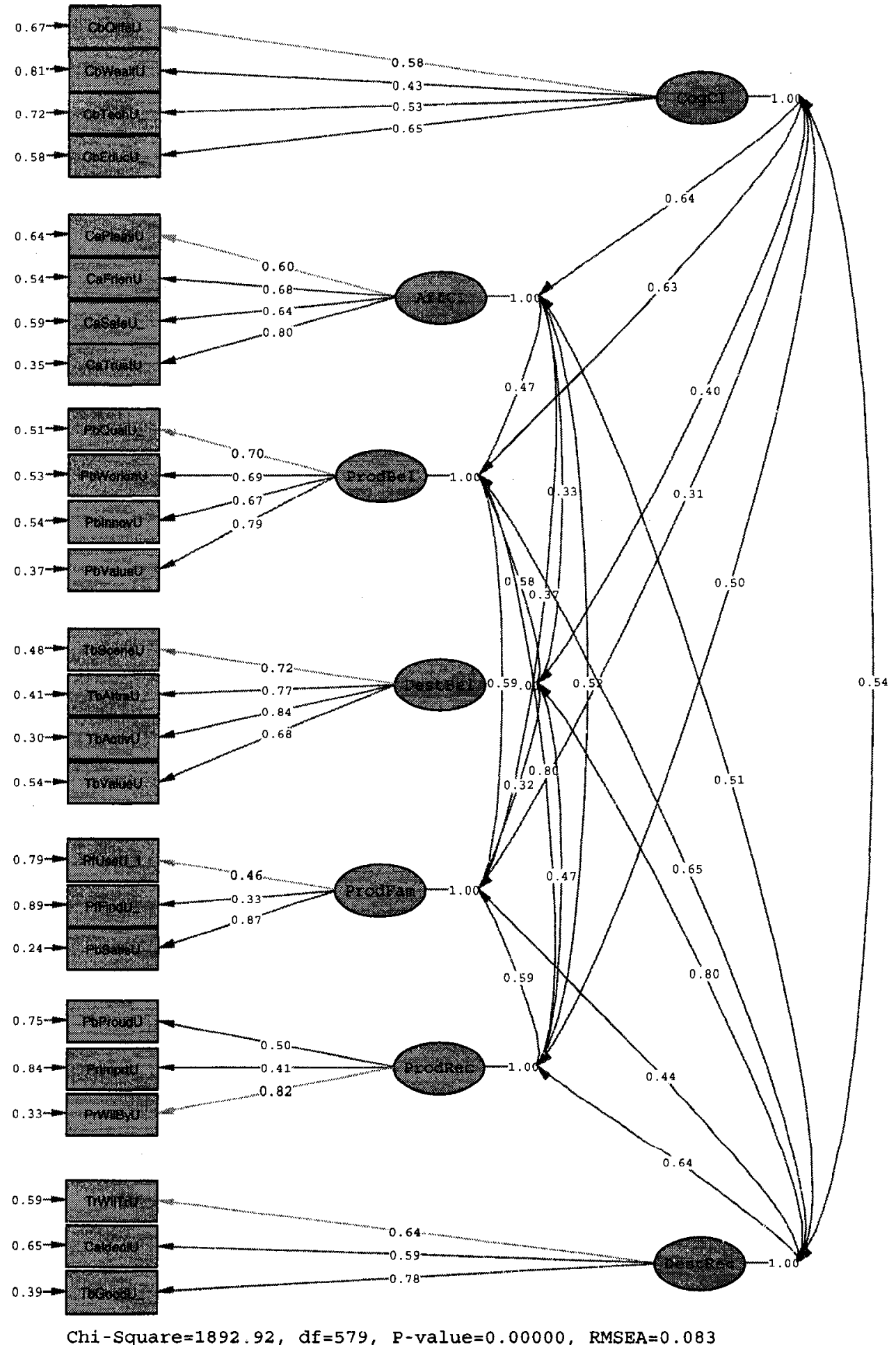

Chi-Square $=1892.92, d f=579, p-$ value $=0.00000, \quad$ RMSEA $=0.083$ 
Figure J-2: Alternative Hypothesis Test of Unequality for S. Korean \& Canadian US Models

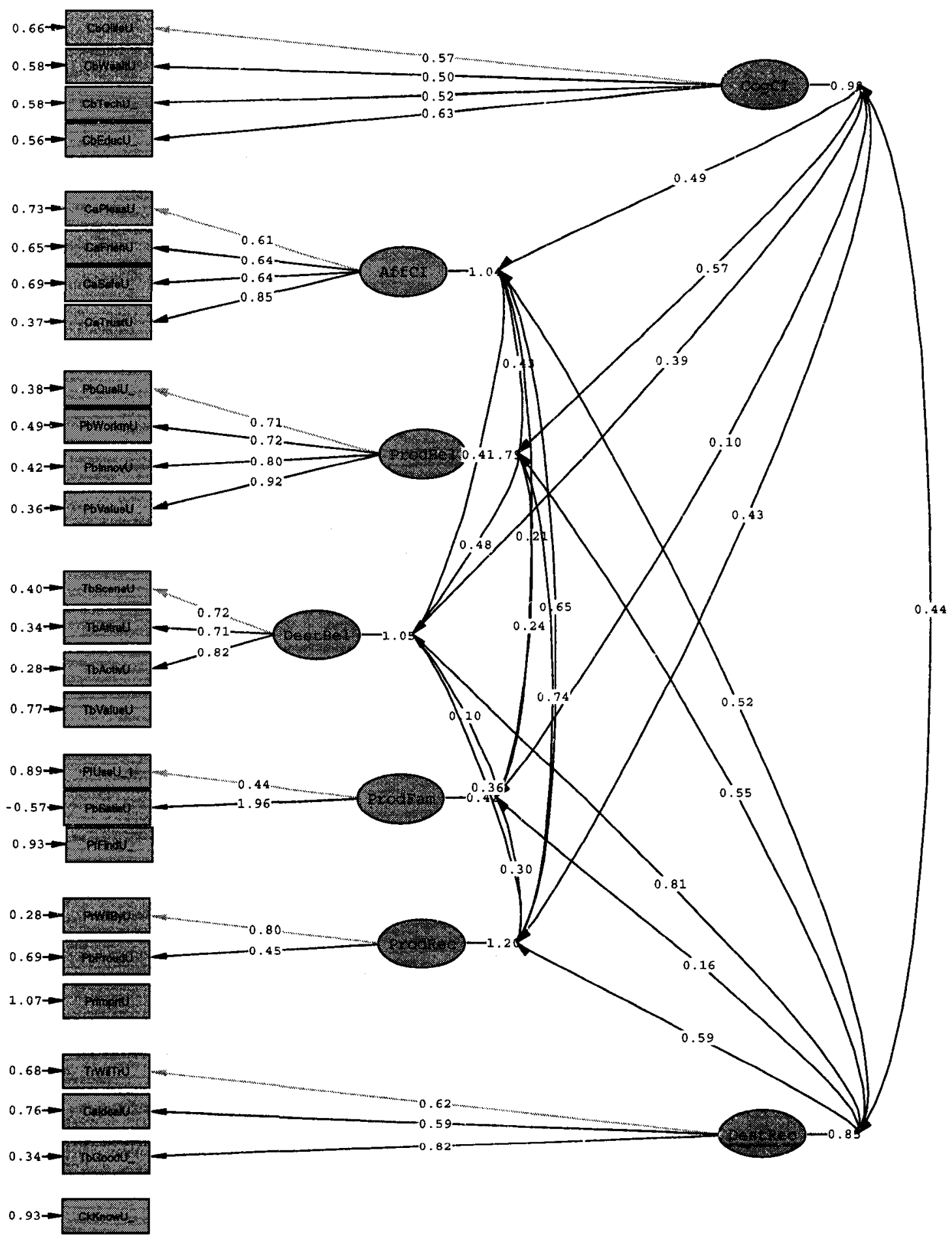

Chi-Square $=2082.59, d f=564, P$-value $=0.00000, \operatorname{RMSEA}=0.091$ 
APPENDIX K QUESTIONNAIRE on International Products and Tourism

Dear Survey Respondent,

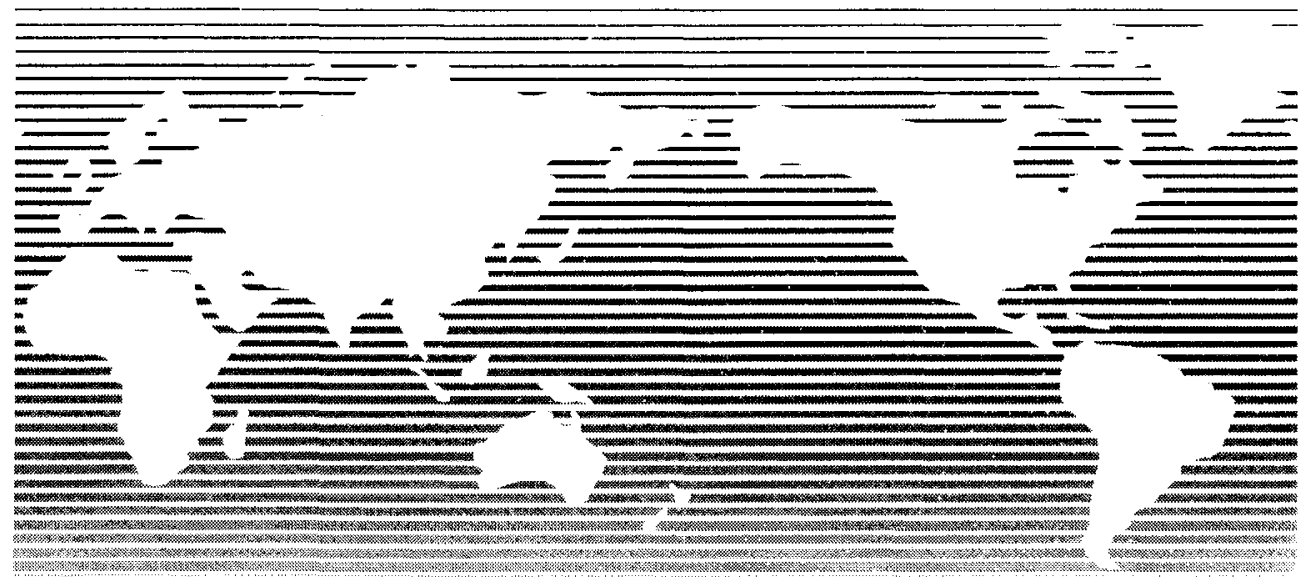

As a consumer in today's global market, you have a lot of choice in what products you buy and where you travel. To understand how consumers evaluate foreign products and tourism destinations, researchers from Carleton University are conducting this survey in Canada and other countries.

You have been selected to give your opinion based on a random sample. Your views are very important. Your answers will remain completely confidential - please do not identify yourself on this questionnaire. We will use only combined data from all respondents in our analysis.

Thank you very much for your help.

Sincerely,

Statia Elliot

Ph.D. Candidate

Sprott School of Business

Carleton University

Ottawa, Canada
Dr. Nicolas Papadopoulos

Professor

Sprott School of Business

Carleton University

Ottawa, Canada

\section{How to answer the main part of the questionnaire...}

In the next pages you will find questions that examine how you feel about four countries, their products, and their tourism - the United States, Japan, Australia, and South Korea. It does not matter how well you may or may not know them. We ask for your general impression. The questions are in the form of "scales", with words that describe the countries and their products or tourism. To answer each scale, simply put an " $\mathrm{X}$ " in the space that is closest to your opinion.

For example, if your opinion is very close to the word on the left, please mark the scale as follows:

$$
\text { Rich : } \underline{\mathrm{X}}: \text { :_____________: Poor Note Please put all your " } \mathrm{X} \text { " }
$$
marks in the middile of the spaces, not on the dividing lines.

Or, if your opinion is slightly related to the word on the right:

$$
\text { Rich :_________ : } \underline{\mathrm{X}}:
$$

Please answer every scale for every country and do not omit any. Work fairly rapidly through the questionnaire, without looking back and forth. Judge each country independently from the others. There is no "right" answer - your immediate "feeling" about each question is what counts! 
1 This first section is about the countries and their people

UNITED STATES AND AMERICANS
Good quality of life
Pleasant
Poor

JAPAN AND THE JAPANESE

Good quality of life

\section{Pleasant}

$:[\ldots: \ldots: \ldots: \ldots$

Poor quality of life

.

Poor

:___:_:_:_:_:_

Unpleasant

Rich

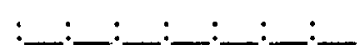

Boring

Technologically advanced

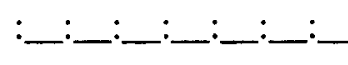

Friendly people

Highly educated people
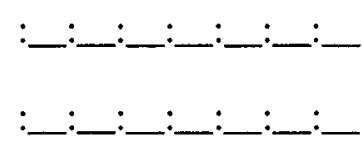

:_____:_:_____:

Safe

Trustworthy people

I know very little about Japan and the Japanese

We should have closer ties with Japan

I would welcome more imports here from

Japan
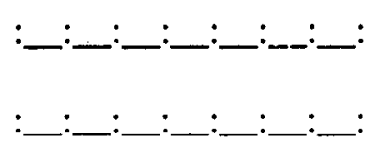

:___:___:_:__:

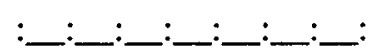

:_______________:
Exciting

Not technologically advanced

Unfriendly people

Not highly educated people

Dangerous

Not trustworthy people

I know a lot about Japan and the Japanese

We should not have closer ties with Japan

I would not welcome more imports here from Japan 


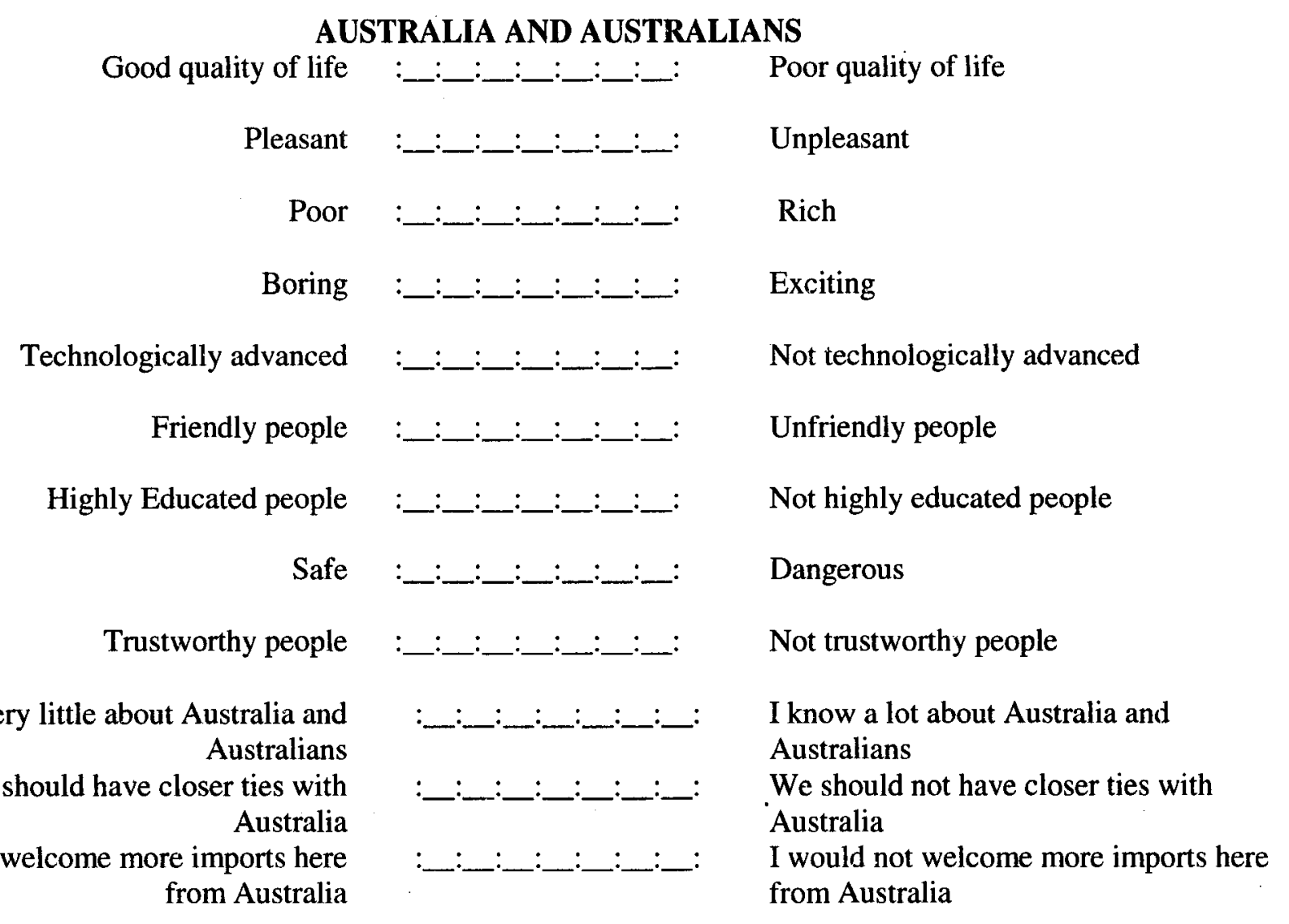

SOUTH KOREA AND THE SOUTH KOREANS

Good quality of life

:___:_:_:_:___:

Poor quality of life

Pleasant

:___:___:___:_:

Unpleasant

Poor

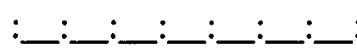

Rich

Boring

:_:_:_:_____:

Exciting

Technologically advanced

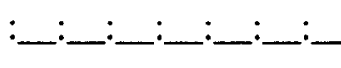

Not technologically advanced

Friendly people

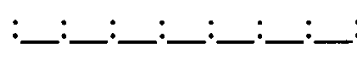

Unfriendly people

Highly educated people

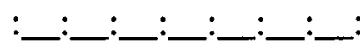

Not highly educated people

Safe

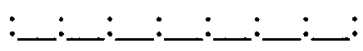

Dangerous

Trustworthy people

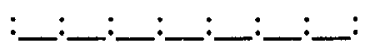

Not trustworthy people

I know very little about South Korea and

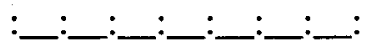

I know a lot about South Korea and

South Koreans

We should have closer ties with

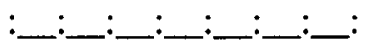
South Koreans

South Korea

We should not have closer ties with South Korea

I would welcome more imports here

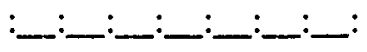
I would not welcome more imports here from South Korea 
2 This section is about the countries' products

\section{AMERICAN PRODUCTS}

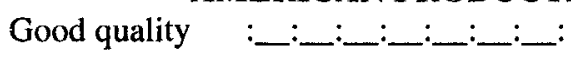

Unreliable :________________:

I know a lot about American products :_:_:_:_:___:

Good workmanship :__:_____________:

Recognizable brands :___:___:___:__:

Innovative

Good value for the money

I am willing to buy American products

I rarely use American products

American products are hard to find

I am not satisfied with American products

I would be proud to own American products

Good quality

$$
\text { Unreliable }
$$

I know a lot about Japanese products

Good workmanship

Recognizable brands

$$
\text { Innovative }
$$

Good value for the money

I am willing to buy Japanese products

I rarely use Japanese products

Japanese products are hard to find

I am not satisfied with Japanese products

I would be proud to own Japanese products
Poor quality

Reliable

I know little about American products

Poor workmanship

Unrecognizable brands

Imitative

Poor value for the money

I am not willing to buy American products

I often use American products

American products are easy to find

I am satisfied with American products

I would not be proud to own American products

Poor quality

Reliable

I know little about Japanese products

Poor workmanship

Unrecognizable brands

Imitative

Poor value for the money

I am not willing to buy Japanese products

I often use Japanese products

Japanese products are easy to find

I am satisfied with Japanese products

I would not be proud to own Japanese products 


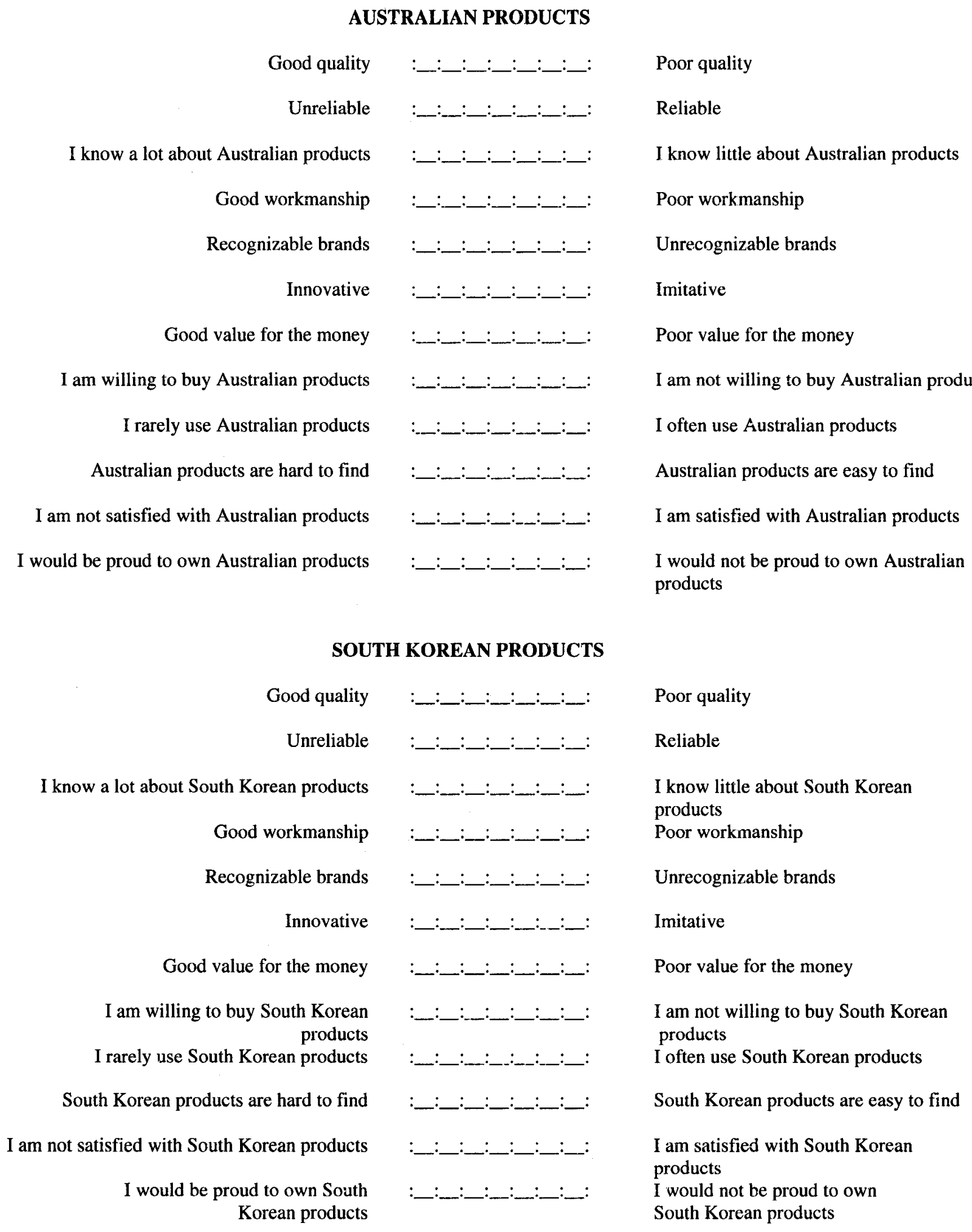


3 This section is about the countries' tourism

UNITED STATES as a TOURISM DESTINATION
Appealing scenery
Unsuitable accommodation
High quality attractions
Lots to see and do
Good value for the money
willing to travel to the U.S.
Appealing scenery
Unsuitable accommodation
High quality attractions
Lots to see and do

\begin{aligned} \multicolumn{2}{c}{ AUSTRALIA as a TOURISM DESTINATION } \\ Appealing scenery \\ Unsuitable accommodations \end{aligned}

\begin{tabular}{|c|c|c|}
\hline \multicolumn{3}{|c|}{ SOUTH KOREA as a TOURISM DESTINATION } \\
\hline Appealing scenery & $: \_: \_: \_: \_: \_: \ldots:$ & Unappealing scenery \\
\hline Unsuitable accommodation & :___:_:_:_:_:_: & Suitable accommodation \\
\hline High quality attractions & $: \ldots$ :____: & Low quality attractions \\
\hline Lots to see and do & :_:_:_:_:_:_:_: & Little to see and do \\
\hline Good value for the money & :_______________: & Poor value for the money \\
\hline $\begin{array}{r}\text { I am willing to travel to South } \\
\text { Korea }\end{array}$ & $: \ldots$ & $\begin{array}{l}\text { I am not willing to travel to } \\
\text { South Korea }\end{array}$ \\
\hline
\end{tabular}


4 Just before concluding, we ask your general views

What images or characteristics come to mind when you think of these countries?

2 . United States

Japan

Australia

South Korea

2.

3.
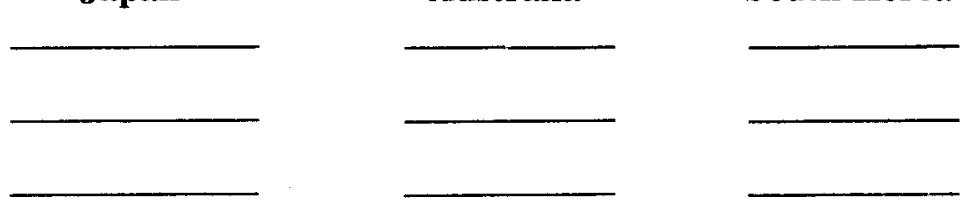

What products come to mind? You may write a brand, product category, or company name.

1.

United States

Japan

Australia

South Korea

2.

3.
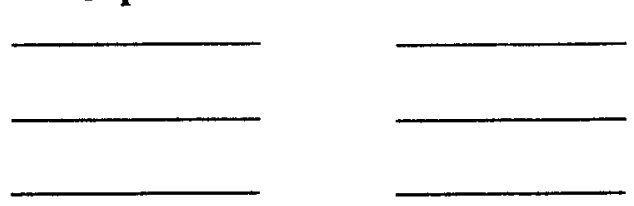

What tourism characteristics come to mind? You may write an attraction, location, or feature.

\section{United States}

1.

2.

3.

Compared to any other country (not only those in this questionnaire) please rate the following:
Australia

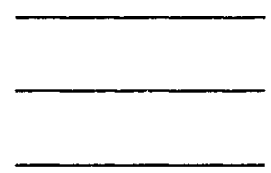

South Korea

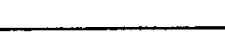

\section{UNITED STATES}

\begin{tabular}{|c|c|c|}
\hline An ideal country & $:$ ___:__________: & Not an ideal country \\
\hline Good overall products & $:[$ :___:_: & Poor overall products \\
\hline Good tourism destination & $:[$ : & Poor tourism destination \\
\hline \multicolumn{3}{|c|}{ JAPAN } \\
\hline An ideal country & :_: & Not an ideal country \\
\hline Good overall products & $:$ :__ : & Poor overall products \\
\hline Good tourism destination & $:$ & Poor tourism destination \\
\hline
\end{tabular}

\section{AUSTRALIA}

An ideal country $:$ :__:__:_________:

Not an ideal country

Good overall products :________________:

Poor overall products

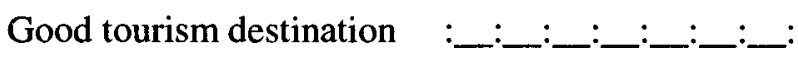

Poor tourism destination 


\begin{tabular}{|c|c|c|}
\hline \multicolumn{3}{|c|}{ SOUTH KOREA } \\
\hline An ideal country & :_:__:______________ & Not an ideal country \\
\hline Good overall products & :_:_:__:_:_:_:_: & Poor overall products \\
\hline ood tourism destination & :_______________ & Poor tourism destinatior \\
\hline
\end{tabular}

5 In this last section we ask some classification questions

(please remember - all your answers are anonymous and strictly confidential)

Are you male ___ or female ___?

In which bracket is your age? (check one)

\begin{tabular}{|c|c|c|}
\hline Less than 20 & & $45-49$ years \\
\hline 20-24 years & & $50-54$ years \\
\hline 25-29 years & & $55-59$ years \\
\hline $\begin{array}{l}30-34 \text { years } \\
35-39 \text { years }\end{array}$ & & $\begin{array}{l}60-64 \text { years } \\
65 \text { or older }\end{array}$ \\
\hline $40-44$ years & & \\
\hline
\end{tabular}

What is your education level? (check one)

No high school

College graduate

Some high school

Some university

High school graduate $\_$University graduate

Some college

Other (please specify)

How many persons are there living in your household? (write in the number)

In which range is the total income of your household? Check one:

$$
\begin{array}{lll}
\text { Up to } \$ 29,999 & & \$ 75,000-\$ 99,999 \\
\$ 30,000-\$ 49,999 & - & \$ 100,000-\$ 149,999 \\
\$ 50,000-\$ 74,999 & - & \$ 150,000 \text { or more }
\end{array}
$$

How many trips have you taken outside Canada since January 2004? (write the number)

Have you ever been to any of these countries? (write number of trips) United States Japan Australia South Korea
For what purpose? (check as many as apply) Tourism Study Work $\underline{\text { Other }}$

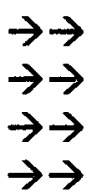


Have any of the following played a role in shaping your views? (check as many as apply)

1. Things I learned in school

United Japan Australia South

\section{States}

Korea

2. Things I learned from the media (TV, radio, newspapers, magazines, etc.)

3. I have family roots there (immigrated from there, or have relatives who live there)

Thank you sincerely for your opinions!

Would you like to make any additional comments? Your opinion counts, and anything you might want to add about this survey will be very valuable. You may comment on the countries included in the survey, or any other country that interests you and you might compare to those we asked about. Please use the back of this page or a member of our research team can provide you with additional sheets if you would like. 